ANNA KLINGE

CRANIOFACIAL HEIGHT

IN RELATION TO ALVEOLAR BONE MORPHOLOGY
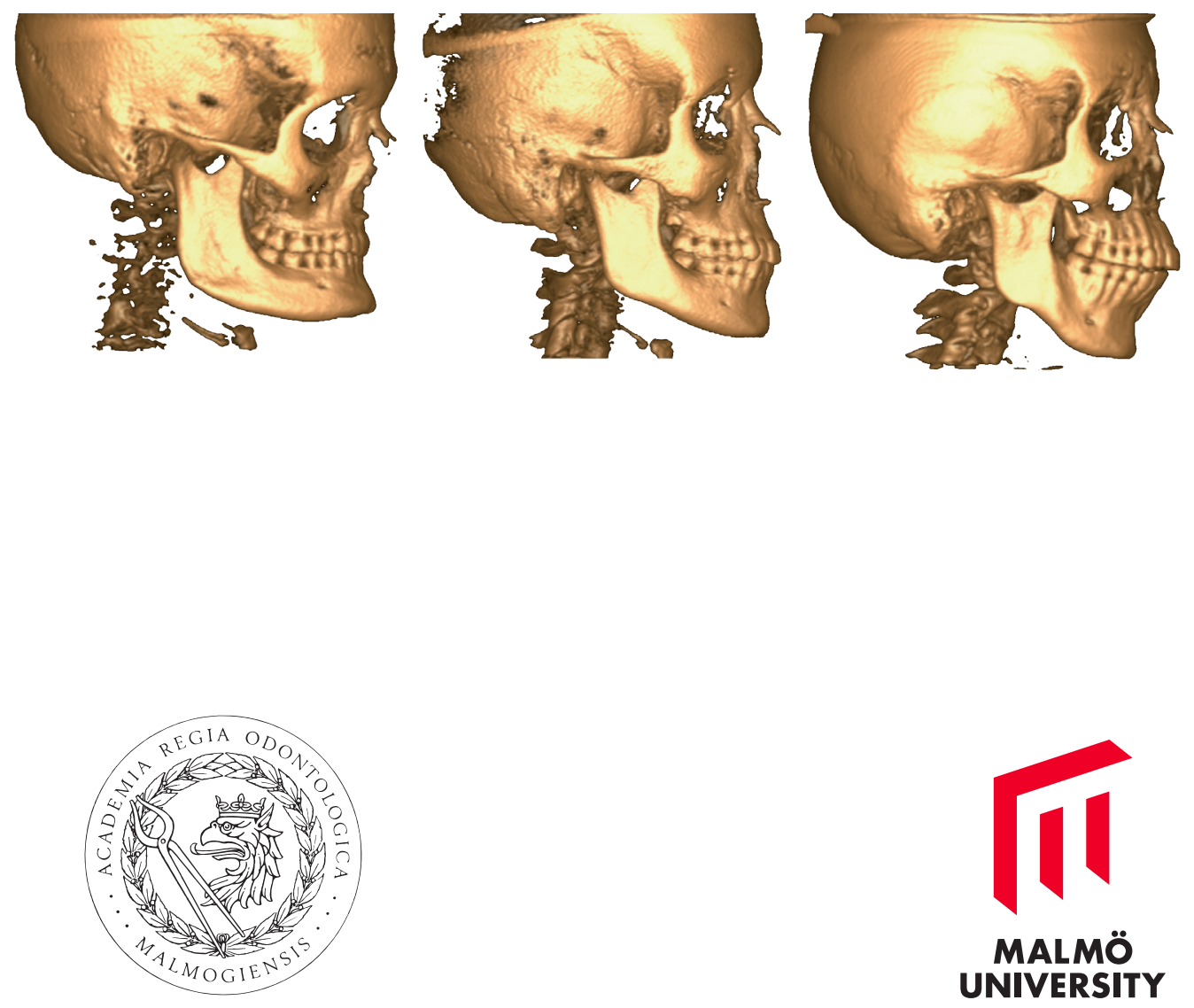

CRANIOFACIAL HEIGHT IN RELATION TO ALVEOLAR BONE MORPHOLOGY 
Malmö University

Faculty of Odontology Doctoral Dissertation 2020

(C) Copyright Anna Klinge 2020

Foto/illustration: Carina Chi

ISBN 978-9I-7877-I49-3 (print)

ISBN 978-9I-7877-I 50-9 (pdf)

DOI I0.24834/isbn.9789I 7877 I 509

Holmbergs, Malmö 2020 


\section{ANNA KLINGE \\ CRANIOFACIAL HEIGHT IN \\ RELATION TO ALVEOLAR \\ BONE MORPHOLOGY}

Malmö University, 2020

Faculty of Odontology Department of Oral and Maxillofacial Surgery and Oral Medicine 
Publication also available online,

www.mau.se/muep or muep.mau.se 
This work is dedicated to the light and vision: To the light-my family: Ellie, my daughter, and Dennis, my love, Björn, my father and inspiration in many aspects of life, my mother Kerstin and brother Magnus whose love, encouragement, and patience made this work a goal to be reached. To the vision-Dr. Jonas Becktor and Dr. Karin Binner Becktor whose clinical experience and interdisciplinary knowledge instigated this project. 



\section{CONTENTS}

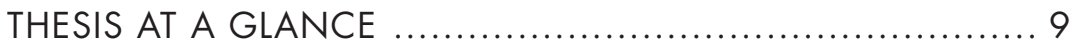

ABSTRACT [................................................ 10

POPULÄRVETENSKAPLIG SAMMANFATTNING .............. 13

LIST OF PAPERS .............................................. 16

Contribution by the respondent …..................................... 17

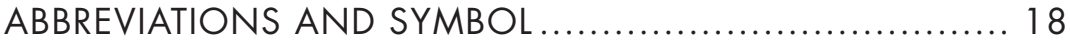

DEFINITIONS ................................................. 19

INTRODUCTION .............................................. 20

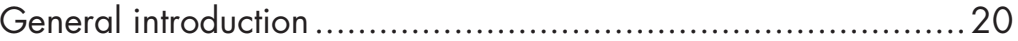

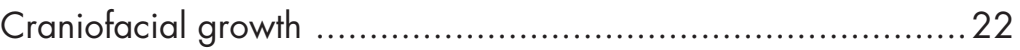

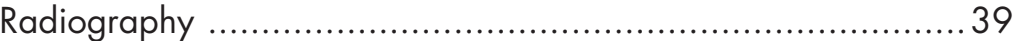

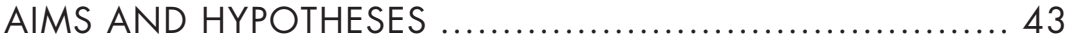

SUBJECTS AND METHODS .................................. 45

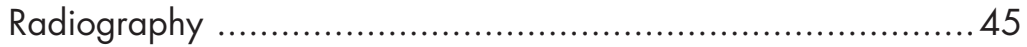

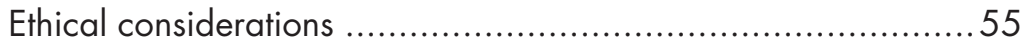

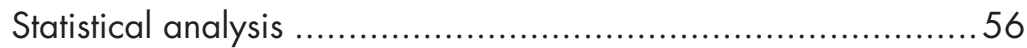

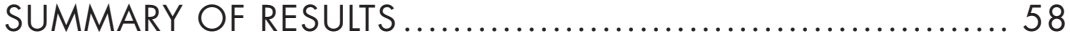

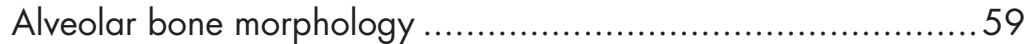

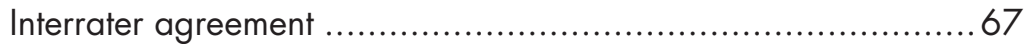

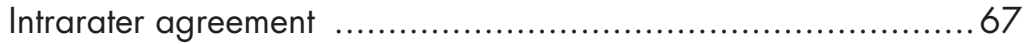

DISCUSSION............................................... 81 
CONCLUSIONS AND FUTURE RESEARCH ..................100 ACKNOWLEDGEMENTS ..................................... 102

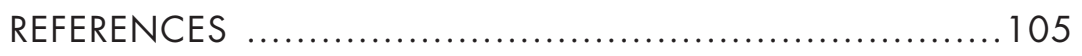

PAPERS I-IV .................................................. 117 


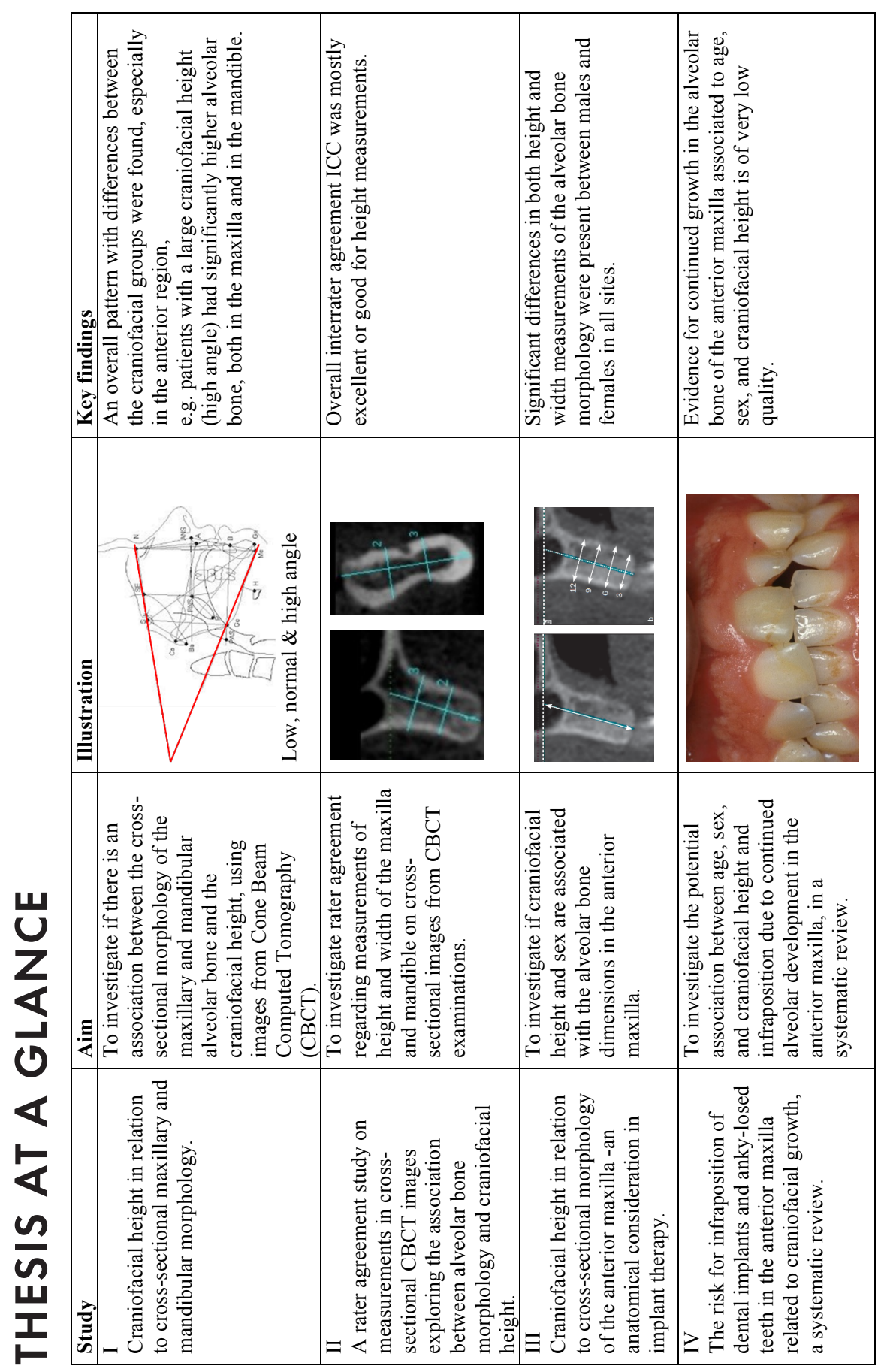




\section{ABSTRACT}

There is a constant development towards a more aesthetically oriented dentistry. New techniques and new materials are introduced to improve and optimise treatment results and shorten treatment time. This development can be favourable for both the dentist and the patient. If missing one or more teeth due to congenital reason or an incident (dental trauma), it is often challenging to already at an early stage choose the best and most optimal treatment for the particular clinical situation and individual. This thesis presents an overview of the basic biological factor of importance for a succesful treatment outcome: the relation between craniofacial height and alveolar bone height and width (morphology). The idea is to not just focus on the area of the missing tooth, but to incorporate other important factors, such as craniofacial height, sex, and age, in a broader context.

The overall aim of this thesis is to investigate the relation between craniofacial height and alveolar bone morphology (height and width of the maxilla and mandible) as a support and tool in therapy planning of individuals in need of tooth replacement through orthodontic treatment and/or dental implant treatment.

Paper I reports results of an investigation regarding the relation between the craniofacial height and height and width of the maxilla and mandible. The craniofacial height of the patients is divided into three groups: low, normal, and high angle. A radiographic profile image was used to establish the craniofacial height. Two separate lines are traced between anatomical structures on the radiographic 
image. The angle formed between these two lines is used for the classification of craniofacial height (low $<27^{\circ}$, normal $27-37^{\circ}$, high $\left.>37^{\circ}\right)$.

The alveolar bone is measured in millimeter with a digital caliper on radiographs obtained in three planes. The measurements of the jaws are performed both in the maxilla and in the mandible, between the teeth in the front (midline), between the premolars, and between the molars, on the right and left side respectively. An association between the craniofacial height and the height and width of the alveolar bone (morphology) was found. The greatest differences between the three craniofacial groups were seen in the anterior region, both in the maxilla and in the mandible. This means that an individual from the high-angle group displays a higher alveolar bone which also is more narrow in the anterior region, especially in the mandible. The opposite pattern is displayed in the low-angle group where the subjects present a low and wide alveolar bone.

In paper II, the measurement technique for the maxilla and mandible was evaluated. Five raters with different experiences within the field of dentistry repeats the same measurements, independent of each other. The results show strong reliability of the measurement technique.

In paper III, new measurements of the alveolar bone were presented, however this time focus was on the anterior part of the maxilla, which is a more aesthetically challenging area. The results from this study strengthen the association previously reported between the craniofacial height and height and width of the maxilla measured on cross-sectional images.

Paper IV is a systematic review of the scientific literature, evaluating risk factors for a maxillary anterior tooth to end up in infraposition over time and to not follow the growth pattern of the adjacent teeth. Infraposition occurs when a tooth or dental implant does not continue to erupt and follow the anticipated growth pattern of the individual. This results in a growth cessation of the topical area and a dental implant still remain in the same place as immediately following treatment, whereas the surrounding teeth continue to erupt 
as the jaw grows. Dental infraposition can be a disadvantage from both an aesthetic and a functional perspective. An individual with a high angle (high craniofacial height), who presents with a thinner and longer alveolar bone, especially in the anterior part of the jaw, seems to be at a greater risk of developing infraposition of a traumatised tooth or a dental implant since growth seems to continue for longer (both as measured in $\mathrm{mm}$ and in years) compared to individuals with a low craniofacial height. The different risk factors investigated were age, sex, and craniofacial height. According to the findings in our systematic review, there is a lack of new scientific papers of high quality and the topic needs to be explored further in order for any conclusions to be drawn.

In conclusion, the results of the present thesis show that craniofacial height should be considered in therapy planning in order to achieve the best long-term treatment results for the patients. This seems to be especially relevant in young individuals where continued growth is expected. 


\section{POPULÄRVETENSKAPLIG SAMMANFATTNING}

Det pågår en ständig utveckling mot en mer estetisk tandvård. Nya tekniker och nya material introduceras för att optimera behandlingsresultatet och vinna tid, vilket kan vara en fördel för både behandlare och patient. Om en eller flera tänder saknas på grund av medfödd orsak eller olycksfall är det ofta en utmaning att i ett tidigt stadie välja bästa behandlingsalternativ för just den individen. Med denna avhandling ges en överblick över grundläggande biologiska faktorer som är av betydelse för framgångsrik behandling: relationen mellan ansiktetshöjden (kraniofacial höjd) och käkbenets höjd och bredd (alveolarutskottets morfologi). Avsikten är att inte bara se luckan där tanden saknas och tekniska möjligheter, utan lyfta blicken och se ett större sammanhang.

Övergripande mål med denna avhandling är att undersöka relationen mellan individens ansiktshöjd och käkbenets höjd och bredd som underlag för behandlingsplanering av individer i behov av exempelvis tandreglering och/eller tandimplantat (som består av en titan eller keramisk skruv inopererad och fastläkt i käkbenet för att ersätta en tandrot och fästa en konstgjord tandkrona på implantatskruven).

I delarbete I undersöks och kartläggs sambandet mellan ansiktshöjd och käkbenets höjd och bredd. Ansiktshöjden delas in i tre olika grupper: låg, normal och hög. En profilröntgenbild används för att fastställa ansiktshöjden. Två separata linjer dras mellan olika 
anatomiska strukturer på röntgenbilden. Det gradtal på vinkeln som formas mellan dessa två linjer ligger till grund för klassificeringen (låg $<27^{\circ}$, normal $27-37^{\circ}$, hög $>37^{\circ}$ ).

Käkbenet mäts i millimeter med digital linjal på röntgenbilder i tre mot varandra vinkelräta plan. Mätningen av käkbenet görs separat i över- och underkäken, mellan tänderna längst fram i mitten, mellan tänderna längst bak i munnen och vid ett ställe mellan dessa två mätområden (på höger och vänster sida). Vi ser ett samband mellan ansiktshöjden och käkbenets höjd och bredd. De största skillnaderna mellan de tre grupperna uppmäts mellan framtänderna i både överoch underkäken. Där ser man att en individ med hög ansiktshöjd också har ett långt/högt, men smalt käkben jämfört med någon med låg ansiktshöjd. Där ser man istället ett lågt/kort och även bredare käkben.

I delarbete II utvärderas mätmetoden av käkbenet. Fem tandläkare med olika lång erfarenhet inom yrket gör om alla mätningarna, helt oberoende av varandra. Hög överrensstämmelse uppmäts inom och mellan observatörerna vid upprepning av mätningarna. Detta visar att det är god tillförlitlighet i mätmetoden.

I delarbete III presenteras nya mätningar av käkbenet, med fokus längst fram i överkäken, vilket är ett område som anses vara extra krävande estetiskt vid behandling av tandförluster. Resultaten från denna studie stärker sambandet mellan ansiktshöjd och käkbenets höjd och bredd.

Delarbete IV är en systematisk litteraturöversikt med syfte att inventera och undersöka dagens vetenskapliga kunskapsläge gällande olika riskfaktorer för att en framtand inte ska följa med i käkbenets utveckling över tid. Det kallas på fackspråk att tanden hamnar i "infraposition”. Infraposition är alltså när en tand eller implantat inte följer med i individens tillväxt utan blir kvar på samma ställe som den placerades vid behandlingen, medan övriga tänder fortsätter att följa med i tillväxten av käkbenet. Infraposition kan vara besvärande både estetiskt, men också funktionellt. 
En individ med hög ansiktshöjd, verkar ha högre och smalare käkben särskilt i framtandsområdet, och troligtvis ha en ökad risk för infraposition då käkbenet fortsätter att växa, både i millimeter, men troligen även högre upp i åldern. De olika riskfaktorerna vi undersökte var ålder, kön och ansiktshöjd. Vår genomgång visar att det behövs nya studier med högre kvalité inom ämnet för att det ska vara möjligt att kunna dra några säkra slutsatser.

Sammanfattningsvis visar resultaten $\mathrm{i}$ avhandlingen att ansiktshöjden bör beaktas vid behandlingsplanering för att uppnå bästa resultat för patienten. Detta gäller i synnerhet för unga individer med återstående tillväxt. 


\section{LIST OF PAPERS}

This thesis is based on the following articles. The articles are referred to by their Roman numbers and appended at the end of the thesis.

I. Klinge A, Becktor K, Lindh C, Becktor JP. Craniofacial height in relation to cross-sectional maxillary and mandibular morphology. Prog Orthod. 2017 Oct 23;18(1):32. doi: 10.1186/s40510-017-0187-8. PMID: 29058096

II. Klinge A, Al-Okshi A, Becktor JP, Lindh C. A rater agreement study on measurements in cross-sectional CBCT images exploring the association between alveolar bone morphology and craniofacial height. Submitted.

III. Klinge A, Ahmad M, Eldh P, Ulvan R, Andersson L, Becktor JP. Craniofacial height in relation to crosssectional morphology of the anterior maxilla - an anatomical consideration in implant therapy. Int J Oral Maxillofac Implants. 2020 Mar/Apr;35(2):386-394. doi:10.11607/jomi.7776. PMID: 32142576

IV. Klinge A, Tranæus S, Becktor JP, Winitsky N, Naimi-Akbar A. The risk for infraposition of dental implants and ankylosed teeth in the anterior maxilla related to craniofacial growth, a systematic review. Acta Odont Scand. 2020 Aug 24;1-10. doi: 10.1080/00016357.2020.1807046. PMID: 32835562. 


\section{Contribution by the respondent}

The respondent performed most of the work, from going through the CBCT image database, excluding a vast majority to prepare the final included sample, to being responsible for planning and arranging the measurement sessions, produce spreadsheets for data/measurement management. Assisting during all measurement sessions, compilation of all the data. Main author of the ethical application. The respondent was also the main contributor to writing the manuscripts. 


\section{ABBREVIATIONS AND SYMBOL}

$2 \mathrm{D}$

$3 \mathrm{D}$

ANS

BMD

BMU

CBCT

DACM

FOV

GBD

GBR

Go

$\mathrm{Me}$

ML

$\mathrm{N}$

NL

NSL

PDL

PNS

$\mathrm{S}$

SOS

SR

TADs

TDI

$\bar{x}$
Two dimensional

Three dimensional

Anterior Nasal Spine

Bone Mineral Density

Basic Multicellular Unit of bone remodelling

Cone Beam Computed Tomography

Dentoalveolar Compensatory Mechanism

Field Of View

Global Burden of Disease

Guided Bone Regeneration

Gonion

Menton

Mandibular Line

Nasion

Nasal Line

Nasion Sella Line

Periodontal Ligament

Posterior Nasal Spine

Sella

Spheno-Occipital Synchondrosis

Systematic Review

Temporary Anchorage Devices

Traumatic Dental Injury

Mean 


\section{DEFINITIONS}

Adolescent

Alveolar bone

Alveolar bone morphology

Basal bone

Craniofacial height

Mandibular line

Nasal line

Nasion-Sella line

Normal
A person between 13 and 18 years of age (MeSH)

Refers to the part of the jaw which houses the teeth, (in this thesis) also including the basal bone. The extent in the maxilla is from the top of the alveolar crest to the nasal floor (NL)

Form and structure of the alveolar bone in the maxilla and mandible (height and width) The osseous foundation tissue of the maxilla and mandible (except the alveolar bone)

Defined by the angle formed between the nasion sella line and the mandibular line

A reference line for the lower boarder of the mandible

A reference line from the anterior- to the posterior nasal spine visualising/highlighting the nasal floor in the sagittal direction

A reference line from nasion to the middle part of sella

The craniofacial height "normal" $27-37^{\circ} \mathrm{can}$ preferably be thought of as average 


\section{INTRODUCTION}

\section{General introduction}

The craniofacial complex can be divided into four different components: The cranial base, the maxilla, the mandible and the alveolar bone (Figure 1).

As with all tissues and organs in the body, when it comes to formation of the tissues of the cranium and face, embryotic development and formation takes place around the three primary germinal layers; ectoderm, mesoderm, and endoderm. The cells in the mesodermal layer will develop into skeleton, muscles, and blood cells. Bone and cartilage develop from the mesoderm. Dentin, pulp, cementum, periodontal ligaments (PDL) and alveolar bone have ectomesenchymal origins, whereas the tooth enamel originates from the ectoderm (1). The events required to organise the tissue of the human face occur from the fourth to the seventh prenatal week.

The face starts to develop around day 24-28 of pregnancy. Tooth formation in the region of the future upper and lower jaws also begins at this early stage. The cells of the neural crest are responsible for the initiation of the process by which different genes regulate the migration of ecto-mesenchymal cells (2). Membranous bone, with no cartilage precursor, develops directly from mesenchyme, and forms the facial bones and cranial vault, while the cranial base undergoes an endochondral ossification (3).

The face of an infant is relatively round and wide because the lateral craniofacial growth occurs earlier than the vertical growth (3). 
During the postnatal growth period, growth in the Spheno-Occipital Synchondrosis (SOS) cartilage (Figure 1) and the cartilage of the condyle occur. Both of these growth processes have a considerable influence on craniofacial development. Also, adaptive growth of the maxillary sutures and dentoalveolar bone development will contribute to an increase in facial dimensions (4).

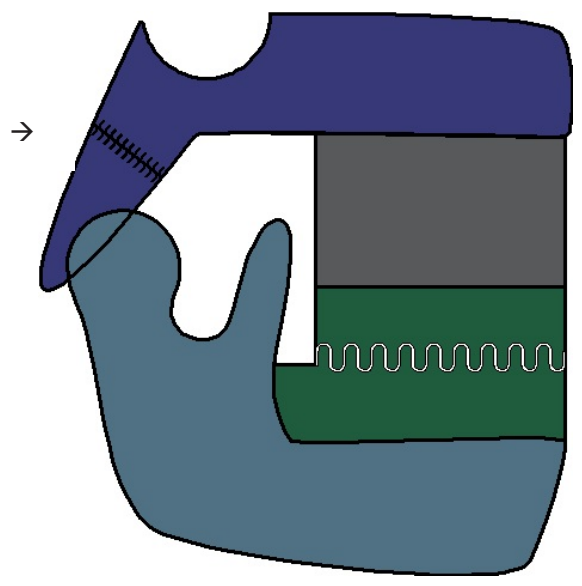

Figure 1. Schematic drawing of the craniofacial complex Blue: the cranial base, grey: the maxilla, light blue: the mandible, green: the dentoalveolar bone and $\rightarrow$ : Spheno-occipital synchondrosis

Most synchondroses ossifies already in the late fetus stage or during the first year of life. However, the growth in the SOS cartilage continues well into adult life (5).

Biologic factors which could have an impact on craniofacial morphology are nutrition (6), growth hormones (7), height, (8, 9) and skeletal maturation (10-12). Even so, the epigenetic and environmental components of craniofacial development are to a large extent still unknown and are the object of intense discussion.

During childhood a significant part of the development of the craniofacial complex takes place, including development of the maxilla and mandible as well as tooth eruption (5). 


\section{Craniofacial growth}

\section{Cranial base}

The flexure of the cranial base is determined by connecting the following anatomical landmarks by a line: Nasion, sella turcica, and basion (Figure 2).

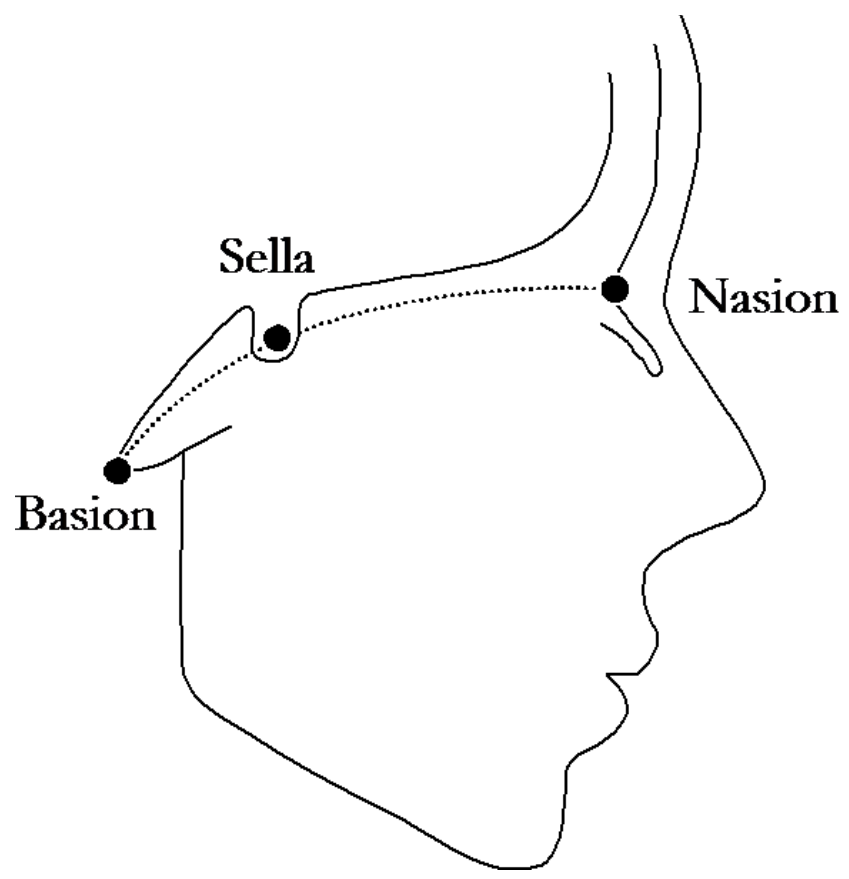

Figure 2. Cranial base: Nasion, Sella, Basion

Development of the neurocranium involves growth of the cranial vault and cranial base which is related to the growth of the brain. The cranial vault grows intensively during the first decade of life, reaching $95 \%$ of its adult size during that period. Predominantly, the growth occurs in the sutural area, which to a large extent decreases and ossifies towards the end of the second decade of life. Growth of the cranial base occur by expansion by sutural growth, and by surface modelling and endochondral growth of the synchondrosis. The SOS is a temporary growth centre that enables a separating 
mechanism and a displacement of the facial bones as it grows. The greatest change in the cranial base occurs during the first two postnatal years, although the SOS shows continued activity until the age of approximately 13 , but not as extensive and in a more stable manner (13). The growth process of the craniofacial complex occurs in a three-dimensional direction including a vertical (height), sagittal (length), and transversal (width) aspect (13). The postnatal growth of the craniofacial skeleton is a complex physiological process including basic growth mechanisms, such as increase in size, bone remodelling, and displacement. Each bone has its own individual growth pattern, which can differ in onset, offset, timing, and velocity.

Bone surface modelling is a mechanism of deposition and resorption which resulting in the change of shape and size of the bones. Displacement is the movement of bones away from each other resulting from enlargement in size and can be due to forces of a primary or secondary nature, also referred to as active and passive displacement. Primary displacement is caused by enlargement and growth of the bone itself, while secondary displacement is due to enlargement and growth of the other bones in the area, which then leads to changes in the location of the neighbouring bones $(14,15)$.

During embryo and fetal development, bone formation can occur in three different ways. The different mechanisms are endochondral growth, where the cartilage is replaced by bone, intra-membranous growth, where bone formation occur in the mesenchyme, and, finally, sutural growth. The base of the skull and the articular region of the mandible develop from endochondral bone formation. In intramembranous bone formation, the bone forms directly in the soft connective tissue such as in the maxilla and mandibular body during fetal development. Sutural bone growth play an important role in the growth and development of the skull and face. The sutures are the fibrous joints between the bones and the growth mechanism is based on the knowledge of the periosteum of the bone as a two-layer structure (3). 
Bone growth and development during childhood and onward can according to Björk (5) be divided into four mechanisms and named depending on location, e.g. periosteal, endosteal, sutural, and periodontal. Periosteal bone growth cessation occur at around 20-25 years. The endosteal growth is located in the trabecles of the bone, resulting in a gain in bone density. The sutural bone growth, as previously mentioned. The sutures of the face are named according to the adjacent bones. The periodontal growth, described as a form of appositional growth, takes place at the PDL. The new formation of bone in the site of the alveolus wall are one of the factors contributing to tooth eruption. These are all growth sites contributing to development of the facial form (5).

\section{Maxilla}

Arne Björk (16) inserted mini implants into the maxilla in growing individuals, and by subsequently making lateral radiographs at several occasions it was possible to superimpose the images and study maxillary growth and development.

The maxilla and mandible are both formed from tissues of the first branchial arch. The pre-maxilla, maxilla, and palatine bones form the upper jaw. The first two fuse at an early stage. Growth of the upper jaw occurs mainly through two mechanisms: the surface modelling and the sutural growth. Surface modelling play a major role in the overall increase in size. The midface accommodates the circummaxillary- and intermaxillary sutures. These sutures are important sites of growth and grow mainly as a consequence of the mid-facial displacement. Growth of the maxilla occurs as a result of both enlargement and passive displacement $(5,17)$. Maxillary enlargement occurs in a three-dimensional manner; in vertical, sagittal, and transversal dimensions. Passive displacement occurs as the maxilla is displaced downward and forward by growth and flexure of the cranial base and a complex system of sutures in the midface $(5,17)$.

The maxilla contains both vertical and horizontal sutures which contribute to the forward and downward growth. There is also a mid-line suture contributing to the transverse growth (Figure 3). 


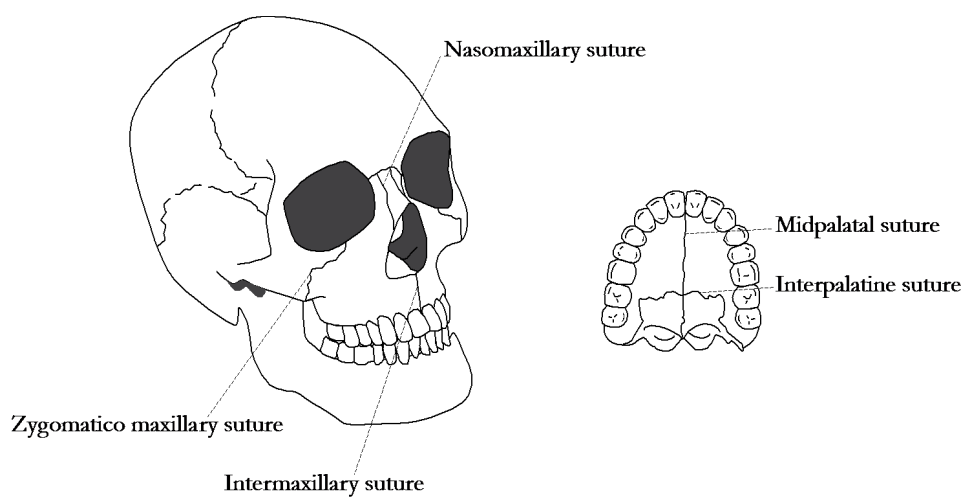

Figure 3. Sutures of the maxilla

Vertical enlargement: The maxillary height increase occurs by sutural growth and growth of the alveolar bone associated with tooth eruption. In connection with the vertical development a remodulation of the hard palate takes place, including apposition on the lower aspect of the hard palate and alveolar bone, and the upper surface of the hard palate is resorbed. An enlargement of the nasal cavity is thus enabled, which would not be possible by a lowering of the maxilla alone. Studies using mini implants have indicated that this re-location increased when sutural lowering was reduced (17).

Sagittal enlargement: From early infancy, growth in the sagittal direction unfolds from the posterior part of the maxilla. Growth in length is known to occur in the sutures towards the frontal bone of the maxilla; the zygomatic- and the palatine bone. There is an increase of about $1 \mathrm{~mm}$ per year, in sagittal dimension due to sutural growth, during the juvenile period and about $2 \mathrm{~mm}$ during the peak of puberty (5). There is also an sagittal enlargement by periosteal apposition at the maxillary tuberosity. In a study by Björk et al. no cases showed growth in length by periosteal apposition on the anterior surface of the maxilla, except from the alveolar bone (5, $16)$. 
Transversal enlargement: The most important factor for enlargement in the transversal dimension of the maxilla is growth in the midpalatal suture. The posterior part enlarges three and a half times more than the anterior part of the palate. Growth of the maxilla will take place until sutural fusion occur (17). The transversal enlargement by growth in the median palatine suture proceed until about 17 years of age in boys and about 15-16 years of age in girls.

During the infantile period ( $0-2$ years), the growth rate increases steeply to a point where there is a sudden change to a much slower phase; this phase continues during the juvenile period towards a minimum at the pre-pubertal stage. During the adolescence period the growth rate increases towards a pubertal maximum and thereafter it decreases until adulthood when there is a growth cessation.

The timing of the pubertal growth spurt in general height/stature of adolescents differed between girls and boys. For girls, average age at the beginning of the spurt were 9.0-10.4 years, 11.7-12.2 years at peak height velocity and 12.9-14.8 at end of the spurt. The corresponding age in boys were 10.7-12.8 at beginning of the spurt, 13.9-14.1 years at peak height velocity and 15.4-17.1 years at end of the spurt. To summarise, all the events occurred later in boys, with a difference of 1.6-2.2 years between the sexes (18).

Björk compared growth intensity variation between growth in stature, mandibular condyles, and sutures. The age at pubertal growth peak coincided between sutural and condylar growth and occurred at around 14 years of age. Pubertal growth peak in stature occurred a couple of months earlier. Age at growth cessation coincided between height in stature and mandibular condyles, at just before 19 years of age. The sutural growth cessation occurred earlier, at about 17 years of age (for boys).

\section{Mandible}

During the first year of life the mandible consists of two bones, they then fuse in the midline and are thereafter regarded as one bone (1). 
Arne Björk also inserted mini implants into the mandible, and due to the subsequent lateral radiographs it was possible to superimpose the images and study mandibular growth and development (19). The major growth site of the mandible is the condyles, as confirmed by the tantalum mini implant method in humans (16). Surface modelling of the mandible maintains and modifies the shape until adulthood. From a growth and developmental perspective, the mandible consists of basal bone, (corpus, ramus, and symphysis) and the alveolar bone. There are also several processes present: coronoid, condylar and gonial angle (5) (Figure 4).

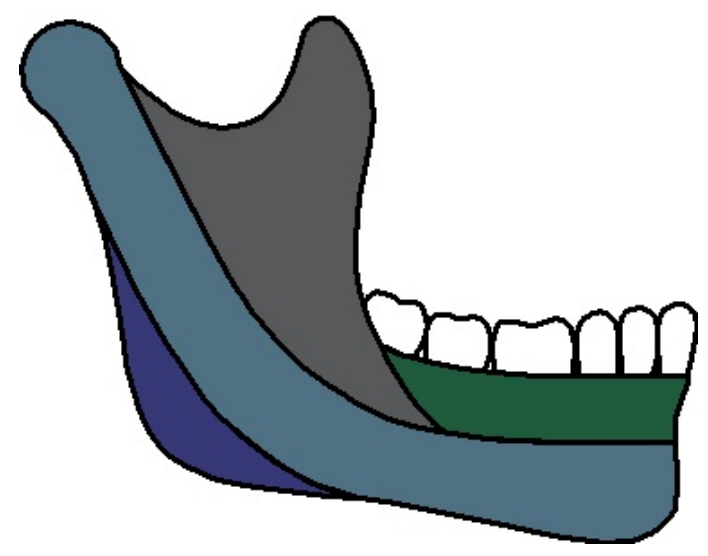

Figure 4. Schematic drawing of the processes of the mandible Grey: coronoid, light blue: condylar, blue: gonial angle and green: alveolar bone (5).

Condylar growth will be accompanied by a displacement of the mandible relative to the articular fossae, in the opposite direction, but of the same magnitude (5). As described by Björk, the yearly condylar growth increase was on average $3 \mathrm{~mm}$ during the juvenile period, and on average $5 \mathrm{~mm}$ per year at maximum pubertal growth in boys. However, it was emphasised that development of the mandible encompasses the largest individual variation of the entire facial skeleton (5). In a study by Björk and Skieller it was shown that the mandible rotated, in average, six degrees in a forward direction 
during the six years of puberty, in orthodontically untreated subjects (Range: $16^{\circ}$ forward to five degrees backward (20).

The rotations give rise to different craniofacial types and posteruptive tooth movement patterns (Figure 5) (20,21).

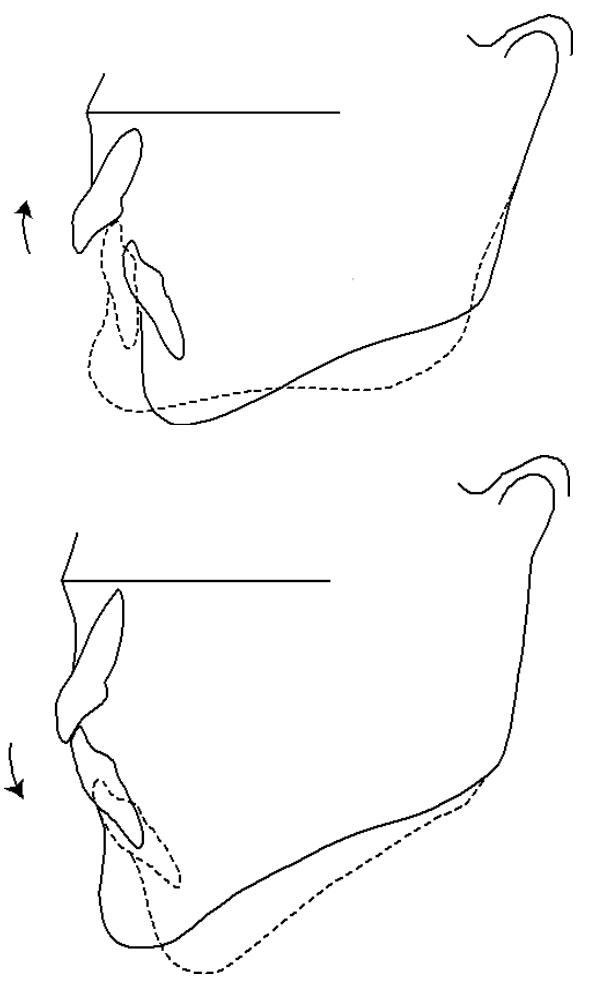

Figure $5 a$ and $b$. Anterior (a) vs. posterior (b) rotation of the mandible.

Solid outer line of the mandible: before rotation

Broken lines: after rotation

Post-eruptive compensation of the incisors in the mandible at backward rotation (22) (Figure 6). 


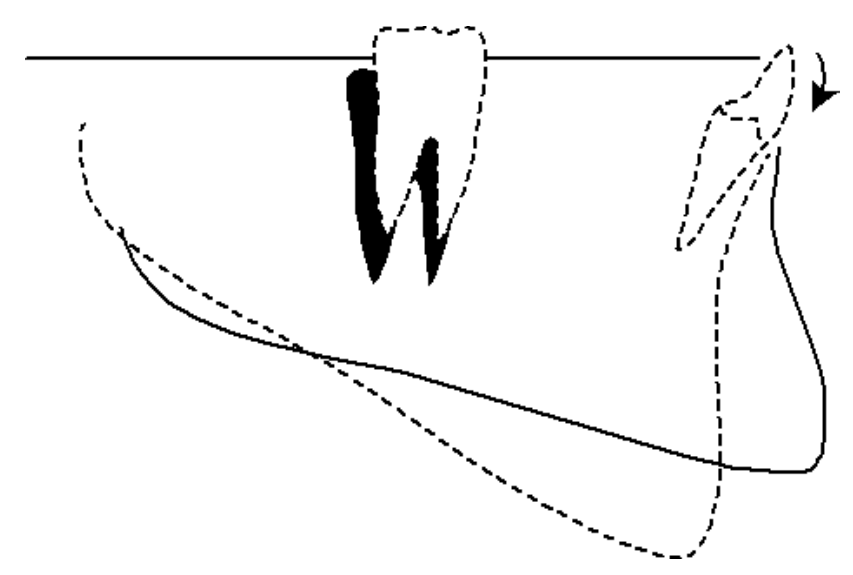

Figure 6. Posterior rotation of the mandible.

Solid outer line of the mandible: before rotation

Black shadow at molar region: before rotation

Broken lines: after rotation

\section{The alveolar bone}

The formation of the alveolar bone begins early in fetal life, around the tooth germs. The growth of the dentoalveolar bone is associated with tooth eruption, and is therefore dependent on a normal eruption process (23). The more the teeth are erupting, the larger the alveolar bone will be (24). The existence of alveolar bone is entirely dependent on the presence of teeth (3). Thus, there seems to be a somewhat mutual relation between the alveolar bone and the teeth, in which both are dependent on one another. In the vertical plane, a positive relationship between craniofacial height and height of the alveolar bone in both the maxilla and mandible was demonstrated in an adult sample by Beni Solow (25). This means that in subjects with a high craniofacial dimension, the alveolar bone will be longer in the incisor region, and comparatively shorter in the molar region, which generates a downward inclined occlusal plane. On the contrary, subjects with a low craniofacial height display a shorter alveolar bone in the incisor region, with a similar height towards the molar region, generating a more parallel occlusal plane (20).

Similar to other skeletal bones, the alveolar bone consists of an outer layer of cortical (compact) bone and an inner layer of trabecular bone. This architectural construction offer a combination of rigidity 
and low weight. The size and morphology are in part genetically determined and in part the result of functional loading. The outer part of the bone surface is covered by the periosteum (24).

There is also compact bone at the outer layer of the tooth socket. It looks like two types viewed microscopically; a compact bone and also a part perforated by periodontal ligament fibres (PDL). The perforating bundles of collagen fibres are knows as Sharpey's fibres. Due to the bundles of collagen fibres in this area this can also be called bundle bone, also synonymous with lamina dura which is observed as a thin radiopaque layer of dense bone around sound teeth (3).

The development of the alveolar bone takes place in three dimensions in the maxilla and mandible. Vertical growth of the alveolar bone is depended on the height development of the face and in accordance with the mandibular rotation (Figure 6). Normally the teeth adapt to the overall changes induced by growth and rotation by compensation in eruption and inclination (26).
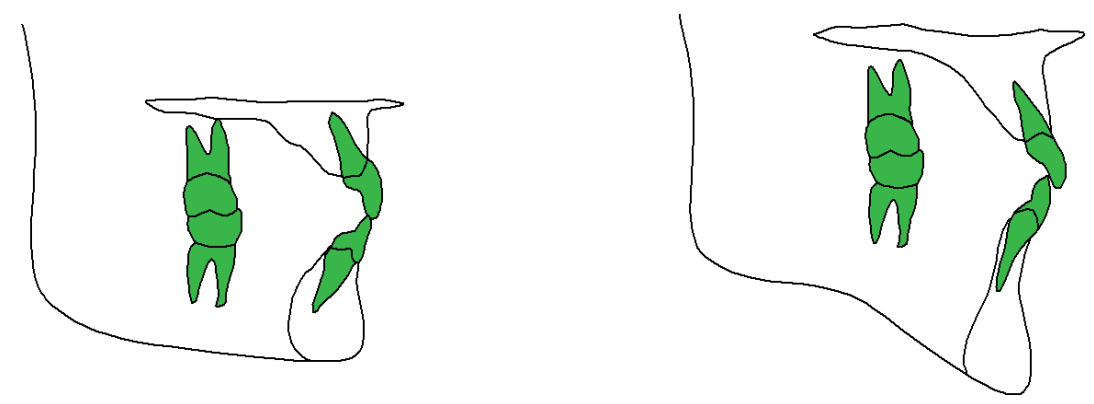

Figure 7. DACM

Low angle, short anterior alveolar bone height High angle, long anterior alveolar bone height

Growth in sagittal dimension will take place through forward directed tooth eruption and by maturation of the molar tooth germs. The sagittal growth also evolves in connection with apposition at 
the maxillary tuberosity and resorptions on the anterior surface of the mandibular ramus (25). Transverse growth takes place through buccal periosteal apposition and surface resorption on the lingual side (25).

The alveolar bone of the jaw are intriguing since, multiple interventions can be applied e.g. teeth can be moved, extracted, transplanted and replaced by implants with favourable results. The continued turnover of the alveolar bone allows a response to manipulation (3).

\section{Tooth eruption and root development}

All human teeth, primary and permanent dentition, develops through successive stages known as the bud, cap, and bell stage. During the bud stage differentiation of the cells forming the hard tissue of the teeth takes place and sets the stage for enamel and dentin formation. During the crown formation and development of teeth a pre-eruptive movement begins (27). After crown formation and mineralisation, the root development starts, with subsequent development of the supporting tissue of the teeth, namely the cementum, PDL, and alveolar bone. Thereafter the crown starts to erupt into the oral cavity (3). The teeth are surrounded by mesenchymal cells known as the dental follicle.

\section{Dental follicle}

Before emersion of the teeth into the oral cavity, the intraosseous stage of eruption occurs. The dental follicle overlying the teeth changes during the last stage of eruption and forms a pathway for the tooth emerging. Macrophages (large white specialised blood cells) appear in the tissue of the eruption pathway leading to a release of enzymes aiding in the destruction of cells and fibres that hinder tooth eruption. Osteoclasts (cells that break down bone tissue) responsible for bone resorption, are found in the bone area overlying the teeth. Osteoblasts (bone forming cells) work constantly in orchestra with osteoclasts to enable the new space needed at movement and tooth development (28). In a dog experiment that involved removal of the dental follicle, eruption of the tooth was prevented and there was a lack of signs of enlargement of the eruptive pathway, or root elongation (radiographically or histologically). This was evaluated 
at a follow-up time when the contralateral, (un-operated) tooth erupted. According to these data, the intraosseous tooth eruption does not take place in the absence of the dental follicle (29).

\section{Periodontal ligament (PDL)}

The PDL, the alveolar bone and the cementum develop from cells from the dental follicle surrounding the tooth (1). The PDL comprises collagen fibres attaching the cementum and the alveolar bone. The minimal periodontal space is between $0.06-0.025 \mathrm{~mm}$, with a average measure of $0.12 \mathrm{~mm}(30)$. Interstitial spaces contain nerve bundles and blood vessels. The PDLs function is to support the teeth and also transmit neural input at/during masticatory function. Another very important role of the PDL is to function as a suture, forming intramembranous bone during continued tooth eruption (5). In addition epithelial cells in the PDL have an important role in keeping the alveolar bone at a distance from the tooth (31).

\section{Dentoalveolar compensatory mechanism (DACM)}

As a result of the mid-facial and mandibular growth and rotation, there is a post-eruptive movement of the teeth which will occur to compensate for the rotations and to attain and preserve an occlusal stability (20) (Figure 6 and 7). This phenomenon is referred to as the dentoalveolar compensatory mechanism (DACM) (25). Interjaw and inter-dental space, created by craniofacial growth and displacement is the main reason for this mechanism and depends on the dental balance and the strive to achieve equilibrium in relation to the neighbouring teeth (13). Forces caused by lip, tongue, and cheek muscles also influence the movements of the teeth (32).

The DACM acts as the link between the growth of the cranial base, the maxilla and the mandible and the alveolar bone (25). The mechanism is meant to adapt and maintain a sufficient occlusion of the teeth.

Growth of the alveolar bone takes place in connection with tooth eruption, and is therefore dependent on a normal eruption process (23). Significant adaptation in the magnitude and direction of tooth eruption can occur especially in the vertical, but also the transverse and sagittal development of the face (5). There is a noticeable 
variation in the rate of tooth eruption, with an increase in eruption velocity at the time of the puberty peak in body height growth (33). Presuming that continued eruption is a compensatory mechanism for craniofacial growth, the tooth eruption ought to follow the general pattern of craniofacial growth (23). A structure that most likely play an important role for the continued eruption is the PDL which functions as a suture forming intramembranous bone as the teeth erupt (5). The PDL has also been described as a suture with only one periosteal layer (5).

Growth of the alveolar bone can be influenced by soft tissue, function (e.g sucking and swallowing habits) and orthodontic treatment (23). For example, orthodontic treatment can be used in an attempt to prevent DACM by maintaining the teeth in a more optimal position in relation to the jaw base in young individuals with extreme growth where a need for orthognatic surgery appears early on. Early transverse expansion in the midpalatal suture of the maxilla can also be used in order to prevent the DACM and thus buccal inclination of the teeth (34). The amount of eruption, especially in the incisor region, seems to differ depending on craniofacial height. Therefore, knowledge of the expected growth pattern of the alveolar bone is important in relation to orthodontic treatment of growing individuals and dental implant treatment after growth cessation.

The main movement of the teeth occur during eruption. However, the post-eruptive compensatory movements will continue even though occlusion is reached (13), e.g. as a response to mandibular rotation and toothwear. Change is the only constant throughout aging, development is present through all stages of life although it differs in the relative amount and activity (35).

\section{Bone remodelling}

Bone is a living tissue, which responds continuously to mechanical stress, nutritional status, hormones, and concentrations of circulating calcium.

Bone modelling dominates in growing individuals and bone remodelling is dominant in adults. Bone modelling is the process by 
which bones are shaped or reshaped. In growing individuals, bone formation exceeds bone resorption. In bone modelling, osteoclasts and osteoblasts work independently, whereas they are coupled in bone remodelling (e.g. resorption is followed by bone formation).

In remodelling, the shape of the bone is not changed, but damaged or old bone is detected by osteocytes, removed by osteoclasts, and thereafter an equal amount of new bone is formed by osteoblasts at the resorption site. In adults, the resorption and formation of bone is balanced, whereas bone resorption exceeds bone formation after menopause and in old age. The active bone resorption period in adults is approximately 29 days, and the bone formation period 134 days (36). In the first year of life, almost $100 \%$ of the skeleton is replaced, whereas in adults, the skeleton is renewed by remodelling every 10 years.

In a study by Pietrokovski (37) it was shown that the amount of resorption of the alveolar bone width after single tooth loss was greater along the buccal surface than along the lingual/palatal surface in all subjects. However, the individual variation was extensive and the absolute amount lost varied widely. The measurement range in the maxilla was between $2.58-5.25 \mathrm{~mm}$ on the buccal surface and $0.86-3.12 \mathrm{~mm}$ in the palatal surface (depending on tooth position), mean value 3.58 and $1.99 \mathrm{~mm}$. The corresponding measurements in the mandible were between $2.08-4.69 \mathrm{~mm}$ on the buccal surface and $0.91-3.0 \mathrm{~mm}$ in the palatal surface (depending on tooth position), mean value 3.51 and $1.69 \mathrm{~mm}$. The post-extraction alteration caused a shift in the centre of the edentulous alveolar bone toward the lingual/palatal side.

Araújo and Lindhe (2005) also investigated the dimensional ridge alterations after tooth extraction. Alterations of the height of the alveolar bone during healing showed that the buccal bone wall after two to eight weeks post extraction was consistently located more apically compared to its lingual counterpart. Regarding the alterations of the width of the alveolar bone during healing, the buccal bone wall was thinner than the lingual bone wall. Further, the buccal and the lingual bone walls were thicker apically than coronally (38). 
In a study by Schropp et al. (2003) an investigation of bone healing and soft tissue contour was performed. The alveolar bone width immediately after tooth extraction was on average $12.0 \mathrm{~mm}$ (range $8.6-16.5 \mathrm{~mm})$. The width of the ridge was reduced, approximately $50 \%$, from $12.0-5.9 \mathrm{~mm}(6.1 \mathrm{~mm}$; range $2.7-12.2 \mathrm{~mm})$. There was alterations in both height and width, where the largest changes and reduction occurred within the first three month after extraction (39).

Other factors influencing the alveolar bone morphology

The role of the alveolar bone in orthodontic treatment, as well as in implant treatment, is well-known. In terms of morphology, inadequacy of alveolar bone dimensions limits the amount of tooth movement and may lead to treatment complications. Besides individual growth patterns, other factors influence the shape and size of the alveolar bone.

\section{Tooth loss}

In connection with tooth loss due to, for instance, tooth extraction, the alveolus is filled with a blood coagulum which will be replaced by fibrous tissue. A couple of weeks after the loss of the tooth, bone remodelling begins and initial bone formation occurs (24). After approximately two months the alveolus appears healed but with a reduction of hard tissue, most apparent in the buccal marginal area (40). A maturation of the trabecular bone morphology occurs to match the surrounding bone and the gingiva will also regain its original appearance (24).

After tooth extraction, the alveolar bone is resorbed to varying degrees (41). The decrease in size can be comprehensive (37) (Figure $8)$. 


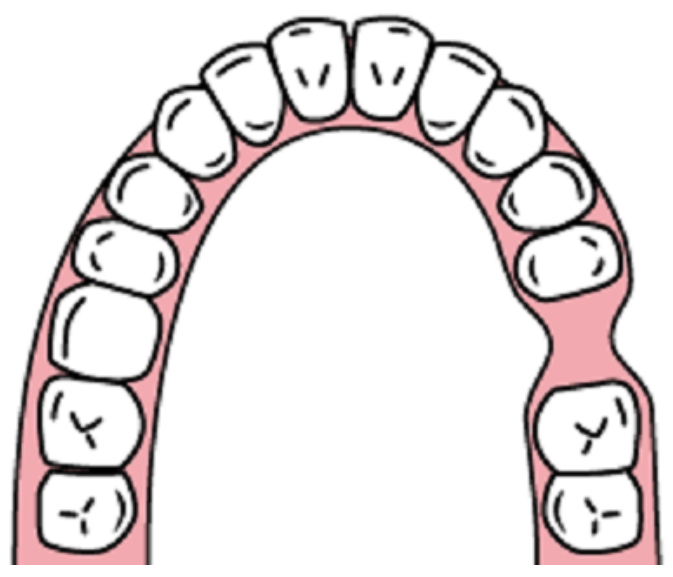

Figure 8. Example of horizontal bone resorption after tooth extraction.

There are some factors that seem to play an evident role regarding the amount of resorption that occurs, such as the length of time that the patient has been edentulous, denture wear, and consumption of tobacco (41). However, the basal parts of the jaws are more resilient and e.g. not resorbed by denture wear (42).

Additional factors involved in determining the degree of alveolar bone resorption after tooth loss are e.g. muscular activity, prosthetic rehabilitation, age, sex, and metabolic disease (43). The amount of bone that is originally present (in $\mathrm{mm}$ ) is individual and as is the amount of resorption. This should be kept in mind when evaluating data in the literature presenting bone loss in $\mathrm{mm}$ and/or \%.

The functional loading of the edentulous area may be reduced after tooth extraction, leading to bone loss. There is a great variation between individuals regarding remodelling of the edentulous areas, where some individuals lose less bone and others undergo a more extensive resorption $(42,44)$. 

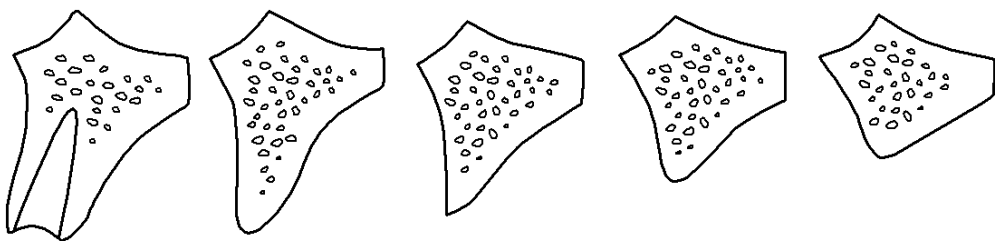

Figure 9. Bone resorption after tooth extraction (vertical and horizontal). III. Fredrik Persson.

Bones adapt their strength to the physiological load placed on them (Frost, 2003). Frost theorises about two loading thresholds. Modelling takes place above a threshold (weightlifter's hip and spine) and a remodelling occurs below a threshold because of disuse (e.g. after leg or hip fracture).

This theory can also be applied to alveolar bone. Teeth are loaded intermittently during biting/chewing and the reaction to changes in loading has been shown in a study of the alveolar bone in growing rats. Depending on whether or not the rats were given a soft or hard diet, the bone was more or less dense (Kiliaridis, Bresin, Holm, \& Strid, 1996).

\section{Agenesis}

Tooth agenesis is a condition in which teeth are missing. Hypodontia is of genetic origin and usually involves one to five absent teeth. The prevalence of a single congenitally missing permanent tooth (28 tooth dentition) was between $2-10 \%$ summarised from both Nordic countries as well as other countries (45). The mandibular second premolar was found to be the most affected tooth, followed by the maxillary lateral incisor (45). In patients with ectodermal dysplasia (ED) severe oligodontia (six or more missing teeth) may be displayed, which subsequently requires implant therapy. Mandibular bone hypoplasia, both in bone quality and quantity was observed in association with tooth agenesis, and both are determining factors in the success of implant therapy $(46,47)$. The effect on craniofacial development in subjects with multiple missing teeth have been investigated by Johnson et al. Their findings suggested that the craniofacial morphology could be adversely affected by the lack of function due to severe hypodontia (48). A positive relation between 
the severity in numbers of missing permanent teeth and severity of craniofacial dysmorphology in ED children was presented (48). In the ED patients, vertical growth of the mandible by condylar growth and increase in ramus height occur, however the alveolar bone remains atrophic resulting in a low-angle vertical growth pattern (49).

Another condition where subjects are often affected by tooth agensis is osteogenesis imperfecta (OI). Investigations of the craniofacial development of subjects with OI show an association to smaller vertical craniofacial dimensions $(50,51)$.

\section{Traumatic dental injuries (TDI)}

TDI occurs very frequently and affects younger patients to a greater extent (52-54). Approximately one in five children have experienced a TDI to their permanent anterior teeth before leaving school (52). The prevalence is about $20 \%$ and the incidence about $1-2 \%$ overall. The numbers presented are based on global data. Thus, there are variations both between and within countries $(54,55)$.

The majority of the TDIs involve the anterior teeth, especially the maxillary central and lateral incisors (55). Overall, an estimation of $71-92 \%$ of all TDIs sustained during a lifetime occur before the age of 19 (55). This means that a treatment plan needs to be initiated in still growing individuals.

\section{Ankylosis after TDI}

In situations where the PDL has been severely damaged, especially in tooth avulsion and intrusion, there is a high risk for irreversible injury to the PDL, which will result in ankylosis of the tooth (5658). Ankylosis is a bony ingrowth in the PDL, fusing the tooth to the alveolar bone (57-59). Ankylosis will result in the tooth being osseointegrated and unable to contribute to the growth of the alveolar bone (60). The region of such a tooth will be inhibited, so called infraposition $(56,60,61)$.

Infraposition of a tooth can lead to tilting of the adjacent teeth as there is a local arrest of dentoalveolar development at the traumatic tooth area $(56,60,61)$. 


\section{Osseointegrated implants and infraposition}

Ossointegration of dental implants is a condition similar to tooth ankylosis. The implant is fused to the bone and inhibits growth of the alveolar bone in young, growing patients in the same way that an ankylosed tooth inhibits growth (Figure 10). Infraposition is observed in implants in a manner similar to what is observed with ankylosed teeth (61-66).

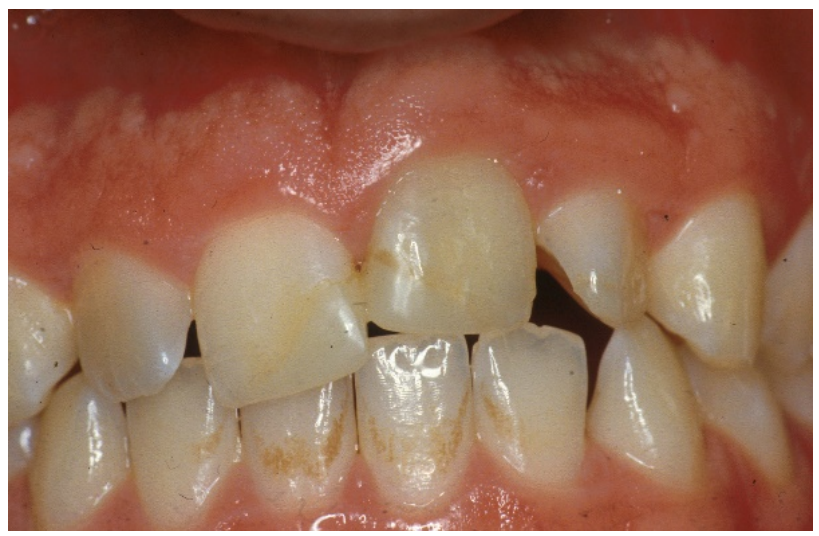

Figure 10. Infraposition of the upper left central and lateral incisor. Photo: Courtesy of Prof. Lars Andersson.

\section{Radiography}

Radiography has long been the method of choice to investigate the relationship between craniofacial height and the morphology of the alveolar bone. Until the early 2000s the available methods were panoramic and lateral cephalometric imaging.

\section{Panoramic imaging}

Panoramic radiography produces a single image including both the maxillary and mandibular dental arches as well as the teeth and other facial structures (67). There are a number of advantages associated with panoramic imaging e.g. the image provides an overview of the facial bones and teeth, and the examination is convenient for the patient (68). However, panoramic radiography is sensitive to patient positioning because of a narrow sharp layer and shape of the focal trough. Interpretation of the radiographs is uncertain especially in the anterior regions of the jaws. Furthermore, the cervical vertebrae 
generates artefacts in the anterior region of the mandible and maxilla complicating assessments in these regions (69).

\section{Cephalometric imaging}

The standard radiographs obtained with a cephalostat are lateral and postero-anterior cephalograms. They are mainly used to evaluate dental and skeletal relationships in the sagittal and vertical plane as well as asymmetries (70).

By combining the information provided by the lateral cephalometric image and the panoramic radiograph, an evaluation of the patient's craniofacial height and alveolar bone height in the maxilla and mandible can be used to investigate an association.

Neither with panoramic radiography nor with lateral or posterioranterior cephalometric imaging is it possible to obtain cross-sectional site-specific images of the maxilla and mandible. Technological advancements in radiological imaging have moved the technique from film radiography towards digital 3D $(68,70,71)$. This has been achieved through the use of conventional tomography (72), computed tomography (70) and, more recently, CBCT (73).

\section{CBCT}

CBCT was introduced in the early 1980 s, primarily for angiography (74), but has since become the most significant advance in dentaland maxillofacial imaging. Development of specialised CBCT scanners for use in dentistry begun in the late 1990s (75). The first commercial CBCT (NewTom 9000) was introduced on the European market in 1999 (76). CBCT utilises a cone-shaped ionizing radiation source, in shape similar to the beam of conventional 2D-imaging.

CBCT in dental practice is an emerging technique for diagnostic imaging, and provides images with a high level of detail, in three planes. The additional information regarding the width dimension that CBCT supplies is the missing piece previously not provided by the two-dimensional images. 


\section{Rater agreement}

For imaging methods, both reliability and agreement are important concepts intended to provide information about the amount of error inherent in any diagnosis, score, or measurement (77) which in turn determins the validity of the study results (78). Agreement "is the degree to which scores or ratings are identical". Interrater agreement refer to different raters, using the same scale or classification when assessing the same subjects/objects. Intrarater agreement refers to the same rater, using the same scale or classification when assessing the same subjects/object at different times (77). Consequently, for studies on imaging methods and validity of study results, several raters should be included to provide information about the generalisability of results (77).

With regards to measurements of alveolar bone height and width and the association to craniofacial height, presentation of intrarater and interrater agreement is infrequent. Furthermore, studies presenting intrarater agreement have either used dry skulls with only three raters (79) or a patient sample but with only two raters (80). The limited number of raters result in questionable study results.

Consequently, there is a need for studies on rater agreement regarding measurements in CBCT images to establish the relationship between alveolar bone morphology and craniofacial height in adherence with the guidelines for Reporting Reliability and Agreement Studies (GRRAS) that have been proposed (Kottner 2011) in order to validate a conceivable relationship.

\section{Systematic reviews}

The continuous growth of research publications generates an increased need to systematically summarise the available scientific evidence. To give a brief history of systematic reviews, the first known example of a systematic review was conducted by James Lind in 1753 . He published a paper with the aim of providing an unbiased and concise summary of evidence on scurvy $(81,82)$.

Systematic reviews (SR) have a number of benefits. Primarily, they deliver a clear and comprehensive overview of existing available 
evidence on a given topic. In addition, SRs can be used to identify where evidence and clear answers already exists in the available literature and where no further research is necessary at present. This helps avoid duplicate research, waste of production and reporting research (83). Finally, SRs also help to identify research gaps within the field of interest. Methodological concerns in research studies can be highlighted and thereafter used to improve future research in the topic area (84). 


\section{AIMS AND HYPOTHESES}

The difference in the duration and amount of DACM seems associated with vertical craniofacial height. Knowledge in this area could benefit in treatment planning of young individuals. Therefore this thesis will investigate further the alveolar bone morphology in relation to craniofacial height.

The overriding aim of this thesis was to investigate the morphology of the alveolar bone in relation to the vertical craniofacial development using measurements in CBCT images. In addition, the thesis sought to investigate the existing scientific knowledge related to dental infraposition, in order to clarify if the degree of infraposition was associated to craniofacial heigh.

Specific aims and hypotheses:

\section{Paper I}

- To investigate if there is an association between the crosssectional morphology of the maxillary and mandibular alveolar bone and the craniofacial height, using images from Cone Beam Computed Tomography (CBCT).

- To investigate differences between male and female patients regarding the association between the cross-sectional morphology of the maxillary and mandibular alveolar bone and the craniofacial height. 
Hypothesis: There is an association between the morphology of the alveolar bone and the craniofacial height.

Null hypothesis: There is no association between the morphology of the alveolar bone and the craniofacial height.

\section{Paper II}

- To investigate rater agreement regarding measurements of height and width of the maxilla and mandible on crosssectional images from CBCT examinations.

Hypothesis: There is an agreement between raters when measuring the morphology of the alveolar bone.

Null hypothesis: There is no agreement between raters when measuring the morphology of the alveolar bone.

\section{Paper III}

- To investigate if craniofacial height and sex are associated with the alveolar bone dimensions in the anterior maxilla.

Hypothesis: There is an association between the craniofacial height, sex, and morphology of the alveolar bone in the anterior maxilla.

Null hypothesis: There is no association between the craniofacial height, sex, and morphology of the alveolar bone in the anterior maxilla.

\section{Paper IV}

- To investigate the potential association between age, sex, and craniofacial height and infraposition due to continued alveolar development in the anterior maxilla, in a systematic review. 


\section{SUBJECTS AND METHODS}

The present thesis is based on both measurements on pre-treatment CBCT images from patients as well as a thorough literature review. The materials in paper I-III are based on a group of patients collected from a database with 450 pre-treatment CBCT scans at a private Scandinavian practice, between the years 2008-2013.

\section{Radiography}

i-CAT CBCT 17-19 were used to perform the CBCT examinations (Imaging Sciences International, Hatfield, Pennsylvania, USA). Field of view (FOV) was $16 \mathrm{~cm} \mathrm{X} 13 \mathrm{~cm}$ and voxel size $0.3 \mathrm{~mm}$. Exposure was $120 \mathrm{kVp}$ and $18.54 \mathrm{mAs}$ with a scanning time of $17.8 \mathrm{sec}$. The patients were in an upright position during scanning. Calibration of the machine was performed twice a year (according to the manufacturer's requirements). A fully reconstructed 3D image with sagittal, coronal, and axial slices was generated, using i-CAT Vision software (Imaging Sciences International, Hatfield, Pennsylvania, USA) (85).

\section{Categorisation of craniofacial height}

A lateral head image was generated from the CBCT scans using the i-CAT software program. A cephalometric analysis was performed to determine craniofacial height, using the Total Interactive Orthodontic Planning System (TIOPS) program (86). The inclination of the mandible in relation to the anterior cranial base was used for determining craniofacial height, thus, the angle formed between the nasion-sella line (NSL) and the mandibular line (ML) (87) (Figure 11). The subjects were categorised into the three following groups: 
low angle $\left(<27^{\circ}\right)$, normal angle $\left(27-37^{\circ}\right)$ and a high angle group $\left(>37^{\circ}\right)$. Subjects with a low craniofacial angle have a low/short craniofacial height, subjects with a normal/average angle have a normal craniofacial height and subjects with a high angle have a high/long craniofacial height.

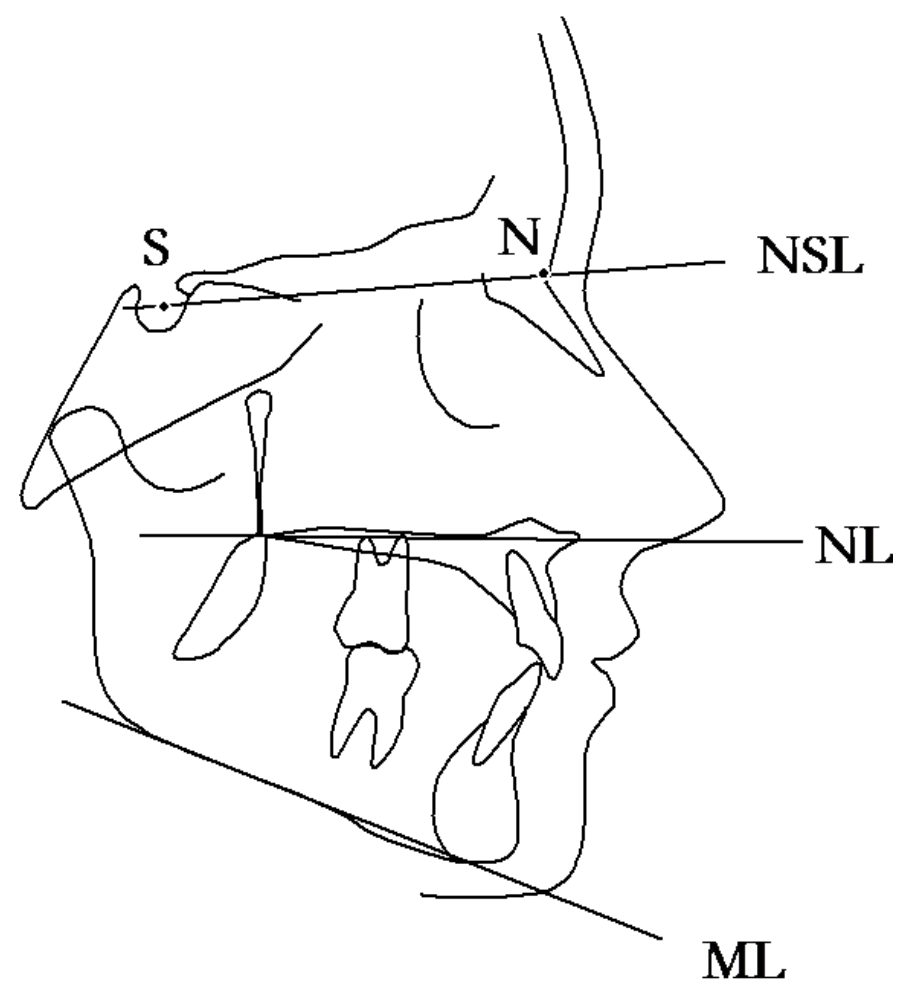

Figure 11. Categorisation of craniofacial height Landmarks and reference lines used for angular measurements in the lateral cephalogram, NSL= Nasion Sella line, $\mathrm{ML}=$ Mandibular line, $\mathrm{NL}=$ nasal line.

\section{Inclusion criteria}

All CBCT volumes were initially included/selected and screened. If a subject had more than one CBCT taken, the first one (pre-treatment) was chosen. After exclusion criteria was applied a total of 180 subjects were included in the study. 
Exclusion criteria are presented in table 1.

Table 1. Exclusion criteria.

\begin{tabular}{ll}
\hline Age & $\begin{array}{l}\text { Female }<15 \text { years, male }<16 \text { years } \\
\text { Too small FOV e.g.: not including anatomical } \\
\text { structures as: Sella turcica, Nasion, maxilla, } \\
\text { and mandible } \\
\begin{array}{l}\text { Permanent teeth missing, not counting the } \\
\text { wisdom teeth }\end{array}\end{array}$ \\
$\begin{array}{l}\text { Missing teeth } \\
\text { Decidious teeth } \\
\text { Large asymetry }\end{array}$ & $\begin{array}{l}\text { Between right and left side } \\
\text { Periodontal disease }\end{array}$ \\
$\begin{array}{l}\text { Extreme crowding } \\
\text { If impossible to measure the interdental bone } \\
\text { due to overlapping } \\
\text { Orthodontic treatment }\end{array}$ & $\begin{array}{l}\text { Ongoing orthodontic treatment } \\
\text { Major prosthodontic } \\
\text { treatment }\end{array}$ \\
Orthognatic surgery & $\begin{array}{l}\text { Artefacts on the images } \\
\text { Titanium bar fixation visible on the images }\end{array}$ \\
\hline
\end{tabular}

\section{Final included sample}

Sixty scans of the low-angle subjects were identified, this number was set as the limit for the number of scans to be consecutively included in the normal- and high-angle groups. This yielded a total of 180 subjects, consisting of three groups of 60 subjects in each group for comparison. The sample consisted of 63 males and 117 females, distribution presented by group in figure 12 . The age range in the total sample were 15-71 years with a mean value of 27.3 years. As displayed in figure 13, the age distribution is offset to the left, representing a higher number of younger subjects/individuals in the sample. The mean age in the male group was 27.6 and 27.2 in the female group. There were more female than male subjects in all of the three craniofacial type groups. 


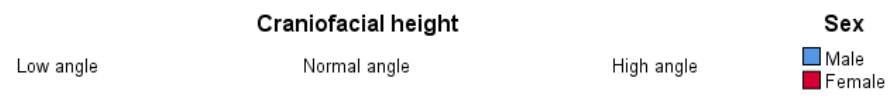

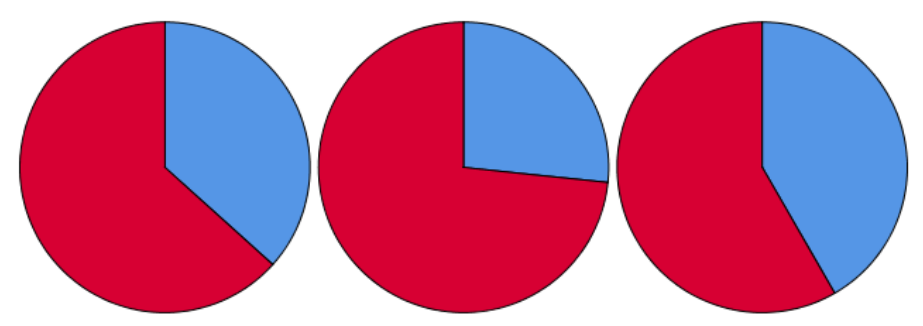

Figure 12. Distribution between male and female subjects in the different craniofacial height groups.

Characteristics in more detail are also presented for the different craniofacial groups (low, normal, high). The number of female subjects in each craniofacial group were 38,44 , and 35 . The number of male subjects in each group were 22, 16, and 25. Mean age and age span presented for the female subjects in each group were 30.1 (15-70), 25.5 (15-58) and 26.2 (15-49). Mean age and age span calculated for the male subjects were 28.8 (17-47), 32.0 (16-71) and $23.7(16-43)$.

By using iCATVision ${ }^{\mathrm{TM}}$ software, a fully reconstructed threedimensional image with axial, coronal and sagittal slices was generated. All cephalometrical measurements were performed by one clinician, who has 15 years of experience as a specialist in orthodontics. 


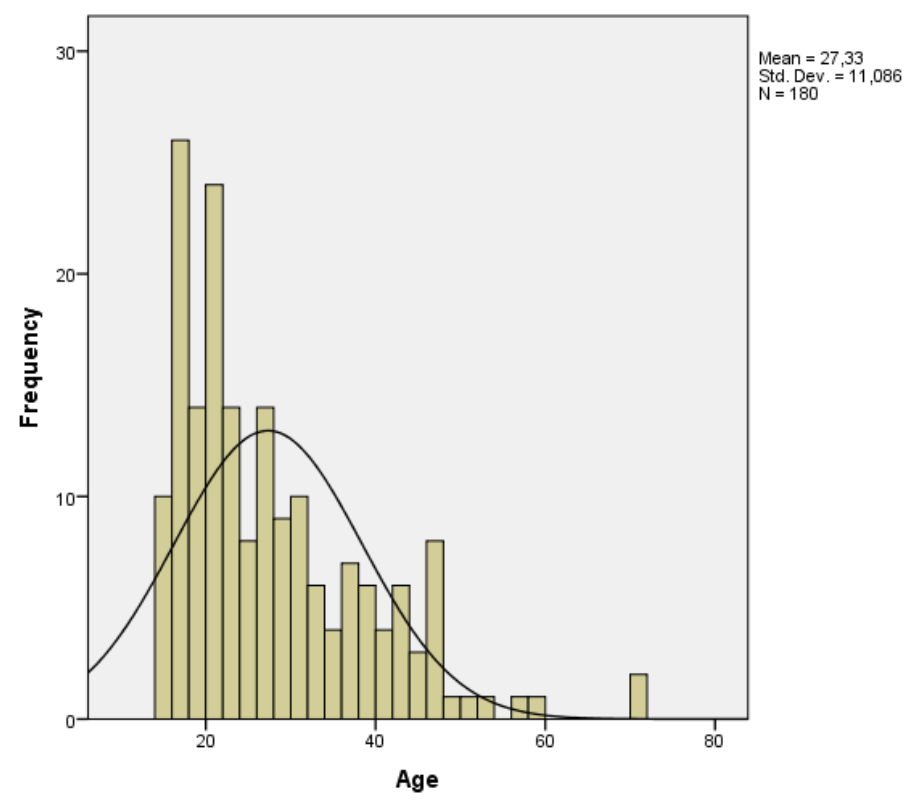

Figure 13. Age distribution of the total included sample

\section{Alignment of images}

Pre-measurement alignment of the skull was performed step-by-step to adjust for small deviations in the patient's head position during image acquisition. An adjustment of the images in the sagittal, coronal and axial planes was possible using the software program tool (paper I-III) (Figure 14).
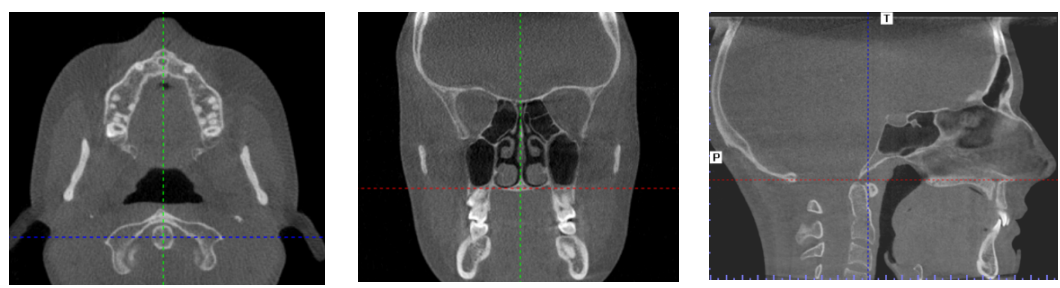

Figure 14. Alignment of the skull

The anatomical structures used for alignment in the first step was the incisive foramen and posteriorly the vertebra. These anatomical references were aligned using a vertical line straight through the 
centres of both anatomical structures. In a second step, the nasal septa was adjusted vertically. The upper supraorbital limitations were horisontally adjusted at the same level and the occlusal plane was taken into account by alignment in the horizontally direction (right and left side). In a third step, the NL (Figure 11) was adjusted parallel to the horizontal reference line (Figure 14) prior to measurements in the maxilla.

For measurements in the mandible, an additional step was performed (Figure 15). By aligning the mandibular line (ML) parallel to the horizontal digital reference line. Thus the mandibular line (drawn between menton and gonion) clarifying the lower boarder of the mandible.

Since the angulation of the mandible differ between the low and high angle, the pre-measurement alignment was performed (Figure 15).

A
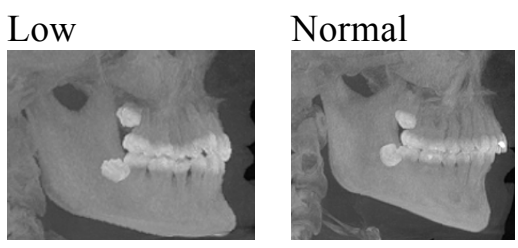

High

B
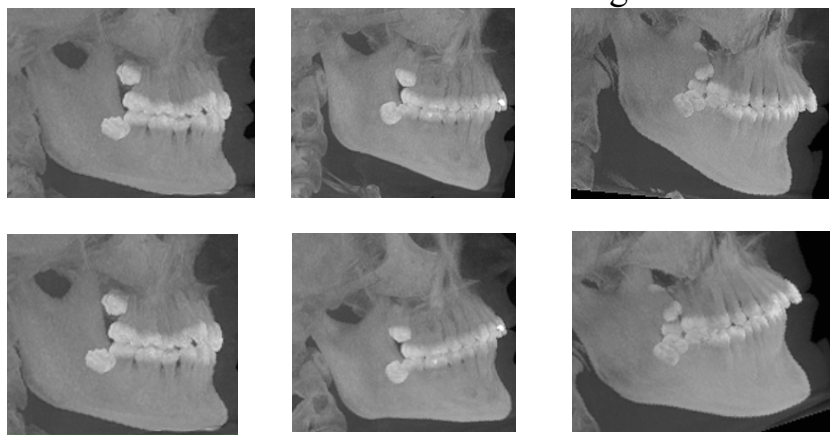

Figure 15.

A. Mandible prior adjustment

B. Mandible after adjustment

\section{Cross-sectional measurements} Paper I

In the first study, measurements of the alveolar bone, including the basal bone, were performed between the teeth in the maxilla and mandible between the first and second molar, between the first and second premolar on both right and left side and in the midline area. 
The measurements were performed on CBCT images, with one height and two width measurements at every cross-sectional image, giving a total of 5400 measurements.

The hight measurements in the maxilla were performed from the top of the alveolar bone crest to the border of the hard palate/nasal floor (ANS to PNS were used as reference line). The height measurement in the mandible were measured from the top of the alveolar bone crest to the outer inferior border of the mandible.

The width measurements were measured at $1 / 3$ and $2 / 3$ of the total height measurement. e.g. if the total height was $21 \mathrm{~mm}$, two new height measures were drawn, using the digital measurement device in i-CAT vision, from the top of the alveolar bone crest to $7 \mathrm{~mm}$ and $14 \mathrm{~mm}$ respectively. Thereafter perpendicular width measurements were performed at the newly marked heights (Figure 16). All crosssectional measurements of the maxilla and mandible were performed by one clinician/specialist who only had access to the decoded CBCT scans and were blinded to all other patient information. Measurement values were simultaneously recorded in a statistical spread sheet (Statistical Package for the Social Sciences, SPSS) by another clinician/researcher.

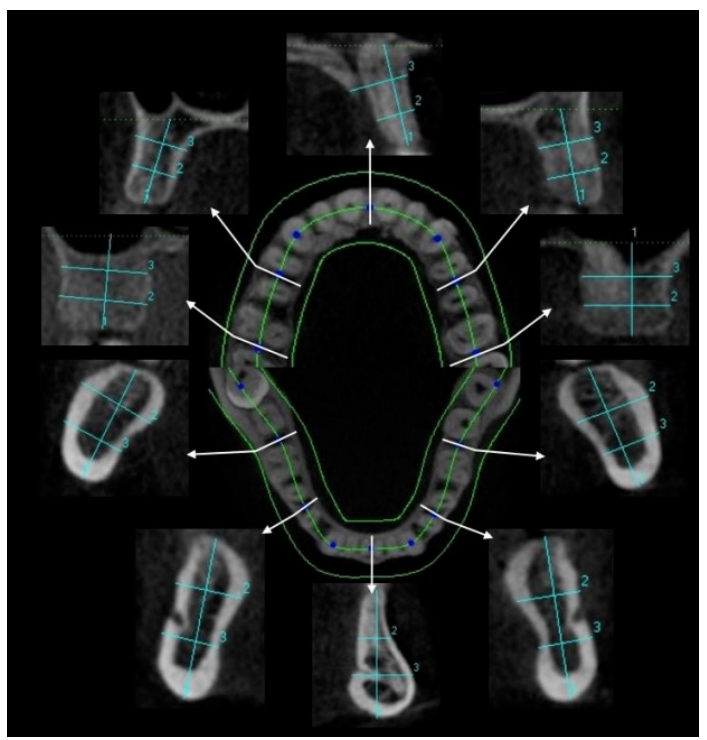

Figure 16. Alveolar bone cross-sectional measurement 


\section{Paper II}

Paper II is a rater based study, executed in accordance with the Guidelines for Reporting Reliability and Agreement Studies (GRRAS). In the second study, the same pre-measurement alignments of the skull performed in the first study were performed by five raters. All raters are dentists with different experience within the clinical field. One of the raters is a specialist in oral and maxillofacial radiology (29 years of experience), and one is a post-doc in oral and maxillofacial radiology (5 years of experience). Furthermore, one is a specialist in oral and maxillofacial surgery (16 years of experience), one were at the time a resident at the oral and maxillofacial surgery department (6 years of experience in general dentistry, including experience in oral and maxillofacial surgery) and one is a general dental practitioner (4 years of experience in general dentistry, including experience from oral and maxillofacial surgery).

The height and width measurements were performed at three locations, distributed in the midline, one in the premolar and one in the molar region in the maxilla and likewise in the mandible. One third of the subjects from each craniofacial group had measurements taken in the molar area, one third of the subjects in the premolar area and one third in the midline area by using random selection in the SPSS software program. A total of 1080 measurements were performed per rater, and five raters were involved in the study (Table 2 ). The height and width measurements were performed as previously described in paper I. Prior to the first measurement session, a joint information session and calibration exercise took place with all the raters, and the assessment instructions were specified both verbally and in writing. During all measurement sessions a researcher assisted the raters and manually documented the measurement values in an Excel file (Microsoft Office Excel® 2010; Microsoft Corporation, Redmond, WA). All raters performed a second session after approximately two months where $10 \%$ of the sites were randomly selected and re-measured for calculation of intra-rater agreement. 
Table 2. Locations and number of cross-sectional sites measured in the maxilla and mandible on CBCT images performed at the first step, per observer (for inter-observer agreement).

\begin{tabular}{|c|c|c|c|c|c|c|c|c|c|c|c|c|c|c|c|c|c|c|c|c|}
\hline \multirow{3}{*}{$\begin{array}{c}\begin{array}{c}\text { Pat gr } \\
(1-3)\end{array} \\
1\end{array}$} & \multicolumn{10}{|c|}{ Site (maxilla) } & \multicolumn{8}{|c|}{ Site (mandible) } & \multirow{3}{*}{$\begin{array}{c}\begin{array}{c}N \\
\text { (Pat.) }\end{array} \\
20\end{array}$} & \multirow{3}{*}{$\begin{array}{c}\mathbf{N} \text { (measurements) } \\
3 \times 2 \times 20\end{array}$} \\
\hline & \multicolumn{3}{|c|}{ Molar } & \multicolumn{3}{|c|}{ Premolar } & \multicolumn{3}{|c|}{ Incisive } & & \multicolumn{2}{|c|}{ Incisive } & \multicolumn{3}{|c|}{ Premolar } & \multicolumn{3}{|c|}{ Molar } & & \\
\hline & H & W1 & W2 & & & & & & & & & & & & & H & W1 & W2 & & \\
\hline 2 & $\mathrm{H}$ & W1 & W2 & & & & & & & & & & & & & $\mathrm{H}$ & W1 & W2 & 20 & $3 \times 2 \times 20$ \\
\hline 3 & H & W1 & W2 & & & & & & & & & & & & & H & W1 & w2 & 20 & $3 \times 2 \times 20$ \\
\hline 1 & & & & $H$ & W1 & W2 & & & & & & & $\mathrm{H}$ & W1 & W2 & & & & 20 & $3 \times 2 \times 20$ \\
\hline 2 & & & & H & W1 & W2 & & & & & & & H & W1 & W2 & & & & 20 & $3 \times 2 \times 20$ \\
\hline 3 & & & & H & W1 & w2 & & & & & & & H & W1 & W2 & & & & 20 & $3 \times 2 \times 20$ \\
\hline 1 & & & & & & & H & W1 & W2 & H & W1 & W2 & & & & & & & 20 & $3 \times 2 \times 20$ \\
\hline 2 & & & & & & & H & W1 & W2 & H & W1 & W2 & & & & & & & 20 & $3 \times 2 \times 20$ \\
\hline 3 & & & & & & & $\mathrm{H}$ & W1 & W2 & $\mathrm{H}$ & W1 & W2 & & & & & & & 20 & $3 \times 2 \times 20$ \\
\hline & & & & & & & & & & & & & & & & & & & 180 & 1080 (total) \\
\hline
\end{tabular}

$\mathrm{H}$ = alveolar bone height, $\mathrm{W} 1$ = coronal width, $\mathrm{W} 2$ = apical width. Pat. = patient, Gr. = group

Patient group 1,2,3=low, normal, high (craniofacial height).

\section{Paper III}

In the third study, the alveolar bone was measured in the aesthetic zone of the maxilla. Measurements were performed at six crosssectional sites: between the canine and first premolar, between the canine and the lateral incisor and between the second incisor and the central incisor on both sides (left and right). One height and four width measurements were performed at every site, giving a total of 30 measurements per subject and a total of 5400 measurements when calculated for the 180 subjects included. The height measurement were performed as previously stated, but the width measurements were performed at a distance of three, six, nine and twelve millimeter from the alveolar bone crest. The height distances were marked using the digital measurement tool and therafter perpendicular width measurements were performed at each height location. The measurements were performed by one clinician who was in the last year of dental school (Figure 17).

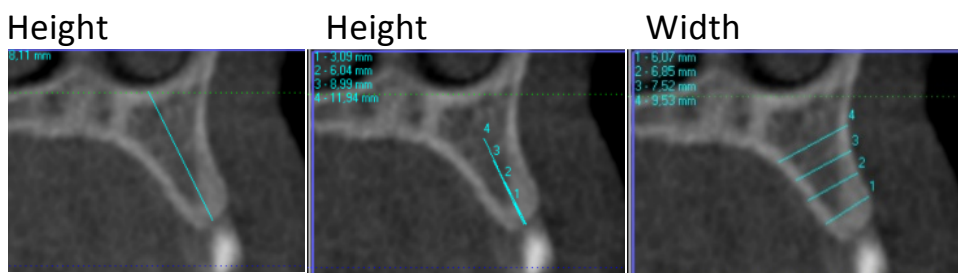

Figure 17. Example of height and width measurements on i-CAT vision cross-sectional images. 


\section{Paper IV}

The fourth paper is a systematic review of the literature on infraposition (of ankylosed teeth or dental implant crowns in the anterior maxilla) associated with craniofacial height. The paper examines the available scientific literature regarding evidence for possible riskfactors associated with infraposition e.g. age, sex, and craniofacial height.

Search protocol: An electronic search was conducted using three different bibliographic databases: MEDLINE (PubMed), Scopus, and Web of Science. Additionally, the reference lists from the selected publications were screened for any other relevant articles. The search was conducted on June 3rd, 2019. The search used the PICO format (Population, Intervention/Exposure, Control/Comparison, Outcome). Population: Adolescents, young adults, and adults with ankylosed teeth or who had been treated with dental implants in the anterior maxilla. Exposure: Age, sex, craniofacial morphology, diseases, or other potential studied riskfactors. Control: Other levels of the same exposures. Outcome: Infraposition of implant (crown) or infraposition of teeth. In this manner, the literature was screened according to the following search terms; "continued eruption" OR infraposition OR infraocclusion OR growth OR development AND jaw OR maxillary OR maxilla OR mandibular OR mandible OR "alveolar bone" OR "alveolar process" OR "dental arch" AND "dental Implant" " OR "tooth ankylos"”.

\section{Exclusion criteria}

Guidelines, letter, position paper, consensus statements, animal studies, in vitro studies, lack of follow-up, non-English abstract.

\section{Study selection}

The Rayyan software program (Qatar Computing Research Institute (Data Analytics)) was used to manage the references and remove duplicates. A calibration exercise took place before evaluating the articles. The retrieved publications were subject to a crude exclusion of irrelevant publications based on title. The abstracts were read by four reviewers independently in pairs of two (AK and ST; ANA and JB). Selected studies were read in full-text by four reviewers 
respectively (AK, ANA, ST, NW). Any disagreement during the screening process was resolved by discussion in the project group. Duplicates, non-clinical studies, case reports, animal studies, guidelines, letters, position papers, studies on patients with systemic diseases or syndromes, studies on implant-supported overdentures or tooth-and-implant restorations, studies on surgical or short-term outcomes, and studies with non-relevant outcomes were excluded (Figure 18).

\section{Data extraction}

\section{Systematic reviews}

One systemic review was identified, although excluded due to employing a different methodological approach than the present review. If any systematic reviews had remained and been the subject of data extraction, "objectives, main results, authors' estimated certainty of evidence, and knowledge gaps according to authors" would have ben assessed.

\section{Primary studies}

Data extraction regarding population (number of included patients), study period (length of follow-up), age, sex, craniofacial height, and type of outcome (infraposition measured or other relevant outcomes) were performed.

Certainty of the evidence was assessed according to GRADE (GRADing quality of Evidence and strength of recommendations). Four steps of evidence grading are applicable; high, moderate, low, and very low.

\section{Ethical considerations}

Paper I-III was conducted in accordance with the ethical principles of the World Medical Association Declaration of Helsinki (2008 version), approved by the Regional Ethical Review Board, Lund, Sweden (8 May 2014, Dnr 2014/288), the Danish Health and Medicines Authority, Denmark (20 July 2015, Sagsnr. 3-30-13877/1/), and the Danish Data Protection Agency, Denmark (7 July 2015, J.nr. 2015-41-4117). Ethical application is not applicable for paper IV. 
PRISMA 2009 Flow Diagram ${ }^{1}$

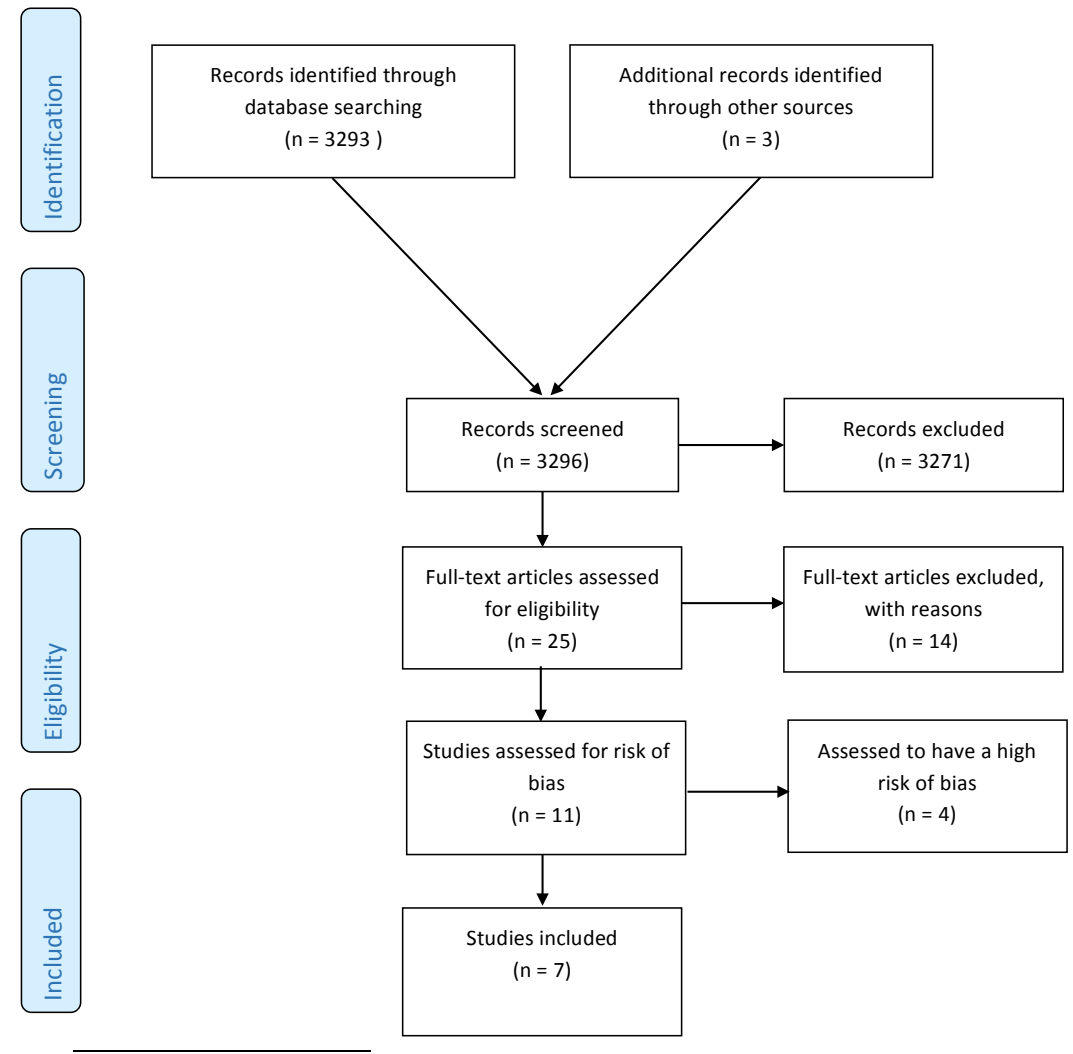

rrom: Moher D, Liberati A, Tetzlaff J, Altman DG, The PRISMA Group (2009). Preferred Reporting Items for Systematic Reviews and Meta-Analyses: The PRISM, Statement. PLoS Med 6(6): e1000097. doi:10.1371/journal.pmed1000097. For more information, visit www.prisma-statement.org.

Figure 18. PRISMA

\section{Statistical analysis}

\section{Paper I}

All statistical analysis was performed using IBM SPSS software (version 22.0; IBM Corp Armonk, NY, USA). For all variables, the three groups (low, normal, high) were compared using One-way analysis of variance with a Tukey's post-hoc test. A significance level of $5 \%$ was used in all comparisons.

To include a multivariate analysis exploring the associations between predictive factors and the different outcome measures a linear 
regression model was performed. The model included the measures of height and width as dependent variable, sex, and age modeled as continuous variables) and craniofacial height (modeled as dichotomous dummy variables). The linear regression was performed in Stata 15 SE, and a significance level of 5\% was used.

\section{Paper II}

All computations necessary for the statistical analysis were performed using IBM SPSS software (Version 22.0; IBM Corp Armonk, NY, USA). For all variables, the three groups (low, normal, high) were compared using One-way analysis of variance with a Tukey's posthoc test. A significance level of $5 \%$ was used in all comparisons.

Intrarater agreement of measurements in selected cross-sectional sites was calculated as Intra class Correlation Coefficients (ICCs 2.1) with $95 \%$ confidence interval (CI). Only the first measurements performed by each rater was used to calculate the interrater ICC.

The level of agreement was interpreted according to the guideline proposed by Koo and $\mathrm{Li}$ as follows : $<0.50$, poor; between 0.50 and 0.75 , fair; between 0.75 and 0.90 good; above 0.90 , excellent agreement. (88).

To investigate the precision of a single measurement, figures from height measurements in the midline of the maxilla and mandible were used. Calculations using the formula suggested by Dahlberg (Dahlberg 1940), $\sqrt{ } \sum \mathrm{d} 2 / 2 \mathrm{n}$, where $\mathrm{d}$ is the difference between two measurements and $\mathrm{n}$ is the number of double measurements (89).

\section{Paper III}

A One-way analysis of variance with Tukey's post-hoc test was used to compare the variables. A significance level of $5 \%$ was set in all comparisons. Statistical analysis was performed using IBM SPSS software (Version 22.0; IBM Corp Armonk, NY, USA).

\section{Paper IV}

Metaanalysis was precluded due to the studies' differing aims and heterogeneity between the seven primary studies. 


\section{SUMMARY OF RESULTS}
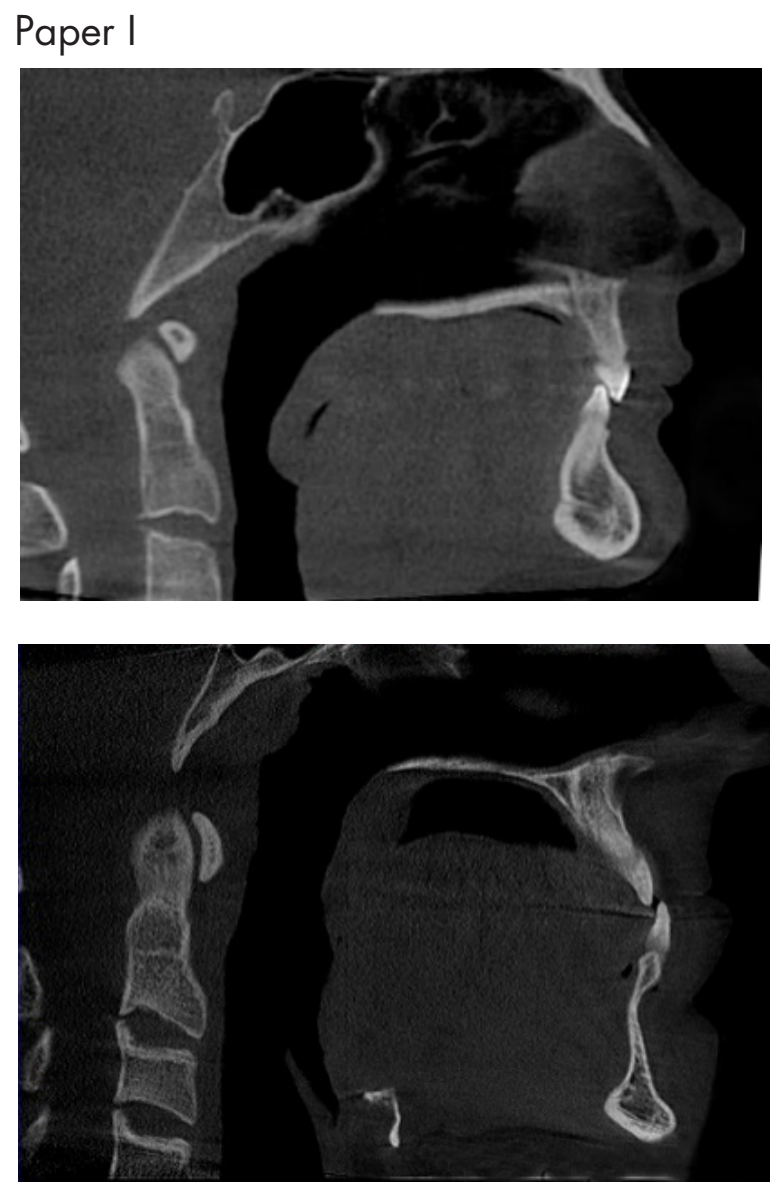

Figure 19. Lateral projections.

Anterior differences in height and width of the alveolar bone between a low and high angle subject. 


\section{Alveolar bone morphology}

An overall pattern with differences between the craniofacial groups was displayed, especially in the anterior region, e.g patients with a large craniofacial height (high angle) had significantly higher alveolar bone, both in the maxilla and in the mandible. In the same group, the measured cross-sectional sites were significantly thinner in the mandible compared with the other two groups, normal and low angle, especially in the anterior region.

\section{Alveolar bone height}

There was an increase in height from the posterior region to the midline region in all three groups, both in the maxilla and in the mandible. The increase was most pronounced in the high-angle group and least pronounced in the low-angle group.

The molar region, the premolar region, and the midline region of the maxilla were significantly higher in the high-angle group compared to the normal and the low-angle groups.

The premolar region, and the midline region of the mandible were significantly higher in the high-angle group compared to the normal and the low-angle group. However, there were no significant differences between the groups in the molar region of the mandible.

In the maxilla, the mean alveolar bone height in the molar region were $16.3 \mathrm{~mm}$ in the high angle group and $14.2 \mathrm{~mm}$ in the low angle group. An increase towards the midline area were displayed, showing a mean value in alveolar bone height of $20.0 \mathrm{~mm}$ in the high angle group and $16.4 \mathrm{~mm}$ in the low angle group in the premolar region. In the midline region, a mean value of $22.9 \mathrm{~mm}$ in the high angle group and $18.3 \mathrm{~mm}$ in the low angle group were evident.

The overall height range in the different regions were as follows: $9.6-23.6 \mathrm{~mm}$ in the molar region, $11.3-27.1 \mathrm{~mm}$ in the premolar region and $11.6-28.4 \mathrm{~mm}$ in the midline region. 
In the mandible, the mean alveolar bone height in the molar region were $26.7 \mathrm{~mm}$ in the high angle group and $26.2 \mathrm{~mm}$ in the low angle group. The mean alveolar bone height in the premolar region were $32.2 \mathrm{~mm}$ in the high angle group and $28.7 \mathrm{~mm}$ in the low angle group. An increase towards the midline area were displayed, showing a mean value in alveolar bone height of $35.3 \mathrm{~mm}$ in the high angle group and $29.5 \mathrm{~mm}$ in the low ange group. The corresponding values for the normal group were always between the high and low angle group in all sites calculated with statistical significant differences.

The overall height range in the different regions are summarised and presented as follows: $19.4-36.6 \mathrm{~mm}$ in the molar region, 23.2-41.9, $\mathrm{mm}$ in the premolar region and $24.7-42.1 \mathrm{~mm}$ in the midline region summarised for the three groups (Table 3 ).

\section{Alveolar bone width}

The cross-sectional coronal alveolar bone width measurements decreases towards the midline region in all three groups, both in the maxilla and mandible. A pattern where the premolar region was wider than the midline region and the molar region was wider than the premolar region was displayed. Concerning the apical width measurement, the cross-sectional measurements were narrower in the premolar region compared to the molar and midline region both in the maxilla and in the mandible for all three groups. The apical cross-sectional width measurements were widest in the molar region in the maxilla and in the midline region in the mandible.

There were no statistically significant differences between the three groups in width measurements in the maxilla, neither in the coronal nor in the apical width measurements.

In the coronal and apical midline region in the mandible, the crosssectional bone was significantly more narrow in the high-angle group compared to the normal- and the low-angle groups (Table 4). There were statistical differences between the groups when measuring coronal width in the mandibular premolar region on both the right and left side. The same tendency was displayed in the apical premolar region of the mandible, although only statistically evident on the left side. 
Table 3. Avleolar bone height measurements of the maxilla and mandible in $\mathrm{mm}$.

\begin{tabular}{|c|c|c|c|c|c|c|c|c|c|c|c|c|c|}
\hline & \multicolumn{3}{|c|}{ High angle group } & \multicolumn{3}{|c|}{ Normal angle group } & \multicolumn{3}{|c|}{ Low angle group } & \multicolumn{4}{|c|}{ Significance } \\
\hline & & & & & & & & & & Overall & $\begin{array}{c}\text { High- } \\
\text { normal }\end{array}$ & $\begin{array}{c}\text { Normal- } \\
\text { low }\end{array}$ & $\begin{array}{c}\text { High- } \\
\text { low }\end{array}$ \\
\hline MAXILLA & $\bar{x}$ & Range & SD & $\bar{x}$ & Range & SD & $\bar{x}$ & Range & SD & & & & \\
\hline URM & 16.2 & $\begin{array}{l}9.6- \\
23.6\end{array}$ & 2.5 & 15.1 & $\begin{array}{l}9.7- \\
21.0\end{array}$ & 2.4 & 14.3 & $\begin{array}{l}9.6- \\
21.0\end{array}$ & 2.2 & $0.000^{*}$ & $0.024^{*}$ & 0.169 & $0.000 *$ \\
\hline URP & 20.0 & $\begin{array}{c}13.0- \\
27.1\end{array}$ & 2.7 & 18.2 & $\begin{array}{c}12.8- \\
24.5\end{array}$ & 2.4 & 16.3 & $\begin{array}{l}11.3- \\
20.6\end{array}$ & 2.1 & $0.000^{*}$ & $0.000^{*}$ & $0.000^{*}$ & $0.000^{*}$ \\
\hline UMi & 22.9 & $\begin{array}{c}15.3- \\
28.4\end{array}$ & 2.7 & 20.6 & $\begin{array}{c}15.3- \\
25.8\end{array}$ & 2.3 & 18.3 & $\begin{array}{c}11.6- \\
26.1\end{array}$ & 2.7 & $0.000^{*}$ & $0.000^{*}$ & $0.00 *^{*}$ & $0.000^{*}$ \\
\hline ULP & 20.0 & $\begin{array}{l}12.7- \\
26.8\end{array}$ & 2.8 & 18.4 & $\begin{array}{c}14.3- \\
24.2\end{array}$ & 2.3 & 16.4 & $\begin{array}{l}11.3- \\
20.7\end{array}$ & 2.1 & $0.000^{*}$ & $0.002^{*}$ & $0.000^{*}$ & $0.000^{*}$ \\
\hline ULM & 16.3 & $\begin{array}{c}10.4- \\
23.3\end{array}$ & 2.6 & 15.4 & $\begin{array}{l}9.9- \\
20.4\end{array}$ & 2.5 & 14.1 & $\begin{array}{c}10.2- \\
19.5\end{array}$ & 2.2 & $0.000^{*}$ & 0.128 & $0.011^{*}$ & $0.000 *$ \\
\hline MANDIBL & & & & & & & & & & & & & \\
\hline LRM & 26.7 & $\begin{array}{c}19.4- \\
36.6\end{array}$ & 2.6 & 26.8 & $\begin{array}{c}20.43- \\
33.5\end{array}$ & 2.6 & 26.2 & $\begin{array}{c}20.3- \\
31.5\end{array}$ & 2.6 & 0.455 & 0.994 & 0.492 & 0.558 \\
\hline LRP & 32.3 & $\begin{array}{c}25.1- \\
41.9\end{array}$ & 3.3 & 30.7 & $\begin{array}{c}25.0- \\
38.0\end{array}$ & 2.8 & 28.7 & $\begin{array}{l}23.2- \\
34.6\end{array}$ & 2.6 & $0.000^{*}$ & $0.011^{*}$ & $0.001^{*}$ & $0.000^{*}$ \\
\hline LMi & 35.3 & $\begin{array}{c}29.0- \\
42.1\end{array}$ & 3.3 & 32.3 & $\begin{array}{c}26.4- \\
40.0\end{array}$ & 3,0 & 29.5 & $\begin{array}{c}24.7- \\
36.9\end{array}$ & 2.8 & $0.000^{*}$ & $0.000^{*}$ & $0.000^{*}$ & $0.000^{*}$ \\
\hline LLP & 32.1 & $\begin{array}{c}24.8- \\
41.8\end{array}$ & 3.6 & 30.7 & $\begin{array}{c}25.2- \\
38.3\end{array}$ & 3.0 & 28.7 & $\begin{array}{c}23.7- \\
34.4\end{array}$ & 2.6 & $0.000^{*}$ & $0.025^{*}$ & $0.001^{*}$ & $0.000^{*}$ \\
\hline LLM & 26.7 & $\begin{array}{c}20.3- \\
36.3\end{array}$ & 3.3 & 26.6 & $\begin{array}{c}21.2- \\
33.7\end{array}$ & 2.8 & 26.2 & $\begin{array}{c}20.4- \\
32.0\end{array}$ & 2.6 & 0.587 & 0.993 & 0.683 & 0.611 \\
\hline
\end{tabular}

URM (upper right molar), URP (upper right premolar), UMi (upper midline), ULP (upper left premolar), ULM (upper left molar).

LRM (lower right molar), LRP (lower right premolar), LMi (lower midline), LLP (lower left premolar), LLM (lower left molar). ${ }^{*}=$ statistically significant difference $(p$ value $<0.05) \cdot \bar{x}=$ Mean value. $S D=$ standard deviation.

In the maxilla, the mean coronal alveolar bone width, in the molar region, was $13.8 \mathrm{~mm}$ overall (low-, normal-, high angle). In the premolar region $9.2 \mathrm{~mm}$ and the corresponding numbers for the midline region were $7 \mathrm{~mm}$.

The coronal width range was as follows: $9.9-18.1 \mathrm{~mm}$ in the molar region, $5.5-12.4 \mathrm{~mm}$ in the premolar region and $4.1-10.5 \mathrm{~mm}$ in the midline region summarised for the three groups (Table 4).

In the mandible, the mean coronal alveolar bone width, in the molar region, was $13.1 \mathrm{~mm}$ overall (low-, normal-, high angle). No statistical differences between the three groups. The mean coronal alveolar bone width in the premolar region were $9.6 \mathrm{~mm}$ in the high angle group and $10.6 \mathrm{~mm}$ in the low angle group. The corresponding 
values for the midline area were $6.4 \mathrm{~mm}$ in the high angle group and $8.2 \mathrm{~mm}$ in the low angle group.

The coronal width range were as follows:

$6.2-17.8 \mathrm{~mm}$ in the molar region, $5.1-15.8 \mathrm{~mm}$ in the premolar region and $2.5-12.1 \mathrm{~mm}$ in the midline region summarised for the three groups. The full numbers are presented in table 4 .

At the cross-sectional regions with statistical significant differences, the minimum height measurement was found in the low-angle group and the maximum measurement was usually found in the highangle group. The opposite pattern was noticed regarding the width measurements where the minimum measurement was usually found in the high-angle group and the maximum width measurement in the low-angle group (Table 3 and 4).

\section{Differences between the sexes}

The male subjects tended to have wider and higher alveolar bone compared to female subjects in a majority of the cross-sectional measurements $(73 \%)$. Significant differences were evident both in the maxilla and mandible.

A multivariate regression analysis was performed (age, sex, craniofacial height, alveolar bone morphology). A pattern was detected where the largest differences were displayed between the female and male group. When adjusted for confounding factors the sex parameter was evidently even stronger (Table 5). 
Table 4. Avleolar bone width measurements of the maxilla and mandible in $\mathrm{mm}$.

\begin{tabular}{|c|c|c|c|c|c|c|c|c|c|c|c|c|c|c|}
\hline & & \multicolumn{3}{|c|}{ High angle group } & \multicolumn{3}{|c|}{ Normal angle group } & \multicolumn{3}{|c|}{ Low angle group } & \multicolumn{4}{|c|}{ Significance } \\
\hline & & & & & & & & & & & \multirow[t]{2}{*}{ Overall } & \multicolumn{3}{|c|}{ Multiple Comparisons } \\
\hline & & & & & & & & & & & & $\begin{array}{l}\text { High- } \\
\text { normal }\end{array}$ & $\begin{array}{c}\text { Normal- } \\
\text { low }\end{array}$ & $\begin{array}{l}\text { High- } \\
\text { low }\end{array}$ \\
\hline MAXILLA & & $\bar{x}$ & Range & SD & $\bar{x}$ & Range & SD & $\bar{x}$ & Range & SD & & & & \\
\hline \multirow{2}{*}{ URM } & W1 & 14.2 & $\begin{array}{c}10.2- \\
17.7\end{array}$ & 1.6 & 14.1 & $\begin{array}{c}11.7- \\
17.6\end{array}$ & 1.3 & 13.7 & $\begin{array}{l}9.9- \\
17.1\end{array}$ & 1.5 & 0.263 & 0.953 & 0.425 & 0.272 \\
\hline & W2 & 16.1 & $\begin{array}{l}10.5- \\
21.4\end{array}$ & 2.4 & 15.9 & $\begin{array}{c}12.7- \\
21.9\end{array}$ & 1.9 & 15.9 & $\begin{array}{l}10.5- \\
21.0\end{array}$ & 2.1 & 0.899 & 0.913 & 1.000 & 0.919 \\
\hline \multirow{2}{*}{ URP } & W1 & 9.0 & $\begin{array}{l}5.5- \\
11.7\end{array}$ & 1.3 & 9.3 & $\begin{array}{l}7.0- \\
11.9\end{array}$ & 1.1 & 9.2 & $\begin{array}{c}7.13- \\
11.8\end{array}$ & 1.2 & 0.239 & 0.208 & 0.655 & 0.690 \\
\hline & W2 & 10.4 & $\begin{array}{l}6.6- \\
16.4\end{array}$ & 2.2 & 10.4 & $\begin{array}{l}6.2- \\
15.5\end{array}$ & 1.8 & 10.6 & $\begin{array}{l}7.3- \\
15.9\end{array}$ & 2.0 & 0.815 & 0.976 & 0.908 & 0.804 \\
\hline \multirow{2}{*}{ UMi } & W1 & 6.9 & $\begin{array}{l}4.8- \\
10.5\end{array}$ & 1.4 & 7.1 & $\begin{array}{l}4.9- \\
8.8\end{array}$ & 1.0 & 6.9 & $\begin{array}{l}4.1- \\
10.5\end{array}$ & 1.4 & 0.631 & 0.652 & 0.721 & 0.993 \\
\hline & W2 & 12.6 & $\begin{array}{l}7.4- \\
17.1\end{array}$ & 2.1 & 12.0 & $\begin{array}{l}7.5- \\
16.4\end{array}$ & 2.5 & 12.3 & $\begin{array}{l}8.4- \\
19.3\end{array}$ & 2.5 & 0.262 & 0.231 & 0.724 & 0.657 \\
\hline \multirow{2}{*}{ ULP } & W1 & 9.0 & $\begin{array}{l}5.7- \\
12.1\end{array}$ & 1.2 & 9.3 & $\begin{array}{l}6.2- \\
12.3\end{array}$ & 1.1 & 9.1 & $\begin{array}{l}7.3- \\
12.4\end{array}$ & 1.2 & 0.539 & 0.508 & 0.873 & 0.813 \\
\hline & W2 & 10.0 & $\begin{array}{l}6.5- \\
16.3\end{array}$ & 1.9 & 10.4 & $\begin{array}{l}7.1- \\
14.1\end{array}$ & 1.7 & 10.5 & $\begin{array}{l}6.4- \\
17.1\end{array}$ & 2.0 & 0.345 & 0.458 & 0.990 & 0.381 \\
\hline \multirow{2}{*}{ ULM } & W1 & 13.8 & $\begin{array}{l}10.8- \\
18.1\end{array}$ & 1.7 & 13.8 & $\begin{array}{l}11.4- \\
16.0\end{array}$ & 1.2 & 13.4 & $\begin{array}{c}10.2- \\
16.8\end{array}$ & 1.3 & 0.175 & 0.994 & 0.261 & 0.218 \\
\hline & W2 & 15.9 & $\begin{array}{l}10.2- \\
20.4\end{array}$ & 2.1 & 15.9 & $\begin{array}{c}12.0- \\
18.9\end{array}$ & 1.8 & 15.3 & $\begin{array}{c}10.2- \\
19.8\end{array}$ & 1.9 & 0.292 & 0.728 & 0.694 & 0.259 \\
\hline \multicolumn{15}{|l|}{ MANDIBLE } \\
\hline \multirow{2}{*}{ LRM } & W1 & 12.8 & $\begin{array}{l}7.5- \\
17.0\end{array}$ & 1.9 & 13.0 & $\begin{array}{l}9.2- \\
16.4\end{array}$ & 1.9 & 13.2 & $\begin{array}{l}6.8- \\
17.8\end{array}$ & 2.0 & 0.460 & 0.730 & 0.879 & 0.432 \\
\hline & W2 & 10.8 & $\begin{array}{l}6.3- \\
14.3\end{array}$ & 1.6 & 11.0 & $\begin{array}{l}6.2- \\
14.1\end{array}$ & 1.6 & 10.7 & $\begin{array}{l}6.2- \\
14.6\end{array}$ & 1.6 & 0.661 & 0.817 & 0.646 & 0.956 \\
\hline \multirow{2}{*}{ LRP } & W1 & 9.7 & $\begin{array}{l}7.0- \\
13.5\end{array}$ & 1.7 & 10.4 & $\begin{array}{l}5.1- \\
15.8\end{array}$ & 2.1 & 10.6 & $\begin{array}{l}6.3- \\
15.4\end{array}$ & 1.9 & $0.035^{*}$ & 0.138 & 0.824 & $0.035^{*}$ \\
\hline & W2 & 9.4 & $\begin{array}{l}5.6- \\
12.4\end{array}$ & 1.7 & 10.0 & $\begin{array}{l}5.6- \\
13.7\end{array}$ & 1.8 & 9.8 & $\begin{array}{l}5.8- \\
14.2\end{array}$ & 1.7 & 0.122 & 0.111 & 0.801 & 0.352 \\
\hline \multirow{2}{*}{ LMi } & W1 & 6.4 & $\begin{array}{l}2.5- \\
10.3\end{array}$ & 1.5 & 7.3 & $\begin{array}{l}4.0- \\
11.6\end{array}$ & 1.6 & 8.2 & $\begin{array}{l}4.8- \\
12.1\end{array}$ & 1.6 & $0.000^{*}$ & $0.004 *$ & $0.006^{*}$ & $0.000^{*}$ \\
\hline & W2 & 12.3 & $\begin{array}{l}7.7- \\
17.0\end{array}$ & 2.1 & 13.5 & $\begin{array}{l}8.6- \\
22.8\end{array}$ & 2.4 & 14.1 & $\begin{array}{l}7.3- \\
17.7\end{array}$ & 1.9 & $0.000 *$ & $0.005^{*}$ & 0.282 & $0.000 *$ \\
\hline \multirow{2}{*}{ LLP } & W1 & 9.5 & $\begin{array}{l}6.5- \\
13.7\end{array}$ & 1.6 & 10.4 & $\begin{array}{l}5.8- \\
15.5\end{array}$ & 2.0 & 10.5 & $\begin{array}{l}6.5- \\
15.4\end{array}$ & 2.0 & $0.005^{*}$ & $0.025^{*}$ & 0.914 & $0.008^{*}$ \\
\hline & W2 & 9.4 & $\begin{array}{l}5.7- \\
12.9\end{array}$ & 1.8 & 10.2 & $\begin{array}{l}6.2- \\
13.9\end{array}$ & 1.7 & 10.0 & $\begin{array}{l}6.2- \\
14.6\end{array}$ & 1.7 & $0.045^{*}$ & $0.045^{*}$ & 0.833 & 0.164 \\
\hline \multirow{2}{*}{ LLM } & W1 & 13.0 & $\begin{array}{l}7.0- \\
17.1\end{array}$ & 1.9 & 13.3 & $\begin{array}{l}9.0- \\
17.0\end{array}$ & 1.9 & 13.3 & $\begin{array}{l}6.2- \\
17.1\end{array}$ & 2.0 & 0.528 & 0.677 & 0.970 & 0.529 \\
\hline & W2 & 10.6 & $\begin{array}{l}7.0- \\
14.0\end{array}$ & 1.4 & 11.0 & $\begin{array}{l}5.4- \\
14.6\end{array}$ & 1.7 & 10.9 & $\begin{array}{l}7.1- \\
14.9\end{array}$ & 1.6 & 0.812 & 0.420 & 0.888 & 0.706 \\
\hline
\end{tabular}

URM (upper right molar), URP (upper right premolar), UMi (upper midline), ULP (upper left premolar), ULM (upper left molar).

LRM (lower right molar), LRP (lower right premolar), LMi (lower midline), LLP (lower left premolar), LLM (lower left molar). W1 demonstrate the coronally width measurements and $\mathrm{W} 2$ demonstrate the apically width measurements. ${ }^{*}=$ statistically significant difference $(\mathrm{p}$ value $<0.05)$.

$\bar{x}=$ Mean value. $\mathrm{SD}=$ standard deviation. 


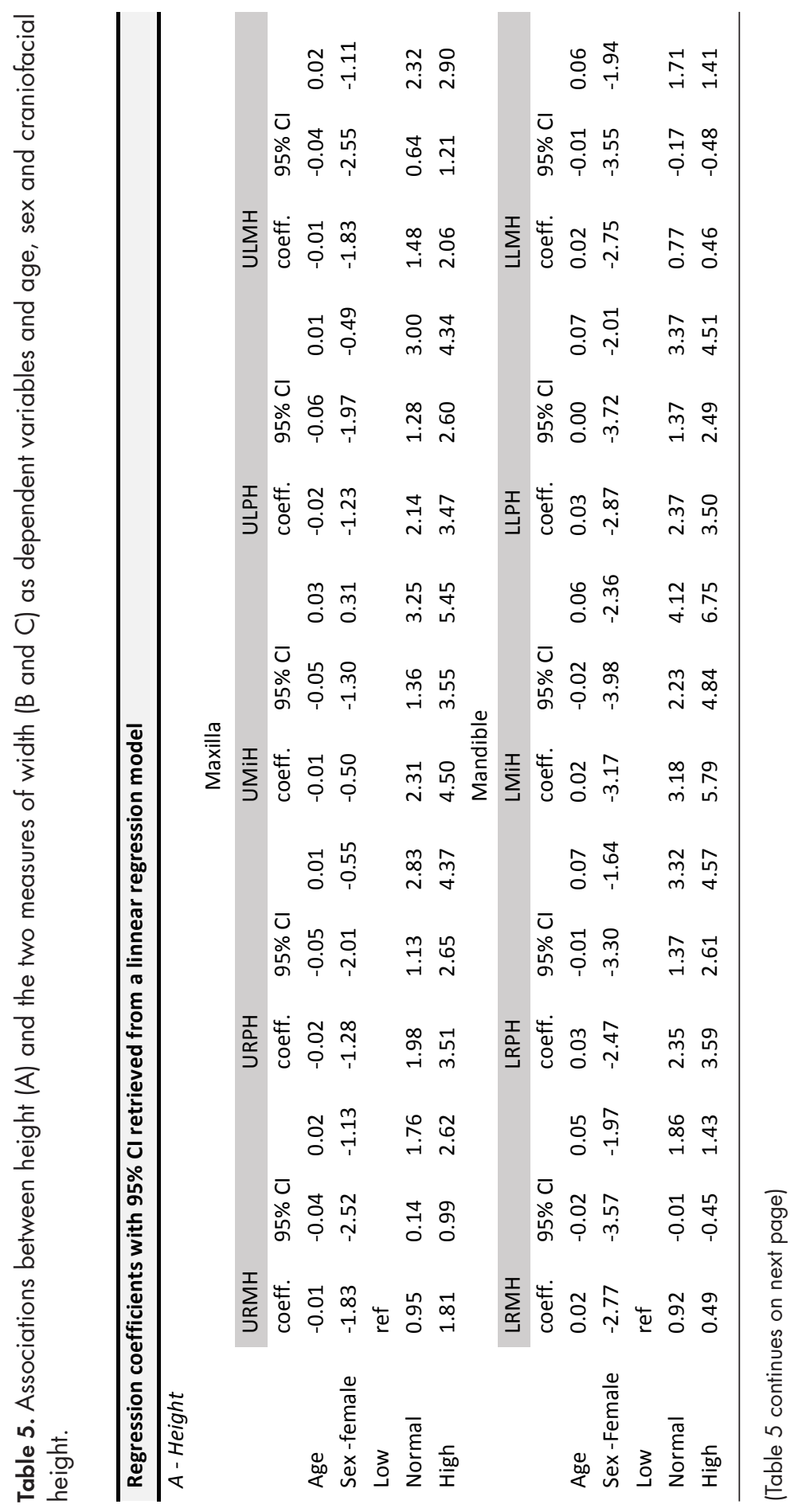




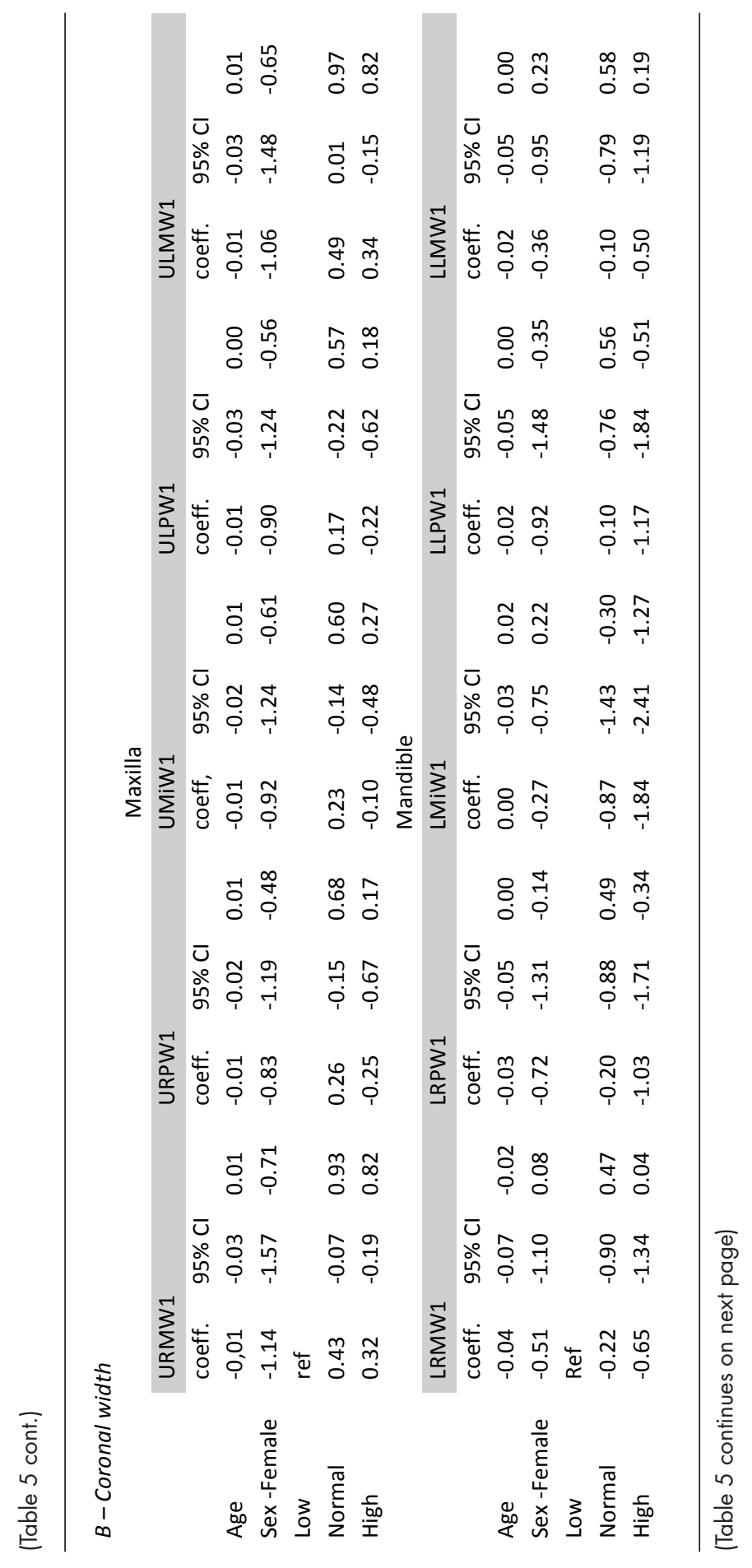




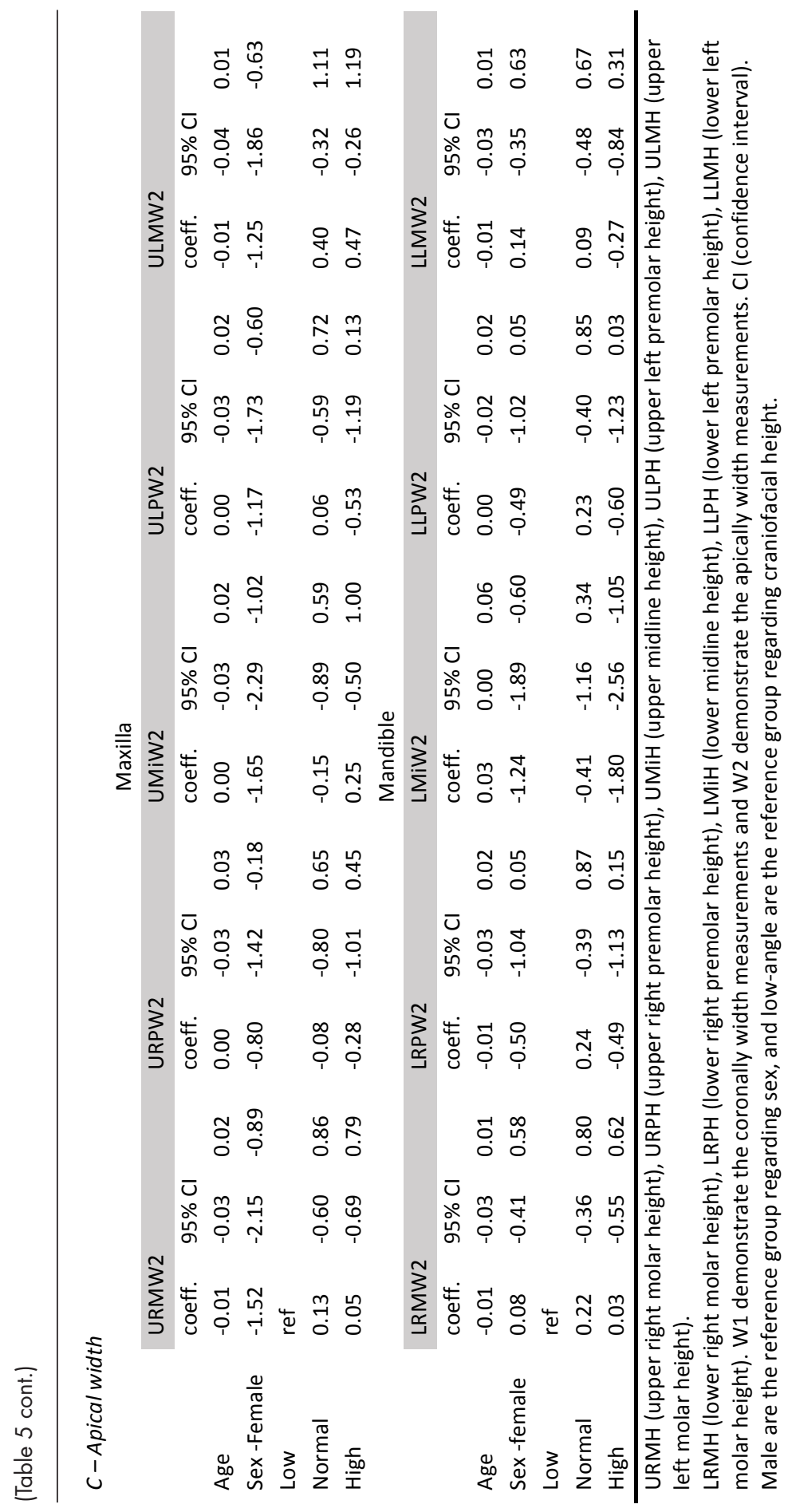




\section{Paper II}

When measuring height and width of the maxilla and mandible in cross-sectional CBCT images, the rater agreement was high.

\section{Interrater agreement}

\section{Alveolar bone height measurements}

Overall interrater agreement ICC was in general good or excellent agreement for height measurements and varied between 0.75 and 0.91 (CI 0.67-0.83 and 0.88-0.94) depending on measured site. The values were higher for measurements in the mandible compared to for measurements in the maxilla.

\section{Alveolar bone width measurements}

Corresponding ICC values for width measurements were in general lower compared to height measurements. Coronal measurements in general showed higher ICC than apical measurements. Overall interrater agreement ICC for coronal measurements varied between 0.55 and 0.88 (CI 0.43-0.66 and 0.83-0.92) with the highest value found in the mandible. For apical measurements, ICC varied between 0.50 and 0.78 (CI $0.37-0.63$ and $0.70-0.85$ ) with the highest value also found in the mandible.

The same pattern was observed for pairwise interrater agreement, e.g. the highest ICC values were achieved for measurements in the mandible compared with the maxilla. Also, the values for height measurements were in general higher, and when comparing coronal and apical width measurements the highest values were seen for coronal measurements. To summarise all pairwise interrater agreements, $\approx 8 \%$ excellent agreement, $\approx 47 \%$ good agreement, $\approx$ $39 \%$ fair agreement and $\approx 5 \%$ poor agreement, interpreted according to the scale suggested by Koo and $\mathrm{Li}(88)$.

\section{Intrarater agreement}

For calculation of intrarater agreement re-measurements were performed by all raters at $10 \%$ of the sites. No rater consistently presented the highest/lowest intrarater agreement, but the CI was somewhat wider for some raters. The highest agreement was found in the mandible when measuring the height. 


\section{Alveolar bone height measurements}

When measuring height of the alveolar bone, statistically significant differences were registered between the low- and the high-angle group for all five observers, when measuring in the premolar and midline region, both in the maxilla and in the mandible.

\section{Alveolar bone width measurements}

Coronal and apical width measurements in the maxilla at molar, premolar, and midline region displayed no statistically significant differences between any of the three craniofacial groups for the five raters.

Coronal and apical width measurement, in the mandible at incisal/ midline region, displayed statistically significant differences between the low- and the high-angle group for four out of five raters. But in the molar region, coronal and apical width measurements in the mandible showed no statistically significant differences between the three craniofacial groups.

\section{Dahlbergs formula}

The measurement error for measurements in the midline of the maxilla and mandible were calculated according to Dahlberg's formula (89). The precision estimated for each rater is presented in table 6 . The precision of a single measure for pairwise mean calculations was estimated to be $1.53(0.99-2.28)$ in the maxilla and $0.87(0.49-1.15)$ in the mandible for the high angle group, 1.29 $(0.83-1.86)$ in the maxilla and $1.31(0.72-2.23)$ in the mandible for the normal angle group, $1.3(0.73-1.87)$ in the maxilla and 0.93 (0.54-1.22) in the mandible for the low angle group.

Table 6. Dahlbergs formula intra. Alveolar bone height measurement in the midline of the maxilla and mandible in $\mathrm{mm}$.

\begin{tabular}{lllll}
\hline Rater 1 & Rater 2 & Rater 3 & Rater 4 & Rater 5 \\
\hline UMiH & & & & \\
2.48 & 1.10 & 0.62 & 1.03 & 1.49 \\
LMiH & & & & \\
1.10 & 3.16 & 1.06 & 0.37 & 1.06 \\
\hline
\end{tabular}

UMiH (upper midline height), LMiH (lower midline height). 
Paper III

Alveolar bone height

A significant difference was evident between the low-, normaland high-angle groups in almost all evaluated cross-sectional sites. The high-angle subjects displayed a greater alveolar bone height in comparison to normal- and low-angle subjects. Further, the normal angle subjects had a greater alveolar bone height compared to the low-angle subjects (Table 7). One exception was noted on the left maxillary side when comparing the normal- and high-angle groups, where no significancant difference was seen (Table 7). The alveolar bone height, mean value, between the central and lateral incisor, was $22.1 \mathrm{~mm}$, between the lateral incisor and canine it was $21.1 \mathrm{~mm}$ and between the canine and the premolar it was $19.5 \mathrm{~mm}$. An overall pattern of declining heights in a posterior direction was observed. A minimum of height recorded was $11.5 \mathrm{~mm}$ and the maximum height recorded was $30.6 \mathrm{~mm}$. All descriptive statistics including height and width is visualised in table 7 .

\section{Alveolar bone width at $3 \mathrm{~mm}$}

Recorded width ranged from 4.3 to $11.5 \mathrm{~mm}$. No significant differences were found between the angle groups at any site. The mean value increased in posterior direction displaying a wider alveolar bone in the premolar region compared to the more anterior region.

\section{Alveolar bone width at $6 \mathrm{~mm}$}

Recorded width ranged from 4.2 to $11.9 \mathrm{~mm}$. There were no significant differences found between the angle groups at any site. The overall width was greater in the premolar area compared to the more anterior region.

\section{Alveolar bone width at $9 \mathrm{~mm}$}

Recorded width ranged from 3.3 to $15.7 \mathrm{~mm}$. The low-angle subjects had significantly wider measurements than the high-angle and normal-angle subjects in the incisor region bilaterally.

\section{Alveolar bone width at $12 \mathrm{~mm}$}

A significant difference was presented between the low-, normaland high-angle groups in nearly all the regions. A width ranging 
from 3.1 to $17.6 \mathrm{~mm}$ was recorded. Low-angle subjects presented a wider alveolar bone compared to the high-angle group in all measured regions. Furthermore, the same relationship was shown between low- and normal-angle subjects, except for the premolar region. Additionally, the mean value for the premolar region was greater than the anterior region, defining a wider alveolar bone in the premolar region.

\section{Differences between sexes when measuring alveolar bone morphology}

Significant differences in both height and width measurements of the alveolar bone morphology was present between males and females in all sites. Females were shown to have an alveolar bone which is both slightly lower and more narrow in the anterior part of the maxilla on all measured regions and levels (3, 6, 9 and $12 \mathrm{~mm})$. The average differences (in $\mathrm{mm}$ ) based on mean values for all regions are: height $1.5 \mathrm{~mm}$, width $10.6 \mathrm{~mm}$, width $21.1 \mathrm{~mm}$, width $31.5 \mathrm{~mm}$, width 4 $1.4 \mathrm{~mm}$ (Table 8 ).

\section{Paper IV}

Literature search and study selection

The systematic literature search resulted in 3'296 publications. A complementary search of HTA organisations did not result in any additional studies. Articles clearly regarded as non-relevant to the current systematic review were excluded at this stage as were duplicates. In the next step, title and abstract screening yielded 28 potential publications gathered for full-text inspection and inclusion for further analysis. Flowcharts of the screening process for the studies are shown in figure 18.

Studies read in full text were summarised with reason for exclusion, being either "does not adress the present research question", "neither primary nor a SR study", "SR with differences in methodological approach compared to the present review" or "duplicate/same subjects as another study". 


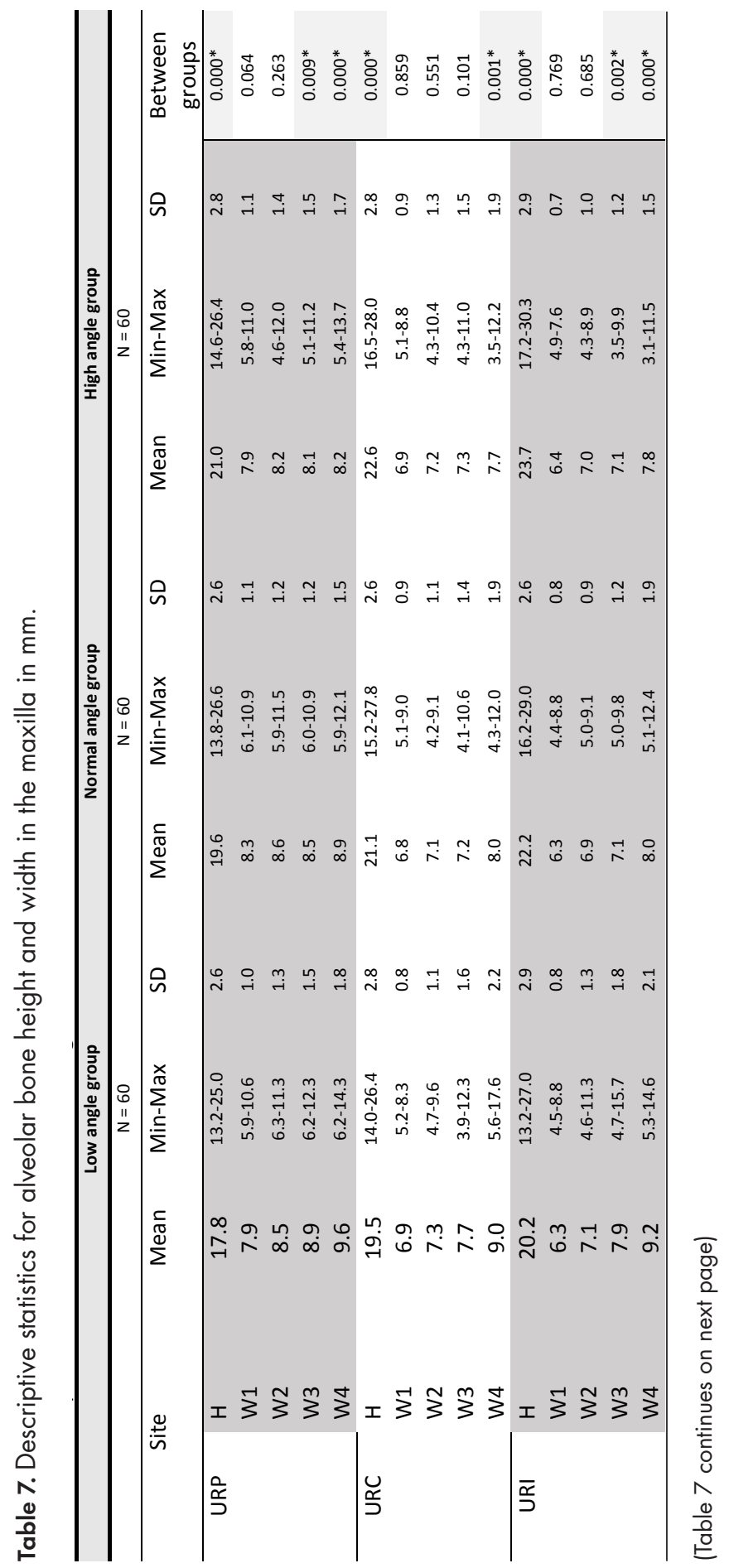




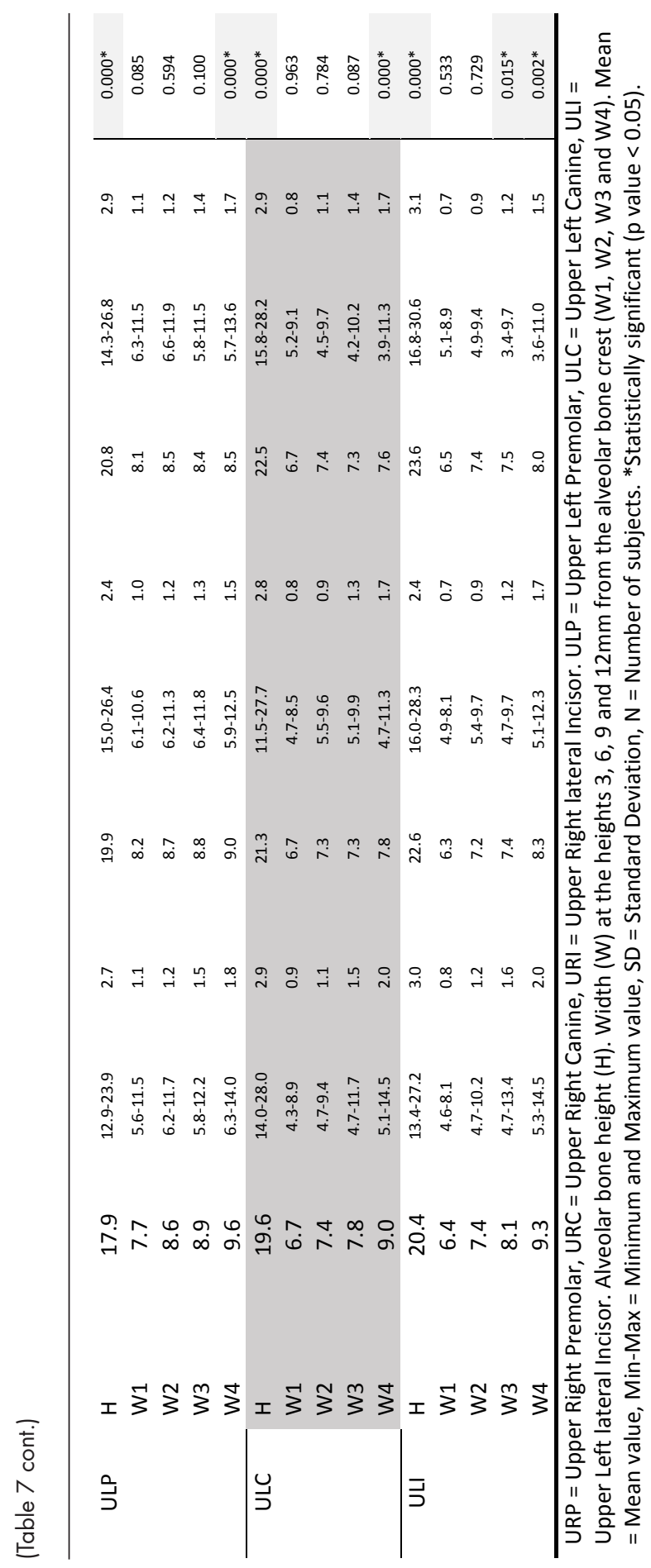


Table 8. Difference between male and female when comparing measurements of alveolar bone height and width in $\mathrm{mm}$.

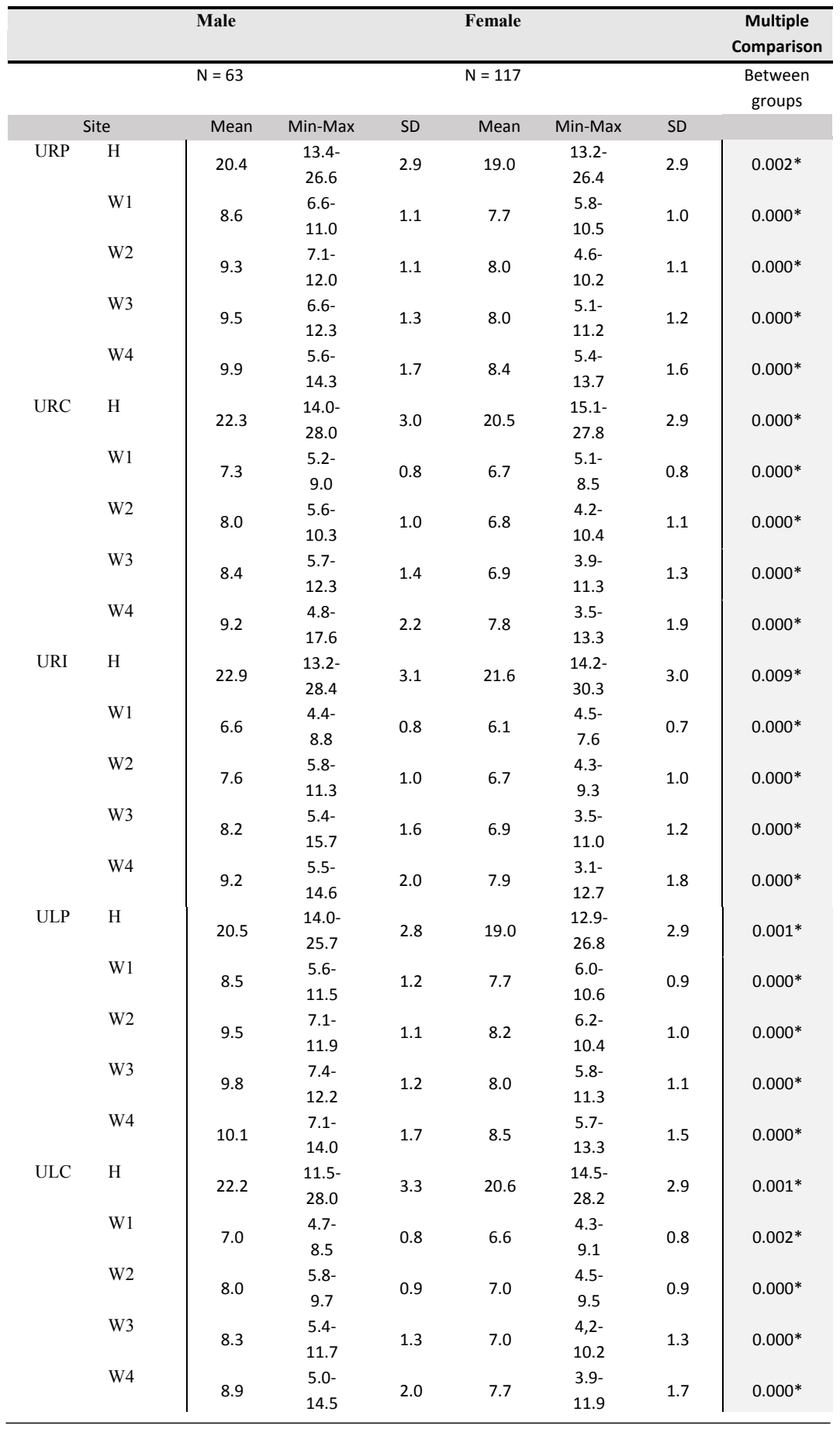

(Table 8 continues on next page) 


\begin{tabular}{|c|c|c|c|c|c|c|c|c|}
\hline \multirow{2}{*}{\multicolumn{2}{|c|}{ W1 }} & \multirow[b]{2}{*}{8.5} & \multicolumn{2}{|l|}{$\angle 3.1$} & \multicolumn{3}{|c|}{$\angle 0.8$} & \multirow[b]{2}{*}{$0.000^{*}$} \\
\hline & & & $\begin{array}{l}5.6- \\
11.5\end{array}$ & 1.2 & 7.7 & $\begin{array}{l}6.0- \\
10.6\end{array}$ & 0.9 & \\
\hline \multicolumn{2}{|r|}{ W2 } & 9.5 & $\begin{array}{l}7.1- \\
11.9\end{array}$ & 1.1 & 8.2 & $\begin{array}{l}6.2- \\
10.4\end{array}$ & 1.0 & $0.000^{*}$ \\
\hline \multicolumn{2}{|r|}{ W3 } & 9.8 & $\begin{array}{l}7.4- \\
12.2\end{array}$ & 1.2 & 8.0 & $\begin{array}{l}5.8- \\
11.3\end{array}$ & 1.1 & $0.000^{*}$ \\
\hline \multicolumn{2}{|r|}{ W4 } & 10.1 & $\begin{array}{l}7.1- \\
14.0\end{array}$ & 1.7 & 8.5 & $\begin{array}{l}5.7- \\
13.3\end{array}$ & 1.5 & $0.000^{*}$ \\
\hline \multirow[t]{5}{*}{ ULC } & $\mathrm{H}$ & 22.2 & $\begin{array}{l}11.5- \\
28.0\end{array}$ & 3.3 & 20.6 & $\begin{array}{l}14.5- \\
28.2\end{array}$ & 2.9 & $0.001 *$ \\
\hline & W1 & 7.0 & $\begin{array}{c}4.7- \\
8.5\end{array}$ & 0.8 & 6.6 & $\begin{array}{c}4.3- \\
9.1\end{array}$ & 0.8 & $0.002 *$ \\
\hline & W2 & 8.0 & $\begin{array}{c}5.8- \\
9.7\end{array}$ & 0.9 & 7.0 & $\begin{array}{c}4.5- \\
9.5\end{array}$ & 0.9 & $0.000 *$ \\
\hline & W3 & 8.3 & $\begin{array}{l}5.4- \\
11.7\end{array}$ & 1.3 & 7.0 & $\begin{array}{l}4,2- \\
10.2\end{array}$ & 1.3 & $0.000 *$ \\
\hline & W4 & 8.9 & $\begin{array}{l}5.0- \\
14.5\end{array}$ & 2.0 & 7.7 & $\begin{array}{l}3.9- \\
11.9\end{array}$ & 1.7 & $0.000^{*}$ \\
\hline \multirow[t]{5}{*}{ ULI } & $\mathrm{H}$ & 23.1 & $\begin{array}{l}13.4- \\
29.6\end{array}$ & 3.0 & 21.7 & $\begin{array}{c}15.5- \\
30.6\end{array}$ & 3.1 & $0.006^{*}$ \\
\hline & W1 & 6.7 & $\begin{array}{c}5.1- \\
8.9\end{array}$ & 0.8 & 6.3 & $\begin{array}{c}4.6- \\
8.0\end{array}$ & 0.7 & $0.001^{*}$ \\
\hline & W2 & 7.9 & $\begin{array}{l}6.3- \\
10.2\end{array}$ & 0.8 & 7.0 & $\begin{array}{c}4.7- \\
8.9\end{array}$ & 1.0 & $0.000^{*}$ \\
\hline & W3 & 8.5 & $\begin{array}{l}5.1- \\
13.4\end{array}$ & 1.3 & 7.2 & $\begin{array}{c}3.4- \\
9.7\end{array}$ & 1.2 & $0.000^{*}$ \\
\hline & W4 & 9.4 & $\begin{array}{l}5.1- \\
14.5\end{array}$ & 1.7 & 8.1 & $\begin{array}{l}3.6- \\
12.3\end{array}$ & 1.7 & $0.000 *$ \\
\hline
\end{tabular}

URP = Upper Right Premolar, URC = Upper Right Canine, URI = Upper Right lateral Incisor. ULP = Upper Left Premolar, ULC = Upper Left Canine, ULI = Upper Left lateral Incisor. Alveolar bone height $(\mathrm{H})$. Width (W) at the heights $3,6,9$ and $12 \mathrm{~mm}$ from the alveolar bone crest $(\mathrm{W} 1, \mathrm{~W} 2, \mathrm{~W} 3$ and W4). Mean $=$ Mean value, Min-Max $=$ Minimum and Maximum value, $\mathrm{SD}=$ Standard Deviation, $\mathrm{N}=$ Number of subjects.

*Statistically significant ( $\mathrm{p}$ value $<0.05$ ).

\section{Assessment of risk of bias and data extraction} Systematic reviews

One systematic review was eligible for quality assessment (90). However, since a different methodological approach was used compared to the present systematic review, that review was excluded.

\section{Primary studies}

The quality assessment resulted in seven studies with a low/moderate risk of bias. Study population, type of exposure, characteristics and outcome are shown in table 9. Due to the variety in study design and outcome, statistical analysis as metaanalysis was not applicable. 
Summary of the studies of low/moderate risk of bias

In a study by Aarts et al. from 2015 the potential difference in craniofacial growth cessation between subjects with short, average, or long faces as an implication for timing of implant placement was investigated. 169 patients were included. Orthodontic treatment was completed and cessation of facial growth was evaluated at 2 , 5 and 10 years follow-ups. No statistical difference between the craniofacial height groups was found (91).

Bernard and co-workers evaluated the effects of the tooth-eruption process of teeth adjacent to implant-borne restorations in adult patients compared to patients in their late adolescence. The study included 28 subjects, divided into a young group (15.5-21 years), $\mathrm{n}=14$ and a mature group (40-55 years), $\mathrm{n}=14$. Craniofacial height was not evaluated. No difference was found in the amount of vertical displacement of the adjacent teeth between male and female patients (62).

In the study sample of Brahem et al. 2017 measurement of the extent of tooth displacement in relation to implants after insertion were investigated. Dental implant treatment was performed after documented stabilisation of growth height by measuring standing height. Fifty-seven patients (37 with pre-implant orthodontic treatment and 20 without) were included. Infraposition was evaluated according to a score (modified Jemt) (92). Craniofacial height was not evaluated. No relationship was found between maximal tooth displacement of incisors, pre-implant orthodontic treatment and orthodontic retention, sex, and age at the end of treatment (93).

In a study by Fudalej et al. 2007 the purpose was to evaluate the amount of craniofacial growth and the amount of eruption of the central incisors after puberty. Over half of the measured increase in anterior facial height (AFH) took place before the age of 15 in men. In females, about $40 \%$ of the growth in AFH occurred before the age of 15 . For both sexes, the majority of the increase in AFH occurred in the lower anterior face height. Most of the changes in both facial height and in amount of eruption of central icisors occured at an 
early age but changes could be observed throughout the whole observation period (94).

In the study by Kawanami et al. 1999, the purpose was to evaluate the extent of infraposition after replantation of avulsed teeth and to relate this event to the age and sex of the patient. Craniofacial height was not evaluated. Almost all cases demonstrated increasing infraposition over time. More rapid increase in infraposition was identified in patients where ankylosis occurred earlier during childhood. Additionally, infraposition was also detected when ankylosis occurred after the age of 20-30 years, but then in a slower and less noticeable manner (63).

Schwartz-Arad et al. 2013 investigated the submersion rate of single dental implants in the central maxillary incisor region compared with the adjacent natural tooth and the association with age. Craniofacial height was not evaluated. The mean submersion rate of the implant supported restoration was more than three times greater in patients $<30$ years compared to patients $>30$ years $(64)$.

In the studies by Thilander et al. 1994 and 2001 dental implants in adolescents were investigated. Lateral cephalograms were taken pre-operatively, at crown placement and at the end of followup. By super-imposing the lateral cephalograms a tracing of the craniofacial vertical growth was evaluated. But information regarding craniofacial height was not used for categorisation of the subjects into low-, normal- and high-angle groups. In four of the patients, the position of the implant-crowns was vertically changed which also involved the gingival margin leading to an unacceptable position from a clinical point of view. Due to replacement of a small number of crowns there was a drop out, which may influence the results since the study population was relatively small to begin with (11 patients and 17 fixtures in the anterior maxilla) $(65,95)$.

Quality assessment resulted in four studies with a high risk of bias. Selection bias, exposure bias, detection bias, attrition bias, and reporting bias were evaluated. 
Summary of findings

Evidence for continued growth in the alveolar bone of the anterior maxilla associated to age is of very low quality. 


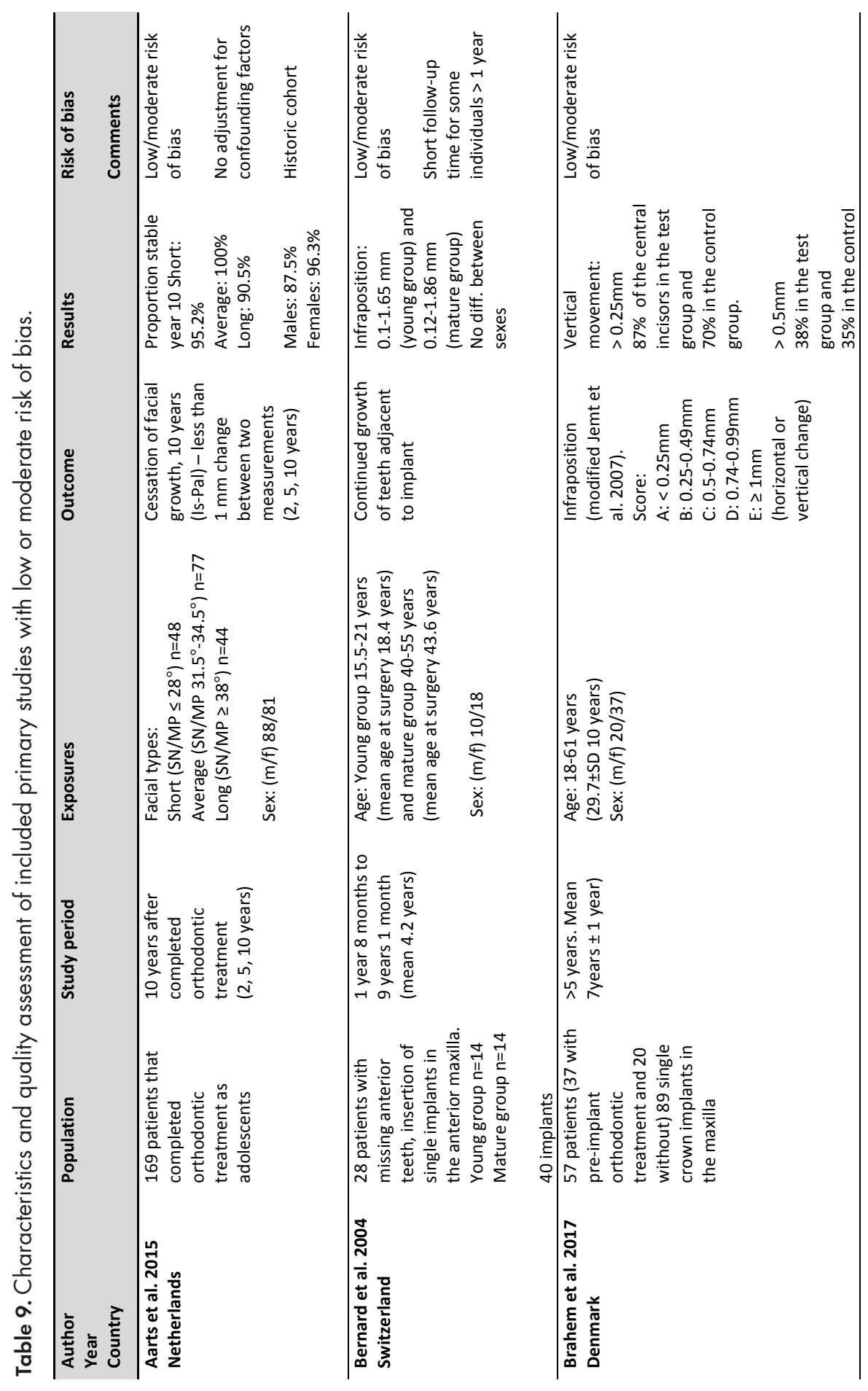




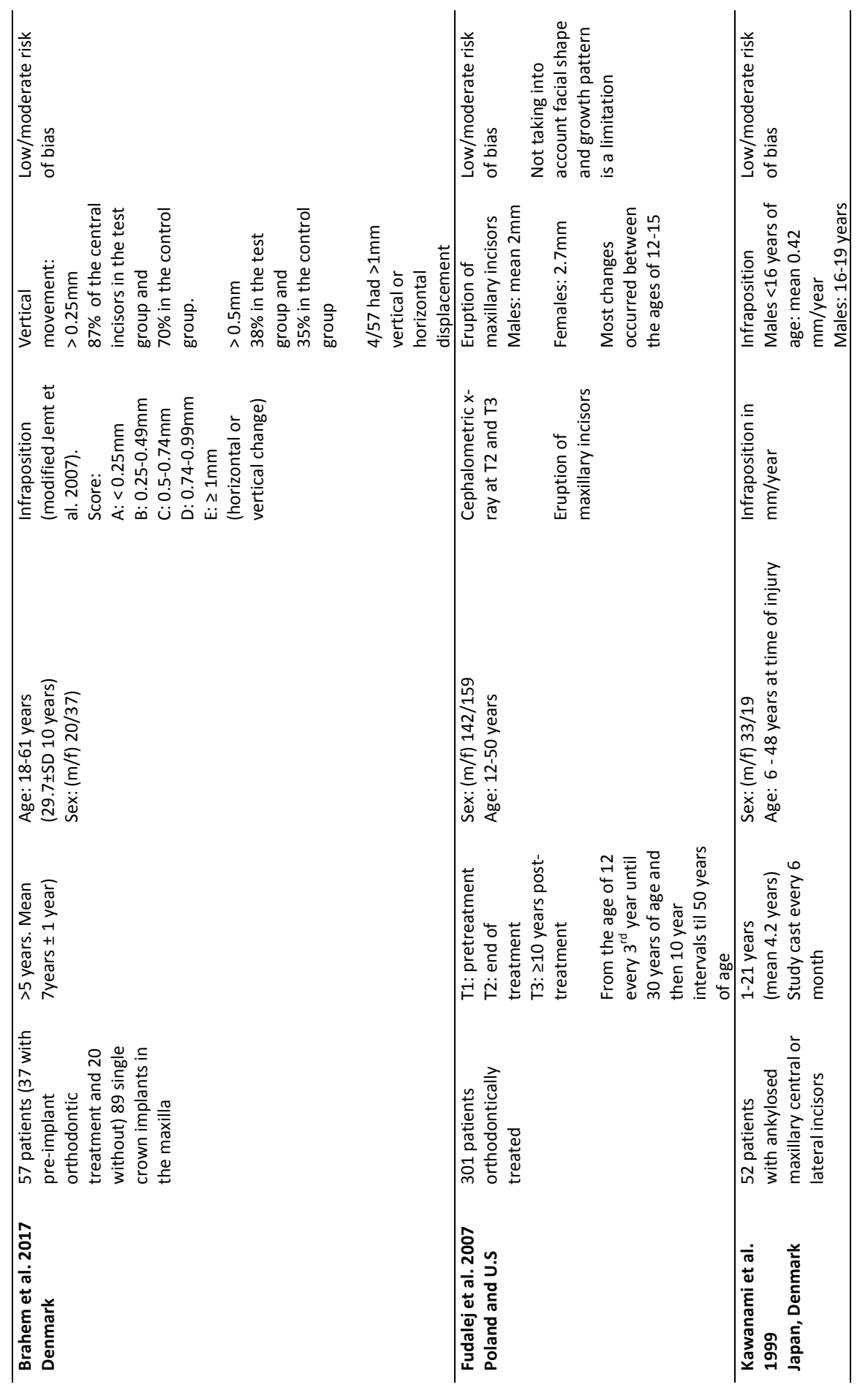




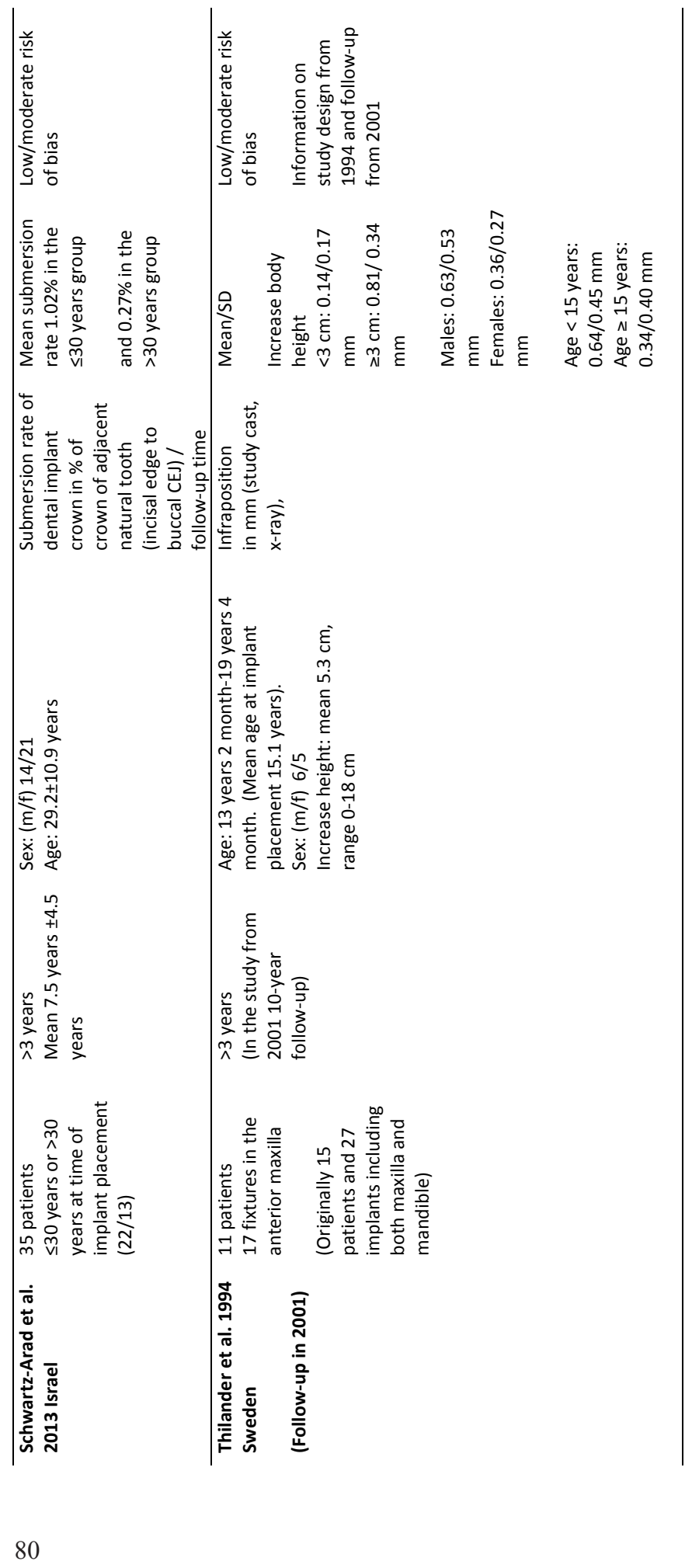




\section{DISCUSSION}

The main result reached in this thesis concern the association of the alveolar bone morphology and the subject's craniofacial height. Measurements of the alveolar bone of fully dentate individuals illustrate the differences in height and width morphology which is considered to be within the normal anatomy. The knowledge of these normal variations could be beneficial for the patient and clinician in therapy planning. Furthermore, continued craniofacial growth and DACM are mechanisms that clinicians should be familiar with in order to be able to deliver the best long-term results for the patients.

Craniofacial morphology evolves through an interaction between the supporting skeletal framework and the development of the craniofacial tissues. In this thesis, focus has been on an aspect of craniofacial development called the DACM. Results of statistically significant differences in height and width of the alveolar bone that are to a large extent associated with the craniofacial height and sex are presented. Evidence is presented that individuals with a highangle craniofacial height are more prone to a more narrow alveolar bone in the anterior part of the maxilla, compared to subjects with a low-angle craniofacial height. The presented results also indicate that high-angle craniofacial subjects have a pattern of more high and narrow alveolar bone in the midline region of the mandible, whereas in comparison, the low-angle craniofacial morphology display shorter and wider bone. 


\section{Radiography}

Panoramic and cephalometric radiographs have limited visualisation of the dentition and surrounding structures, as it only provides twodimensional depictions of the anatomical relationship (69).

Also, some magnification may occur even with a properly positioned patient. Superimposition of the head and neck structures seen on these views can make certain regions more difficult to interpret. The introduction of CBCT in orthodontics provided a three-dimensional view of oral and craniofacial structures that could function as an diagnostic aid. Due to the reduced radiation dose compared to conventional CT, CBCT can work as a diagnostic tool and treatmentplanning tool in orthodontics (96) and dental implant treatment (97).

\section{Mesurement of craniofacial height}

Radiographic cephalometry are used to caracterise the patient's skeletal and dental relationships (98). The development and advances in imaging over time deepened the knowledge of craniofacial growth.

There are various ways to measure the craniofacial height, e.g. Frankfort mandibular angle (FMA) (99), the ratio between the anterior upper and lower facial height or the ratio between the anterior and posterior facial height. The method to measure the craniofacial height in this thesis is based on the angle formed between the nasion-sella line and the mandibular line as previously described in the subjects and methods section. The anatomical points $\mathrm{N}$ and $\mathrm{S}$ are located in hard tissue and are easily visible and easy to find on a profile x-ray image. Because they are located in the midsagittal plane, they are displaced to a minimum degree by movement of the head. Therefor the NSL is used as one of the reference lines for assessment of the vertical craniofacial height. The other line used was the ML, defined by menton and gonion which are used to represent the lower border of the mandible.

A categorisation of the three craniofacial groups was made for the purpose of comparison $\left(<27^{\circ}, 27-37^{\circ}\right.$ and $>37^{\circ}$ group $)$. This partition is dervied from Steiner's cephalometric norms for Caucasians, where $32^{\circ}+1-5^{\circ} \mathrm{SD}$ are set as average. 
Maxilla

Alveolar bone height

Differences between the three craniofacial groups were evident in the molar, premolar, and midline area as presented in paper I and III. The differences were more pronounced in the anterior area compared to the molar region. In an investigation by Sadek et al. (80), the same tendency with significant difference in height of the maxillary crosssectional sites was also reported. However, these findings were only registered in the midline area, no significant differences were found in the molar region, while the premolar area was not measured.

In a study by Gracco et al. 2009 (99) no statistical differences were shown in the midline area of the maxilla between high-, normaland low-angle subjects on CBCT images. However, the expected differences in millimeter might be too small to investigate with the limiting number of total 60 subjects (20 in each group). The results obtained by Gracco and co-workers are not in agreement with our findings, which could also be due to the fact that the study sample included growing individuals (12-40 years) where some changes of the morphology of the maxillary alveolar bone are expected as the individuals grow, keeping in mind that the teeth continue to erupt as long as craniofacial growth takes place (23). Slight differences in the measuring techniques used could also explain the differences in findings.

\section{Alveolar bone width}

In paper I, no significant difference was found in width (coronal and apical) measurements in the maxilla when comparing the three groups. Since measurements in the anterior region were performed in the midline, these results could be explained by anatomical structures, e.g. insicive foramen and anterior nasal spine complicating the measurements in that region.

In paper III, a significant difference was found between the craniofacial groups when measuring width at the 9 and $12 \mathrm{~mm}$ locations, especially in the incisor region bilaterally. Low-angle subjects presented a wider alveolar bone compared to the high-angle subjects. The findings in paper III are in accordance with the results 
reported by Gracco et al. (99) who described a negative association between width of the alveolar bone and craniofacial height dimension. Further, in a study by Sadek et al. (80), a significant difference in alveolar bone width between high- and low-angle subjects was reported in the midline area both in the coronal and apical region where high-angle subjects had a more narrow alveolar bone. There are various reasons for these findings differing from our results e.g. different measurement techniques, number of patients, and location of measurement. Sadek et al. measured the bone at the teeth location, whereas we measured between the teeth.

\section{Mandible}

\section{Alveolar bone height}

In paper I, a pronounced difference in height from the molar to the midline region was displayed in the high-angle group. The least apparent change in height proceeding from the molars to the midline was described in the low-angle group, this was also described in studies by Swasty et al. and Sadek et al. (80, 100). Figure 20.
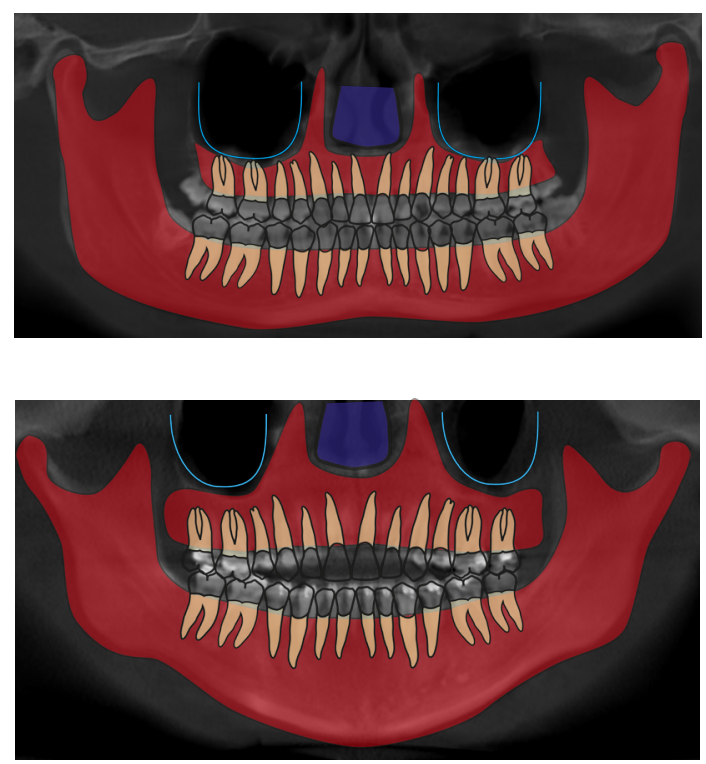

Figure 20. Panoramic images displaying differences in alveolar bone height between low- and high-angle subjects. Most pronounced differences in the anterior region. Courtesy of Dr. Karin Binner Becktor. 
Considering the growth pattern of the mandible in high-angle subjects, the observations reflect the posterior rotation of the mandible, where the incisors have to erupt significantly in order to compensate and reach an occlusion, thereby bringing the alveolar bone along with them. In the same scenario (high angle) the molars have to erupt less. On the contrary, when anterior rotation of the mandible is the case, the incisors have to erupt less to obtain occlusion and the molars have to erupt more or equally to the incisors (5). Subjects with a high-angle morphology displayed a significantly higher mandibular alveolar bone height in the premolar region and, in particularly, in the midline when compared to the other groups.

Mandibular width decreased along the dental arch towards the midline. In the coronal alveolar region, the mandible was significantly thinner in the midline and premolar region in all three groups. And concerning the measurements of the apical region, the cross section was significantly wider in the midline area compared to the premolar and molar area in all three groups. This finding could e.g. be due to the mental spine anatomy.

\section{Alveolar bone morphology differences between male and female}

A general pattern was displayed where the male subjects presented a greater height and width dimension compared to the females when measuring the alveolar bone. The same pattern was found by Swasty et al. (100) which strengthens the sex-associated differences.

The rater agreement study is, to our knowledge, the first of its kind to investigate the measurement technique of alveolar bone morphology and its relation to craniofacial height using CBCT data from patient examinations $(80,100,101)$. Several raters should be included in a study in order to provide information about the method for generalisability of the results.

High interrater agreement was presented for measurements of the height of the maxillary and mandibular alveolar bone and for the width measurements at most sites using CBCT data. Statistical differences in height of the alveolar bone between the low- and highangle subjects, in both premolar and midline regions, were found for all raters. This reinforces the results of paper I, where an association 
between craniofacial height and alveolar bone morphology was found.

The images from the CBCT examinations were acquired with an i-CAT CBCT machine with a voxel size of $0.3 \mathrm{~mm}$. Higher resolution can be obtained with other CBCT machines and other scanning protocols but for measurements of craniofacial structures it has been shown that a resolution of $0.4 \mathrm{~mm}$ voxel size is adequate (102). With the aid of laser markers, the midsagittal and occlusal planes were adjusted perpendicular to each other during scanning. The patient positioning could vary to some extent, and possibly influence the result of the measurements. However, several studies have shown that accuracy and reliability of measurements in CBCT images are not affected by changing the skull orientation (103-105). The sample size of 180 subjects that represented a wide age range ( $15-71$ years) and included images allowed us to have a representative sample of subjects wih different craniofacial morphology.

The raters in the present study represented professional experience from different fields of expertise and various length of experience. These are factors that can potentially influence the results. However, since this is also the case with all potential users in a clinical situation, it is a strength and enables wider generalisability of the results. The raters were blinded to all patient information and to the other raters' measurements in order to minimise the risk of bias.

The results were expressed as pairwise interrater calculations to detect if any rater differed considerably from the others, and if this was the case the results could be analysed further. Misinterpretation of the instructions or an unfavourable measurement technique can explain any potential differences. In this study, no clear deviation was observed for any rater.

The results were also expressed as overall ICC. The raters received instructions to search for the approximal cross-sectional sites predetermined to measure height and width. This may have given a lower ICC score and also wider confidence intervals (CI) compared to use of pre-selected sites. Nevertheless, the choosen approach 
mimics the clinical situation and has the advantages of external validity of the results compared to a staged research environment.

Overall interrater agreement was in general higher for cross-sectional measurements in the mandible compared with the maxilla. This might indicate that the borders and anatomical landmarks in the mandible are easier to identify.

Pairwise interrater agreement varied, but a majority of the agreements were in the category "excellent or good" (88). The lowest agreement was noted for measurements in the upper midline region. This might be explained by the difficulty in determining the proper demarcation due to, for example, anatomical variations such as the incisive foramen.

The CI of the ICC was in some measurements negative which indicates considerable uncertainty. In the study by Sadek et al (2015), inter-and intrarater agreement was reported as ICC with paired t-test (80). However, the number of observers was vaguely described as "other orthodontists" without mentioning exact numbers or professional experience and no CI was reported. CI should be reported in order to display the statistical uncertainty, particularly the lower level of reliability/agreement.

ICC is a well-known and frequently used statistical method to present comparable values/measurements. However, it is "non-dimensional" and the results are interpreted in accordance with a scale (88). Another way of presenting the results are to use Dahlberg's formula. An advantage of this method is the ability to compare values in the same scale as the measurements are performed in, e.g in $\mathrm{mm}$. Since $\mathrm{mm}$ are more commonly used in clinical situations this might be easier to relate to. However, since no scale is used, the assessment of the results have to be interpreted in that specific context.

In paper III, a different approach regarding measurement technique was applied. The cross-sectional width measurements were set at the height locations $(3,6,9$ and $12 \mathrm{~mm})$ and therefore standardised at the same level for all subjects. The height of up to $12 \mathrm{~mm}$ was choosen in order to reflect a clinical situation with restoration using 
dental implants with a standard length of up to $12 \mathrm{~mm}$.

Our findings suggest that craniofacial height is important for the development of the alveolar bone dimensions (height and width) in the anterior region of the maxilla. This knowledge may be of value in identifying risk patients where implant treatment may be less suitable, because of the non-desirable growth pattern and, consequently, alveolar bone deficiency.

The majority of the absent permanent teeth in the anterior region of the maxilla in children and adolescent patients are due to TDI or agenesis (106). Dental implant treatment is contraindicated in growing patients until growth is completed (107). However, treatment planning with the final results in mind, including tooth replacement, usually begins when the patient is still growing. There are many factors to consider in connection with the replacement of a lost tooth in the anterior maxilla. The patient's growth status in stature as well as craniofacial height and dental situation should always be taken into account. Orthodontic space closure, autotransplantation, and prosthetic rehabilitation might, in some cases, be more suitable treatment options than implant treatment, while in other cases dental implant treatment is a better choice (108).

Malmgren and Malmgren (2002) reported an association between infraposition of ankylosed roots and craniofacial growth pattern where individuals with a more vertical growth showed a more pronounced alveolar bone growth and thus can be regarded as risk patients for infraposition (109). These patients also have an increased risk for infraposition of implants and may for this reason be more complicated, or not suited for dental implant treatment. It has been suggested that cephalometric radiographs are important for evaluating the direction of growth of the jaws since there is a difference between horizontal and vertical growth (109). It may be concluded that it is of value to identify the growth pattern of the patients early in the treatment planning.

The results in paper III indicate that patients with a high craniofacial growth pattern are also more prone to a thinner alveolar bone phenotype. The dimension of the buccal bone plate in the anterior 
region (prior to tooth extraction) is a major factor influencing the amount of resorption after tooth extraction as indicated in a study by Ferrus et al. 2010 (110).

At the time of treatment planning, assessment of craniofacial height of the patient can be a valuable tool in identifying patients at risk of bone deficiency and accentuated vertical growth and for whom implant treatment may be less suitable. Nevertheless, it is also important to identify the subjects with low craniofacial height who seem to be more stable and more suitable for dental implant treatment. Identifying this early on in the treatment planning is relevant for the clinician and also considered favourable from a patient perspective.

There are similar studies where the height and width of the alveolar bone are investigated based on CBCT images, however the majority of studies are focused on mandibular dimensions and the thickness of the cortical buccal bone $(111,112)$.

In paper I-III, fully dentate, untreated subjects were choosen for inclusion. That enables evaluation of anatomical differences in the morphology of the alveolar bone without tooth loss and the change on the alveolar bone that entails (Figure 21). In areas exposed to trauma and dental loss, atrophy of the alveolar bone and local inhibition of growth will take place.

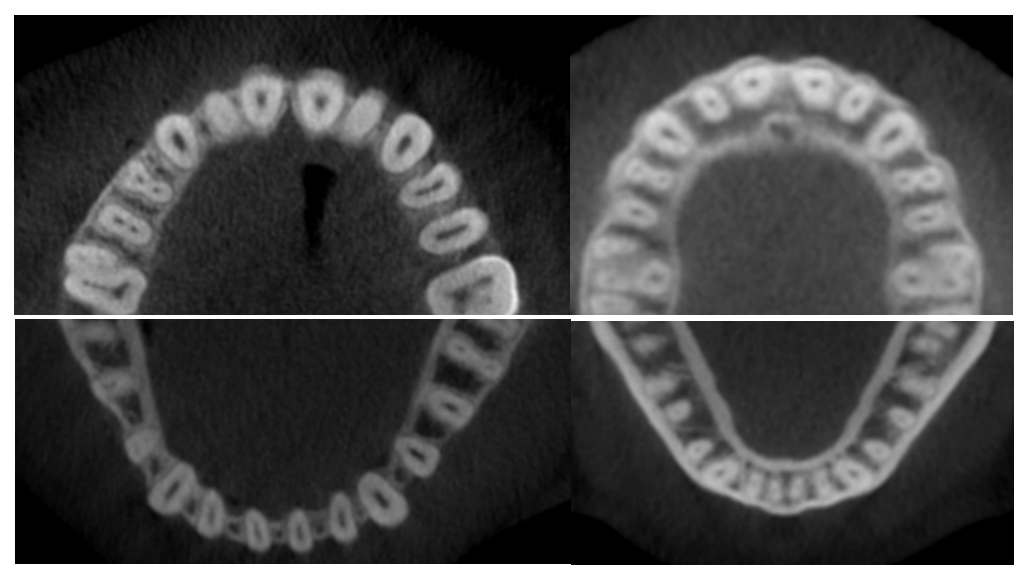

Figure 21. Axial view from i-CAT vision $\mathrm{CBCT}$ images 
Normal anatomy from a low- and high-angle subject.

The alveolar bone width was measured at the heights of 3 (w1), $6(\mathrm{w} 2), 9(\mathrm{w} 3)$ and $12(\mathrm{w} 4) \mathrm{mm}$ from the top of the alveolar bone crest, since most implants are preferably installed within this range in the bone. Comparison between craniofacial height and the alveolar bone width at level $\mathrm{w} 1$ and $\mathrm{w} 2$ revealed no statistical significance. However, at level w3 and w4 statistically significant differences were shown at a majority of the measured sites.

Gracco et al. (2009) found a significant difference in alveolar bone width between the vertical craniofacial dimension groups at $20 \mathrm{~mm}$ from the incisal tip at the left and right central and lateral incisors. The result concurs with the results in the current study, since w 3 and w4 corresponds approximately to the cross-sectional measurement at the height of $20 \mathrm{~mm}$. The results of Gracco et al. correspond to our measurements at $\mathrm{w} 1$ and $\mathrm{w} 2$ and no significant difference in the height of $15 \mathrm{~mm}$ was found (113). These results demonstrate that the strongest correlation between craniofacial height and alveolar bone measures are located in the region least exposed to the bone resorption pattern observed after tooth loss.

Similar to our results, Sadek et al. (2015) found that the high-angle group had significantly thinner alveolar bone anteriorly in the maxilla compared to the low-angle group (111). This was presented both at mid-root level and the level of the root-apex. In contrast to the significant difference at $\mathrm{w}_{4}$ in the premolar site in the present study, they found no statistical difference posterior to the canine.

The multiple comparison between males and females displayed a significant difference at all sites. Alveolar bone height and width cross-sectional measurements of the male subjects were greater overall. From a theoretical perspective, this aspect could be interpreted as males being more suited for implant treatment based on their anatomical conditions. In the clinical situation this is probably of great relevance as the results of this study reveals what the sufficient average value of height and width is for both sexes to install implants. Nevertheless, in some extreme high-angle cases, mostly female, implant treatment might not be possible due 
to deficiency in the alveolar bone volume. Implant treatment might not be the first choice of treatment in patients with a high-angle craniofacial type, since they tend to display more gingiva and also a more pronounced continued eruption due to the DACM.

In light of the results from papers I and III, it is recommended that craniofacial height should be assessed in order to identify risk cases where implant treatment may be less suitable. Performing such an analysis in growing individuals in need of oral rehabilitation due to missing teeth, opens up the possibility to set out an optimal treatment plan, such as orthodontic space closure, autotransplantation or dental implant treatment.

The aim of the systematic review (paper IV) was to evaluate an association between continued growth in the anterior maxilla and craniofacial height, age, and sex, which might result in infraposition of ankylosed teeth or dental implants adjacent to teeth. Seven primary studies were identified, all with different aims and at low or moderate risk of bias. The heterogeneity between the seven studies precluded meta-analysis.

There is a lack of well-designed studies with multivariate analysis including investigation of craniofacial height, age, and sex. Consequently, it was not possible to pinpoint and grade the certain predisposing risk factors for infraposition of dental implants in the anterior maxilla. A previous systematic review on a similar topic was identified (90), but unlike the current systematic review, they included studies at either high risk or unclear risk of bias in their meta-analyses.

The description "unclear risk of bias" when there is a lack of information about material and methods in the included primary studies, precludes the option that the assessment of scientific quality can be acceptable. Including such studies in the meta-analysis as comparable to studies of either low or moderate risk of bias seems speculative and this should be kept in mind by the reader when interpreting the results. 
In summary, careful quality assessment of primary studies and reviews are important before drawing conclusions, especially when the conclusions are relevant to clinical practice. Our findings highlight the need of new studies with accurate study protocols, including an appropriate number of subjects, and a well-defined and calibrated investigation technique, in order to improve the future scientific knowledge whithin the field.

\section{Clinical implications}

DACM

Understanding the link between craniofacial growth and tooth eruption might be a valuable support when it comes to planning for the appropriate age for treatment. For example, since the teeth in the anterior region of an individual with low craniofacial height have a shorter way to erupt and less alveolar bone growth compensation inherent to reach occlusion, the suitable age for dental implant treatment might be earlier than for an individual with a high craniofacial height.

The results of this thesis can support the idea that the DACM aims to maintain a functional occlusion along with craniofacial growth. In the high-angle group, the alveolar bone seems to grow more in order to fully or partly compensate for the vertical craniofacial growth. As a result, the alveolar bone of the maxilla and mandible becomes higher, especially in the anterior region. The finding that the alveolar bone became narrower in the midline of the mandible might be due to the difference in loading. In a study by LL Sonnesen, an association between high craniofacial height (long face) and a lower bite force was investigated. The opposite would be displayed in lowangle subjects (short face) where the jaws are more parallel and the alveolar bone is loaded with more bite force in comparison to the high-angle subjects (114). In the low-angle group, the root resides in most of the body of the maxilla and mandible, whereas in the highangle group, the root resides only in part of the body and mostly in the alveolar bone wich leaves more space apically. According to Wolff's law, less force applied will result in a less developed bone (115). 


\section{Post-eruptive tooth movement}

There are different opinions/doctrines regarding the continued use of the word eruption after the stage where teeth have emerged into the oral cavity and reached occlusion. Regardless of referring to the process as continued eruption or post-eruptive tooth movement or continued growth there seems to be a, perhaps lifelong, continued movement of the teeth and alveolar bone to adapt for tooth-wear induced new conditions.

\section{Dental trauma}

The presence of dental trauma can be presented as prevalence or incidence. The difference is that prevalence refers to all cases, new or old, in a population at a given time, whereas incidence refers to the number of new patients with a TDI during a given period, generally 1 year, in a specified population. In other words, incidence presents information regarding the risk of contracting a TDI, whereas prevalence conveys information about how widespread TDIs are. Regardless of statistical approach to present the numbers/condition, the TDI is one of the most common worldwide conditions (52).

\section{Treatment options and planning}

Absence of teeth in the permanent dentition of a child could be due to different reasons, e.g trauma, aplasia or caries and periodontitis. To restore or create a functional and aesthetic dentition there are various treatment options available. The different treatment options available in a growing individual are more complex compared to an adult. Treatment planning is of the outmost importance to achieve a successful long-term treatment result. Age, sex, and genetical (heredity) factors are some of the necessary pieces to take into account. Treatment options available could be autotransplantation, orthodontic treatment, prosthetic treatment, dental implant treatment or a combination.

In cases with single agenesia of permanent teeth it is important to keep the precursor (primary/decidious teeth) to maintain the alveolar bone for future treatment possibilities and perhaps enable a longterm provisional replacement. 
One option could be autotransplantation. The treatment option is favourable for growing individuals. Autotransplantation is a procedure where a tooth is surgically transplanted from one site in the mouth to another in the same individual (116). This treatment option enables dental reconstruction using only biocompatible material, since it is the patient's own tooth (117). The benefits of tooth transplantation are many, e.g. that it can be performed at an early age, when the incidence of trauma is the highest. Transplanted teeth can after healing be moved orthodontically (118) and preserve the bone and even induce alveolar bone growth during the eruption process $(119,120)$.

During donor tooth surgery a total rupture of the neurovascular bundle and periodontal fibres occurs, and the success of autotransplantation is dependent on the subsequent tissue-healing process (117). The predictability of the pulp healing appears to be strongly related to the dimensions of the apical foramen (121). Advantageous healing of the periodontal ligaments is dependent on the number of viable cells preserved at the root surface. For a successful healing, the donor teeth needs to be removed with minimal mechanical damage to the PDL (120).

Prosthodontic alternatives such as resin bonded bridge, removable dentures or conventional prosthodontics are possible treatment options (108).

Another treatment option is orthodontic treatment (122). In orthodontic treatment, knowledge of how the development of the lower third of the face is closely linked to the DACM is important, since the DACM can be influenced in connection with treatment. During active orthodontic treatment, knowledge of the morphology of the alveolar bone is important, e.g. in thin ridges where the buccal and lingual cortical bone can be in contact or in close approximity with very little cancellous bone. The risk for root resorption increases if the roots are moved into the surrounding cortical bone. An additional risk may be that the teeth are moved out of the alveolar bone if it is of a narrow width (123). 
In connection with insertions of skeletal temporary anchorage devices (TADs) (124), knowledge of difference in alveolar bone morphology in different craniofacial growth patterns is valuable. The present study has demonstrated that the alveolar bone is shorter in the mid-palatal area in the low-angle subjects and less space is available superior to the apex of the incisors compared to the normal and high-angle subjects. Accordingly, an increased risk of root damage and a risk of inserting the miniscrew into the nasal cavity can be expected in low-angle patients.

An interesting finding is that the alveolar bone volume can be reshaped by active orthodontic tooth movement and therefore might be an alternative for bone augmentation (125). An edentulous area with a reduced bucco-lingual dimension can attain increased bucco-lingual width of the alveolar bone if a tooth is moved into the area orthodontically, e.g. by orthodontically moving a tooth anteriorly to an edentulous site, the gap is then transferred distally. A dental implant can then be placed more posteriorly which might be aesthetically more favourable, offering a wider alveolar bone and minimising the risk of infraposition (126).

During treatment planning for growing patients with congenital missing teeth, the decision to replace missing teeth with implants or by orthodontic closure could be influenced by the expected development of the DACM.

Dental implant treatment is the newest treatment option, although it is no longer that novel. The titanium implant started out as a fortuitus discovery, and was first used as a chamber investigating blood flow in the bone of a rabbit, but later led to the invention of the osseointegrated dental implant $(127,128)$. A treatment method originally used as anchorage for prosthesis with a sole mission of the functional purpose of keeping the prosthesis in place. Over time the method transformed into a more sophisticated treatment method applied e.g. as anchorage for multi-unit bridges and single crowns in the aesthetic zone. Since then the treatment possibilities have developed towards a more aesthetic solution. 


\section{DACM and osseointegrated dental implants}

After the supposed cessation of craniofacial growth, continued positional changes may occur (129). This could lead to infraposition of an implant-supported crown after placement of a dental implant in the anterior region of the maxilla in a post-adolescent patient (130). Differences in craniofacial growth pattern between subjects with low, normal, and high craniofacial dimensions, might be reflected in the timing of completion of craniofacial growth. Since the lowangle subjects have a shorter distance for the incisors to erupt, it can be expected that the risk of infrapositioned implant-supported crowns is low. Whereas in the high-angle subjects, an extensive tooth eruption in the anterior region is present, and the risk for infrapositioned implant-supported crowns is greater. Accordingly, it might be advisable to postpone implant insertion a couple of years beyond completion of skeletal growth in the high-angle individuals, compared to the low-angle individuals in order to minimise this risk.

In treatment with dental implants, a thorough pre-operative evaluation is important in order to achieve a predictable, successful aesthetic outcome. The thickness of the buccal bone wall is of crucial importance for selection of the appropriate treatment approach (131). In paper I, the range in width of the coronal part of the crosssection in the midline area was between $2.5 \mathrm{~mm}$ (high angle) and 12.1 $\mathrm{mm}$ (low angle) in the mandible (Table 4). To achieve an aesthetic and functional successful outcome in dental implant treatment, it is of importance to take into account the three-dimensional aspects of the alveolar bone as suggested by Buser et al. (132).

The dental implants are placed with the purpose of placing a prosthetic restauration on top. With a limited amount of bone volume width, the direction might be compromised.

\section{Bone augmentation}

In a systematic review by Milinkovic and Cordaro 2014, indications for bone augmentations were investigated. There are different techniques used to increase the bone volume in partially edentulous patients. To gain horizontal bone, there is strong evidence to support the use of guided bone regeneration (GBR) at the time of implant 
placement, when experiencing a fenestration defect or dehiscence. There is also evidence in favour of using staged GBR for horizontal augmentation in preparation for implant placement (with a residual crest of $2.9 \mathrm{~mm}$ or wider initially). Two-stage procedures is also supported by evidence when bone block grafts are used for augmentation of horizontal defects, with an initial ridge width of $3.2 \mathrm{~mm}$. Additionally, there is support for the use of ridge splitting/ expansion technique in augmentation of horizontally deficient ridges (mean ridge width $3.37 \mathrm{~mm}$ ). Possible complications of the aforementioned techniques could be fracture of the buccal bone or exposure of the membrane. Regarding the vertical defects, they can be treated with GBR simultaneously with the implant placement. Distraction osteogenesis is another possibility for vertical alveolar ridge augmentation in more extraordinary cases in need of a larger vertical bone gain (133).

There are a few predisposing factors of gingival recession, with and without fixed orthodontic treatment. Decreased alveolar bone thickness is one predisposing factor. According to our results the high-angle cases display a thinner alveolar bone width especially in the anterior region which would entail a higher risk for gingival recession (134). The thickness of the mucosa is also important in the aesthetic appearance and risk for discolouration. A thinner gingiva is more prone to be discoloured by titanium abutments (135) or discolouration of a thinner peri-implant mucosa caused by dental implants (136).

\section{Ethical aspects}

CBCT is a rather modern imaging modality as it was introduced in the late 1990s. At the time when a majority of the images used in these studies were obtained, no European guidelines on the use of CBCT for different dental- and maxillofacial conditions had been established. In 2012, European guidelines for the use of CBCT were published (137). Work is ongoing stating the precise selection criteria following the principle of As Low As Reasonable Achievable (ALARA) for the use of X-rays (138). The selection criteria for performing CBCT were skeletal and craniofacial deviations, patients planned for orthognathic surgery, impacted teeth, and trauma patients, none of which can be specifically disputed for image 
acquisition. However, if a prospective study would be performed, the selection criteria might be adjusted to obtain the present radiographic hygiene regimen.

Having access to the CBCT database, from which a selection of images were collected retrospectively and used for this study, it was considered unethical not to utilise clinically valuable data. Ethical approval was obtained in order to be able to use these available CBCT images for research purposes.

Craniofacial height was determined by cephalometric analysis using the Total Interactive Orthodontic Planning System (TIOPS) program (86). The cephalometric analysis was performed by one of the authors, who is a specialist in orthodontics. This analysis is a standard procedure in orthodontic assessment and treatment planning. In order to correctly interpret the attained measurement results, one has to consider how precise/imprecise the tracing of landmarks are. Both in conventional lateral radiographs and in CBCT skull images, observer reliability of this technique has shown to be high $(139,140)$. When height and width measurements were repeated at $20 \%$ of the maxillary and mandibular alveolar bone sites, a "excellent" or "good" agreement was shown (interpreted according to Koo and Li) (88).

\section{Statistics}

\section{Power}

Depending on the anticipated difference in height and width of the alveolar bone in $\mathrm{mm}$ between the craniofacial groups and the $\mathrm{CI}$, the number of subjects necessary to include can be calculated. This thesis is based on existing pretreatment CBCT images from a database and no additional images were acquired. A power analysis is a tool to calculate the required number of subjects neccesary to establish a certain association. Used in the proper way this helps to avoid initiating research that no conclusions can be drawn from due to too few participants as well as avoids meaningsless spending of economical and time resourses. A study with too few participants can never demonstrate a relationship even though there might be a relationship. On the other hand, an unlimited number of participants can always demonstrate a relationship even if none exists. 
An estimated sample size for a two-sample means test was calculated to 158 ( $\mathrm{N}$ total), and 79 ( $\mathrm{N}$ per craniofacial group) for one region of the alveolar bone and $52(\mathrm{~N}$ total) and $26(\mathrm{~N}$ per group) for another region. The numbers are based on the following study parameters: $0.05 \%$ significance level, desired power of $80 \%$ and delta (the difference between the means of the two populations) of 1.1 and 1.9 respectively. Depending on the anticipated measured differences (in this case of the alveolar bone morphology) between the groups and the SD, the numbers necessary to include differs. A smaller anticipated difference needs a larger number of subjects to demonstrate that.

\section{Clinical implications and limitations}

According to a study of Buser et al. (2004) the buccal and lingual bone should be at least $1.5 \mathrm{~mm}$ respectively to harbour a dental implant without compromising the integrity of the bone. The crest width should accordingly measure at least $3 \mathrm{~mm}$, plus the width of the implant diameter inserted. Elevation of a periosteal flap and insertion of a implant disrupts the blood supply locally. The thicker the bone volume, the smaller is the area in risk of negative influence. Embedding of the micro-rough implant surface in bone in the longterm seems important in order to minimise the risk of postsurgical boneloss and possibly periimplantitis. 


\section{CONCLUSIONS AND FUTURE RESEARCH}

The DACM is under less genetic control than the craniofacial growth including growth in the cartilages and sutures. In combination with careful planning the DACM can be influenced by orthodontic appliances, thus making a thoughtful, biologically facilitated orthodontic treatment possible.

Knowledge of how the DACM works is therefore just as important for the modern clinician today, as it was more that 50 years ago when Arne Björk and Beni Solow comprehensively described it. Knowledge of the morphological features of the alveolar bone is of importance when planning orthodontic or dental implant treatment. The results presented in this thesis show the significant association between craniofacial height and alveolar bone dimensions, also verified by several raters.

Height and width of the alveolar bone also seems to be strongly related to the sex of the patient. This is a statistically evident finding, and translating that into a clinical situation, the results might not impact the treatment in some cases. However in the "extreme" cases of large vertical craniofacial height the treatment with dental implants might not be suitable due to anatomical limitations. Evidence shows that individuals with a high-angle craniofacial height are more prone to a thinner alveolar bone in the anterior part of the maxilla and mandible compared to subjects with low-angle craniofacial height. 
Already during adolescence, a clinical examination could reveal the vertical craniofacial growth pattern and thereby give the clinician an indication of which treatment option to choose in cases of tooth loss or agenesis.

The influence of the craniofacial height in association with infraposition needs to be further investigated. Craniofacial height in relation to alveolar bone morphology is a research area which has so far been neglected, probably due to its complex nature. Nevertheless, knowledge concerning the growth mechanism is of importance for the majority of the dental specialties and this thesis underlines that more multidisciplinary research and interaction is vital. 


\section{ACKNOWLEDGEMENTS}

The journey of completing this thesis have been both an academic and personal experience for me. There are a great number of people that I met along the way who made this possible. I am grateful for all the encouragement, curios questions and engagement I have encountered.

I would especially like to thank:

My main supervisor, associate professor Jonas Becktor, co-supervisor Dr Karin Binner Becktor, co-supervisor professor Christina Lindh and co-supervisor Aron Naimi Akbar for your ideas and scientific contributions that has been most valuable to this research project.

Co-authors Ayman Al-Okshi, Marianne Ahmad, Peter Eldh, Rasmus Ulvan and Nicole Winitsky for your contributions.

Co-author and source of inspiration professor Sofia Tranaeus for the knowledge and encouragement you provided.

Co-author professor Lars Andersson for inspiration, valuable contribution and for always encouraging me.

All my dear colleagues, past and present, at the Faculty of Odontology, Malmö University. Especially, my dear colleagues at the Department of Oral Surgery and Oral Medicine, Lars, Anna, Rolf, Fredrik, Sten, Marianne, Martin, Krister, Tania, Yohei, Ryo. To the wonderful Selma, Monica, Samra, Eva, Magda, Christine, Nathalie, Helén and Yvonne. For the clinical surgery training and for always greeting me with a smile. I will truly miss you! 
To all my fellow PhD students/colleagues at Malmö University.

Lisa and Manjula, I truly appreciate your knowledge and input in the writing process.

To my Italian colleagues Francesca Cecchinato, Marco Toia, Michele Stocchero, Silvia Galli, you are the best combination of hard work and having a good time.

Per Erik Isberg for your statistical consultations, great knowledge and ability to convey your input in the best way.

To Cecilia Hallström for your valuable linguistic guidance.

To the staff at Malmö University Library for always assisting and helping out with both big and small inquiries from reference management to the construction of a systematic review search.

To my peers at the National Clinical Research School in Odontology who made the journey of research education a great experience, we have shared many cherished memories and I have made some friends for life.

To Ann Wennerberg, Margareta Hultin, Carina Krüger Weiner, Bodil Lund and Patricia De Palma for inspiring me through your hard work.

Liv and Zdenka for always asking me how things are going and providing advice when needed.

Gunilla and Per for your encouragement and help when it was needed.

To Tina for your great assistance along the way.

To my friends, for your love and support in both small and large issues.

A special thank you to Fredrika who has always been there. 
To my wonderful family, I can never thank you enough for what you give me in life.

To my late grandfather Bengt and my grandmother Margit for everything you have done for me. 


\section{REFERENCES}

1. Nanci A, Ten Cate ARo. Ten Cate's oral histology : development, structure, and function. 8. ed. ed: Mosby Elsevier; 2013.

2. Nanci A, Ten Cate ARo. Ten Cate's oral histology : development, structure, and function. 7. ed. ed: Mosby Elsevier; 2008.

3. Avery JK, Steele PFe. Essentials of oral histology and embryology : a clinical approach. 2. ed. ed: Mosby; 2000.

4. Coben SE. The spheno-occipital synchondrosis: the missing link between the profession's concept of craniofacial growth and orthodontic treatment. American journal of orthodontics and dentofacial orthopedics. 1998;114(6):709-12.

5. Björk A. Käkarnas tillväxt och utveckling i relation till kraniet i dess helhet. Nordisk Klinisk Odontologi Copenhagen Forlaget for faglitteratur. 1964:1-44.

6. Sadeghianrizi A, Forsberg C-M, Marcus C, Dahllöf G. Craniofacial development in obese adolescents. The European Journal of Orthodontics. 2005;27(6):550-5.

7. Pirinen S. Endocrine regulation of craniofacial growth. Acta Odontologica Scandinavica. 1995;53(3):179-85.

8. Pelin C, Zağyapan R, Yazıcı C, Kürkçüoğlu A. Body height estimation from head and face dimensions: a different method. Journal of forensic sciences. 2010;55(5):1326-30.

9. Shrestha R, Shrestha PK, Wasti H, Kadel T, Kanchan T, Krishan K. Craniometric analysis for estimation of stature in Nepalese population-A study on an autopsy sample. Forensic science international. 2015;248:187. e1-. e6.

10. Flores-Mir C, Nebbe B, Major PW. Use of skeletal maturation based on hand-wrist radiographic analysis as a predictor of facial growth: a systematic review. The Angle Orthodontist. 2004;74(1):118-24. 
11. Mellion ZJ, Behrents RG, Johnston Jr LE. The pattern of facial skeletal growth and its relationship to various common indexes of maturation. American Journal of Orthodontics and Dentofacial Orthopedics. 2013;143(6):845-54.

12. Verma D, Peltomäki T, Jäger A. Reliability of growth prediction with hand-wrist radiographs. The European Journal of Orthodontics. 2009;31(4):438-42.

13. Graber LWe, Vanarsdall RLe, Vig KWLe. Orthodontics: current principles and techniques. 5. rev. ed. ed: Mosby; 2011.

14. Moyers RE. Handbook of orthodontics. 4. ed. ed: Year Book Medical Publishers; 1988.

15. Enlow DH. Facial growth. 3. ed. ed: Saunders; 1990.

16. Björk A. Facial growth in man, studied with the aid of metallic implants. Acta odontologica scandinavica. 1955;13(1):9-34.

17. Björk A, Skieller V. Growth of the maxilla in three dimensions as revealed radiographically by the implant method. British Journal of Orthodontics. 1977;4(2):53-64.

18. Taranger J, Hägg U. The timing and duration of adolescent growth. Acta Odontologica Scandinavica. 1980;38(1):57-67.

19. Björk A. Variations in the growth pattern of the human mandible: longitudinal radiographic study by the implant method. Journal of dental Research. 1963;42(1):400-11.

20. Bjo A, Skieller V. Facial development and tooth eruption: an implant study at the age of puberty. American journal of orthodontics. 1972;62(4):339-83.

21. Björk A. Prediction of mandibular growth rotation. American journal of orthodontics. 1969;55(6):585-99.

22. Skieller V, Björk A, Linde-Hansen T. Prediction of mandibular growth rotation evaluated from a longitudinal implant sample. American journal of orthodontics. 1984;86(5):359-70.

23. Björk A, Skieller V. Normal and abnormal growth of the mandible. A synthesis of longitudinal cephalometric implant studies over a period of 25 years. The European Journal of Orthodontics. 1983;5(1):1-46.

24. Lindhe J, Lang NP. Clinical Periodontology and Implant Dentistry. 6th ed. ed: John Wiley \& Sons, Incorporated; 2015.

25. Solow B. The dentoalveolar compensatory mechanism: background and clinical implications. British journal of orthodontics. 1980;7(3):145-61.

26. Solow B. The pattern of craniofacial associations: A morphological and methodological correlation and factor analysis study on young male adults. Acta Odontol Scand 24. 1966;46:123-35. 
27. Marks Jr SC, Schroeder HE. Tooth eruption: theories and facts. The Anatomical Record: An Official Publication of the American Association of Anatomists. 1996;245(2):374-93.

28. Cahill DR. Histological changes in the bony crypt and gubernacular canal of erupting permanent premolars during deciduous premolar exfoliation in beagles. Journal of dental research. 1974;53(4):786-91.

29. Cahill DR, Marks Jr SC. Tooth eruption: evidence for the central role of the dental follicle. Journal of Oral Pathology \& Medicine. 1980;9(4):189-200.

30. Ralph W, Jefferies J. The minimal width of the periodontal space. Journal of oral rehabilitation. 1984;11(5):415-8.

31. Xiong J, Gronthos S, Bartold PM. Role of the epithelial cell rests of M alassez in the development, maintenance and regeneration of periodontal ligament tissues. Periodontology 2000. 2013;63(1):217-33.

32. Foster TD. A textbook of orthodontics. 3. ed. ed: Blackwell Scientific; 1990.

33. Siersbaek-Nielsen S. Rate of eruption of central incisors at puberty: an implant study on eight boys. Tandlaegebladet. 1971;75(12):1288.

34. Becktor $\mathrm{B}, \mathrm{K}$. The link between craniofacial growthand growth of the alveolar process. The dentoalveolar compensatory mechanism. Revista Española de Ortodontica. 2015(45):211-6.

35. Behrents RG. Growth in the aging craniofacial skeleton: Center for human growth and development, University of Michigan Ann Arbor; 1985 .

36. Eriksen E, Mosekilde L, Melsen F. Trabecular bone remodeling and balance in primary hyperparathyroidism. Bone. 1986;7(3):213-21.

37. Pietrokovski J, Massler M. Alveolar ridge resorption following tooth extraction. Journal of Prosthetic Dentistry. 1967;17(1):21-7.

38. Araújo MG, Lindhe J. Dimensional ridge alterations following tooth extraction. An experimental study in the dog. Journal of clinical periodontology. 2005;32(2):212-8.

39. Schropp L, Wenzel A, Kostopoulos L, Karring T. Bone healing and soft tissue contour changes following single-tooth extraction: a clinical and radiographic 12-month prospective study. International Journal of Periodontics \& Restorative Dentistry. 2003;23(4).

40. Misawa M, Lindhe J, Araújo MG. The alveolar process following singletooth extraction: a study of maxillary incisor and premolar sites in man. Clinical oral implants research. 2016;27(7):884-9.

41. Pietrokovski J, Harfin J, Levy F. The influence of age and denture wear on the size of edentulous structures. Gerodontology. 2003;20(2):100-5. 
42. Tallgren A. The effect of denture wearing on facial morphology: a 7-year longitudinal study. Acta odontologica scandinavica. 1967;25(5):563-92.

43. Ulm C, Solar P, Gselimann B, Matejka M, Watzek G. The edentulous maxillary alveolar process in the region of the maxillary sinus-a study of physical dimension. International journal of oral and maxillofacial surgery. 1995;24(4):279-82.

44. Carlsson G, Persson G. Morphologic changes of the mandible after extraction and wearing of dentures. A longitudinal, clinical, and x-ray

cephalometric study covering 5 years. Odontologisk revy. 1967;18(1):27.

45. Graber TM. Consensus conference on oral implants in young patients: Goran Koch, Tom Bergendal, Sven Kvint, and Ulla-britt JohanssonStockholm, Sweden: Forlagshuset Gothia A.B., 135 pages, illustrated. American Journal of Orthodontics \& Dentofacial Orthopedics. 1997;111(3):352-.

46. de Oliveira RCG, Leles CR, Normanha LM, Lindh C, Ribeiro-Rotta RF. Assessments of trabecular bone density at implant sites on CT images. Oral Surgery, Oral Medicine, Oral Pathology, Oral Radiology, and Endodontology. 2008;105(2):231-8.

47. Lesot $\mathrm{H}$, Clauss F, Manière $\mathrm{M}$, Schmittbuhl $\mathrm{M}$. Consequences of X-linked hypohidrotic ectodermal dysplasia for the human jaw bone. Comparative Dental Morphology. 13: Karger Publishers; 2009. p. 93-9.

48. Johnson EL, Roberts MW, Guckes AD, Bailey LTJ, Phillips CL, Wright JT. Analysis of craniofacial development in children with hypohidrotic ectodermal dysplasia. American journal of medical genetics. 2002;112(4):327-34.

49. Lexner MO, Bardow A, Bjorn-Jorgensen J, Hertz JM, Almer L, Kreiborg S. Anthropometric and cephalometric measurements in X-linked hypohidrotic ectodermal dysplasia. Orthodontics \& craniofacial research. 2007;10(4):203-15.

50. Jensen BL, Lund AM. Osteogenesis imperfecta: clinical, cephalometric, and biochemical investigations of OI types I, III, and IV. Journal of craniofacial genetics and developmental biology. 1997;17(3):121-32.

51. Waltimo-Sirén J, Kolkka M, Pynnönen S, Kuurila K, Kaitila I, Kovero O. Craniofacial features in osteogenesis imperfecta: a cephalometric study. American Journal of Medical Genetics Part A. 2005;133(2):142-50.

52. Andersson L. Epidemiology of traumatic dental injuries. Journal of endodontics. 2013;39(3):S2-S5.

53. Andersson L, Petti S, Day P, Kenny K, Glendor U, Andreasen JO. Classification, epidemiology and etiology. Textbook and color atlas of traumatic injuries to the teeth: Wiley-Blackwell; 2019. p. 252-94. 
54. Petti S, Glendor U, Andersson L. World traumatic dental injury prevalence and incidence, a meta-analysis-One billion living people have had traumatic dental injuries. Dental traumatology. 2018;34(2): 71-86.

55. Glendor U. Epidemiology of traumatic dental injuries-a 12 year review of the literature. Dental traumatology. 2008;24(6):603-11.

56. Andersson L, Blomlöf L, Lindskog S, Feiglin B, Hammarström L. Tooth ankylosis: clinical, radiographic and histological assessments. International Journal of Oral Surgery. 1984;13(5):423-31.

57. Andreasen JO, Hjørting-Hansen E. Replantation of teeth. I. Radiographic and clinical study of 110 human teeth replanted after accidental loss. Acta Odontologica Scandinavica. 1966;24(3):263-86.

58. Andreasen JO, Hjørting-Hansen E. Replantation of teeth. II. Histological study of 22 replanted anterior teeth in humans. Acta Odontologica Scandinavica. 1966;24(3):287-306.

59. Pindborg J. Pathology of the dental hard tissues. 1970. Munksgaard, Copenhagen.

60. Malmgen B, Malmgren O, Andersson L. Dentoalveolar ankylosis, decoronation and alveolar bone preservation. Textbook and Color Atlas of Traumatic Injuries of the Teeth, 5th Edition: Wiley Blackwell; 2018. p. 834-52.

61. Andersson L, Malmgren B. The problem of dentoalveolar ankylosis and subsequent replacement resorption in the growing patient. Australian Endodontic Journal. 1999;25(2):57-61.

62. Bernard J, Schatz J, Christou P, Belser U, Kiliaridis S. Long-term vertical changes of the anterior maxillary teeth adjacent to single implants in young and mature adults: A retrospective study. Journal of clinical periodontology. 2004;31(11):1024-8.

63. Kawanami M, Andreasen J, Borum M, Schou S, Hjerting-Hansen E, Kato H. Infraposition of ankylosed permanent maxillary incisors after replantation related to age and sex. Dental Traumatology. 1999;15(2):50-6.

64. Schwartz-Arad D, Bichacho N. Effect of age on single implant submersion rate in the central maxillary incisor region: a long-term retrospective study. Clinical implant dentistry and related research. 2015;17(3):509-14.

65. Thilander B, Ödman J, Gröteborg K, Friberg B. Osseointegrated implants in adolescents. An alternative in replacing missing teeth? The European Journal of Orthodontics. 1994;16(2):84-95.

66. Thilander B, Ödman J, Jemt T. Single implants in the upper incisor region and their relationship to the adjacent teeth. An 8-year follow-up study. Clinical Oral Implants Research. 1999;10(5):346-55. 
67. Paatero YV. Pantomography in theory and use. Acta radiologica. 1954(4):321-35.

68. White SC, Pharoah MJ. The evolution and application of dental maxillofacial imaging modalities. Dental Clinics of North America. 2008;52(4):689-705.

69. Truhlar RS, Morris HF, Ochi S. A review of panoramic radiography and its potential use in implant dentistry. Implant dentistry. 1993;2(2):12230.

70. Boeddinghaus R, Whyte A. Current concepts in maxillofacial imaging. European journal of radiology. 2008;66(3):396-418.

71. Robinson S, Suomalainen A, Kortesniemi M. micro-CT. European Journal of Radiology. 2005;56(2):185-91.

72. Tanimoto K, Hansson L-G, Petersson A, Rohlin M, Johansen CC. Computed tomography versus single-contrast arthrotomography in evaluation of the temporomandibular joint disc: A study of autopsy specimens. International journal of oral and maxillofacial surgery. 1989;18(6):354-8.

73. Arai Y, Tammisalo E, Iwai K, Hashimoto K, Shinoda K. Development of a compact computed tomographic apparatus for dental use. Dentomaxillofacial Radiology. 1999;28(4):245-8.

74. Robb RA, Sinak L, Hoffman E, Kinsey J, Harris L, Ritman E. Dynamic volume imaging of moving organs. Journal of medical systems. 1982;6(6):539-54.

75. Miracle A, Mukherji S. Conebeam CT of the head and neck, part 1: physical principles. American Journal of Neuroradiology. 2009;30(6):1088-95.

76. Angelopoulos C, Scarfe WC, Farman AG. A comparison of maxillofacial CBCT and medical CT. Atlas of the oral and maxillofacial surgery clinics of North America. 2012;20(1):1-17.

77. Kottner J, Audigé L, Brorson S, Donner A, Gajewski BJ, Hróbjartsson A, et al. Guidelines for reporting reliability and agreement studies (GRRAS) were proposed. International journal of nursing studies. 2011;48(6):66171.

78. Rohlin M, Horner K, Lindh C, Wenzel A. Through the quality kaleidoscope: reflections on research in dentomaxillofacial imaging. Dentomaxillofacial Radiology. 2020;49:20190484.

79. Tsunori M, Mashita M, Kasai K. Relationship between facial types and tooth and bone characteristics of the mandible obtained by CT scanning. The Angle Orthodontist. 1998;68(6):557-62.

80. Sadek MM, Sabet NE, Hassan IT. Alveolar bone mapping in subjects with different vertical facial dimensions. European journal of orthodontics. 2015;37(2):194-201. 
81. Lind J. A treatise on the scurvy: in three parts, containing an inquiry into the nature, causes, and cure, of that disease: A. Millar; 1757.

82. Clarke M, Chalmers I. Reflections on the history of systematic reviews. Royal Society of Medicine; 2018.

83. Chalmers I, Glasziou P. Avoidable waste in the production and reporting of research evidence. The Lancet. 2009;374(9683):86-9.

84. Eagly AH, Wood W. Using research syntheses to plan future research. 1994.

85. KaVo. i-CAT ${ }^{\mathrm{TM}}$ [Internet]. KaVo; [updated 2020; cited 2020 Oct 11]. Available from: https://www.kavo.com/en-us/i-cat.

86. Bjoern-Joergensen J, Bjoern-Joergensen P. Total Interactive Orthodontic Planning System: Total Interactive Orthodontic Planning System; 2020 [cited 2020 Oct 11]. Internet]. Available from: http://www.tiops.com/.

87. Steiner CC. Cephalometrics for you and me. American journal of orthodontics. 1953;39(10):729-55.

88. Koo TK, Li MY. A guideline of selecting and reporting intraclass correlation coefficients for reliability research. Journal of chiropractic medicine. 2016;15(2):155-63.

89. Dahlberg G. Statistical methods for medical and biological students. Statistical methods for medical and biological students. 1940.

90. Papageorgiou SN, Eliades T, Hämmerle CH. Frequency of infraposition and missing contact points in implant-supported restorations within natural dentitions over time: A systematic review with meta-analysis. Clinical oral implants research. 2018;29:309-25.

91. Aarts B, Convens J, Bronkhorst E, Kuijpers-Jagtman A, Fudalej P. Cessation of facial growth in subjects with short, average, and long facial types-Implications for the timing of implant placement. Journal of Cranio-Maxillofacial Surgery. 2015;43(10):2106-11.

92. Jemt T, Gunilla A, Henriksson K, Bondevik O. Tooth movements adjacent to single-implant restorations after more than 15 years of follow-up. International Journal of Prosthodontics. 2007;20(6).

93. Brahem E, Holm B, Sonnesen L, Worsaae N, Gotfredsen K. Positional changes of maxillary central incisors following orthodontic treatment using single-crown implants as fixed reference markers. Clinical oral implants research. 2017;28(12):1560-6.

94. Fudalej P, Kokich VG, Leroux B. Determining the cessation of vertical growth of the craniofacial structures to facilitate placement of singletooth implants. American Journal of Orthodontics and Dentofacial Orthopedics. 2007;131(4):S59-S67. 
95. Thilander B, Ödman J, Lekholm U. Orthodontic aspects of the use of oral implants in adolescents: a 10-year follow-up study. European Journal of Orthodontics. 2001;23(6):715-31.

96. Kapila S, Nervina J. CBCT in orthodontics: assessment of treatment outcomes and indications for its use. Dentomaxillofacial radiology. 2015;44(1):20140282.

97. Chan H-L, Misch K, Wang H-L. Dental imaging in implant treatment planning. Implant dentistry. 2010;19(4):288-98.

98. Broadbent BH. A new x-ray technique and its application to orthodontia. The Angle Orthodontist. 1931;1(2):45-66.

99. Gracco A, Lombardo L, Mancuso G, Gravina V, Siciliani G. Upper incisor position and bony support in untreated patients as seen on CBCT. The Angle Orthodontist. 2009;79(4):692-702.

100. Swasty D, Lee J, Huang JC, Maki K, Gansky SA, Hatcher D, et al. Cross-sectional human mandibular morphology as assessed in vivo by cone-beam computed tomography in patients with different vertical facial dimensions. American Journal of Orthodontics and Dentofacial Orthopedics. 2011;139(4):e377-e89.

101. Klinge A, Becktor K, Lindh C, Becktor JP. Craniofacial height in relation to cross-sectional maxillary and mandibular morphology. Progress in orthodontics. 2017;18(1):32.

102. Damstra J, Fourie Z, Slater JJH, Ren Y. Accuracy of linear measurements from cone-beam computed tomography-derived surface models of different voxel sizes. American Journal of Orthodontics and Dentofacial Orthopedics. 2010;137(1):16. e1-. e6.

103. Berco M, Rigali Jr PH, Miner RM, DeLuca S, Anderson NK, Will LA. Accuracy and reliability of linear cephalometric measurements from cone-beam computed tomography scans of a dry human skull. American Journal of Orthodontics and Dentofacial Orthopedics. 2009;136(1):17. e1-. e9.

104. El-Beialy AR, Fayed MS, El-Bialy AM, Mostafa YA. Accuracy and reliability of cone-beam computed tomography measurements: Influence of head orientation. American journal of orthodontics and dentofacial orthopedics. 2011;140(2):157-65.

105. Hassan B, van der Stelt P, Sanderink G. Accuracy of three-dimensional measurements obtained from cone beam computed tomography surfacerendered images for cephalometric analysis: influence of patient scanning position. The European Journal of Orthodontics. 2009;31(2):129-34.

106. Andersson L, Andreasen JO, Day P, Heithersay G, Trope M, Diangelis AJ, et al. International Association of Dental Traumatology guidelines for the management of traumatic dental injuries: 2. Avulsion of permanent teeth. Dent Traumatol. 2012;28(2):88-96. 
107. Op Heij DG, Opdebeeck H, van Steenberghe D, Quirynen M. Age as compromising factor for implant insertion. Periodontology 2000. 2003;33(1):172-84.

108. Andersson L, Malmgen B, Malmgen $\mathrm{O}$, Storgård Jensen S. Strategies for treatment of Tooth Loss after Trauma in the Anterior region of young patients. Textbook and Color Atlas of Traumatic Injuries of the Teeth, 5th Edition: Wiley Blackwell; 2018. p. 878-87-87.

109. Malmgren B, Malmgren O. Rate of infraposition of reimplanted ankylosed incisors related to age and growth in children and adolescents. Dent Traumatol. 2002;18(1):28-36.

110. Ferrus J, Cecchinato D, Pjetursson EB, Lang NP, Sanz M, Lindhe J. Factors influencing ridge alterations following immediate implant placement into extraction sockets. Clinical oral implants research. 2010;21(1):22-9.

111. Sadek MM, Sabet NE, Hassan IT. Alveolar bone mapping in subjects with different vertical facial dimensions. Eur J Orthod. 2015;37(2):194201.

112. Swasty D, Lee J, Huang JC, Maki K, Gansky SA, Hatcher D, et al. Cross-sectional human mandibular morphology as assessed in vivo by cone-beam computed tomography in patients with different vertical facial dimensions. Am J Orthod Dentofacial Orthop. 2011;139(4 Suppl):e377-89.

113. Gracco A, Lombardo L, Mancuso G, Gravina V, Siciliani G. Upper incisor position and bony support in untreated patients as seen on CBCT. Angle Orthod. 2009;79(4):692-702.

114. Sonnesen L, Bakke M, Solow B. Temporomandibular disorders in relation to craniofacial dimensions, head posture and bite force in children selected for orthodontic treatment. European journal of orthodontics. 2001;23(2):179-92.

115. Frost HM. Wolff's Law and bone's structural adaptations to mechanical usage: an overview for clinicians. The Angle Orthodontist. 1994;64(3):175-88.

116. Howlader M, Begum S, Naulakha D. Autogenous tooth transplantation from ectopic position: a case report and review of literature. Journal of Bangladesh College of Physicians and Surgeons. 2006;24(2):79-85.

117. Chwaja-Pawelec K. Tissue healing after autologous tooth transplantation. Dental and Medical Problems. 2010;47(3):359-64.

118. Andreasen JO, Schwartz O, Kofoed T, Daugaard-Jensen J.

Transplantation of premolars as an approach for replacing avulsed teeth. Pediatric dentistry. 2009;31(2):129-32. 
119. Paulsen HU, Andreasen JO. Eruption of premolars subsequent to autotransplantation. A longitudinal radiographic study. The European Journal of Orthodontics. 1998;20(1):45-55.

120. Tsukiboshi M. Autotransplantation of teeth: requirements for predictable success. Dental Traumatology. 2002;18(4):157-80.

121. Andreasen J, Paulsen H, Yu Z, Bayer T, Schwartz O. A long-term study of 370 autotransplanted premolars. Part II. Tooth survival and pulp healing subsequent to transplantation. The European Journal of Orthodontics. 1990;12(1):14-24.

122. Zachrisson BU, Rosa M, Toreskog S. Congenitally missing maxillary lateral incisors: canine substitution. American journal of orthodontics and dentofacial orthopedics. 2011;139(4):434.

123. Handelman CS. The anterior alveolus: its importance in limiting orthodontic treatment and its influence on the occurrence of iatrogenic sequelae. The Angle Orthodontist. 1996;66(2):95-110.

124. Feng X, Li J, Li Y, Zhao Z, Zhao S, Wang J. Effectiveness of TADanchored maxillary protraction in late mixed dentitionA systematic review. The Angle Orthodontist. 2012;82(6):1107-14.

125. Lindskog-Stokland B, Hansen K, Ekestubbe A, Wennström JL. Orthodontic tooth movement into edentulous ridge areas-a case series. The European Journal of Orthodontics. 2013;35(3):277-85.

126. INCISORS MML. The Space-Closure Alternative for Missing Maxillary Lateral Incisors: An Update. 2010.

127. Adell R, Lekholm U, Rockler B, Brånemark P-I. A 15-year study of osseointegrated implants in the treatment of the edentulous jaw. International journal of oral surgery. 1981;10(6):387-416.

128. Brånemark P-I, Breine U, Adell R, Hansson B, Lindström J, Ohlsson Å. Intra-osseous anchorage of dental prostheses: I. Experimental studies. Scandinavian journal of plastic and reconstructive surgery. 1969;3(2):81100.

129. Oesterle LJ, Cronin Jr RJ. Adult Growth, Aging, and the Single-Tooth Implant. International Journal of Oral \& Maxillofacial Implants. 2000;15(2).

130. Thilander B. Dentoalveolar development in subjects with normal occlusion. A longitudinal study between the ages of 5 and 31 years. The European Journal of Orthodontics. 2009;31(2):109-20.

131. Braut V, Bornstein MM, Belser U, Buser D. Thickness of the anterior maxillary facial bone wall—a retrospective radiographic study using cone beam computed tomography. International Journal of Periodontics and Restorative Dentistry. 2011;31(2):125. 
132. Buser D, Martin W, Belser UC. Optimizing esthetics for implant restorations in the anterior maxilla: anatomic and surgical considerations. International Journal of Oral \& Maxillofacial Implants. 2004;19(7).

133. Milinkovic I, Cordaro L. Are there specific indications for the different alveolar bone augmentation procedures for implant placement? A systematic review. International journal of oral and maxillofacial surgery. 2014;43(5):606-25.

134. Jati AS, Furquim LZ, Consolaro A. Gingival recession: its causes and types, and the importance of orthodontic treatment. Dental press journal of orthodontics. 2016;21(3):18-29.

135. Jung RE, Sailer I, Hammerle C, Attin T, Schmidlin P. In vitro color changes of soft tissues caused by restorative materials. International Journal of Periodontics and Restorative Dentistry. 2007;27(3):251.

136. Thoma DS, Ioannidis A, Cathomen E, Hammerle C, Husler J, Jung RE. Discoloration of the peri-implant mucosa caused by zirconia and titanium implants. Int J Periodontics Restorative Dent. 2016;36(1):3945.

137. Sedentexct. Cone Beam CT for Dental and Maxillofacial Radiology. Evidence based guidelines [Internet]. European Commission; 2012 [cited 2017 Apr 4]. Available from: http://www.sedentexct.eu/files/radiation_ protection_172.pdf.

138. International Commission on Radiation Protection. The 2007 recommendations of the international commission on radiation protection. ICRP publication 103. Ann ICRP. 2007;37(2-4).

139. Albarakati S, Kula K, Ghoneima A. The reliability and reproducibility of cephalometric measurements: a comparison of conventional and digital methods. Dentomaxillofacial Radiology. 2012;41(1):11-7.

140. Hariharan A, Diwakar N, Jayanthi K, Hema H, Deepukrishna S, Ghaste SR. The reliability of cephalometric measurements in oral and maxillofacial imaging: Cone beam computed tomography versus twodimensional digital cephalograms. Indian Journal of Dental Research. 2016;27(4):370. 
I 



\title{
Craniofacial height in relation to cross- sectional maxillary and mandibular morphology
}

Anna Klinge ${ }^{1 *}$, Karin Becktor ${ }^{2}$, Christina Lindh $^{1}$ and Jonas P Becktor ${ }^{1}$

\section{Abstract}

Background: In order to gain a better understanding of how growth of the alveolar bone is linked to the vertical development of the face, the purpose of this study was to investigate if there is an association between the cross-sectional morphology of the maxillary and mandibular bodies with the craniofacial height, using images from cone beam computed tomography (CBCT).

Methods: From 450 pre-treatment CBCT scans, 180 were selected to be included in the study. Lateral head images were generated from the CBCT scans and were used to categorise subjects into three groups based on their vertical craniofacial height. Cross-sectional images from CBCT volumes were reformatted of the maxillary and mandibular bodies at five locations in the maxilla and five in the mandible. Each image was measured at one height and two width measurements. Statistical analysis performed was the one-way analysis of variance with a Tukey post hoc test. A significance level of 5\% was used in all comparisons.

Results: Patients with large vertical craniofacial height had a significantly higher cross-sectional area both in the maxilla and in the mandible. In the same group, the cross-sectional area was significantly thinner in the mandible compared with the other two groups, especially in the anterior region.

Conclusions: This study further highlights the close relationship between craniofacial height and alveolar bone dimensions and contributes with important knowledge for planning and follow-up of comprehensive dental-and orthodontic treatments.

Keywords: Craniofacial development, Treatment planning, Treatment timing, Cephalometrics, Biological basis of orthodontics
\end{abstract}

\section{Background}

Craniofacial growth is a complex process, and understanding the factors involved is important in connection with orthodontic treatment of children and adolescents. The growth of the craniofacial complex can be divided into four different components: (1) growth of the cranial base, (2) growth of the maxilla, (3) growth of the mandible and (4) growth of the dentoalveolar bone [1].

In the postnatal growth period, growth in the sphenooccipital synchondrosis cartilage and the cartilage of the condyle has a large influence on the vertical development

\footnotetext{
Correspondence: anna.klinge@mah.se

'Department of Oral and Maxillofacial Surgery and Oral Medicine, Faculty of Odontology, Malmö University, SE-205 06 Malmö, Sweden
} Full list of author information is available at the end of the article of the face, and adaptive growth of the maxillary sutures and growth of the dentoalveolar bone will fill out the face [2]. The link between the predominately genetically determined growth of these two cartilages and growth of the dentoalveolar bone is also known as the dentoalveolar compensatory mechanism [3, 4]. The factors that are responsible for this dentoalveolar mechanism are not fully understood. However, it has been demonstrated that growth of the dentoalveolar bone is taking place in connection with tooth eruption and is accordingly dependent on a normal eruption process [4].

The vertical development of the face has a significant impact on the direction and magnitude of tooth eruption [5]. There is a noticeable variation in the eruption rate of the teeth, with a peak in eruption velocity at the time 
of the maximum pubertal rate of growth in body height [6]. Assuming that continued eruption is a compensatory mechanism for facial growth, it seems reasonable to conclude that eruption follows the general pattern of craniofacial growth [1, 4].

The growth of the alveolar bone is less genetically determined compared to the rest of the skeleton and can be influenced by functional conditions and orthodontic treatment [7]. Accordingly, knowledge of the expected growth pattern of the alveolar bone is important in relation to orthodontic treatment of growing individuals. Furthermore, the morphology of the alveolar bone in three dimensions is important when it comes to the planning of orthodontic tooth movement as well as in connection with insertion of skeletal, temporary anchorage devises (TADs) and dental implants for restorative purpose [8-13].

There are, however, only limited reports where the craniofacial morphology has been used as a guideline for evaluation of height and width of the alveolar bone. A comprehensive thesis on the various facial anatomical components and the relationship between them was presented in 1966 by Solow [3]. In this thesis, a nontopographical positive correlation between height of the alveolar bone both in the maxilla and in the mandible, in relation to craniofacial height, was demonstrated in an adult sample. In more recent years, some studies have reported height and width of either maxillary or mandibular alveolar bone in relation to craniofacial height in dry skulls $[14,15]$ or patients [16-18].

Since its introduction in the late 1990s, cone beam computed tomography (CBCT) has become a common imaging modality that provides a three-dimensional data set of the facial skeleton. To our knowledge, only one study investigated the relationship between facial height and alveolar bone morphology in the incisor and molar regions of the maxilla and the mandible [19]. The aim of this study was therefore, based on CBCT images of subjects, to explore the association between the crosssectional morphology of the maxillary and mandibular bodies at several sites of the tooth-bearing regions and craniofacial height.

\section{Methods}

The study is conducted in accordance with the REporting of studies Conducted using Observational Routinelycollected health Data (RECORD) guidelines [20].

\section{Subjects}

This study was conducted on pre-treatment CBCT scans collected from the archive at a private practice of orthodontics in Scandinavia. Images were obtained from patients, females over 15 years and males over 16 years, which were referred for specialist orthodontic and orthognathic treatment during 2008-2013.

CBCT scans from individuals with either missing permanent teeth other than third molars, periodontal disease visually detected on the radiographs, major asymmetries of the jaws or who had previously undergone orthodontic treatment were excluded.

\section{Radiography and categorisation of craniofacial height}

Radiography was performed using an i-CAT CBCT (Imaging Sciences International, Hatfield, Pennsylvania, USA). The patients were seated in an upright position, with the head in natural head position. Field of view (FOV) was $16 \times 13 \mathrm{~cm}$, acquisition time was $8.9 \mathrm{~s}$ with a voxel size of $0.3 \mathrm{~mm}$ and exposure was set at $120 \mathrm{kVp}$ and $18.54 \mathrm{mAs}$ with a total radiation dose of $458.6 \mathrm{mGy}$ $\mathrm{cm}^{2}$. Calibration of the i-CAT CBCT was performed according to the manufacturer's requirements twice a year.

Lateral head images were generated from the CBCT scan using the i CAT software program. Cranio-facial height was determined cephalometrically using the Total Interactive Orthodontic Planning System (TIOPS) program [21].

The measurement used was the inclination of the mandible in relation to the anterior cranial base. This is the angle formed between the nasion-sella line (NSL) and the mandibular line (ML), formed between menton and gonion (Fig. 1). The subjects were categorised in the three following groups: (i) a low angle $\left(<27^{\circ}\right)$, (ii) a normal angle $\left(27-37^{\circ}\right)$ and (iii) a high angle $\left(>37^{\circ}\right)$.

Scans from 450 patients were available from CBCT examinations performed during 2008-2013. After exclusion due to criteria previously stated, craniofacial height was cephalometrically determined for the rest of the scans. After identifying 60 scans from low-angle subjects, this number was set as the limit for the number of scans to be consecutively included in the normal- and high-angle groups for equal comparison. The number of individuals in each group was consequently set at 60 subjects.

By using iCATVision ${ }^{\text {tx }}$ software [22], a fully reconstructed three-dimensional image with sagittal, coronal and axial slices was generated. When measuring in the maxilla, the nasion line $(\mathrm{NL}=\mathrm{a}$ line from the anterior nasal spine continuing posteriorly through the hard palate/nasal floor to the posterior nasal spine) was used as the horizontal plane and upper limit for vertical measurements in the maxilla. When measuring in the mandible, the lower border of the mandible was repositioned horizontally prior to measurements. All measurements were performed by one of the authors who only had access to the decoded CBCT scans and blinded to all other patient information. Measurement values were simultaneously recorded in a statistical spread sheet by one of the other authors. 


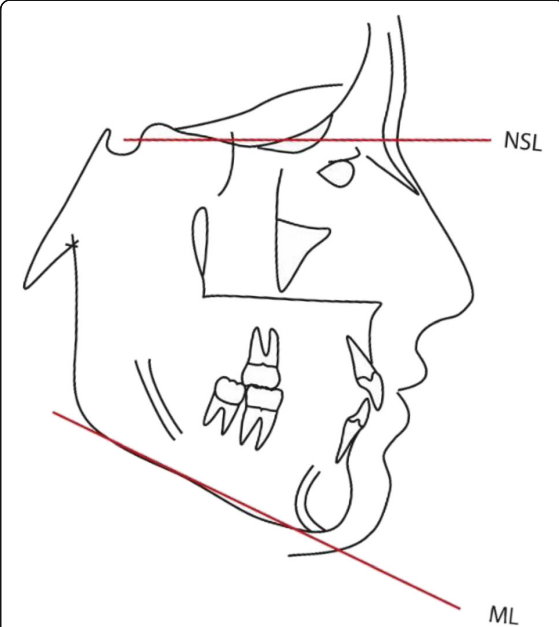

Fig. 1 Cephalometric analysis. Landmarks and reference lines used for angular measurements in the lateral cephalograms, NSL nasion-sella line, ML mandibular line.

Measurements of the cross-sectional maxillary and mandibular height and width

Three-dimensional images were reconstructed by the iCATVision $^{\mathrm{Tx}}$ software (version 1.7.0.7, Imaging Sciences International) and saved in digital imaging [22]. Generation of cross sections: A curved line was mapped to fit an axial CBCT section of the maxilla and mandible. Five cross sections (facial-lingual) were generated on each arch perpendicular to a tangent formed at these sites. Facial-lingual $=$ width and vertical long axis $=$ height .

The height and width of the maxillary and mandibular cross sections where measured between the dentition at ten locations, five in the maxilla and five in the mandible. Each cross-sectional slide was measured at three sites, including one height and two width measurements (Fig. 2). The sites were named according to location in the following way: upper or lower jaw (UP or LO), molar (MOL), premolar (PRE) and midline (MID) and finally right (R) or left (L). Accordingly, UP-MOL-R stands for upper molar on the right side, height $(\mathrm{H})$ (total length of the cross section), coronal width (W1) and apical width (W2) (Fig. 2).

The height was determined and measured by a line drawn through the long axis of the maxillary- or mandibular cross-sectional area. When measuring in the maxilla, the line was drawn perpendicular from the alveolar crest to the NL which was set as the upper limit. When measuring in the mandible, the line was drawn

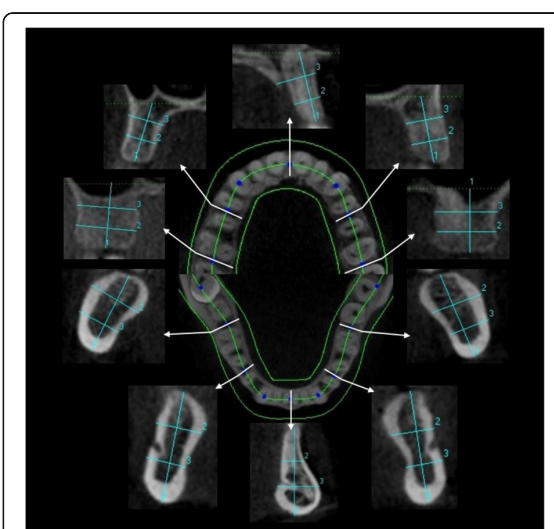

Fig. 2 Cross-sectional bone measurements of the maxilla and mandible. One height and two width measurements at each site were measured. The sites were named according to location to the neighbouring teeth. I.e UP-MOL R upper molar right (side).

perpendicular from the alveolar crest to the ML. The height measurements then represented a total height, which included both alveolar bone and basal bone. The width measurements were recorded perpendicular to the long axis line at two locations. One line was drawn at a distance of one third and the other at two thirds of the alveolar length. Fifteen measurements were performed in the maxilla and mandible, respectively, giving a total of 30 measurements (Fig. 2).

Measurements were performed by one observer. To calculate intra-observer agreement, expressed as intraclass-correlation (ICC), the observer re-measured $20 \%$ of the sites in all the subjects after approximately 2 months. These sites were chosen by using random sampling.

\section{Statistical analysis}

All statistical analysis was performed using IBM SPSS software (version 22.0; IBM Corp Armonk, NY, USA). For all variables, the three groups (low, normal, high) were compared using a one-way analysis of variance with a Tukey post hoc test. A significance level of $5 \%$ was used in all comparisons.

\section{Ethical approval}

The study was conducted in accordance with the ethical principles of the World Medical Association Declaration of Helsinki (2008 version), approved by the Regional Ethical Review Board, Lund, Sweden (8 May 2014, Dnr 2014/288), the Danish Health and Medicines Authority, Denmark (20 July 2015, Sagsnr. 3-30-13-877/1/), and the 
Danish Data Protection Agency, Denmark (7 July 2015, J.nr. 2015-41-4117).

\section{Results}

\section{Height measurements}

In both the maxilla and in the mandible, there was an increase in height from the molar region to the incisal region (midline) in all three groups. This increase was more pronounced in the high-angle group (displaying a steeper curve) and less pronounced in the low-angle group (a flatter curve) (Fig. 3a).

The midline area (UP-MID), the premolar area (UPPRE) and the molar area (UP-MOL) of the maxillary cross section were significantly higher in the high-angle group compared to the normal- and the low-angle groups (Table 1).

The midline area (LO-MID) and the premolar area (LO-PRE) of the mandibular cross section were significantly higher in the high-angle group compared to the normal- and the low-angle group. However, in the molar region, there were no significant differences between the groups (Table 1).

The range in height of the bone in the midline area was between $11.6 \mathrm{~mm}$ (low angle) and $28.4 \mathrm{~mm}$ (high angle) in the maxilla (Table 1).

The range in height of the bone in the midline area was between $24.7 \mathrm{~mm}$ (low angle) and $42.1 \mathrm{~mm}$ (high angle) in the mandible (Table 1).

\section{Width measurements}

Concerning the cross-sectional coronal width measurements in the maxilla, Fig. 3b shows a V-shaped pattern, meaning that there was a decrease in width of the alveolar bone towards the midline area in all three groups. This decrease was more pronounced from the molar to premolar region for all three groups. Concerning the apical width measurement, the figure showed that the cross section was narrower in the premolar region compared to the molar and midline area (Fig. 3b).

Concerning the cross-sectional coronal width measurements in the mandible, Fig. 3c showed a V-shaped pattern, meaning that there was a decrease in width towards the midline area in all three groups. With reference to the apical width measurement, the figure showed that the cross section was significantly wider in the midline area compared to the premolar and molar area in all three groups (Fig. 3c).

There were no statistically significant differences in width measurements in the maxilla when comparing the three groups, neither in the coronal nor in the apical width measurements (Table 2).

In the coronal and apical midline area in the mandible (LO-MID), the bone was significantly narrower in the high-angle group compared to the normal- and the low- angle groups. In the molar area, there were no statistically significant differences in the coronal or in the apical width measurements between the three groups (Table 2).

The range in width, of the cross sections in the coronal midline area, was between $4.1 \mathrm{~mm}$ (low angle) and $10.5 \mathrm{~mm}$ (high angle/low angle) in the maxilla (Table 2).

The range in width of the coronal part of the cross section in the midline area was between $2.5 \mathrm{~mm}$ (high angle) and $12.1 \mathrm{~mm}$ (low angle) in the mandible (Table 2).

\section{Gender differences}

In a majority of the cross-sectional measurements (73\%), significant differences were evident; male subjects tended to have wider and higher cross sections compared to female subjects. Males displayed approximately $1 \mathrm{~mm}$ larger dimension of the maxillary and mandibular bone both in vertical and horizontal measurements (Table 3).

\section{Intra-observer agreement}

One thousand eighty (20\%) out of 5400 measurements were randomly selected for re-measurement, and intraclass correlation (ICC) was calculated for intra-observer agreement. The correlation in height measures were between 0.858 and 0.989 . The correlation in width I measures were between 0.762 and 0.944 , and the correlation in width II measures were between 0.696 and 0.923 .

\section{Discussion}

As CBCT is a rather new imaging modality, introduced in the late 1990s, there were no European guidelines on the use of CBCT for different dental- and maxillofacial conditions at the time when the majority of images used in this study were obtained. In 2012, European guidelines for the use of CBCT were published [23] and there is a continuous interest in stating precise selection criteria following the principle of As Low As Reasonable Achievable (ALARA) for the use of X-rays [24]. The selection criteria for performing CBCT were craniofacialand skeletal deviations, impacted teeth, patients planned for orthognathic surgery and trauma patients, none of which can be specifically disputed. It might be, however, if a study like this should be performed prospectively that selection criteria might be adjusted. Having access to these retrospectively collected images, from which a selection was used for this study, we considered it unethical not to obtain clinically valuable data. Ethical approval was obtained for the use of these available CBCT images for research purpose.

Craniofacial height was determined cephalometrically using the Total Interactive Orthodontic Planning System (TIOPS) program [21] by one of the authors, a specialist in orthodontics. This analysis is a standard tool in orthodontic assessment and treatment planning. Observer reliability of this technique has shown to be high, both in 


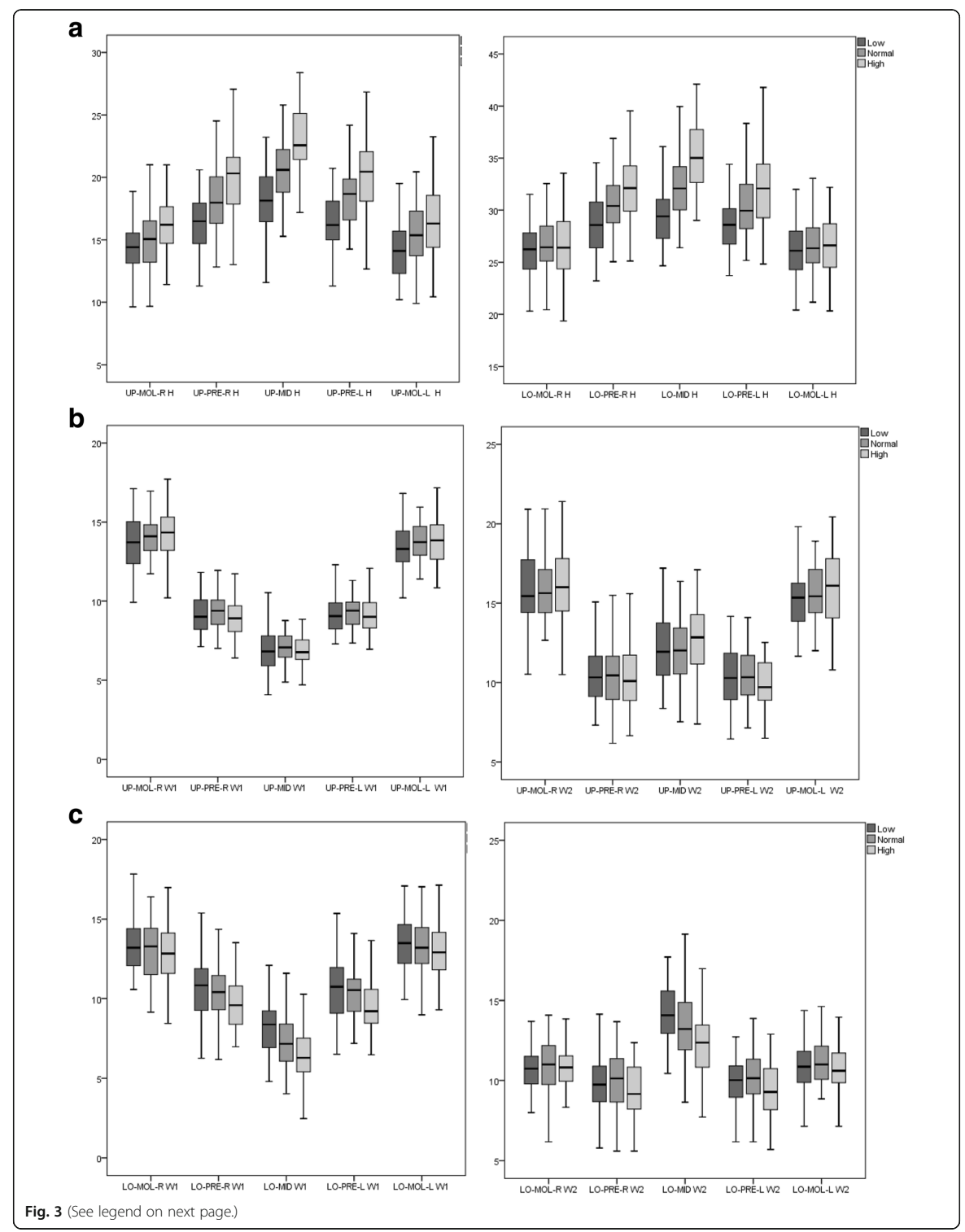


(See figure on previous page.)

Fig. 3 Cross-sectional height and width morphology measurements of the maxilla and mandible in the three groups (low-, normal-and high angle). UP-MOL-R (upper molar right), UP-PRE-R (upper premolar right), UP-MID (upper midline), UP-PRE-L (upper premolar left), UP-MOL-L (upper molar left), LO$M O L-R$ (lower molar right), LO-PRE-R (lower premolar right), LO-MID (lower midline), LO-PRE-L (lower premolar left), LO-MOL-L (lower molar left). Y-axis $(\mathrm{mm})$. $\mathbf{a}$ Height $(H)$ measurement at five cross-sectional sites in the maxilla and five in the mandible. $\mathbf{b}$ Width $(\mathrm{W})$ measurement at five cross-sectional sites in the maxilla. W1 demonstrates the coronal width measurements, and $W 2$ demonstrates the apical width measurements. $\mathbf{c}$ Width ( $W$ ) measurement at five cross-sectional sites in the mandible. W1 demonstrates the coronal width measurements, and W2 demonstrates the apical width measurements. a Height in maxilla and mandible. b Coronal width. c Apical width

conventional lateral radiographs and in $\mathrm{CBCT}$ scull images $[25,26]$. Height and width measurements of the maxillary and mandibular bodies was repeated at $20 \%$ of the sites showing a moderate to almost perfect agreement interpreted according to Landis and Koch [27].

Craniofacial morphogenesis evolves through an interaction between the development of the facial tissue and that of the supporting skeletal framework. In the present study, focus has been on an aspect of craniofacial morphogenesis, which is known as the dentoalveolar compensatory mechanism. The present study indicates that in a high-angle craniofacial pattern, the bone in the mandibular midline is high and narrow, whereas in the low-angle morphology, the bone is shorter and wider.

\section{Maxillary height}

Gracco et al. showed no statistical difference in the midline area of the maxilla between high-, normal- and low-angle subjects on $\mathrm{CBCT}$ images. However, they investigated only the anterior region of the maxilla [16]. These results are not in agreement with our findings, which could be due to that growing individuals (12-40 years) were part of the study and some changes of the morphology of the maxillary bone must be anticipated to occur as the individuals grow [16]. The differences could also be due to a slightly different measuring technique. In a recent investigation by Sadek et al. [19], a significant difference in height of the maxillary cross-sectional sites in the midline area was also reported. However, no significant differences were found in the molar region.

\section{Mandibular height}

The subjects with the high-angle morphology revealed a significant higher mandibular cross section in the midline and premolar region when compared to the other groups. These results are in accordance with Sadek et al. [19] and almost in accordance with the findings by Swasty et al. [18]. The only difference was that Swasty et al. demonstrated a negative correlation of the mandibular body in the molar region, where the high-angle group had a shorter body in the molar region compared to the lowangle group [18]. The same feature was also described by Kohakura et al. [28]. However, in the present investigation, we could not demonstrate a statistical difference in height in the molar region when comparing the groups. The difference between the findings can be explained by the fact that individuals who were still growing were included in the Swasty study [18].

Table 1 Bone height measurements of the maxillary and mandibular body in millimeters

\begin{tabular}{|c|c|c|c|c|c|c|c|c|c|c|c|c|c|}
\hline & \multicolumn{3}{|c|}{ High-angle group } & \multicolumn{3}{|c|}{ Normal-angle group } & \multicolumn{3}{|c|}{ Low-angle group } & \multicolumn{4}{|c|}{ Significance } \\
\hline & $\bar{x}$ & Range & SD & $\bar{x}$ & Range & SD & $\bar{x}$ & Range & SD & Overall & High-normal & Normal-low & High-low \\
\hline \multicolumn{14}{|l|}{ Maxilla } \\
\hline UP-MOL-R & 16.2 & $9.6-23.6$ & 2.5 & 15.1 & $9.7-21.0$ & 2.4 & 14.3 & $9.6-21.0$ & 2.2 & $0.000^{*}$ & $0.024^{*}$ & 0.169 & $0.000^{*}$ \\
\hline UP-PRE-R & 20.0 & $13.0-27.1$ & 2.7 & 18.2 & $12.8-24.5$ & 2.4 & 16.3 & $11.3-20.6$ & 2.1 & $0.000^{*}$ & $0.000^{*}$ & $0.000^{*}$ & $0.000^{*}$ \\
\hline UP-MID & 22.9 & $15.3-28.4$ & 2.7 & 20.6 & $15.3-25.8$ & 2.3 & 18.3 & $11.6-26.1$ & 2.7 & $0.000^{*}$ & $0.000^{*}$ & $0.000^{*}$ & $0.000^{*}$ \\
\hline UP-PRE-L & 20.0 & $12.7-26.8$ & 2.8 & 18.4 & $14.3-24.2$ & 2.3 & 16.4 & $11.3-20.7$ & 2.1 & $0.000^{*}$ & $0.002^{*}$ & $0.000^{*}$ & $0.000^{*}$ \\
\hline UP-MOL-L & 16.3 & $10.4-23.3$ & 2.6 & 15.4 & $9.9-20.4$ & 2.5 & 14.1 & $10.2-19.5$ & 2.2 & $0.000^{*}$ & 0.128 & $0.011^{*}$ & $0.000^{*}$ \\
\hline \multicolumn{14}{|l|}{ Mandible } \\
\hline LO-MOL-R & 26.7 & $19.4-36.6$ & 2.6 & 26.8 & $20.43-33.5$ & 2.6 & 26.2 & $20.3-31.5$ & 2.6 & 0.455 & 0.994 & 0.492 & 0.558 \\
\hline LO-PRE-R & 32.3 & $25.1-41.9$ & 3.3 & 30.7 & $25.0-38.0$ & 2.8 & 28.7 & $23.2-34.6$ & 2.6 & $0.000^{*}$ & $0.011^{*}$ & $0.001^{*}$ & $0.000^{*}$ \\
\hline LO-MID & 35.3 & $29.0-42.1$ & 3.3 & 32.3 & $26.4-40.0$ & 3.0 & 29.5 & $24.7-36.9$ & 2.8 & $0.000^{*}$ & $0.000^{*}$ & $0.000^{*}$ & $0.000^{*}$ \\
\hline LO-PRE-L & 32.1 & $24.8-41.8$ & 3.6 & 30.7 & $25.2-38.3$ & 3.0 & 28.7 & $23.7-34.4$ & 2.6 & $0.000^{*}$ & $0.025^{*}$ & $0.001^{*}$ & $0.000^{*}$ \\
\hline LO-MOL-L & 26.7 & $20.3-36.3$ & 3.3 & 26.6 & $21.2-33.7$ & 2.8 & 26.2 & $20.4-32.0$ & 2.6 & 0.587 & 0.993 & 0.683 & 0.611 \\
\hline
\end{tabular}

UP-MOL-R upper molar right, UP-PRE-R upper premolar right, UP-MID upper midline, UP-PRE-L upper premolar left, UP-MOL-L upper molar left, LO-MOL-R lower molar right, LO-PRE-R lower premolar right, LO-MID lower midline, LO-PRE-L lower premolar left, LO-MOL-L lower molar left, $\bar{x}$ mean value *Statistically significant difference $(p$ value $<0.05)$ 
Table 2 Bone width in millimeters of the maxillary and mandibular body

\begin{tabular}{|c|c|c|c|c|c|c|c|c|c|c|c|c|c|c|}
\hline & & \multicolumn{3}{|c|}{ High-angle group } & \multicolumn{3}{|c|}{ Normal-angle group } & \multicolumn{3}{|c|}{ Low-angle group } & \multicolumn{4}{|c|}{ Significance } \\
\hline & & \multirow[t]{2}{*}{$\overline{\bar{x}}$} & \multirow[t]{2}{*}{ Range } & \multirow[t]{2}{*}{ SD } & \multirow[t]{2}{*}{$\overline{\bar{x}}$} & \multirow[t]{2}{*}{ Range } & \multirow[t]{2}{*}{ SD } & \multirow[t]{2}{*}{$\bar{x}$} & \multirow[t]{2}{*}{ Range } & \multirow[t]{2}{*}{ SD } & \multirow[t]{2}{*}{ Overall } & \multicolumn{3}{|c|}{ Multiple comparisons } \\
\hline & & & & & & & & & & & & High-normal & Normal-low & High-low \\
\hline \multicolumn{15}{|l|}{ Maxilla } \\
\hline \multirow[t]{2}{*}{ UP-MOL-R } & W1 & 14.2 & $10.2-17.7$ & 1.6 & 14.1 & $11.7-17.6$ & 1.3 & 13.7 & $9.9-17.1$ & 1.5 & 0.263 & 0.953 & 0.425 & 0.272 \\
\hline & W2 & 16.1 & $10.5-21.4$ & 2.4 & 15.9 & $12.7-21.9$ & 1.9 & 15.9 & $10.5-21.0$ & 2.1 & 0.899 & 0.913 & 1.000 & 0.919 \\
\hline \multirow[t]{2}{*}{ UP-PRE-R } & W1 & 9.0 & $5.5-11.7$ & 1.3 & 9.3 & $7.0-11.9$ & 1.1 & 9.2 & $7.13-11.8$ & 1.2 & 0.239 & 0.208 & 0.655 & 0.690 \\
\hline & W2 & 10.4 & $6.6-16.4$ & 2.2 & 10.4 & $6.2-15.5$ & 1.8 & 10.6 & $7.3-15.9$ & 2.0 & 0.815 & 0.976 & 0.908 & 0.804 \\
\hline \multirow[t]{2}{*}{ UP-MID } & W1 & 6.9 & $4.8-10.5$ & 1.4 & 7.1 & $4.9-8.8$ & 1.0 & 6.9 & $4.1-10.5$ & 1.4 & 0.631 & 0.652 & 0.721 & 0.993 \\
\hline & W2 & 12.6 & $7.4-17.1$ & 2.1 & 12.0 & $7.5-16.4$ & 2.5 & 12.3 & 8.4-19.3 & 2.5 & 0.262 & 0.231 & 0.724 & 0.657 \\
\hline \multirow[t]{2}{*}{ UP-PRE-L } & W1 & 9.0 & $5.7-12.1$ & 1.2 & 9.3 & $6.2-12.3$ & 1.1 & 9.1 & $7.3-12.4$ & 1.2 & 0.539 & 0.508 & 0.873 & 0.813 \\
\hline & W2 & 10.0 & $6.5-16.3$ & 1.9 & 10.4 & $7.1-14.1$ & 1.7 & 10.5 & $6.4-17.1$ & 2.0 & 0.345 & 0.458 & 0.990 & 0.381 \\
\hline \multirow[t]{2}{*}{ UP-MOL-L } & W1 & 13.8 & $10.8-18.1$ & 1.7 & 13.8 & $11.4-16.0$ & 1.2 & 13.4 & $10.2-16.8$ & 1.3 & 0.175 & 0.994 & 0.261 & 0.218 \\
\hline & W2 & 15.9 & $10.2-20.4$ & 2.1 & 15.9 & $12.0-18.9$ & 1.8 & 15.3 & $10.2-19.8$ & 1.9 & 0.292 & 0.728 & 0.694 & 0.259 \\
\hline \multicolumn{15}{|l|}{ Mandible } \\
\hline \multirow[t]{2}{*}{ LO-MOL-R } & W1 & 12.8 & $7.5-17.0$ & 1.9 & 13.0 & $9.2-16.4$ & 1.9 & 13.2 & $6.8-17.8$ & 2.0 & 0.460 & 0.730 & 0.879 & 0.432 \\
\hline & W2 & 10.8 & $6.3-14.3$ & 1.6 & 11.0 & $6.2-14.1$ & 1.6 & 10.7 & $6.2-14.6$ & 1.6 & 0.661 & 0.817 & 0.646 & 0.956 \\
\hline \multirow[t]{2}{*}{ LO-PRE-R } & W1 & 9.7 & $7.0-13.5$ & 1.7 & 10.4 & $5.1-15.8$ & 2.1 & 10.6 & $6.3-15.4$ & 1.9 & $0.035^{*}$ & 0.138 & 0.824 & $0.035^{*}$ \\
\hline & W2 & 9.4 & $5.6-12.4$ & 1.7 & 10.0 & $5.6-13.7$ & 1.8 & 9.8 & $5.8-14.2$ & 1.7 & 0.122 & 0.111 & 0.801 & 0.352 \\
\hline \multirow[t]{2}{*}{ LO-MID } & W1 & 6.4 & $2.5-10.3$ & 1.5 & 7.3 & $4.0-11.6$ & 1.6 & 8.2 & $4.8-12.1$ & 1.6 & $0.000^{*}$ & $0.004^{*}$ & $0.006^{*}$ & $0.000^{*}$ \\
\hline & W2 & 12.3 & $7.7-17.0$ & 2.1 & 13.5 & $8.6-22.8$ & 2.4 & 14.1 & $7.3-17.7$ & 1.9 & $0.000^{*}$ & $0.005^{*}$ & 0.282 & $0.000^{*}$ \\
\hline \multirow[t]{2}{*}{ LO-PRE-L } & W1 & 9.5 & $6.5-13.7$ & 1.6 & 10.4 & $5.8-15.5$ & 2.0 & 10.5 & $6.5-15.4$ & 2.0 & $0.005^{*}$ & $0.025^{*}$ & 0.914 & $0.008^{*}$ \\
\hline & W2 & 9.4 & $5.7-12.9$ & 1.8 & 10.2 & $6.2-13.9$ & 1.7 & 10.0 & $6.2-14.6$ & 1.7 & $0.045^{*}$ & $0.045^{*}$ & 0.833 & 0.164 \\
\hline \multirow[t]{2}{*}{ LO-MOL-L } & W1 & 13.0 & $7.0-17.1$ & 1.9 & 13.3 & $9.0-17.0$ & 1.9 & 13.3 & $6.2-17.1$ & 2.0 & 0.528 & 0.677 & 0.970 & 0.529 \\
\hline & W2 & 10.6 & $7.0-14.0$ & 1.4 & 11.0 & $5.4-14.6$ & 1.7 & 10.9 & $7.1-14.9$ & 1.6 & 0.812 & 0.420 & 0.888 & 0.706 \\
\hline
\end{tabular}

W1 demonstrates the coronal width measurements, and W2 demonstrates the apical width measurements. $Y$-axis (mm)

UP-MOL-R upper molar right, UP-PRE-R upper premolar right, UP-MID upper midline, UP-PRE-L upper premolar left, UP-MOL-L upper molar left, LO-MOL-R lower molar right, LO-PRE- $R$ lower premolar right, LO-MID lower midline, LO-PRE-L lower premolar left, LO-MOL-L lower molar left, $\bar{x}$ mean value *Statistically significant difference ( $p$ value $<0.05$ )

In our study as well as in Swasty et al. and Sadek et al. $[18,19]$, a pronounced difference in height from the molar to the midline region was described in the high-angle group and the least change in height proceeding from the molars to the midline was displayed in the low-angle group. Considering the growth pattern of the mandible, these observations reflect the rotation of the mandible, where the incisors have to erupt significantly in order to compensate for the posterior rotations and the molars have to erupt less, whereas the incisors have to erupt less in subjects with an anterior rotating mandible [5].

\section{Maxillary width}

No significant difference was found in width measurements in the maxilla when comparing the three groups, neither in the coronal nor in the apical width measurements in the present study. This is not in accordance with the results reported by Gracco et al. [16] who described a negative correlation in width measurements in the midline region between subjects with different vertical craniofacial dimensions. In the study by Sadek et al. [19], significant difference between high- and low-angle individuals in width was reported in the midline area both in the coronal and apical region. The reasons for this difference could be the following: (1) they did not measure between the teeth, but across the incisors, and (2) the measurements were obtained at the mid-root level and at the apex making the measurements dependent more on the lengths of the root than on the length of the alveolar bone. Since the length of the bone seems to vary more than the length of the root, which is a more stable reference point, the crosssectional measurements will not be equal.

\section{Mandibular width}

Figure $3 \mathrm{c}$ demonstrated a V-shaped pattern when presenting the measurements of the coronal region, as the width decreased along the dental arch towards the 
Table 3 Difference between male and female when comparing measurements of jaw bone height and width in millimeters

\begin{tabular}{|c|c|c|c|c|c|}
\hline & & \multicolumn{2}{|l|}{ Male } & \multicolumn{2}{|c|}{ Female } \\
\hline \multicolumn{6}{|l|}{ Maxilla } \\
\hline \multirow[t]{4}{*}{ UP-MID } & Height & \multicolumn{2}{|c|}{21.0} & \multicolumn{2}{|c|}{20.4} \\
\hline & Width I & \multicolumn{2}{|c|}{$7.5^{*}$} & \multicolumn{2}{|c|}{$6.7^{*}$} \\
\hline & Width II & \multicolumn{2}{|c|}{$13.4^{*}$} & \multicolumn{2}{|c|}{$11.7^{*}$} \\
\hline & & Right & Left & Right & Left \\
\hline \multirow[t]{3}{*}{ UP-PRE } & Height & $19.0^{*}$ & $19.1^{*}$ & $17.7^{*}$ & $17.8^{*}$ \\
\hline & Width I & $9.7^{*}$ & $9.7^{*}$ & $8.9^{*}$ & $8.8^{*}$ \\
\hline & Width II & $11.0^{*}$ & $10.9^{*}$ & $10.2^{*}$ & $9.9^{*}$ \\
\hline \multirow[t]{3}{*}{ UP-MOL } & Height & $16.4^{*}$ & $16.5^{*}$ & $14.6^{*}$ & $14.6^{*}$ \\
\hline & Width I & $14.7^{*}$ & $14.3^{*}$ & $13.6^{*}$ & $13.3^{*}$ \\
\hline & Width II & $17.0^{*}$ & $16.4^{*}$ & $15.4^{*}$ & $15.1^{*}$ \\
\hline \multicolumn{6}{|l|}{ Mandible } \\
\hline \multirow[t]{4}{*}{ LO-MID } & Height & \multicolumn{2}{|c|}{$34.6^{*}$} & \multicolumn{2}{|c|}{$31.2^{*}$} \\
\hline & Width I & \multicolumn{2}{|c|}{7.4} & \multicolumn{2}{|c|}{7.2} \\
\hline & Width II & \multicolumn{2}{|c|}{$14.0^{*}$} & \multicolumn{2}{|c|}{$12.9^{*}$} \\
\hline & & Right & Left & Right & Left \\
\hline \multirow[t]{3}{*}{ LO-PRE } & Height & $32.2^{*}$ & $32.4^{*}$ & $29.7^{*}$ & $29.5^{*}$ \\
\hline & Width I & $10.6^{*}$ & $10.7^{*}$ & $10.0^{*}$ & $9.9^{*}$ \\
\hline & Width II & 10.0 & 10.1 & 9.6 & 9.7 \\
\hline \multirow[t]{3}{*}{ LO-MOL } & Height & $28.3^{*}$ & $28.3^{*}$ & $25.6^{*}$ & $25.6^{*}$ \\
\hline & Width I & 13.3 & 13.4 & 12.9 & 13.0 \\
\hline & Width II & 10.8 & 10.7 & 10.9 & 10.9 \\
\hline
\end{tabular}

Right side, left side, midline (only one/jaw). Width I: The coronal width measurements. Width II: The apical width measurements UP-MID upper midline, UP-PRE upper premolar, UP-MOL upper molar, LO-MID lower midline, LO-PRE lower premolar, LO-MOL lower molar *Statistically significant difference $(p<0.05)$

midline. The same feature was described by Swasty et al. [18]. In the alveolar coronal region, the mandible was significantly thinner in the midline and premolar region in all three groups. This is in accordance with the results of both Swasty et al. and Sadek et al. [18-19]. Concerning the apical measurement, the cross section was significantly wider in the midline area compared to the premolar and molar area in all three groups (Fig. 3c). This could be due to the anatomy of the mental spine and the base of the mandible in the front region.

\section{Gender differences}

A general pattern was displayed, where the males presented a greater height and width compared to the females. Swasty et al. [18] described that there was no statistical differences in cortical bone thickness between the genders. However, they found a statistical difference in height of the cross sections between males and females. Accordingly, it seems reasonable to conclude that at least in height of the bone, there seems to be a gender-correlated difference.

\section{Clinical implications}

The results of this investigation may support the fact that the dentoalveolar compensatory mechanism aims to maintain a functional occlusion in connection with craniofacial growth. In the high-angle group, the alveolar bone had to grow more in order to compensate or partly compensate for the vertical craniofacial growth, and therefore, the bodies of the maxilla and mandible became higher. The fact that the arches became narrower in the midline of the mandible might be due to the difference in loading. It can be hypothesised that the alveolar bone in the high-angle subjects are less loaded than the bone in the low-angle group. In the low-angle group, the root resides in most of the arch, whereas in the high angle group, the root resides only in part of the body, which according to Wolff's law will result in a less developed bone [29].

In orthodontic treatment, it is very important to understand how the development of the lower third of the face is closely linked to the dentoalveolar compensatory mechanism, because the dentoalveolar compensatory mechanism can be influenced in connection with treatment.

Also during active orthodontic treatment, knowledge of the morphology of the alveolar bone is important. In thin ridges, the buccal and lingual cortices can contact or be in close approximation with very little cancellous bone. The risk for root resorption increases if the roots are torqued into the cortex. In addition, there is a risk for moving teeth out of alveolar bone that has a narrow width [30].

In connection with insertions of skeletal TADs, the difference in the morphology of the cross section of the maxillary and mandibular bodies in different growth patterns is valuable information for therapy planning and adequate therapy. It has been proven that in many situations, the palate is an ideal area for screw insertion where the screw is inserted at the third rugae with the tip in an anterior direction [9-11]. However, knowledge of the anatomy at the insertion site is important, and the present study has demonstrated that the alveolar bone is short in the mid-palatal area in the low-angle face compared to the normal- and high-angle cases, with less space superior to the apex of the incisors. Accordingly, an increased risk of root damage and insertion of the screw into the nasal cavity can be expected in low-angle patients.

Likewise, during treatment planning for growing patients with congenital missing teeth, the decision to replace missing teeth with implants or by orthodontic 
closure could be influenced by the expected development of the dentoalveolar compensatory mechanism. The risk of infra-occlusion of the implant supported crowns might be higher in the high-angle group, where the incisors seem to erupt more.

Vertical control is a common treatment approach in high-angle cases, and appliances such as skeletal anchorage devices are described as very useful [31]. However, considering the A-shaped morphology (Fig. 3a) of the maxillary body in the vertical dimension, this treatment approach will actually accentuate the difference in height between the molar and incisor region. In orthognathic surgery, the aim is to increase the vertical dimension in the posterior region, which will flatten the same curve. How this difference in treatment strategies, aiming to solve the same problem, will influence final stability, airways and function should be investigated further.

In treatment with dental implants, a careful preoperative evaluation is important in order to achieve a predictable, successful aesthetic outcome. The buccal bone wall thickness is of crucial importance when it comes to selection of appropriate treatment approach [32]. The overall width of the mandibular body in a high-angle subject tend to be thinner, which probably gives a thinner alveolar bone. In the present study, the range in width of the coronal part of the cross section in the midline area was between $2.5 \mathrm{~mm}$ (high angle) and $12.1 \mathrm{~mm}$ (low angle) in the mandible (Table 2). As suggested by Buser et al., to achieve an aesthetic and functional success in dental implant treatment, it is important to take into account the three-dimensional aspect of the alveolar bone [13]. It is recommended that the dental implant should be placed inside the biological envelope of the alveolar bone in order to obtain the best conditions for success [8].

\section{Conclusions}

The main findings of the present study were:

(1) The high-angle group had a significantly longer cross-sectional area of the maxillary and mandibular body compared to the other two groups.

(2) The high-angle group also had significantly narrower mandibular cross-sectional body compared to the other two groups, especially in the anterior region.

In this retrospective study, it has been demonstrated that there is a close link between vertical craniofacial development and the morphology of cross-sectional sites of the maxillary and mandibular bodies for patients referred for orthodontic and orthognathic treatment. Understanding this biological link is important in connection with many comprehensive dental- and orthodontic treatments.

Acknowledgements

There are no acknowledgements.

\section{Authors' contributions}

$\mathrm{JB}$ and $\mathrm{KB}$ have made substantial contributions to the conception and design of the study. Acquisition of data and analysis and interpretation of data have been made by JB, KB and AK. JB, KB, CL and AK have been involved in drafting the manuscript or revising it critically for important intellectual content. JB and $\mathrm{CL}$ also contributed to the general supervision. All authors contributed significantly to this manuscript and have given final approval of the version to be published.

\section{Ethics approval and consent to participate}

The study was conducted in accordance with the ethical principles of the World Medical Association Declaration of Helsinki (2008 version), approved by the Regional Ethical Review Board, Lund, Sweden (8 May 2014, Dnr 2014/ 288), the Danish Health and Medicines Authority, Denmark (20 July 2015, Sagsnr. 3-30-13-877/1/), and the Danish Data Protection Agency, Denmark (7 July 2015, J.nr. 2015-41-4117).

\section{Consent for publication}

Not applicable. This manuscript has not been published elsewhere in part or in entirety and is not under consideration by another journal.

\section{Competing interests}

The authors declare that they have no competing interests.

\section{Publisher's Note}

Springer Nature remains neutral with regard to jurisdictional claims in published maps and institutional affiliations.

\section{Author details}

'Department of Oral and Maxillofacial Surgery and Oral Medicine, Faculty of Odontology, Malmö University, SE-205 06 Malmö, Sweden. ${ }^{2}$ Clinic for Orthodontics and Oral Surgery, Strandvejen 116A, 2900 Hellerup, Copenhagen, Denmark.

Received: 2 May 2017 Accepted: 17 August 2017

Published online: 23 October 2017

\section{References}

1. Solow B. The dentoalveolar compensatory mechanism: background and clinical implications. Br J Orthod. 1980;7:145-61.

2. Coben SE. The spheno-occipital synchondrosis: the missing link between the profession's concept of craniofacial growth and orthodontic treatment. Am J Orthod Dentofac Orthop. 1998:114:709-14

3. Solow B. The pattern of craniofacial associations: a morphological and methodological correlation and factor analysis study on young male adults. PhD. Thesis, University of Copenhagen. Acta Odontol Scand; 1966;24(Suppl 46). pp. 174.

4. Björk A. The face in profile. An anthropological X-ray investigation on Swedish children and conscripts. PhD. Thesis, Uppsala University Svensk Tandläkare Tidskrift. 1947;40.

5. Björk A. Käkarnas tillväxt och utveckling i relation till kraniet i dess helhet. Holst JJ, Østby BN, Osvald O, editors. Nordisk Klinisk Odontologi. Copenhagen. Forlaget for faglitteratur; 1964. p. 1-44.

6. Siersbaek-Nielsen S. Rate of eruption of central incisors at puberty: an implant study on eight boys. Tandlaegebladet. 1971;75:1288-95.

7. Bjork A, Skieller V. Normal and abnormal growth of the mandible. A synthesis of longitudinal cephalometric implant studies over a period of 25 years. Eur J Orthod. 1983;5:1-46.

8. Qahash M, Susin C, Polimeni G, Hall J, Wikesjo UM. Bone healing dynamics at buccal peri-implant sites. Clin Oral Implants Res. 2008;19:166-72.

9. Wehrbein $\mathrm{H}$. Bone quality in the midpalate for temporary anchorage devices. Clin Oral Implants Res. 2009;20:45-9.

10. Schatzle M, Mannchen R, Zwahlen M, Lang NP. Survival and failure rates of orthodontic temporary anchorage devices: a systematic review. Clin Ora Implants Res. 2009:20:1351-9.

11. Wilmes B, Nanda R, Nienkemper M, Ludwig B, Drescher D. Correction of upper-arch asymmetries using the Mesial-Distalslider. J Clin Orthod. 2013;47:648-55.

12. Feng $X$, Li J, Li Y, Zhao Z, Zhao S, Wang J. Effectiveness of TAD-anchored maxillany protraction in late mixed dentition. Angle Orthod. 2012;82:1107-14. 
13. Buser D, Martin W, Belser UC. Optimizing esthetics for implant restoration in the anterior maxilla: anatomic and surgical considerations. Int J Oral \& Maxillofac Implants. 2004;19:43-61.

14. Tsunori M, Mashita M, Kasai K. Relationship between facial types and tooth and bone characteristics of the mandible obtained by CT scanning. Angle Orthod. 1998;68:557-62.

15. Masumoto T, Hayashi I, Kawamura A, Tanaka K, Kasai K. Relationships among facial type, buccolingual molar inclination, and cortical bone thickness of the mandible. Eur J Orthod. 2001;23:15-23.

16. Gracco A, Lombardo L, Mancuso G, Gravina V, Siciliani G. Upper incisor position and bony support in untreated patients as seen on CBCT. Angle Orthod. 2009:79:692-702

17. Gracco A, Luca L, Bongiorno MC, Siciliani G. Computed tomography evaluation of mandibular incisor bony support in untreated patients. Am J Orthod Dentofac Orthop. 2010;138:179-87.

18. Swasty D, Lee J, Huang JC, Maki K, Gansky SA, Hatcher D, et al. Crosssectional human mandibular morphology as assessed in vivo by cone-beam computed tomography in patients with different vertical facial dimensions. Am J Orthod Dentofac Orthop. 2011:139:377-89.

19. Sadek MM, Sabet NE, Hassan IT. Alveolar bone mapping in subjects with different vertical facial dimensions. Eur J Orthod. 2015;37:194-201.

20. Benchimol El, Smeeth L, Guttmann A, Harron K, Moher D, Petersen I, Sørensen HT, von Elm E, Langan SM. The REporting of studies Conducted using Observational Routinely-collected health Data (RECORD) statement PLoS Med. 2015:1-22.

21. Bjoern-Joergensen JB, Bjoern-Joergensen PB. Tiops. 2015. Available from: http://www.tiops.com/. Accessed 28 Feb 2017

22. i-CAT Cone Beam 3D Imaging. 2015. Available from: http://wwwi--cat.com/. Accessed 20 Nov 2016

23. European Commission. Cone beam CT for dental and maxillofacial radiology (evidence-based guidelines). 2012. http://www.sedentexct.eu/files/radiation protection_172.pdf. Accessed 04 Apr 2017.

24. International Commission on Radiation Protection. The 2007 recommendations of the international commission on radiation protection. ICRP publication 103, 2007. Ann ICRP. 37:2-4.

25. AlBarakati SE, Kula KS, Ghoneima AA. The reliability and reproducibility of cephalometric measurements: a comparison of conventional and digital methods. Dentomaxillofacial Radiology. 2012;41:11-7.

26. Hariharan A, Diwakar NR, Jayanthi K, Hema HM, Deepukrishna S, Ghaste SR. The reliability of cephalometric measurements in oral and maxillofacial imaging: cone beam computed tomography versus two-dimensional digital cephalograms. Indian J Dent Res. 2016;27:370-7.

27. Landis JR, Koch GG. The measurement of observer agreement for categorical data. Biometrics. 1977;33:159-74

28. Kohakura S, Kasai K, Ohno I, Kanazawa E. Relationship between maxillofacial morphology and morphological characteristics of vertical sections of the mandible obtained by CT scanning. J Nihon Univ Sch Dent. 1997;39:71-7.

29. Frost HM. Wolff's law and bone's structural adaptations to mechanical usage: an overview for clinicians. Angle Orthod. 1994;64:175-88.

30. Handelman CS. The anterior alveolar: its importance in limiting orthodontic treatment and its influence on the occurrence of iatrogenic sequelae. Angle Orthod. 1996;66:95-109.

31. Scheffler NR, Proffit WR, Phillips C Outcomes and stability in patients with anterior open bite and long anterior face height treated with temporary anchorage devices and a maxillary intrusion splint. Am J Orthod Dentofac Orthop. 2014;146:594-602.

32. Braut $\mathrm{V}$, Bornstein $\mathrm{MM}$, Belser $\mathrm{U}$, Buser $\mathrm{D}$. Thickness of the anterior maxillany facial bone wall-a retrospective radiographic study using cone beam computed tomography. Int J Periodontics Restorative Dent. 2011;31:125-31.

\section{Submit your manuscript to a SpringerOpen ${ }^{\circ}$ journal and benefit from:}

- Convenient online submission

$\checkmark$ Rigorous peer review

Open access: articles freely available online

- High visibility within the field

- Retaining the copyright to your article

Submit your next manuscript at $\downarrow$ springeropen.com 
II 



\section{A rater agreement study on measurements in cross-sectional CBCT images exploring the association between alveolar bone morphology and craniofacial height}

Anna Klinge ${ }^{1}$, Ayman Al-Okshi ${ }^{1,2}$, Jonas Becktor ${ }^{1}$, Christina Lindh $^{3}$

${ }^{1}$ Malmö University, Faculty of Odontology, Department of Oral and Maxillofacial Surgery and Oral Medicine, Malmö, Sweden

${ }^{2}$ Sebha University, Faculty of Dentistry, Department of Oral Medicine and Radiology, Sebha, Libya

${ }^{3}$ Malmö University, Faculty of Odontology, Oral-and Maxillofacial Radiology, Malmö, Sweden

Corresponding author

Christina Lindh

Professor

Address:

Malmö University

Faculty of Odontology

20506 Malmö, Sweden

E-mail address: $\quad$ christina.lindh@mau.se

Telephone: $\quad+46(0) 406657000$

Mob: $\quad+46(0) 704561191$

All procedures followed were in accordance with the ethical standards of the responsible committee on human experimentation (institutional and national) and with the Helsinki Declaration of 1964 and later versions. Approved by the Regional Ethical Review Board, Lund, Sweden (2014.05.08, Dnr 2014/288), the Danish Health and Medicines Authority, Denmark (2015.07.20, Sagsnr. 3-30-13-877/1/) and the Danish Data Protection Agency, Denmark (2015.07.07, J.nr. 2015-41-4117).

Author Klinge, author Al-Okshi, author Becktor and author Lindh declare that they have no conflict of interest. 


\begin{abstract}
Objectives: To investigate rater agreement regarding measurements of height and width of the maxilla and mandible using cross-sectional images from CBCT examinations.

Furthermore, to explore the association between vertical craniofacial height and alveolar bone morphology.
\end{abstract}

Methods: Pre-treatment CBCT scans from 450 patients referred for treatment to a private clinic for orthodontics and oral surgery in Scandinavia were available and of these, 180 were selected. Lateral head images were generated from the CBCT volumes to categorise subjects into three groups based on their craniofacial height. Cross-sectional images of the maxillary and mandibular bodies at three locations in the maxilla and mandible, respectively, were obtained and measured at one height and two width recordings by five raters. One-way analysis of variance with a Tukey post-hoc test was performed. A significance level of 5\% was used.

Results: Rater agreement was mostly excellent or good when measuring height and width of the maxilla and mandible in cross-sectional CBCT images. For height (of the alveolar bone/bodies), there were statistically significant differences between the low and high angle groups for all the observers, when measuring in the premolar and midline region, both in the maxilla and in the mandible.

Conclusion: The high agreement found ensures a reliable measurement technique and confirms the relation between craniofacial height and alveolar bone height and width.

Key words: Facial bones; Cephalometry; Radiography, cone beam ct; Observer variation 


\section{INTRODUCTION}

Knowledge of the morphological features of the alveolar bone is of great importance for orthodontic tooth movement as well as for the planning and thus, the outcome of dental implant treatment. In orthodontics, movements of teeth in a narrow alveolar bone may cause bone dehiscence, root resorption and gingival recessions, especially in the lower midline region (1). In implant treatment, sufficient bone volume is a prerequisite for satisfactory outcome and the underlying bone structure plays a key role in the establishment of an acceptable aesthetic result, especially in the anterior maxilla. The bone surrounding an implant site must be of sufficient height and thickness in order to obtain and keep a harmonious gingival margin (2). For these clinical situations' assessments and often measurements in radiographs are performed. Before assessment tools can be used for a clinical situation, the reliability of the tool must be established (3) where reliability can be seen as the ability of a measurement to differentiate among subjects or objects. Furthermore, agreement between measurements is an important concept to provide information about the quality of measurements (4).

Several studies have provided evidence that there is a significant association between craniofacial height and the morphology of the alveolar bone (5-7). A majority of these studies have used lateral cephalometric radiographs to analyse the vertical and the sagittal dimensions of the face $(8,9)$ and to some extent these studies have used radiographs obtained with a posterior-anterior projection $(9,10)$. The drawbacks of these two imaging techniques are that the three-dimensional structure of an object is imaged two-dimensionally which causes a loss of information. The use of tomographic imaging provides the possibility to assess the alveolar bone morphology in three dimensions as well as different regions in detail. Computed tomography (CT) of dry skulls has been used to study the association between mandibular structures and craniofacial type as well as between craniofacial type and bucco-lingual molar inclination $(11,12)$. Gracco and co-workers used Cone Beam CT (CBCT) images of patients to investigate associations between the morphology of the upper jaw, the position of the upper incisors, and craniofacial type as well as the association between the morphology of the mandibular symphysis and the various craniofacial types $(13,14)$. Also, based on measurements in CBCT images significant relationships have been found between craniofacial height and alveolar bone height and width in different tooth-bearing regions of 
the maxilla and mandible $(15,16)$. With regards to measurements of alveolar bone height and width and the association to craniofacial height, some studies present intrarater agreement $(12,16)$. However, presentation of interrater agreement is infrequent.

The aim of this study was therefore to investigate rater agreement regarding measurements of height and width of the maxilla and mandible using cross-sectional images from CBCT examinations. Furthermore, to explore the association between craniofacial height and alveolar bone morphology.

\section{MATERIALS AND METHODS}

This is a retrospective rater-based study on agreement of measurements of the maxilla and mandible in CBCT images obtained in patients before orthodontic treatment. It was conducted, analysed, and reported in accordance with the Guidelines for Reporting Reliability and Agreement Studies (GRRAS) (4). An initial study protocol was prepared, including datacollection, raters and statistical analyses. The protocol was discussed and accepted by the raters.

\section{Subjects}

Pre-treatment CBCT scans from 450 patients, females over 15 years and males over 16 years, referred for treatment during 2008-2013 to a private clinic for orthodontics and oral surgery in Scandinavia were available. Either CBCT scans from individuals with missing permanent teeth, other than third molars, periodontal disease visually detected on the radiographs, major asymmetries of the jaws or previous orthodontic treatment was excluded.

\section{Radiography and categorization of subjects}

CBCT examinations were performed using an i-CAT CBCT 17-19 (Imaging Sciences International, LLC 1910 N Penn Road, Hatfield, PA 19440, US). The patients were seated in an upright position during scanning. With the aid of laser markers, the midsagittal and occlusal planes were adjusted perpendicular to each other. Field of view (FOV) was set to $16 \mathrm{~cm} \times 13 \mathrm{~cm}$ with a voxel size of $0.3 \mathrm{~mm}$. Exposure was set at $120 \mathrm{kVp}$ and $18.54 \mathrm{mAs}$ with a 
scanning time of $17.8 \mathrm{sec}$. Calibration of this machine was regularly performed according to the manufacturer's requirements twice a year.

Lateral head images were generated from the CBCT scans using the i-CAT software program (17). Cephalometric analysis of lateral images was done using the computer software program Total Interactive Orthodontic Planning System (18) (TIOPS, www.tiops.com). Mouse-click on the points of landmarks was used to classify subjects into three groups based on their craniofacial height using the angle of the lower mandibular border (Mandibular line, ML) in relation to cranial base (Nasion-Sella line, NSL). The inclination of the angle formed between the NSL line and the ML line was used to categorize the subjects into the following: low angle $<27^{\circ}$, average/normal angle $27-37^{\circ}$ and a high angle group $>37^{\circ}$. After identifying 60 individuals in the low-angle group this number of scans was set as the limit for the number to be included in the normal and high angle group for equal comparisons giving a total of 180 subjects, as described previously (15).

By using i-CAT Vision software (Imaging Sciences International, Hatfield, Pennsylvania, USA) a fully reconstructed three-dimensional image with sagittal, coronal, and axial slices was generated.

\section{Raters and rating (measurements)}

Five raters performed measurements on the $\mathrm{CBCT}$ images. Of the raters, one is a specialist in oral and maxillofacial radiology (with 29 years of experience), and one is a post doc in oral and maxillofacial radiology (with five years of experience). Furthermore, the raters consisted of one specialist in oral and maxillofacial surgery (with 16 years of experience), one resident at the same department and one general dental practitioner. All raters were aware of the purpose of the study and performed the same measurements independently from each other. Prior to the measurements, an information session and calibration exercise took place with all the raters, and the assessment instructions were specified both verbally and in writing. Thus, the instructions were provided to all the raters. All raters were familiar with handling CBCT images. 
All measurement sessions took place in the same room and a BARCO (MFGD 1318; BARCO, Kortrijk, Belgium) 18.10 greyscale liquid crystal display monitor was used with a luminance of $400 \mathrm{~cd} / \mathrm{m}^{2}$ and resolution of $1280 \times 1024$ pixels. The observation room was dimly lit and kept constant below 50 lux as recommended by American Association of Physicists in Medicine Task Group 18 (19). The distance to the screen was approximately 50 $\mathrm{cm}$. There was no restriction on the observation time. The raters were allowed to use the zooming tool. All raters were blinded to clinical features such as craniofacial height and sex.

Before beginning to measure, raters had the possibility to adjust for small deviations in the patient's head position during exposure by re-aligning the skull through an adjustment of the images in the sagittal, coronal and axial planes, respectively. The Nasion line of the subject was oriented horizontally prior to measurements in the maxilla. For mandibular measurements the mandibular base line was set horizontally. For every group of patients (low-, normal-, high- angle) 3 sites (molar, premolar, and midline region) in maxilla and mandible, respectively, were measured by each rater in rotation (Figure 1A). Sites were chosen within the three groups of patients to obtain an even distribution between molar, premolar and midline region. Measurements were performed, with one height and two width measurements between the teeth at selected cross-sectional sites (Figure 1B). The measurements were performed using the measurement tools in the software program i-CAT vision. For calculation of intrarater agreement, $10 \%$ of the sites were randomly selected in IBM SPSS software (version 22.0; IBM Corp Armonk, NY, USA) and measured by all raters in a second session after approximately two months.

The measurements were simultaneously and manually documented in an Excel (Microsoft Office Excel ${ }^{\circledR}$ 2010; Microsoft Corporation, Redmond, WA) file by the responsible researcher.

\section{Data analysis}

All computations necessary for the statistical analysis were performed using IBM SPSS software (Version 22.0; IBM Corp Armonk, NY, USA). For all variables, the three groups (low-, normal-, high-angle) were compared using a One-way analysis of variance with a Tukey post-hoc test. A significance level of 5\% was used in all comparisons. 
Inter- as well as intrarater agreement of measurements in selected cross-sectional sites was calculated as Intra class Correlation Coefficients (ICC's 2.1) with 95\% confidence interval (CI). Only measurements from the first measurement session performed by each rater was used to calculate interrater ICC. The level of agreement was interpreted according to the guideline proposed by Koo and $\mathrm{Li}$ (3) as follows :<0.50, poor; between 0.50 and 0.75 , fair; between 0.75 and 0.90 good; above 0.90 , excellent agreement.

\section{RESULTS}

Characteristics of individuals belonging to the three groups of craniofacial height is seen in Table 1. Height and width of the maxillary and mandibular alveolar bone/bodies were measured by all raters at all selected sites giving a total of 1080 measurements per rater. For calculation of intrarater agreement re-measurements were performed by all raters at $10 \%$ of the sites giving 108 measurements per rater.

\section{Interrater agreement}

Overall interrater agreement ICC for height measurements was in general excellent or good and varied between 0.75 and 0.91 (CI $0.67-0.83$ and $0.88-0.94$ ) depending on the measured site. The values were higher for measurements in the mandible compared with the maxilla and the highest value was recorded in the mandibular premolar region (Figure 2A).

Corresponding ICC values for width measurements were in general lower than for height measurements. In all sites but one, coronal measurements showed higher ICC than apical measurements. Overall interrater agreement ICC for coronal measurements varied between 0.55 and 0.88 (CI 0.43-0.66 and 0.83-0.92) with the highest value in the mandibular premolar region. For apical measurements, ICC varied between 0.50 and 0.78 (CI 0.37-0.63 and 0.700.85 ) with the highest value also being found in the mandibular premolar region (Figure 2B).

For pairwise interrater the highest ICC values were also achieved for measurements in the mandible compared with the maxilla. The values for height measurements were in general higher and when comparing coronal and apical width measurements the highest values were seen for coronal measurements. Taking all pairwise interrater agreements into consideration, 
$8 \%$ was interpreted as excellent, $47 \%$ as good, $39 \%$ as fair and $5 \%$ as poor agreement according to the suggested guidelines for interpretation of ICC values by Koo and Li (3). (Supplementary Table S1).

\section{Intrarater agreement}

No rater consistently presented the highest or the lowest intrarater agreement, but the CI was somewhat wider for some raters. The highest agreement was found in the molar region in the mandible when measuring the height of the alveolar bone (Figure 3).

\section{Height and width measurements related to craniofacial height}

\section{Height measurements}

Statistically significant differences between the low- and high-angle group for all raters were found for measurements in the premolar and midline region, both in the maxilla and in the mandible. Regarding the molar region in the maxilla, there were significant differences between the low- and high-angle group for three of the raters. Regarding the height measurement in the molar region in the mandible, there were no significant differences between any of the groups for any of the five raters (Table 2).

\section{Width measurements}

Coronal width measurements in the maxilla at molar, premolar and midline region displayed no statistically significant differences between any of the groups for the five raters. When measuring in the mandible there were no statistically significant differences between the three craniofacial groups when measuring in the molar region. When measuring in the premolar region statistical differences were seen between the low- and high-angle group for one rater and between high- and normal for one rater. When measuring in the midline region there were statistically significant differences between the low- and high-angle group for four out of five raters, there were also differences between the other craniofacial groups registered for some of the raters (Table 3 ).

Apical width measurement displayed no statistically significant differences between any of the three craniofacial groups when measuring in the molar, premolar, and midline region in the maxilla. No statistical differences were presented between any of the craniofacial groups in the molar and premolar region in the mandible. Although, in the midline region of the 
mandible, there were statistically significant differences between the low- and high-angle group for the majority of the raters, four out of five (Table 4).

\section{DISCUSSION}

The present study demonstrates that it is possible to achieve good agreement between several raters as well as within raters when height and width of the alveolar bones are measured in cross-sectional CBCT images. Furthermore, the association between craniofacial height and alveolar bone height found in this study was statistically significant for all five raters' measurements.

Accuracy is one part of investigating the strength of a diagnostic method, the other is the agreement, which is the degree to which scores, or ratings, are identical (4). Unfortunately, agreement studies are generally neglected and do not appear in the different stages of evaluating studies of diagnostic methods or in studies where diagnostic methods are used to evaluate treatment outcomes $(20,21)$. The results of a study of an imaging method and clinical problem will be influenced not only by the number of objects and raters but also by the rater selection - e.g. their expertise (22). The raters in the present study represented professional experience from different fields of expertise and the length of their experience varied; this is also the case with all potential users in a clinical situation. Since the raters may have different other prior experience and visual concepts, a study with several raters can be anticipated to give a more reliable result. To avoid influence on the assessments and consequently the result, the raters were blinded to all patient information and to the other raters' measurements.

The raters received instructions to choose an approximal cross-sectional site between first and second molar, between first and second premolar and in the midline at which to perform the height and width measurements. This may have given a lower ICC score and wider confidence intervals than if pre-selected sites had been used. On the other hand, this situation mimics the clinical situation better as "free selection" takes place in a clinical situation. It is 
important to be able to apply the results in a clinical setting as the external validity would be limited if the results were only applicable in a staged research environment.

Although a standardised calibration procedure to prevent bias was applied prior to measurements, a variation in rater agreement was found. Overall interrater agreement was in general higher for measurements in cross-sectional CBCT images of the mandible compared with the maxilla and it was the highest in the premolar region for both height and width measurements. This indicates that anatomical landmarks in the mandible might be easier to identify. The marginal bone area and basis of the mandible are probably more distinct in an image than the marginal bone area in the maxilla and the borders to maxillary sinus and nasal cavity. Pairwise interrater agreement was the highest for measurements at mandibular sites and even if agreement varied a majority of the agreements were in the category "good agreement" (Supplementary Table S1) (3). The lowest agreement was noted when the raters measured in the upper midline region. This might be explained by difficulties in the interpretation of sites where there are anatomical variations such as the incisive foramen.

Interrater agreement was expressed as overall ICC as well as pairwise interrater agreement. The pairwise interrater calculations is able to detect if any rater differs considerably from the others, which can then be analysed further. The difference might be due to a misinterpretation of the instructions or an unfavourable measurement technique. In this study, no clear deviation was observed for any rater (Supplementary Table S1).

The CI of the ICC was in some measurements negative which indicates considerable uncertainty. The somewhat low rater agreement can be explained by variations in the steps performed by the raters when adjusting for small deviations in the patient's head positioning and in the selection of sites for measurements as well as difficulties in identifying anatomical structures and handling CBCT volumes. In the study by Sadek et al, inter-and intrarater agreement was reported as ICC with paired t-test (16). However, no confidence interval was reported, and the number of observers were vaguely described as "other orthodontists" without mentioning their exact numbers or professional experience. Regardless of the statistical approach used, confidence intervals as measures of statistical uncertainty should be 
reported to allow the readers to be able to determine, in particular, the lower level of reliability/agreement.

Taking several raters measurements into consideration the results of this study showed that patients with large craniofacial height (high angle) has a significantly higher alveolar bone, both in the maxilla and in the mandible compared to those with low craniofacial height (low angle). The association between craniofacial height and cross-sectional maxillary and mandibular bone height was most evident in the premolar and incisal regions. These results strengthen the findings of our previous study (15) and are to a certain extent in concordance with the results of the study by Sadek et al. (16) where statistical differences were found in the anterior part of the maxilla. Therefore, it can be concluded that the dentoalveolar compensatory mechanism, via continued tooth eruption, respond in the maxilla and mandible by enlarging the vertical size of the frontal dentoalveolar heights in long-face subjects and, conversely, less tooth eruption will take place in short-face subjects (23).

A further indication, on the association between craniofacial height and alveolar bone morphology, especially in the anterior region, is that in this study the coronal and apical width in the midline area of the mandible (LO-MID), was narrower in the group with high craniofacial height compared with the group with low craniofacial height.

\section{Strength and limitations}

Rater agreement has been investigated in order to explore measurement errors and variations in interpretation, which affects the value of measurements in clinical practice (24) and have to be taken into account when evaluating methods in any diagnostic yield. The number of subjects in the study is larger than that included in other comparable studies $(16,25)$. Nevertheless, it is a retrospective study design where CBCT examinations were performed prior to the design of the current study. The subjects included in the study were referred to a specialist clinic for orthodontic and oral surgery which means that the results may not be generally applicable. 


\section{Conclusions and clinical implications}

Knowledge of the morphological features of the alveolar bone is of importance when planning orthodontic tooth movement or dental implant treatment. The results from this study show the significant association between craniofacial height and alveolar bone dimensions as explored by several raters and would provide reference data that can be useful prior to orthodontic or dental implant treatment in subjects with different craniofacial types. 


\section{REFERENCES}

1. Garib DG, Yatabe MS, Ozawa TO, Silva Filho OGd. Alveolar bone morphology under the perspective of the computed tomography: defining the biological limits of tooth movement. Dental Press Journal of Orthodontics. 2010;15(5):192-205.

2. Buser D, Martin W, Belser UC. Optimizing esthetics for implant restorations in the anterior maxilla: anatomic and surgical considerations. International Journal of Oral \& Maxillofacial Implants. 2004;19(7).

3. Koo TK, Li MY. A guideline of selecting and reporting intraclass correlation coefficients for reliability research. Journal of chiropractic medicine. 2016;15(2):155-63.

4. Kottner J, Audigé L, Brorson S, Donner A, Gajewski BJ, Hróbjartsson A, et al. Guidelines for reporting reliability and agreement studies (GRRAS) were proposed. International journal of nursing studies. 2011;48(6):661-71.

5. Janson GR, Metaxas A, Woodside DG. Variation in maxillary and mandibular molar and incisor vertical dimension in 12-year-old subjects with excess, normal, and short lower anterior face height. American Journal of Orthodontics and Dentofacial Orthopedics. 1994;106(4):409-18.

6. Kuitert R, Beckmann S, van Loenen M, Tuinzing B, Zentner A. Dentoalveolar compensation in subjects with vertical skeletal dysplasia. American journal of orthodontics and dentofacial orthopedics. 2006;129(5):649-57.

7. Nanda SK. Growth patterns in subjects with long and short faces. American Journal of Orthodontics and Dentofacial Orthopedics. 1990;98(3):247-58.

8. Björk A, Skieller V. Growth of the maxilla in three dimensions as revealed radiographically by the implant method. British Journal of Orthodontics. 1977;4(2):53-64.

9. Björk A, Skieller V. Normal and abnormal growth of the mandible. A synthesis of longitudinal cephalometric implant studies over a period of 25 years. The European Journal of Orthodontics. 1983;5(1):1-46.

10. Snodell SF, Nanda RS, Currier GF. A longitudinal cephalometric study of transverse and vertical craniofacial growth. American Journal of Orthodontics and Dentofacial Orthopedics. 1993;104(5):471-83.

11. Masumoto T, Hayashi I, Kawamura A, Tanaka K, Kasai K. Relationships among facial type, buccolingual molar inclination, and cortical bone thickness of the mandible. The European Journal of Orthodontics. 2001;23(1):15-23.

12. Tsunori M, Mashita M, Kasai K. Relationship between facial types and tooth and bone characteristics of the mandible obtained by CT scanning. The Angle Orthodontist. 1998;68(6):557-62.

13. Gracco A, Lombardo L, Mancuso G, Gravina V, Siciliani G. Upper incisor position and bony support in untreated patients as seen on CBCT. The Angle Orthodontist. 2009;79(4):692-702.

14. Gracco A, Luca L, Bongiorno MC, Siciliani G. Computed tomography evaluation of mandibular incisor bony support in untreated patients. American Journal of Orthodontics and Dentofacial Orthopedics. 2010;138(2):179-87.

15. Klinge A, Becktor K, Lindh C, Becktor JP. Craniofacial height in relation to crosssectional maxillary and mandibular morphology. Progress in orthodontics. 2017;18(1):32.

16. Sadek MM, Sabet NE, Hassan IT. Alveolar bone mapping in subjects with different vertical facial dimensions. European journal of orthodontics. 2015;37(2):194-201.

17. KaVo. i-CAT ${ }^{\mathrm{TM}}$ [Internet]. KaVo; [updated 2020; cited 2020 Oct 11]. Available from: https://www.kavo.com/en-us/i-cat.

18. Bjoern-Joergensen J, Bjoern-Joergensen P. Total Interactive Orthodontic Planning System: Total Interactive Orthodontic Planning System; 2020 [cited 2020 Oct 11]. Internet]. Available from: http://www.tiops.com/. 
19. Samei E, Badano A, Chakraborty D, Compton K, Cornelius C, Corrigan K, et al.

Assessment of display performance for medical imaging systems: executive summary of AAPM TG18 report. Medical physics. 2005;32(4):1205-25.

20. Farzin B, Gentric J-C, Pham M, Tremblay-Paquet S, Brosseau L, Roy C, et al. Agreement studies in radiology research. Diagnostic and interventional imaging. 2017;98(3):227-33.

21. Swets J, Pickett R. Evaluation of Diagnostic Systems: methods from signal detection theory. 1982. New York, NY: Academic Press.

22. Rohlin M, Horner K, Lindh C, Wenzel A. Through the quality kaleidoscope: reflections on research in dentomaxillofacial imaging. Dentomaxillofacial Radiology. 2020;49:20190484.

23. Solow B. The dentoalveolar compensatory mechanism: background and clinical implications. British journal of orthodontics. 1980;7(3):145-61.

$24 . \quad$ Robinson D, Gajos M, Whyte L. Evidence-based care through clinical practice. Nursing Standard. 1997;11(30):32-3.

25. Swasty D, Lee J, Huang JC, Maki K, Gansky SA, Hatcher D, et al. Cross-sectional human mandibular morphology as assessed in vivo by cone-beam computed tomography in patients with different vertical facial dimensions. American Journal of Orthodontics and Dentofacial Orthopedics. 2011;139(4):e377-e89. 
FIGURE 1

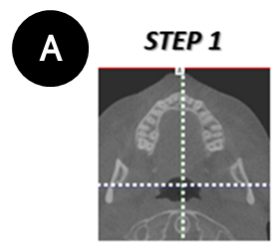

Aligning the skull according to the vertical line in the axial plane.

\section{STEP 4}
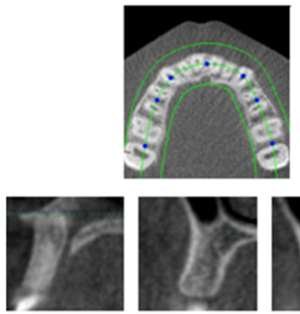

Selecting cross sectional slides for measurements in the maxilla. Between the molars, between the premolars and between the central incisors.
STEP 2

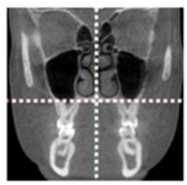

Aligning the skull according to the vertical line in the coronal plan.

STEP 5

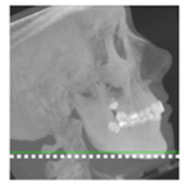

Aligning the skull according to the mandibular line prior to measurements in the mandible.

\section{STEP 3}

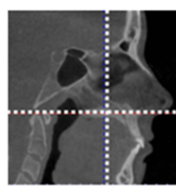

Aligning the skull according to the nassion-sella line in the sagittal plan.
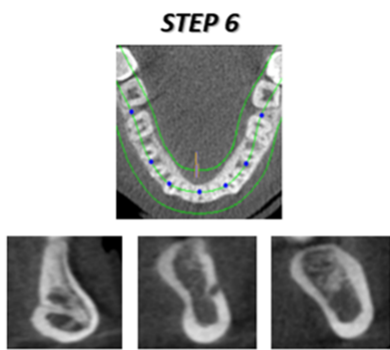

Selecting cross sectional slides for measurements in the mandible. Between the molars, between the premolars and between the central incisors.

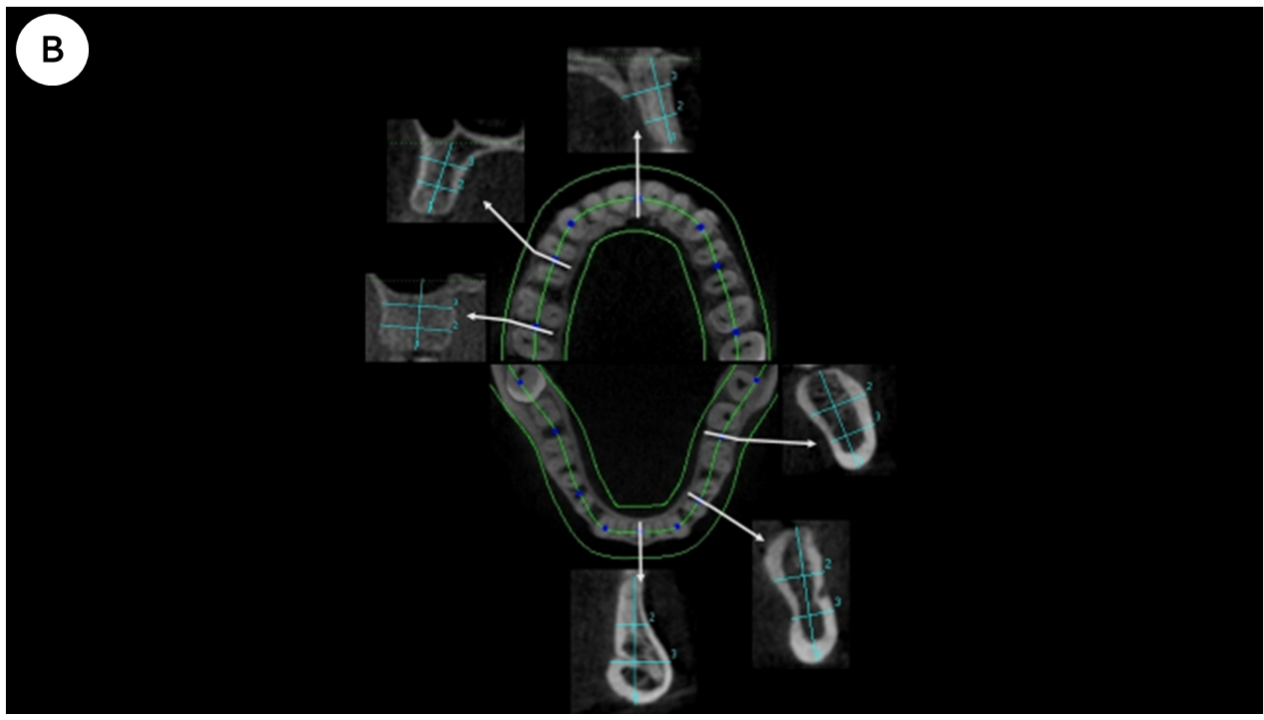

FIGURE 1 (A) When selecting sites for measurements, the steps performed by the raters when adjusting the volumes for small deviations in the patient's head position during exposure. (B) Measurements of height and width in cross sectional CBCT images of the maxilla and mandible. One height and two width measurements at each site were measured. The sites were named according to location of the neighboring teeth, e.g. upper molar $=\mathrm{UM}$. 
FIGURE 2
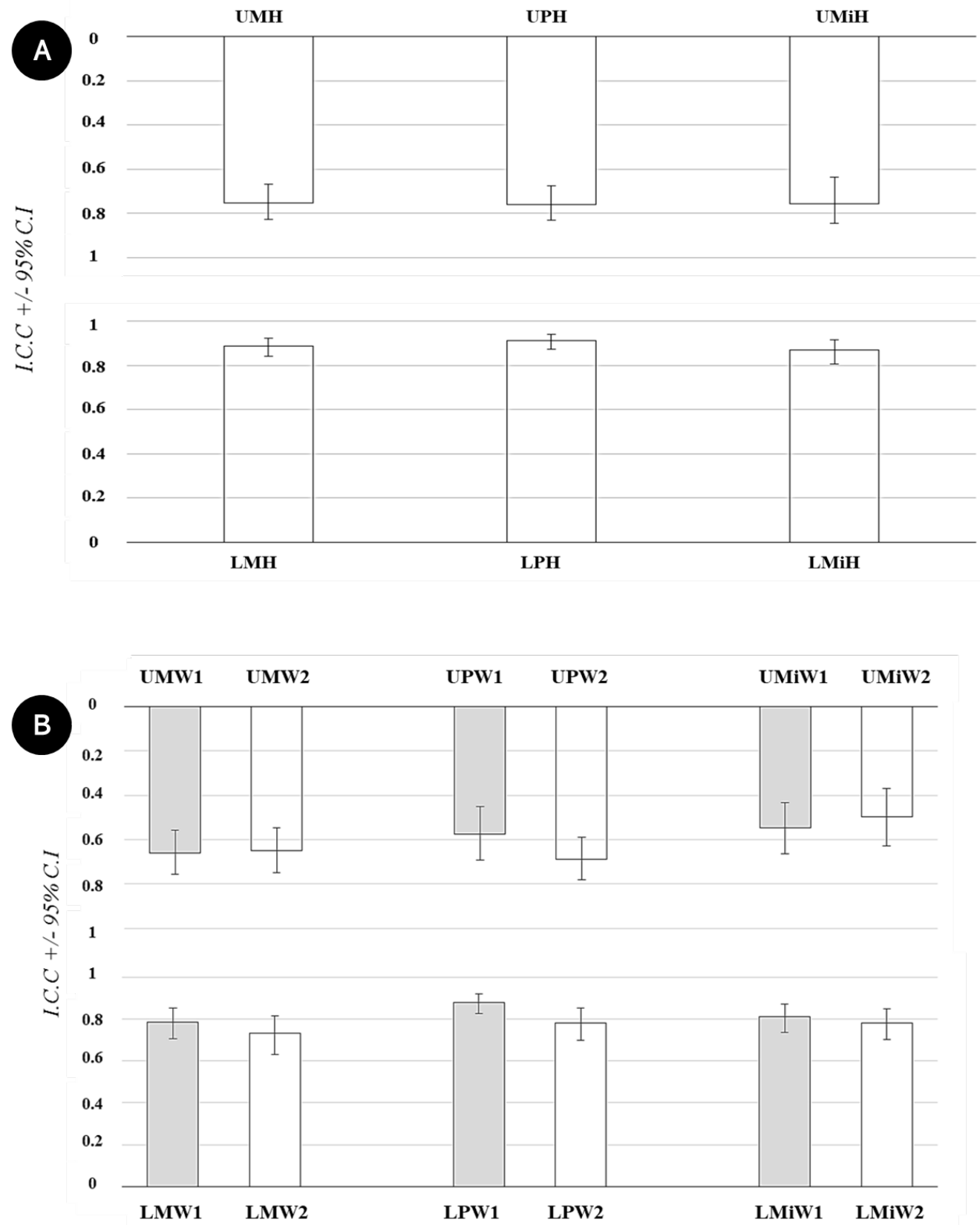

FIGURE 2 (A) Overall interrater agreement expressed as Intraclass Correlation Coefficient (ICC) and Confidence Intervals (CI) for measurements of the height of maxillary and mandibular body in cross sectional CBCT images. (B) Overall interrater agreement expressed as ICC and CI for measurements of the width of maxillary and mandibular body in cross sectional CBCT images.

$U M H$, upper molar height; $U P H$, upper premolar height; $U M i H$, upper midline height; $L M H$, lower molar height; $L P H$, lower premolar height; $L M i H$, lower midline height. $W 1$, coronal width; $W 2$, apical width; $U M$, upper molar; $U P$, upper premolar; $U M i$, upper midline; $L M$, lower molar; $L P$, lower premolar; $L M i$, lower midline. 
FIGURE 3

A Height measurements of the alveolar bone

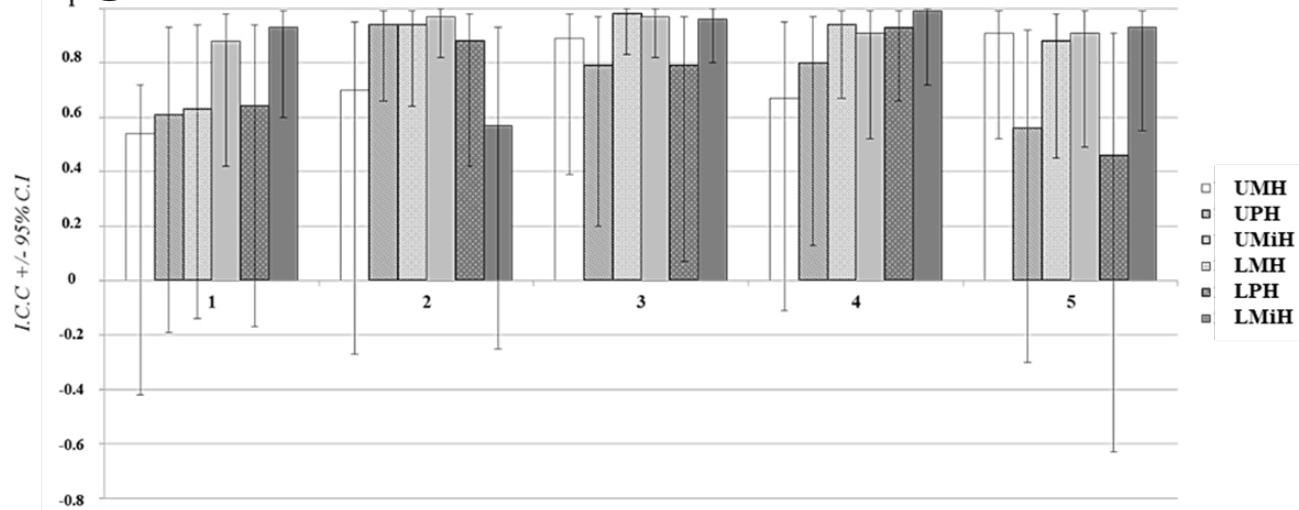

B Width (1/3) measurements of the alveolar bone

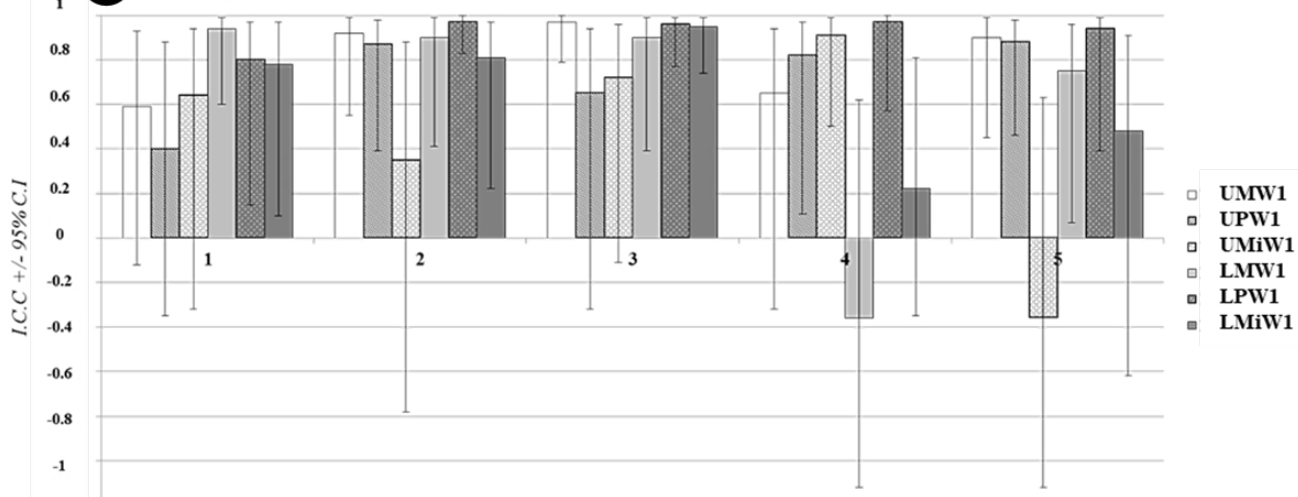

C Width (2/3) measurements of the alveolar bone

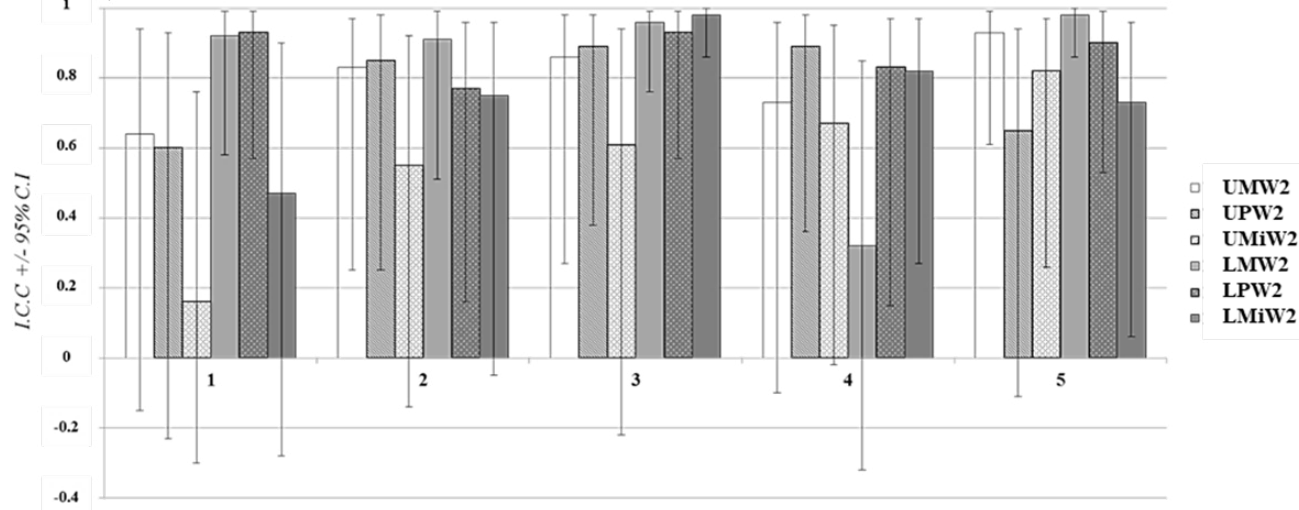

FIGURE 3 Intrarater agreement of five raters (1-5) expressed as Intraclass Correlation Coefficient (ICC) and Confidence Intervals (CI) for the measurements of (A) cross-sectional height measurement; (B) coronal width (1/3) measurement and (C) apical width $(2 / 3)$ measurement of maxillary and mandibular body in cross-sectional CBCT images. 
$W 1$, coronal width; $W 2$, apical width; $U M$, upper molar; $U P$, upper premolar; $U M i$, upper midline; $L M$, lower molar; $L P$, lower premolar; $L M i$, lower midline. 
TABLE 1 Characteristics of individuals from which CBCT scans were obtained belonging to one of three groups of craniofacial height ( $\mathrm{n}=$ number)

\begin{tabular}{l|l|l|l}
\hline \multicolumn{1}{c}{} & \multicolumn{3}{|c}{ Craniofacial height } \\
\cline { 2 - 4 } & $\begin{array}{l}\text { Low angle } \\
\text { n, mean age yrs. } \\
\text { (range) }\end{array}$ & $\begin{array}{l}\text { Normal angle } \\
\text { n, mean age yrs. } \\
\text { (range) }\end{array}$ & $\begin{array}{l}\text { High angle } \\
\text { n, mean age yrs. } \\
\text { (range) }\end{array}$ \\
\hline $\begin{array}{l}\text { Female } \\
\mathrm{n}=117\end{array}$ & $38,30.1(15-70)$ & $44,25.5(15-58)$ & $35,26.2(15-49)$ \\
\hline $\begin{array}{l}\text { Male } \\
\mathrm{n}=63\end{array}$ & $22,28.8(17-47)$ & $16,32.0(16-71)$ & $25,23.7(16-43)$ \\
\hline
\end{tabular}




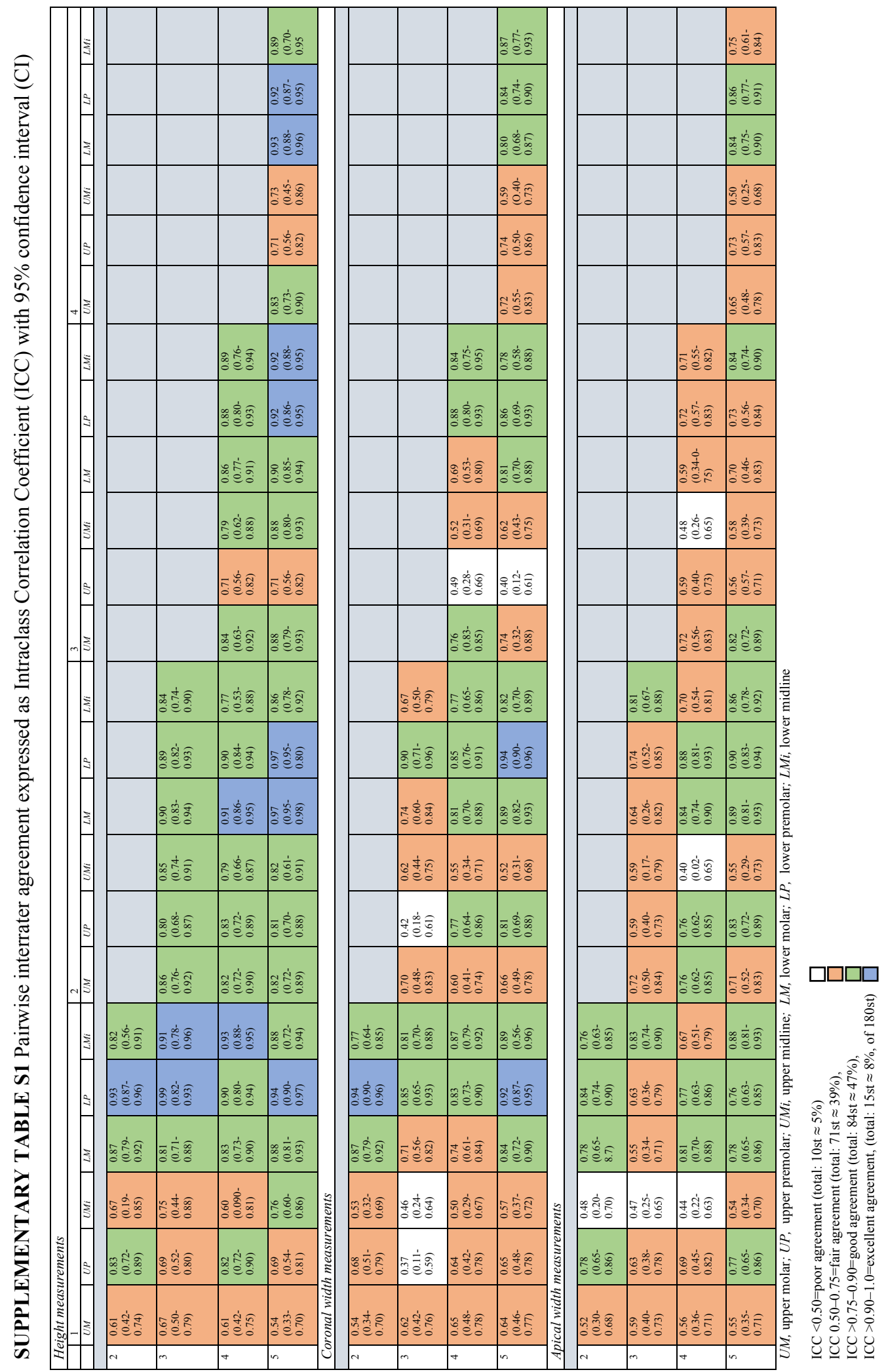




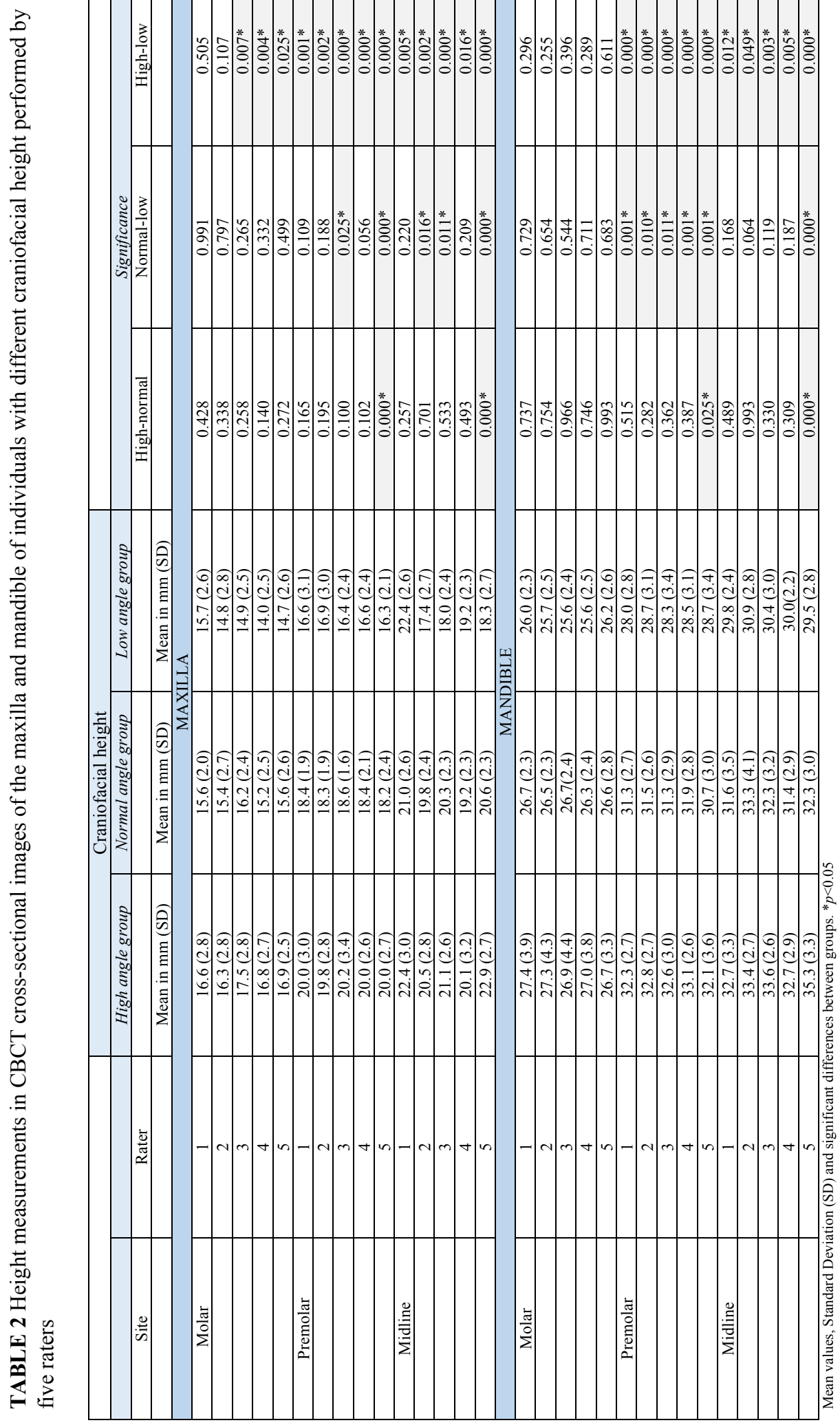




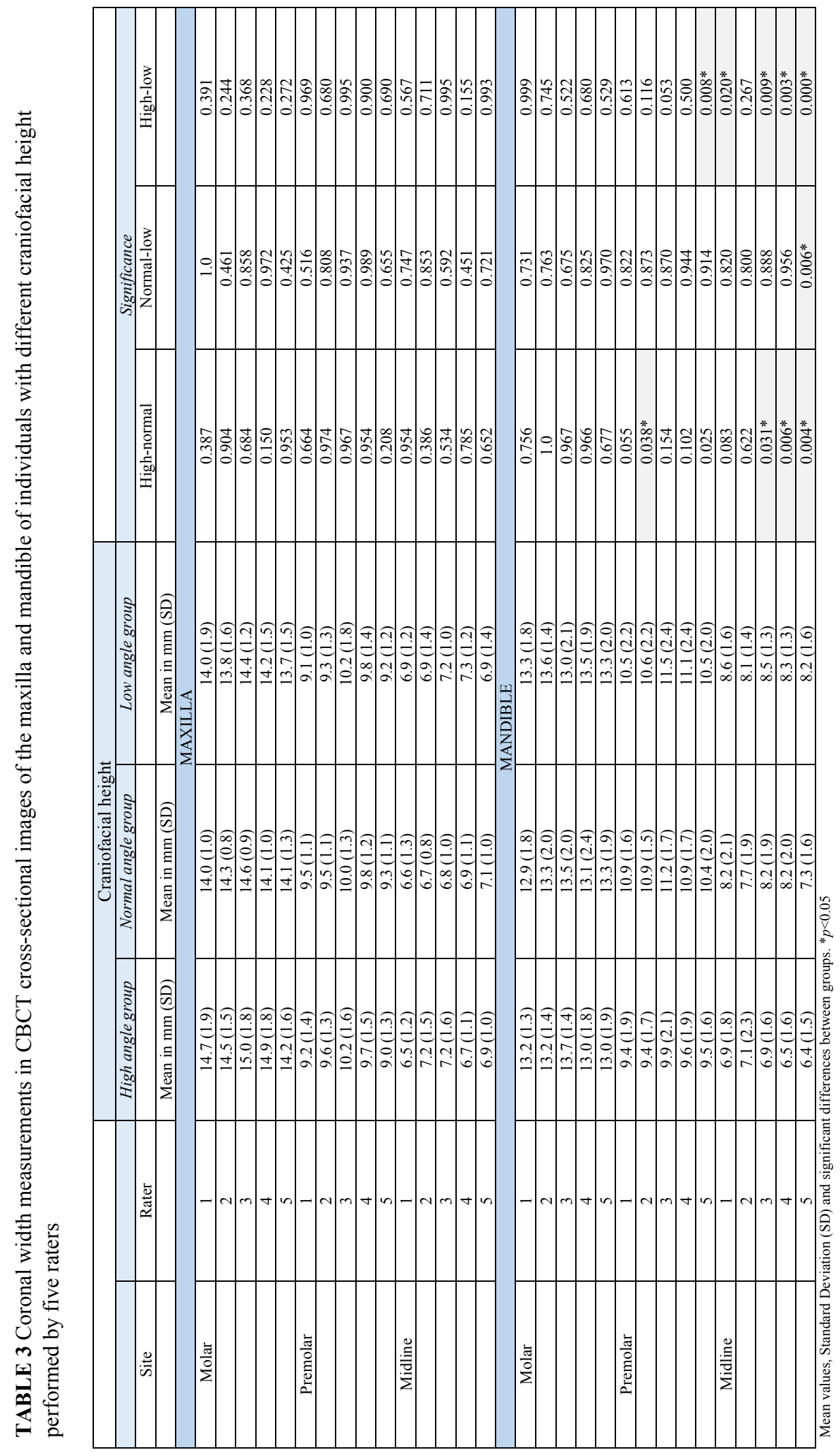




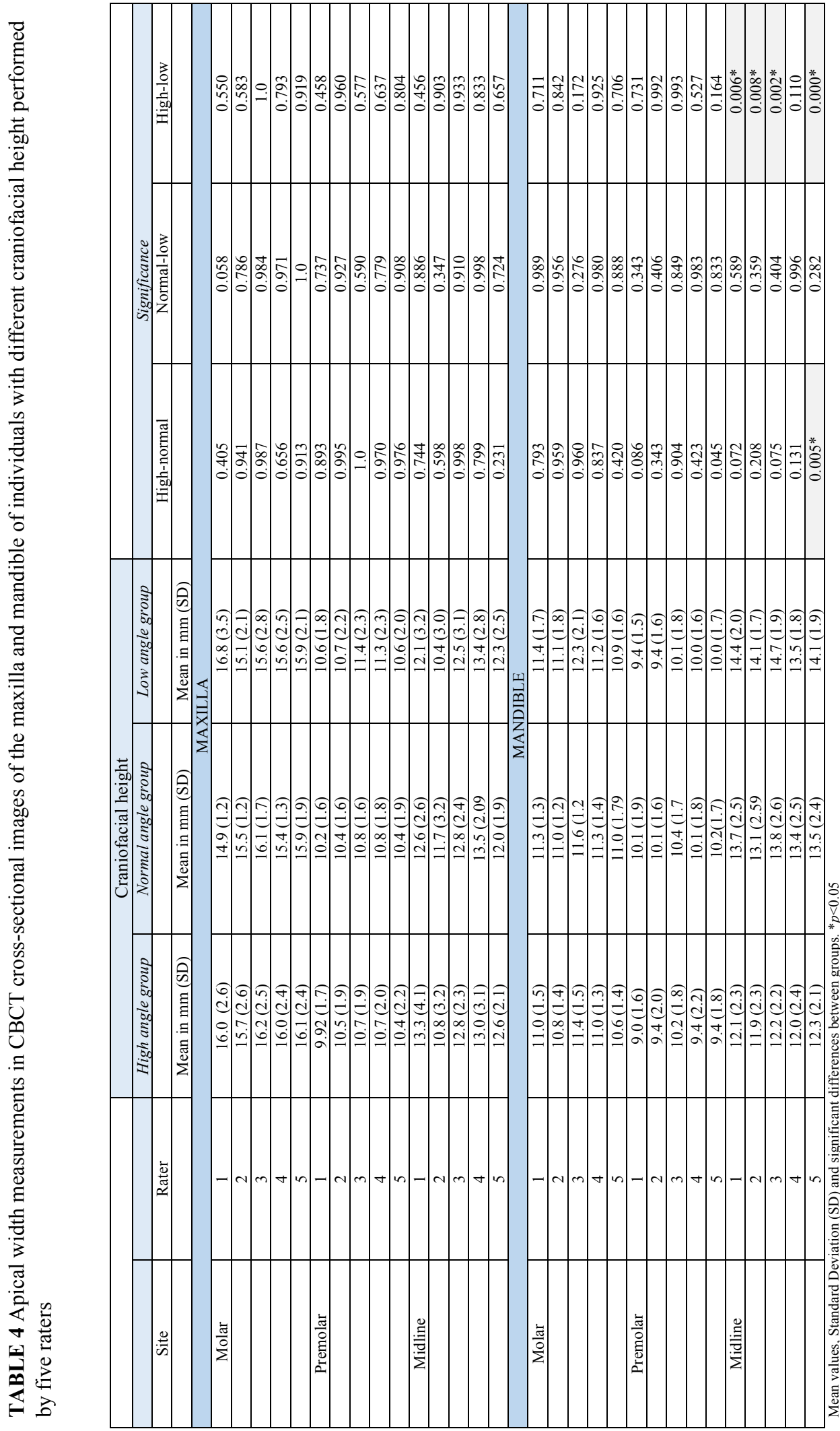





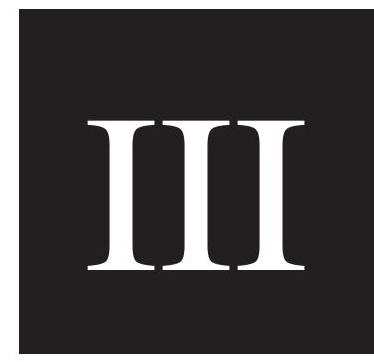





\title{
Craniofacial Height in Relation to Cross-Sectional Morphology of the Anterior Maxilla: An Anatomical Consideration in Implant Therapy
}

\author{
Anna Klinge, DDS, PhD Student ${ }^{1} /$ Marianne Ahmad, DDS $1 /$ Peter Eldh, DDS, $\mathrm{MSc}^{2}$ / \\ Rasmus Ulvan, DDS, $\mathrm{MSc}^{2} /$ Lars Andersson, DDS, $\mathrm{PhD}^{3} /$ Jonas P. Becktor, DDS, $\mathrm{PhD}^{4}$
}

\begin{abstract}
Purpose: Patients who have a vertical growth pattern are more prone to complete alveolar bone growth later and run a higher risk for inhibition of growth and infraposition after implants have been placed. Moreover, it has been suggested for the same category of patients that craniofacial height may influence the alveolar bone morphology of the anterior maxilla during growth. Hence, it is important to identify such patients early when considering implant treatment in young patients. The purpose of this study was to investigate the height and width of the alveolar bone in the anterior maxilla in subjects with different craniofacial heights to assess if there is a relation between craniofacial height and the dimensions of the alveolar bone in the anterior part of the maxilla. Materials and Methods: Measurements on cephalograms and cone beam computed tomography (CBCT) images of the maxilla from 180 fully dentate subjects were analyzed and categorized into three angle groups based on the craniofacial height: low-, normal-, and high-angle groups. Measurements of the alveolar bone were taken interradicular, at six reference points distributed between the first premolar regions in the maxilla. The height and width of the alveolar bone were measured with a standardized technique at 3, 6, 9, and $12 \mathrm{~mm}$ from the top of the alveolar process. Results: Significant differences were found regarding the height of the alveolar bone in all the subgroups and regarding the width in the 9- and 12-mm subgroups, and between low-/normal- and low-/high-angle groups, where the high-angle group represented the thinnest alveolar bone. A significant difference was found between male and female patients concerning all dimensions of the alveolar bone. Conclusion: There is a relation between craniofacial height and the dimensions of the alveolar bone in the anterior part of the maxilla. Craniofacial height is an important factor to analyze when implant treatment is considered in the maxillary anterior region. This identification can preferably be carried out early in young patients who are still growing when various treatment options can still be considered. INT J ORAL MAXILLOFAC IMPLANTS 2020;35:386-394. doi: 10.11607/jomi.7776
\end{abstract}

Keywords: 3D, alveolar bone height, alveolar bone width, craniofacial height, growth, radiology

\footnotetext{
${ }^{1}$ Department of Oral and Maxillofacial Surgery and Oral Medicine, Faculty of Odontology, Malmö University, Malmö, Sweden. ${ }^{2}$ Dentist, Department of Oral and Maxillofacial Surgery and Oral Medicine, Faculty of Odontology, Malmö University, Malmö, Sweden.

${ }^{3}$ Senior Professor, Department of Oral and Maxillofacial Surgery and Oral Medicine, Faculty of Odontology, Malmö University, Malmö, Sweden.

${ }^{4}$ Associate Professor and Head, Department of Oral and Maxillofacial Surgery and Oral Medicine, Faculty of Odontology, Malmö University, Malmö, Sweden.
}

Correspondence to: Dr Jonas P. Becktor, Department of Oral and Maxillofacial Surgery and Oral Medicine, Faculty of Odontology, Malmö University, 20506 Malmö, Sweden. Email: jonas.becktor@mau.se

Submitted April 13, 2019; accepted November 8, 2019.

C2020 by Quintessence Publishing Co Inc.
Datients with limited alveolar bone volume in the anterior maxilla will present a challenge when implant treatment is considered. Alveolar bone development and morphology have been associated with craniofacial height. ${ }^{1-3}$ The morphology of the alveolar process is mainly set during the craniofacial growth and tooth eruption. This development is highly dynamic from early childhood to the end of adolescence. ${ }^{4,5}$ By observing craniofacial height, individuals can be characterized in different vertical facial types. A feature that may disclose morphologic characteristics of the alveolar process is the dentoalveolar compensatory mechanism (DACM). ${ }^{6}$ For individuals with long vertical faces, the anterior teeth must continuously erupt in order to compensate for the vertical enlargement of the anterior face height during facial growth; hence, the alveolar process will be higher. In individuals with a short

386 Volume 35, Number 2, 2020

(c) 2020 BY QUINTESSENCE PUBLISHING CO, INC. PRINTING OF THIS DOCUMENT IS RESTRICTED TO PERSONAL USE ONLY. NO PART MAY BE REPRODUCED OR TRANSMITTED IN ANY FORM WITHOUT WRITTEN PERMISSION FROM THE PUBLISHER. 
anterior face, the incisors erupt less during growth, resulting in a vertically shorter alveolar process.

The control of implant position, and hence the final esthetic outcome, requires an understanding of the morphologic structure and the dimensional dynamics of the alveolar process. The maxillary anterior region of the alveolar process is the most esthetically sensitive site, demanding higher attention, and elaborate preoperative planning should start as early as possible.

Several studies provide evidence of an association between vertical facial dimensions and morphologic features of the alveolar process. ${ }^{7-9}$ Sadek et al demonstrated that individuals with a high craniofacial height also have thinner alveolar bone anteriorly in the maxilla. ${ }^{7}$ Along with these findings, subjects with low craniofacial height also exhibit a larger alveolar bone width in the anterior region of the dentate maxilla. ${ }^{8}$ No significant difference was found for the posterior region of the maxilla. ${ }^{7}$

Regarding alveolar bone height, in a study previously published by Klinge et al, the range of bone height in the midline area of the maxilla was between $11.6 \mathrm{~mm}$ (in subjects with low craniofacial height) and $28.4 \mathrm{~mm}$ (in subjects with high craniofacial height). A similar pattern but with proportionately higher differences was observed in the midline area of the mandible. ${ }^{10}$ Contradictive results were presented in another study, stating that there is no association between vertical facial height and alveolar bone height. ${ }^{8}$ Since the results differ among studies, further investigation implementing both alveolar bone height and width is of interest in order to establish evidence for the association of craniofacial height as a guideline for the prediction of alveolar bone dimensions.

Accordingly, the following criteria have been described to be associated with the morphology and volume of the alveolar bone: craniofacial vertical morphology, the form of the roots, and the inclination of the teeth. When a patient is predisposed to have a smaller volume of alveolar bone, the loss of bone due to normal bone remodeling after tooth loss will be of greater impact, resulting in a more challenging and complicated implant treatment. Based on previous research, it is hypothesized that there are differences in height and width of the alveolar bone in the anterior part of the maxilla between groups with different craniofacial heights and between males and females.

Hence, in an early stage of treatment planning of young still-growing patients, it is important to identify vertically growing patients with a risk of a thin alveolar phenotype, who are prone to developing excessive bone resorption after tooth loss in the esthetic zone of the anterior region of the maxilla. This factor may influence the choice of the most suitable treatment method, and in such cases, implant treatment may not always be the best choice of treatment. The purpose of this study was to investigate if there are any differences in height and width of the anterior region of the maxilla among subjects with different craniofacial heights and between males and females.

\section{MATERIALS AND METHODS}

The present observational study was conducted with the same material as previously reported by Klinge et $\mathrm{al}^{10}$ utilizing pretreatment cone beam computed tomography (CBCT) scans and lateral cephalograms of 180 dentate subjects. This study was carried out in relation to the REporting of studies Conducted using Observational Routinely-collected health Data (RECORD).

\section{Subjects}

The inclusion criteria was subjects referred to a clinic for a CBCT, between the years 2008 and 2013.

Subjects with either missing permanent teeth other than third molars, periodontal disease diagnosed on the radiographs, major asymmetries of the jaws, or who had previously experienced orthodontic treatment were excluded. Cephalometric evaluation and subject classification into three categories were conducted as formerly described by Klinge et al. ${ }^{10}$ Only 60 scans from low-angle subjects were identified; this number was set as the limit for the number of scans to be consecutively included in the normal- and highangle groups for equal comparison. The number of individuals included in each group was consequently set at 60 subjects, giving a total of 180 included scans.

\section{Radiography}

CBCT was performed, by one operator, using an i-Cat Cone Beam CT 17-19 (Imaging Sciences International). Field of view (FOV) was $16 \times 13 \mathrm{~cm}$, acquisition time was 8.9 seconds, with a voxel size of $0.3 \mathrm{~mm}$, and exposure was set at $120 \mathrm{kVp}$ and $18.54 \mathrm{mAs}$, with a total radiation dose of $458.6 \mathrm{mGycm}^{2}$. Calibration of the i-Cat Cone Beam CT was performed according to the manufacturer's requirements twice a year.

Lateral head images were generated from the CBCT scan using the i-Cat software program.

\section{Classification of Craniofacial Height}

Craniofacial height was determined cephalometrically using the Total Interactive Orthodontic Planning System (TIOPS) program. ${ }^{11}$

The radiography alignment and classification of craniofacial height have been described in detail previously. ${ }^{10}$ In brief, the subjects were categorized into three groups: high-, normal-, and low-angle individuals. A sample of morphologic differences between the 

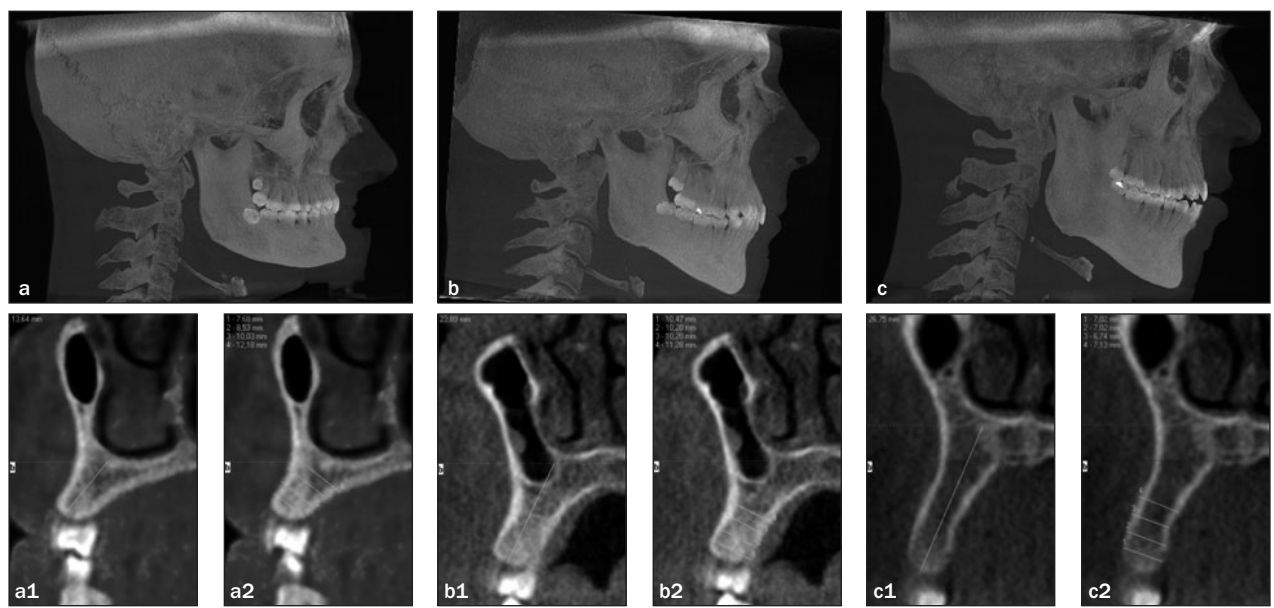

Fig 1 The morphologic differences between the three groups. (a) Low angle. (b) Normal angle. (c) High angle. (a1 to c2) The typical anatomy of the dentoalveolar bone $(1=$ height, 2 = width $)$ in the premolar region for the three groups, respectively.

three groups and the typical anatomy of the dentoalveolar bone for the three groups, respectively, are shown in Fig 1. Before the measurements, adjustments for small deviations in the patient's head position during exposure were corrected for by realigning the skull images in the axial, coronal, and sagittal planes, respectively (Fig 2).

\section{Measurements of Alveolar Dimensions}

A fully reconstructed three-dimensional image with sagittal, coronal, and axial slices was generated using iCATVision software. ${ }^{12}$

In the present study, the area of assessment was selected from the anterior maxilla in the midsection of the interradicular bone between the first premolar and the canine, between the canine and the lateral incisor, and between the lateral and central incisors, bilaterally (Fig 3).

The height and width of the alveolar bone was measured. The vertical measurement was determined by the long axis of the maxillary cross-sectional area. The height was assessed through the line drawn from the top of the alveolar process running perpendicular to the alveolar bone margin and ending at the nasion line as the upper limit (Fig 2c). Horizontally, the widths were measured perpendicular to the height measurement line at the levels of $3,6,9$, and $12 \mathrm{~mm}$ (w1, w2, $w 3$, and w4, respectively) measured from the top of the alveolar process (Fig 4).

All measurements of the alveolar bone height and width were performed, independently, by one of the authors (P.E.) who only had access to the decoded CBCT scans and was blinded to all other patient information.
The operator underwent a trial/test session for calibration prior to the proper measurements. Measurement values were simultaneously recorded in a statistical spreadsheet by one of the other authors (A.K.).

\section{Statistical Analysis}

A one-way analysis of variance with Tukey post hoc test was used to compare the variables. A significance level of $5 \%$ was set in all comparisons. Statistical analysis was performed using IBM SPSS software (Version 22.0; IBM).

\section{Ethical Considerations}

The study was conducted in accordance with the ethical principles of the World Medical Association Declaration of Helsinki (2008 version), approved by the Regional Ethical Review Board, Lund, Sweden (May 8, 2014, Dnr 2014/288), the Danish Health and Medicines Authority, Denmark (July 20, 2015, Sagsnr. 3-30-13$877 / 1 /$ ), and the Danish Data Protection Agency, Denmark (July 7, 2015, J.nr. 2015-41-4117).

\section{RESULTS}

\section{Alveolar Bone Height}

A significant difference was present between the low-, normal-, and high-angle groups in almost all evaluated sites, where high-angle subjects proved to have a greater alveolar bone height in comparison to normaland low-angle subjects, and the normal-angle subjects had a greater alveolar bone height in comparison to low-angle subjects (Table 1). The only exception was 

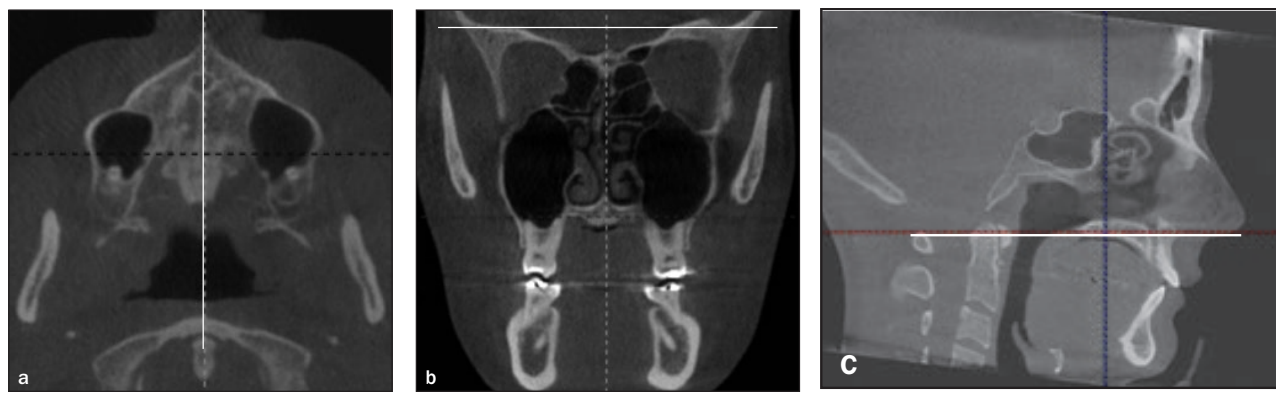

Fig 2 Demonstration of alignment of all subjects according to three planes. (a) Axial: Alignment according to the vertical line passing through the nasal spine and the top of atlas. (b) Coronal: Aligning the skull in an upright position using a line passing the supraorbital rims, perpendicular to the vertical line. (c) Sagittal: Alignment according to the nasion line, horizontal line of the palatine roof/ nasal floor, passing through the anterior and posterior nasal spine.

Fig 3 Demonstration of the location of the measured sites. MRP = maxillary right premolar; $\mathrm{MRC}=$ maxillary right canine; MRI = maxillary right lateral incisor; $\mathrm{MLI}=$ maxillary left lateral incisor; $\mathrm{MLC}=$ maxillary left canine; MLP = maxillary left premolar.
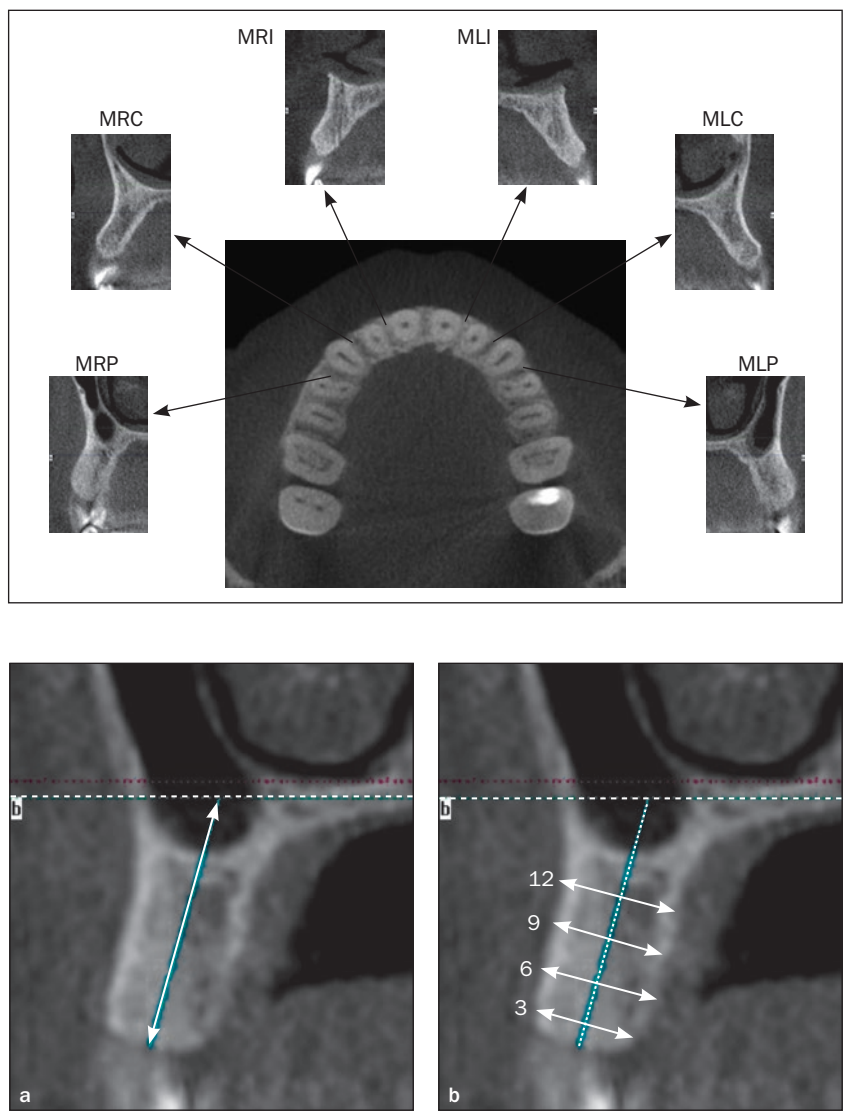

Fig 4 (a) The height (arrow) was measured from the crestal top to the white reference line. (b) The widths (arrows) were measured perpendicular to the center axis (here represented by the white line) at the heights $3,6,9$, and $12 \mathrm{~mm}$ (w1, w2, w3, and $w 4$, respectively). 
Table 1 Descriptive Statistics for Alveolar Bone Height and Width in Maxilla on Right Side (mm)

\begin{tabular}{|c|c|c|c|c|c|c|c|c|c|c|c|c|c|}
\hline \multirow[b]{2}{*}{ Site } & \multicolumn{3}{|c|}{ Low-angle group $n=60$} & \multicolumn{3}{|c|}{ Normal-angle group $n=60$} & \multicolumn{3}{|c|}{ High-angle group $n=60$} & \multicolumn{4}{|c|}{ Multiple comparison } \\
\hline & Mean & $\begin{array}{l}\text { Min- } \\
\text { Max }\end{array}$ & SD & Mean & $\begin{array}{l}\text { Min- } \\
\text { Max }\end{array}$ & SD & Mean & $\begin{array}{l}\text { Min- } \\
\text { Max }\end{array}$ & SD & $\begin{array}{c}\text { Between } \\
\text { groups }\end{array}$ & $\begin{array}{c}\text { Low- } \\
\text { Normal }\end{array}$ & $\begin{array}{l}\text { Low- } \\
\text { High }\end{array}$ & $\begin{array}{c}\text { Normal- } \\
\text { High }\end{array}$ \\
\hline \multicolumn{14}{|l|}{ MRP } \\
\hline $\mathrm{h}$ & 17.8 & $13.2-25.0$ & 2.6 & 19.6 & $13.8-26.6$ & 2.6 & 21.0 & $14.6-26.4$ & 2.8 & $.000 *$ & $.000 *$ & $.000 *$ & $.013 *$ \\
\hline w1 & 7.9 & $5.9-10.6$ & 1.0 & 8.3 & $6.1-10.9$ & 1.1 & 7.9 & $5.8-11.0$ & 1.1 & .064 & .089 & .989 & .122 \\
\hline w2 & 8.5 & $6.3-11.3$ & 1.3 & 8.6 & $5.9-11.5$ & 1.2 & 8.2 & $4.6-12.0$ & 1.4 & .263 & .982 & .386 & .292 \\
\hline w3 & 8.9 & $6.2-12.3$ & 1.5 & 8.5 & $6.0-10.9$ & 1.2 & 8.1 & 5.1-11.2 & 1.5 & $.009 *$ & .339 & $.006 *$ & .207 \\
\hline w4 & 9.6 & $6.2-14.3$ & 1.8 & 8.9 & 5.9-12.1 & 1.5 & 8.2 & $5.4-13.7$ & 1.7 & $.000 *$ & .051 & $.000 *$ & .053 \\
\hline \multicolumn{14}{|l|}{ MRC } \\
\hline $\mathrm{h}$ & 19.5 & $14.0-26.4$ & 2.8 & 21.1 & $15.2-27.8$ & 2.6 & 22.6 & $16.5-28.0$ & 2.8 & $.000 *$ & $.003 *$ & $.000 *$ & $.008 *$ \\
\hline w1 & 6.9 & $5.2-8.3$ & 0.8 & 6.8 & $5.1-9.0$ & 0.9 & 6.9 & $5.1-8.8$ & 0.9 & .859 & .925 & .986 & .853 \\
\hline w2 & 7.3 & $4.7-9.6$ & 1.1 & 7.1 & $4.2-9.1$ & 1.1 & 7.2 & $4.3-10.4$ & 1.3 & .551 & .522 & .890 & .804 \\
\hline w3 & 7.7 & $3.9-12.3$ & 1.6 & 7.2 & $4.1-10.6$ & 1.4 & 7.3 & $4.3-11.0$ & 1.5 & .101 & .120 & .199 & .964 \\
\hline w4 & 9.0 & $5.6-17.6$ & 2.2 & 8.0 & $4.3-12.0$ & 1.9 & 7.7 & $3.5-12.2$ & 1.9 & $.001 *$ & $.009 *$ & $.001 *$ & .810 \\
\hline \multicolumn{14}{|l|}{ MRI } \\
\hline $\mathrm{h}$ & 20.2 & $13.2-27.0$ & 2.9 & 22.2 & $16.2-29.0$ & 2.6 & 23.7 & $17.2-30.3$ & 2.9 & $.000 *$ & $.000 *$ & $.000 *$ & $.011^{*}$ \\
\hline w1 & 6.3 & $4.5-8.8$ & 0.8 & 6.3 & $4.4-8.8$ & 0.8 & 6.4 & $4.9-7.6$ & 0.7 & .769 & .947 & .750 & .912 \\
\hline w2 & 7.1 & $4.6-11.3$ & 1.3 & 6.9 & $5.0-9.1$ & 0.9 & 7.0 & $4.3-8.9$ & 1.0 & .685 & .659 & .910 & .892 \\
\hline w3 & 7.9 & $4.7-15.7$ & 1.8 & 7.1 & $5.0-9.8$ & 1.2 & 7.1 & $3.5-9.9$ & 1.2 & $.002 *$ & $.008 *$ & $.006 *$ & .998 \\
\hline w4 & 9.2 & $5.3-14.6$ & 2.1 & 8.0 & $5.1-12.4$ & 1.9 & 7.8 & $3.1-11.5$ & 1.5 & $.000 *$ & $.002 *$ & $.000 *$ & .807 \\
\hline
\end{tabular}

$\mathrm{MRP}=$ maxillary right premolar, MRC = maxillary right canine, MRI = maxillary right lateral incisor; mean = mean value, min-max = minimum and maximum value; $\mathrm{SD}=$ standard deviation; $\mathrm{n}=$ number of subjects. Alveolar bone height $(\mathrm{h})$; width $(\mathrm{w})$ at the heights $3,6,9$, and $12 \mathrm{~mm}$ from the crestal top (w1, w2, w3, and w4, respectively). *Significant at $P \leq .05$.

Table 2 Descriptive Statistics for Alveolar Bone Height and Width in Maxilla on Left Side (mm)

\begin{tabular}{|c|c|c|c|c|c|c|c|c|c|c|c|c|c|}
\hline \multirow[b]{2}{*}{ Site } & \multicolumn{3}{|c|}{ Low-angle group, $n=60$} & \multicolumn{3}{|c|}{ Normal-angle group, $n=60$} & \multicolumn{3}{|c|}{ High-angle group, $n=60$} & \multicolumn{4}{|c|}{ Multiple comparison } \\
\hline & Mean & $\begin{array}{l}\text { Min- } \\
\text { Max }\end{array}$ & SD & Mean & $\begin{array}{l}\text { Min- } \\
\text { Max }\end{array}$ & SD & Mean & $\begin{array}{l}\text { Min- } \\
\text { Max }\end{array}$ & SD & $\begin{array}{l}\text { Between } \\
\text { groups }\end{array}$ & $\begin{array}{l}\text { Low- } \\
\text { Normal }\end{array}$ & $\begin{array}{l}\text { Low- } \\
\text { High }\end{array}$ & $\begin{array}{c}\text { Normal- } \\
\text { High }\end{array}$ \\
\hline \multicolumn{14}{|l|}{ MLP } \\
\hline $\mathrm{h}$ & 17.9 & $12.9-23.9$ & 2.7 & 19.9 & $15.0-26.4$ & 2.4 & 20.8 & $14.3-26.8$ & 2.9 & $.000 *$ & $.000 *$ & $.000 *$ & .132 \\
\hline w1 & 7.7 & $5.6-11.5$ & 1.1 & 8.2 & $6.1-10.6$ & 1.0 & 8.1 & $6.3-11.5$ & 1.1 & .085 & .087 & .225 & .883 \\
\hline w2 & 8.6 & $6.2-11.7$ & 1.2 & 8.7 & $6.2-11.3$ & 1.2 & 8.5 & $6.6-11.9$ & 1.2 & .594 & .889 & .842 & .564 \\
\hline w3 & 8.9 & $5.8-12.2$ & 1.5 & 8.8 & $6.4-11.8$ & 1.3 & 8.4 & $5.8-11.5$ & 1.4 & .100 & .863 & .098 & .268 \\
\hline w4 & 9.6 & $6.3-14.0$ & 1.8 & 9.0 & $5.9-12.5$ & 1.5 & 8.5 & $5.7-13.6$ & 1.7 & $.000 *$ & .115 & $.001^{*}$ & .238 \\
\hline \multicolumn{14}{|l|}{ MLC } \\
\hline $\mathrm{h}$ & 19.6 & $14.0-28.0$ & 2.9 & 21.3 & $11.5-27.7$ & 2.8 & 22.5 & $15.8-28.2$ & 2.9 & $.000 *$ & $.003^{*}$ & $.000 *$ & .051 \\
\hline w1 & 6.7 & $4.3-8.9$ & 0.9 & 6.7 & $4.7-8.5$ & 0.8 & 6.7 & $5.2-9.1$ & 0.8 & .963 & .960 & .982 & .995 \\
\hline w2 & 7.4 & $4.7-9.4$ & 1.1 & 7.3 & $5.5-9.6$ & 0.9 & 7.4 & $4.5-9.7$ & 1.1 & .784 & .786 & .990 & .858 \\
\hline w3 & 7.8 & $4.7-11.7$ & 1.5 & 7.3 & $5.1-9.9$ & 1.3 & 7.3 & $4.2-10.2$ & 1.4 & .087 & .138 & .129 & .999 \\
\hline w4 & 9.0 & $5.1-14.5$ & 2.0 & 7.8 & $4.7-11.3$ & 1.7 & 7.6 & $3.9-11.3$ & 1.7 & $.000 *$ & $.002 *$ & $.000 *$ & .701 \\
\hline \multicolumn{14}{|l|}{ MLI } \\
\hline $\mathrm{h}$ & 20.4 & $13.4-27.2$ & 3.0 & 22.6 & $16.0-28.3$ & 2.4 & 23.6 & $16.8-30.6$ & 3.1 & $.000 *$ & $.000 *$ & $.000 *$ & .143 \\
\hline w1 & 6.4 & $4.6-8.1$ & 0.8 & 6.3 & $4.9-8.1$ & 0.7 & 6.5 & $5.1-8.9$ & 0.7 & .533 & .788 & .890 & .504 \\
\hline w2 & 7.4 & $4.7-10.2$ & 1.2 & 7.2 & $5.4-9.7$ & 0.9 & 7.4 & $4.9-9.4$ & 0.9 & .729 & .967 & .855 & .717 \\
\hline w3 & 8.1 & $4.7-13.4$ & 1.6 & 7.4 & $4.7-9.7$ & 1.2 & 7.5 & $3.4-9.7$ & 1.2 & $.015^{*}$ & $.025 *$ & $.043^{*}$ & .979 \\
\hline w4 & 9.3 & $5.3-14.5$ & 2.0 & 8.3 & 5.1-12.3 & 1.7 & 8.0 & $3.6-11.0$ & 1.5 & $.002 *$ & $.002 *$ & $.000 *$ & .765 \\
\hline
\end{tabular}

$\mathrm{MLP}=$ maxillary left premolar, $\mathrm{MLC}=$ maxillary left canine, $\mathrm{MLI}=$ maxillary left lateral incisor; mean $=$ mean value, min-max $=$ minimum and maximum value; $\mathrm{SD}=$ standard deviation; $\mathrm{n}=$ number of subjects. Alveolar bone height $(\mathrm{h})$; width $(\mathrm{w})$ at the heights $3,6,9$, and $12 \mathrm{~mm}$ from the crestal top (w1, w2, w3, and w4, respectively). *Significant at $P \leq .05$.

the comparison between the normal- and high-angle groups on the left maxillary side, where no significance was seen (Table 2). The mean value recorded for alveolar bone height between the lateral and central incisors was $22.1 \mathrm{~mm}$, which exceeded the posterior measurement between the premolar and canine of $19.5 \mathrm{~mm}$.
An overall pattern of declining heights in a posterior direction was recognized. The minimum height recorded was $11.4 \mathrm{~mm}$ in the premolar region, and the maximum height recorded was $30.5 \mathrm{~mm}$ in the incisor region. All descriptive statistics including height and width are visualized in Tables 1 and 2. 


\begin{tabular}{|c|c|c|c|c|c|c|c|}
\hline \multirow[b]{2}{*}{ Site } & \multicolumn{3}{|c|}{ Male $n=60$} & \multicolumn{3}{|c|}{ Female $n=120$} & \multirow{2}{*}{$\frac{\text { Multiple comparison }}{\text { Between groups }}$} \\
\hline & Mean & Min-Max & SD & Mean & Min-Max & SD & \\
\hline \multicolumn{8}{|l|}{ MRP } \\
\hline $\mathrm{h}$ & 20.4 & $13.4-26.6$ & 2.9 & 19.0 & $13.2-26.4$ & 2.9 & $.002 *$ \\
\hline w1 & 8.6 & $6.6-11.0$ & 1.1 & 7.7 & $5.8-10.5$ & 1.0 & $.000 *$ \\
\hline w2 & 9.3 & $7.1-12.0$ & 1.1 & 8.0 & $4.6-10.2$ & 1.1 & $.000 *$ \\
\hline w3 & 9.5 & $6.6-12.3$ & 1.3 & 8.0 & $5.1-11.2$ & 1.2 & $.000 *$ \\
\hline w4 & 9.9 & $5.6-14.3$ & 1.7 & 8.4 & $5.4-13.7$ & 1.6 & $.000 *$ \\
\hline \multicolumn{8}{|l|}{ MRC } \\
\hline $\mathrm{h}$ & 22.3 & $14.0-28.0$ & 3.0 & 20.5 & $15.1-27.8$ & 2.9 & $.000 *$ \\
\hline w1 & 7.3 & $5.2-9.0$ & 0.8 & 6.7 & $5.1-8.5$ & 0.8 & $.000 *$ \\
\hline w2 & 8.0 & $5.6-10.3$ & 1.0 & 6.8 & $4.2-10.4$ & 1.1 & $.000 *$ \\
\hline w3 & 8.4 & $5.7-12.3$ & 1.4 & 6.9 & 3.9-11.3 & 1.3 & $.000 *$ \\
\hline w4 & 9.2 & $4.8-17.6$ & 2.2 & 7.8 & $3.5-13.3$ & 1.9 & $.000 *$ \\
\hline \multicolumn{8}{|l|}{ MRI } \\
\hline $\mathrm{h}$ & 22.9 & $13.2-28.4$ & 3.1 & 21.6 & $14.2-30.3$ & 3.0 & $.009 *$ \\
\hline w1 & 6.6 & $4.4-8.8$ & 0.8 & 6.1 & $4.5-7.6$ & 0.7 & $.000 *$ \\
\hline w2 & 7.6 & $5.8-11.3$ & 1.0 & 6.7 & $4.3-9.3$ & 1.0 & $.000 *$ \\
\hline w3 & 8.2 & $5.4-15.7$ & 1.6 & 6.9 & $3.5-11.0$ & 1.2 & $.000 *$ \\
\hline w4 & 9.2 & $5.5-14.6$ & 2.0 & 7.9 & $3.1-12.7$ & 1.8 & $.000 *$ \\
\hline
\end{tabular}

$\mathrm{MRP}=$ maxillary right premolar, $\mathrm{MRC}=$ maxillary right canine, $\mathrm{MRI}=$ maxillary right lateral incisor; mean $=$ mean value, min-max $=$ minimum and maximum value; $\mathrm{SD}=$ standard deviation; $\mathrm{n}=$ number of subjects. Alveolar bone height $(\mathrm{h})$; width $(\mathrm{w})$ at the heights $3,6,9$, and $12 \mathrm{~mm}$ from the crestal top (w1, w2, w3, and w4, respectively). *Significant at $P \leq .05$.

\section{Alveolar Bone Width at $3 \mathbf{~ m m}$}

The recorded width ranged from 4.3 to $11.5 \mathrm{~mm}$. No significant differences were found between any of the angle groups at any site.

The mean value increased in the posterior direction, confirming a wider alveolar bone in the premolar area compared with the incisive area.

\section{Alveolar Bone Width at $6 \mathbf{~ m m}$}

The recorded width ranged from 4.2 to $11.9 \mathrm{~mm}$. There were no significant differences found between the angle groups at any site.

The overall width was greater in the premolar area compared with the anterior region.

\section{Alveolar Bone Width at $\mathbf{9} \mathbf{~ m m}$}

The recorded width ranged from 3.3 to $15.7 \mathrm{~mm}$. A significant difference was present between the low-angle group and both the high- and normal-angle groups in the incisor and premolar regions. Low-angle subjects were wider than the high-angle subjects in the premolar region on the right side and wider than both normal- and high-angle subjects in the incisor region bilaterally. No significant differences were found in the canine region.

The premolar region was significantly wider than the anterior region, and the anterior region was significantly wider than the canine region.

\section{Alveolar Bone Width at 12 mm}

The recorded width ranged from 3.1 to $17.6 \mathrm{~mm}$. A significant difference was present between the low-, normal-, and high-angle groups in nearly all the regions. Low-angle subjects presented a wider alveolar bone compared with the high-angle group in all measured areas. The same relationship was shown between lowand normal-angle subjects, except for the premolar region. Furthermore, the mean value for the premolar region was greater than the anterior region, confirming a wider bone in the premolar region.

\section{Differences Between Males and Females}

A significant difference was present between males and females in both height and width in all sites. Males were proven to have an alveolar bone that is both higher and wider in the anterior part of the maxilla on all measured regions and levels $(3,6,9$, and $12 \mathrm{~mm})$. The average differences based on mean values for all regions were as follows: height, $1.5 \mathrm{~mm}$; w1, $0.6 \mathrm{~mm}$; w2, $1.1 \mathrm{~mm}$; w3, $1.5 \mathrm{~mm}$; and w4, $1.4 \mathrm{~mm}$ (Tables 3 and 4).

\section{DISCUSSION}

The results of the present study suggest that craniofacial height is important for the development of horizontal and vertical bone dimensions of the alveolar process in the anterior region of the maxilla. This may be of value to identify at-risk patients in which implant treatment may 


\begin{tabular}{|c|c|c|c|c|c|c|c|}
\hline \multirow[b]{2}{*}{ Site } & \multicolumn{3}{|c|}{ Male $n=60$} & \multicolumn{3}{|c|}{ Female $n=120$} & \multirow{2}{*}{$\begin{array}{c}\text { Multiple comparison } \\
\text { Between groups }\end{array}$} \\
\hline & Mean & Min-Max & SD & Mean & Min-Max & SD & \\
\hline \multicolumn{8}{|l|}{ MLP } \\
\hline $\mathrm{h}$ & 20.5 & $14.0-25.7$ & 2.8 & 19.0 & $12.9-26.8$ & 2.9 & $.001 *$ \\
\hline w1 & 8.5 & $5.6-11.5$ & 1.2 & 7.7 & 6.0-10.6 & 0.9 & $.000 *$ \\
\hline w2 & 9.5 & $7.1-11.9$ & 1.1 & 8.2 & $6.2-10.4$ & 1.0 & $.000 *$ \\
\hline w3 & 9.8 & $7.4-12.2$ & 1.2 & 8.0 & $5.8-11.3$ & 1.1 & $.000 *$ \\
\hline w4 & 10.1 & $7.1-14.0$ & 1.7 & 8.5 & $5.7-13.3$ & 1.5 & $.000 *$ \\
\hline \multicolumn{8}{|l|}{ MLC } \\
\hline $\mathrm{h}$ & 22.2 & $11.5-28.0$ & 3.3 & 20.6 & $14.5-28.2$ & 2.9 & $.001 *$ \\
\hline w1 & 7.0 & $4.7-8.5$ & 0.8 & 6.6 & 4.3-9.1 & 0.8 & $.002 *$ \\
\hline w2 & 8.0 & $5.8-9.7$ & 0.9 & 7.0 & $4.5-9.5$ & 0.9 & $.000 *$ \\
\hline w3 & 8.3 & $5.4-11.7$ & 1.3 & 7.0 & $4.2-10.2$ & 1.3 & $.000 *$ \\
\hline w4 & 8.9 & $5.0-14.5$ & 2.0 & 7.7 & $3.9-11.9$ & 1.7 & $.000 *$ \\
\hline \multicolumn{8}{|l|}{ MLI } \\
\hline $\mathrm{h}$ & 23.1 & $13.4-29.6$ & 3.0 & 21.7 & $15.5-30.6$ & 3.1 & $.006 *$ \\
\hline w1 & 6.7 & $5.1-8.9$ & 0.8 & 6.3 & $4.6-8.0$ & 0.7 & $.001 *$ \\
\hline w2 & 7.9 & $6.3-10.2$ & 0.8 & 7.0 & $4.7-8.9$ & 1.0 & $.000 *$ \\
\hline w3 & 8.5 & $5.1-13.4$ & 1.3 & 7.2 & $3.4-9.7$ & 1.2 & $.000 *$ \\
\hline w4 & 9.4 & $5.1-14.5$ & 1.7 & 8.1 & $3.6-12.3$ & 1.7 & $.000 *$ \\
\hline
\end{tabular}

$\mathrm{MLP}=$ maxillary left premolar, $\mathrm{MLC}=$ maxillary left canine, $\mathrm{MLI}=$ maxillary left lateral incisor ; mean $=$ mean value, min-max $=$ minimum and maximum value; $\mathrm{SD}=$ standard deviation; $\mathrm{n}=$ number of subjects. Alveolar bone height $(\mathrm{h}) ;$ width $(\mathrm{w})$ at the heights $3,6,9$, and $12 \mathrm{~mm}$ from the crestal top (w1, w2, w3, and w4, respectively). *Significant at $P \leq .05$.

be less suitable due to a nondesirable growth pattern and, as a consequence, alveolar bone deficiency.

The majority of the absence of permanent teeth in the anterior region of the maxilla in children and adolescent patients is caused by traumatic dental injuries or agenesis. ${ }^{13}$ In growing patients, implant treatment is contraindicated until growth is completed. ${ }^{14}$ However, the planning of final treatment, including tooth replacement, starts already when the patient is still growing. Many factors have to be considered to replace a lost tooth in the anterior maxilla, and treatment planning shall always be related to the patient's growth status and dental situation. Orthodontic space closure, prosthetic rehabilitation, or autotransplantation may, in some cases, be better alternatives to implant treatment, while in other cases, implant treatment is a better choice. ${ }^{15}$

Malmgren and Malmgren reported a difference in infraposition of ankylosed roots between the two types of vertical and horizontal growers, where individuals prone to more vertical growth showed the highest risk of alveolar process growth and are regarded as patients at risk for infraposition. ${ }^{16}$ Such patients also have an increased risk for infraposition of implants, and for this reason, may not be suitable for implant treatment. There is value in identifying such patients early in the treatment planning. It has been suggested that cephalometric radiographs are important for evaluating the direction of growth of the jaws since there is a difference between horizontal and vertical growers. ${ }^{16}$
The results of the present study indicate that patients with a long vertical face are also more prone to a thinner alveolar phenotype. When planning such cases, an assessment of which facial type the patient belongs to can be a valuable tool to find the high-angle cases that are patients at risk for bone deficiency and accentuated vertical growth, where implant treatment may be less suitable. Moreover, it is also important to identify the subjects with low facial height who seem to be more stable and more suitable for dental implant treatment. Detecting/identifying this in an early stage of treatment planning is considered highly relevant and favorable from a patient perspective. The purpose of this study was to investigate if there are any differences in height and width of the alveolar bone anteriorly in the maxilla, between subjects with different craniofacial heights, based on CBCT images. There are similar studies where this relationship has been investigated; however, the majority are focused on mandibular dimensions as well as the thickness of the cortical buccal bone. ${ }^{3,7}$ Various results regarding alveolar bone height in relation to craniofacial height have been demonstrated. In a study conducted by Gracco et al, no statistically significant differences among craniofacial heights were found. ${ }^{8}$ However, a majority of studies have in fact obtained similar results to the findings of the present study. Sadek et al found that the high-angle group had the largest anterior dentoalveolar height in the maxilla and the mandible. ${ }^{7}$ The same results were confirmed by Kuitert et al. ${ }^{9}$ These findings 
agree with the theory that the DACM is closely connected to the vertical growth of the face. In contrast to Sadek et al, ${ }^{7}$ the findings of the present study suggest a difference in the first premolar area as well, which might be of interest regarding the extent of DACM, suggesting that it might also influence the alveolar height more posterior in the maxilla area.

In the present study, the method to study dentate subjects was chosen to enable the evaluation of the effect of the genetic component of growth solely without being affected by factors related to areas where teeth already have been lost. In such areas, it is known that atrophy due to trauma and inhibition of growth of the alveolar bone will take place and affect growth locally.

The width of the alveolar process was measured at the heights of 3 (w1), 6 (w2), 9 (w3), and 12 (w4) mm from the top of the alveolar process, while most implants are preferably placed within this range in the bone. Multiple comparison between the alveolar bone width at levels w1 and w2 and craniofacial height revealed no statistical significance at the measured sites. However, statistical significance was shown at levels w3 and w4 at a majority of the measured sites. Gracco et al found a significant difference in alveolar bone width between the vertical facial dimension groups at $20 \mathrm{~mm}$ from the incisal tip at the left and right central and lateral incisors. ${ }^{8}$ The result concurs with the results of the present study, since w3 and w4 correspond approximately to the cross-sectional measurement at the height of $20 \mathrm{~mm}$. The results of Gracco et al also correspond to the measurements of the present study at w1 and $w 2$ and found no significant difference in the height of $15 \mathrm{~mm} .{ }^{8}$ These results demonstrate that the major relationship between facial height and alveolar bone measures is located in the region least exposed to the bone resorption pattern observed after tooth loss.

Similar to the results of the present study, Sadek et al found that the high-angle group had significantly thinner alveolar bone anteriorly in the maxilla compared with the low-angle group. ${ }^{7}$ This was the case at both mid-root-level and at the level of the root-apex. In contrast to the significant difference at w4 in the premolar site in the present study, they found no statistical difference posterior to the canine.

The multiple comparison between sexes proved that there is a significant difference at all sites. Hence, alveolar bone height and width of the males are greater overall. From a statistical perspective, this aspect is interesting since it could be stated that males are more suited for implant treatment based on their anatomical conditions. However, this probably has no clinical relevance because this study reveals average values of height and width for both sexes that are sufficient to place implants, but in the extreme cases of high angles, one can envision that the possibility for immediate implant treatment in women is less likely than men, due to deficiency in the alveolar bone volume.

Implant treatment might not be the first choice of treatment in patients with a high-angle facial type because these individuals also tend to display more gingiva and also may be inclined to have a prolonged, continued eruption due to the DACM compensating for the vertical face height. However, taking into account that the width at w3 and w4 (9 to $12 \mathrm{~mm}$ from the top of the process) of the alveolar bone is significantly thinner in the high-angle subjects, it would be interesting to study if bone augmentation procedures were more frequently needed in high-angle subjects when replacing congenital missing lateral implants in a young adult, compared to subjects with a normal or low craniofacial height.

In summary, it is suggested that assessing craniofacial vertical height is of clinical importance to identify at-risk cases where implant treatment may be less suitable. By doing such an analysis before growth is completed, other treatment options, such as orthodontic space closure, autotransplantation, and prosthetic solutions may be chosen instead of implant treatment.

\section{CONCLUSIONS}

This study claims a statistically significant difference in height and width of the alveolar process in major aspects associated with the craniofacial height and sex. Evidence has been presented that individuals with a high-angle facial type are more prone to a thinner alveolar bone in the anterior part of the maxilla compared to subjects with a low-angle facial type.

Already in adolescence, a clinical examination could reveal the vertical craniofacial morphology and, thereby, give the clinician an indication of which treatment option to choose in the cases of tooth loss or agenesis in the anterior part of the maxilla.

\section{ACKNOWLEDGMENTS}

The authors wish to thank Dr Yohei Jinno, Department of Oral and Maxillofacial Surgery and Oral Medicine, Faculty of Odontology, Malmö University, for data analysis. The authors reported no conflicts of interest related to this study.

\section{REFERENCES}

\footnotetext{
1. Tsunori M, Mashita M, Kasai K. Relationship between facial types and tooth and bone characteristics of the mandible obtained by CT scanning. Angle Orthod 1998;68:557-562.

2. Masumoto T, Hayashi I, Kawamura A, Tanaka K, Kasai K. Relationships among facial type, buccolingual molar inclination, and cortical bone thickness of the mandible. Eur J Orthod 2001;23:15-23.
} 
3. Swasty D, Lee J, Huang JC, et al. Cross-sectional human mandibular morphology as assessed in vivo by cone-beam computed tomography in patients with different vertical facial dimensions. Am J Orthod Dentofacial Orthop 2011;139(suppl 4):e377-e389.

4. Buschang PH, Nass GG, Walker GF. Principal components of craniofacial growth for white Philadelphia males and females between 6 and 22 years of age. Am J Orthod 1982;82:508-512.

5. Thilander B, Persson M, Adolfsson U. Roentgen-cephalometric standards for a Swedish population. A longitudinal study between the ages of 5 and 31 years. Eur J Orthod 2005;27:370-389.

6. Solow B. The dentoalveolar compensatory mechanism: Background and clinical implications. Br J Orthod 1980;7:145-161.

7. Sadek MM, Sabet NE, Hassan IT. Alveolar bone mapping in subjects with different vertical facial dimensions. Eur J Orthod 2015;37:194-201.

8. Gracco A, Lombardo L, Mancuso G, Gravina V, Siciliani G. Upper incisor position and bony support in untreated patients as seen on CBCT. Angle Orthod 2009;79:692-702.

9. Kuitert R, Beckmann S, van Loenen M, Tuinzing B, Zentner A. Dentoalveolar compensation in subjects with vertical skeletal dysplasia. Am J Orthod Dentofacial Orthop 2006;129:649-657.
10. Klinge A, Becktor K, Lindh C, Becktor JP. Craniofacial height in relation to cross-sectional maxillary and mandibular morphology. Prog Orthod 2017;18:32.

11. Bjoern-Joergensen JB, Bjoern-Joergensen PB. Tiops. Available from: http://www.tiops.com/ Accessed February 19, 2020.

12. i-CAT Cone Beam 3D Imaging. Available from: https://www.kavo. com/en-us/i-cat/ Accessed February 19, 2020

13. Andersson L, Andreasen JO, Day P, et al. International Association of Dental Traumatology guidelines for the management of traumatic dental injuries: 2 . Avulsion of permanent teeth. Dent Traumatol 2012;28:88-96.

14. Op Heij DG, Opdebeeck H, van Steenberghe D, Quirynen M. Age as compromising factor for implant insertion. Periodontol 2000 2003;33:172-184.

15. Andersson L, Malmgen B, Malmgen O, Storgård Jensen S. Strategies for treatment of Tooth Loss after Trauma in the Anterior Region of Young Patients. Textbook and Color Atlas of Traumatic Injuries of the Teeth, 5th Edition. Oxford: Wiley Blackwell, 2019:878-887.

16. Malmgren B, Malmgren O. Rate of infraposition of reimplanted ankylosed incisors related to age and growth in children and adolescents. Dent Traumatol 2002;18:28-36. 



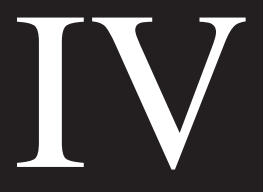





\title{
The risk for infraposition of dental implants and ankylosed teeth in the anterior maxilla related to craniofacial growth, a systematic review
}

\author{
Anna Klinge ${ }^{a}$, Sofia Tranaeus ${ }^{b, c}$, Jonas Becktor ${ }^{a}$, Nicole Winitsky ${ }^{d}$ and Aron Naimi-Akbar ${ }^{a, b, c, d}$ \\ ${ }^{a}$ Department of Oral and Maxillofacial Surgery and Oral Medicine, Malmö University, Malmö, Sweden; ${ }^{b}$ Health Technology Assessment- \\ Odontology (HTA-O), Malmö University, Malmö, Sweden; 'Department of Dental Medicine, Karolinska institutet, Stockholm, Sweden; \\ ${ }^{\mathrm{d}}$ Folktandvården Eastmaninstitutet. Public Dental Health, Stockholm, Sweden
}

\section{ABSTRACT}

Background: The aim of the study was to evaluate a potential association between individuals with different craniofacial types or other exposures, and the risk of infraposition due to continued growth/ eruption of adjacent teeth in the anterior maxilla.

Materials and methods: This is a systematic review in which primary studies as well as other systematic reviews are scrutinised. A search of PubMed (Medline), Scopus, Web of science and Health technology assessment (HTA) organisations and a complementary handsearch was carried out. Selected studies were read in full-text by several reviewers. The quality of the included primary studies was assessed using a protocol for assessment of risk of bias in exposure studies.

Results: The literature search resulted in 3,296 publications. Title and abstract screening yielded 25 whereof one systematic review, potential publications allocated for full-text inspection. The quality assessment resulted in a total of seven studies with a low/moderate risk of bias and four studies with a high risk of bias.

Conclusion: In conclusion, a long-term risk for infraposition of dental implants, or ankylosed teeth, among natural teeth can be observed in some cases. The predisposing factors are still not fully understood since the current scientific evidence is very limited.

\section{ARTICLE HISTORY}

Received 22 April 2020

Revised 27 July 2020

Accepted 2 August 2020

\section{KEYWORDS}

Dental implants; ankylosed teeth; infraposition; continued development systematic review

\section{Introduction}

Missing teeth in the anterior region of the maxilla in young individuals could be due to congenital factors or trauma. External trauma and root fractures were the most common reasons for tooth loss (49\%) whilst congenital factors accounted for $15 \%$ of the single-tooth spaces [1]. Missing teeth can lead to functional as well as aesthetical challenges. Young patients with lost or congenitally missing teeth are often treated early in life, and the aesthetic long-term outcome may be of particular concern. It is important to initiate treatment-planning early in order to have all treatment options available. Treatment alternatives in the dentition of a young individual might be temporary prosthodontic rehabilitation, orthodontic treatment, preservation of the decidious teeth and autotransplantation. Dental implant treatment is considered to be an alternative with a high survival and success rate as shown in several studies [2-7]. However, some negative observations have been reported for long-term aesthetic outcome, e.g. infraposition of the implant-supported crown, marginal bone loss, (fistula), discoloured buccal gingiva (when using titanium metal coloured implants), gingival retraction/recession and periimplantitis [8-11].
In still growing children and young adults, dental implants as well as trauma injured ankylosed teeth might, due to the lack of functioning periodontal ligament, become progressively infrapositioned over time in relation to the surrounding teeth [12-20]. This implies that the crown appears shorter than the adjacent teeth which to a varying degree affects the aesthetic appearance.

For this reason, it has been suggested that an appropriate time-point for implant placement is at the age when skeletal growth is considered to be completed [21,22]. According to a study by Taranger and Hägg [24] the pubertal growth spurt began on average at the age of 10.0 years in girls, and 12.1 years in boys and ceased at 14.8 years and 17.1 years, respectively. Peak height velocity, in both sexes, occurred two years after the onset of the growth spurt (12.0 years and 14.1 years). Growth terminated at 17.5 years in girls and 19.2 years in boys. In adddition to differences between the sexes there is also a large variation between individuals [23]. In a study by Pancherz et al. investigation of the facial skeleton and dental changes over time were performed using cephalometric measurements. On their study sample, they presented results where both the maxillary and mandibular bases grew anteriorly even after puberty [24]. Behrents investigated growth in the aging craniofacial skeleton and found

CONTACT Anna Klinge anna.klinge@mau.se O Oral and Maxillofacial Surgery and Oral Medicine, Malmö University, 205 05, Malmö, Sweden

(C) 2020 The Author(s). Published by Informa UK Limited, trading as Taylor \& Francis Group on behalf of Acta Odontologica Scandinavica Society.

This is an Open Access article distributed under the terms of the Creative Commons Attribution-NonCommercial-NoDerivatives License (http://creativecommons.org/licenses/by-nc-nd/4. $0 /)$, which permits non-commercial re-use, distribution, and reproduction in any medium, provided the original work is properly cited, and is not altered, transformed, or built upon in any way. 
changes even after the age of 40 [25]. Even when growth is finished, continuous eruption or continued positional changes of the adjacent teeth, especially in the maxillary incisor region, may result in infraposition of the implant-supported crown, and potentially even more so in the case of a deviant facial type [26-29]. This could possibly be explained by the disparity between patients with different vertical craniofacial growth pattern (horizontal and vertical growth of the face). Assuming that continued eruption is a compensatory mechanism for facial growth, it seems reasonable to conclude that eruption follows the general pattern of craniofacial growth [30-32]. In a previous study, Klinge et al. investigated the association between craniofacial height and alveolar bone dimensions. They found that patients with large vertical craniofacial height had a significantly higher alveolar bone both in the maxilla and in the mandible compared to the patients with low craniofacial features [33]. These results indicate that in a vertical growing individual there might be a greater risk of developing infraposition due to the growth of the alveolar bone height.

It seems that infraposition is a complex issue where craniofacial type could be one relevant factor (a decisive piece of the puzzle). If it were possible to pinpoint a recommendation for when to insert dental implants based on craniofacial type this would no doubt be of great value to the adolescents/young adults, both from a psychological, functional and aesthetic point of view. The aim of this study is to evaluate a potential association between individuals of different craniofacial types as well as other exposures (e.g. sex and age) and risk of infraposition (of crowns on ankylosed teeth or dental implants) due to continued growth/eruption of adjacent teeth in the anterior maxilla.

\section{Materials and methods}

\section{Objective}

The aim of this study was to investigate risk factors for infraposition during dental implant treatment or in cases of ankylosed teeth. The protocol was registered at PROSPERO International prospective register of systematic reviews: CRD42019136675.

\section{Eligibility criteria for studies}

Eligibility criteria for studies were as follows: a predefined study population, age and sex registered for the patients, and registration of infraposition over time. PICO (Patients, Intervention/Exposure, Control group, Outcome), as well as inclusion and exclusion criteria for the eligible studies are summarised in Table 1.

\section{Literature search}

A literature search was performed ( $3^{\text {rd }}$ June 2019) by two of the authors (AK and ANA) and an scientific information specialist at Malmö university library. No time limitations from
Table 1. PICO and inclusion/exclusion criteria.

\begin{tabular}{|c|c|}
\hline$P$ & $\begin{array}{l}\text { Adolescents, young adults and adults with ankylosed } \\
\text { teeth or who had been treated with dental implant }\end{array}$ \\
\hline I & $\begin{array}{l}\text { Age, sex, facial morphology, diseases, or other potential } \\
\text { studied risk factors }\end{array}$ \\
\hline C & Other levels of the same exposures \\
\hline \multirow[t]{2}{*}{0} & Infraposition \\
\hline & Other measures of continued growth \\
\hline \multirow[t]{10}{*}{ Systematic reviews } & Inclusion criteria \\
\hline & Systematic review \\
\hline & Systematic meta-analysis \\
\hline & English abstract \\
\hline & Exclusion criteria \\
\hline & Non-systematic review \\
\hline & Guidelines \\
\hline & Letter \\
\hline & Position paper \\
\hline & Consensus statements \\
\hline \multirow[t]{7}{*}{ Primary studies } & Inclusion criteria \\
\hline & English abstract \\
\hline & Longitudinal studies \\
\hline & Exclusion criteria \\
\hline & Animal studies \\
\hline & In vitro studies \\
\hline & Lack of follow-up \\
\hline
\end{tabular}

inception up to 03 June 2019. The search only included studies in English. The search strategies are presented in Table 2.

\section{Search strategies}

The following databases were searched: Pubmed (Medline), Scopus and Web of science. The search was performed without any filters. The search terms used for the databases are summarised and presented in Table 2. Search terms used were e.g. continued eruption, infraposition, infraocclusion, growth and development, jaw, maxilla, alveolar bone, dental implant and tooth ankylosis. The following Health technology assessment (HTA) organisations were searched regarding dental implant infraposition or infraocclusion until $3^{\text {rd }}$ June 2019: National Institute for Health and Care Excellence (NICE), http://www.nice.org.uk/; CADTH, http://www.cadth.ca/; CRD database, http://www.crd.york.ac.uk/CRDWeb/; Kunnskapssenteret, http://www.kunnskapssenteret.no/home?language=english, and ASERNIP-S http://www.surgeons.org/ for-health-professionals/audits-and-surgical-research/asernips/ publications/. The reference lists of all the eligible studies were handsearched for potential complementary studies.

\section{Study selection}

The Rayyan software program (Qatar Computing Research Institute (Data Analytics)) was used to manage the references and remove duplicates. The retrieved list of publications was subjected to a crude exclusion of irrelevant publications based on title. In case of uncertainty, a study remained included until the next selection step, which consisted of an assessment of abstracts. The abstracts were read by four reviewers independently in pairs of two (AK and ST; ANA and $\mathrm{JB}$ ). Selected studies were read in full-text by four reviewers respectively (AK, ANA, ST, NW). Any disagreement during the screening process was resolved by discussion in the project group. 
Table 2. Search strategy.

\begin{tabular}{|c|c|}
\hline Database & Search strategy \\
\hline \multirow[t]{2}{*}{ Medline (PubMed) } & $\begin{array}{l}\text { 'continued eruption' OR infraposition OR infraocclusion OR growth OR development OR growth[Mesh] OR growth and } \\
\text { development[Mesh] AND }\end{array}$ \\
\hline & $\begin{array}{l}\text { Jaw OR Jaw[Mesh] OR maxillary OR maxilla OR maxilla[Mesh] OR mandibular OR mandible OR mandible[Mesh] OR 'alveolar } \\
\text { bone' OR 'alveolar process' OR alveolar process[Mesh] OR 'dental arch' OR dental arch[Mesh] AND } \\
\text { 'dental Implant*' OR dental implants[Mesh] OR dental Implantation[Mesh] OR 'tooth ankylos*' OR tooth ankylosis[Mesh] }\end{array}$ \\
\hline Scopus & 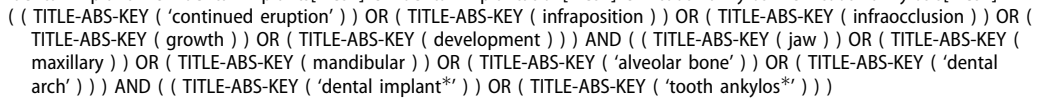 \\
\hline \multirow[t]{19}{*}{ Web of science } & $\# 1$ 'continued eruption' \\
\hline & \#2 infraposition \\
\hline & \#3 infraocclusion \\
\hline & \#4 growth \\
\hline & \#5 development \\
\hline & \#6 \#1 OR \#2 OR \#3 OR \#4 OR \#5 \\
\hline & \#7 jaw \\
\hline & \#8 maxillary \\
\hline & \#9 maxilla \\
\hline & \#10 mandibular \\
\hline & \#11 mandible \\
\hline & \#12 'alveolar bone' \\
\hline & \#13 'alveolar process' \\
\hline & \#14 'dental arch' \\
\hline & $\# 15$ \#7 OR \#8 OR \#9 OR \#10 OR \#11 OR \#12 OR \#13 OR \#14 \\
\hline & \#16 'dental implant*' \\
\hline & $\# 17$ 'tooth ankylos*' \\
\hline & $\# 18$ \#16 OR 17 \\
\hline & $\# 19$ \#6 OR \#15 OR \#18 \\
\hline
\end{tabular}

Duplicates, non-clinical studies, case reports, animal studies, guidelines, letters, position paperstudies on patients with systemic diseases or syndromes, studies on implant-supported overdentures or tooth-and-implant restorations, studies on surgical or short-term outcomes, and studies with nonrelevant outcomes were excluded.

\section{Assessment of risk of bias}

\section{Systematic reviews}

The quality of the included systematic review was assessed using AMSTAR (https://amstar.ca/docs/AMSTAR-2.pdf).

\section{Primary studies}

The risk of bias of the included primary studies was assessed using a protocol for assessment of risk of bias in exposure studies [34]. The assessment comprised selection bias, exposure bias, detection bias, attrition bias, and reporting bias.

\section{Data extraction}

\section{Systematic reviews}

No systematic reviews were eligible for data extraction, the one systemic review identified was excluded due to employing a different methodological approach than the present review. Data extraction would have been the following: objectives, main results, authors' estimated certainty of evidence, and knowledge gaps according to authors.

\section{Primary studies}

Data was extracted from the primary studies regarding population (number of included patients), study period (length of follow-up), age, sex, craniofacial type, type of outcome (infraposition measured or other relevant outcomes).

\section{Certainty of the evidence}

The certainty of the evidence in the studies was rated according to GRADE (GRADing quality of Evidence and strength of recommendations). GRADE has four steps of evidence grading; high, moderate, low, and very low [35].

\section{Results}

\section{Literature search and study selection}

The literature search resulted in 3,296 publications. Search strategy, presented for each database, is shown in Table 2. The search of HTA organisations did not yield any further studies. Flowcharts of the screening process for the studies are shown in Figure 1.

Title and abstract screening yielded 25 potential publications gathered for full-text inspection and inclusion for further analysis. Primary studies that were regarded as nonrelevant to the current systematic review were excluded at this stage and the reason for exclusion was recorded (Table 3) [27,28,36-46].

\section{Assessment of risk of bias and data extraction}

\section{Systematic reviews}

One systematic review was eligible for quality assessment [47]. However, the systematic review was excluded due to it 


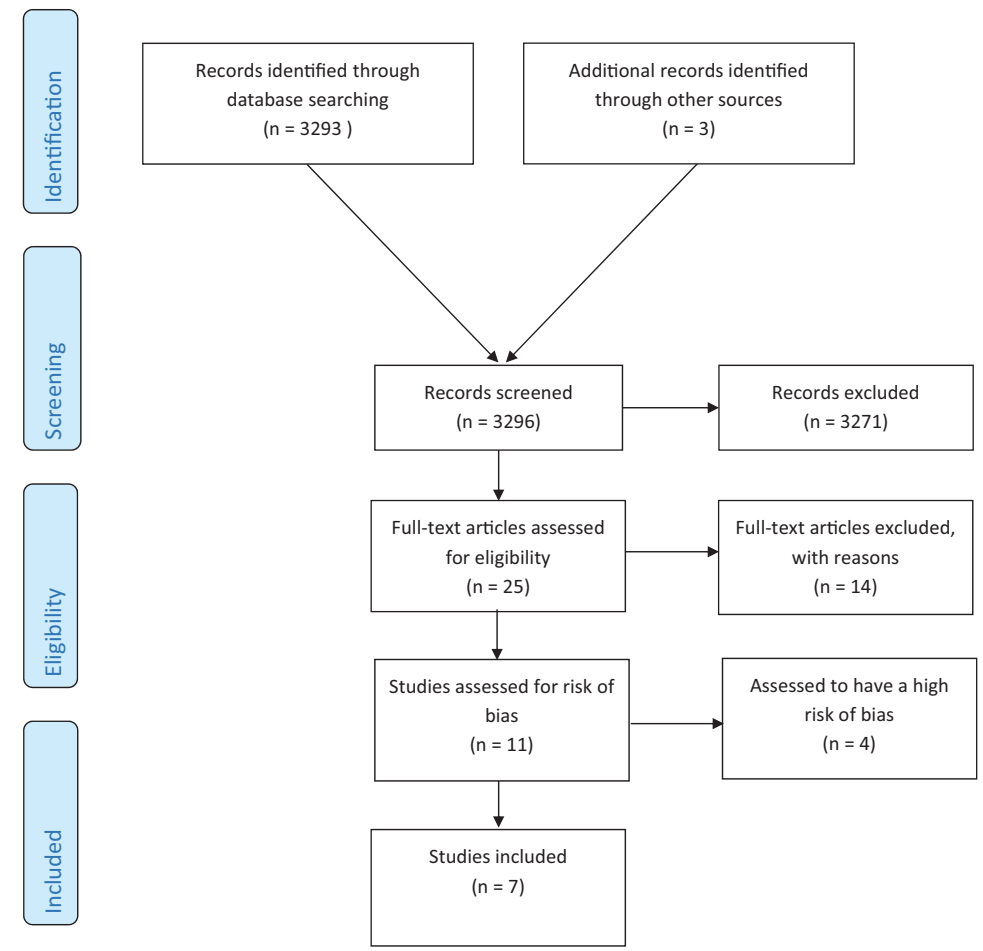

Figure 1. PRISMA 2009 flow diagram. ${ }^{1}$

Table 3. Studies (in full text) excluded due to lack of relevance.

\begin{tabular}{lll}
\hline Author & Year & \multicolumn{1}{c}{ Reason for exclusion } \\
\hline Bohner et al. & 2019 & Does not adress the present research question \\
Carmichael et al. & 2008 & Neither primary nor SR study \\
Chrancanovic et al. & 2019 & Does not adress the present research question \\
Kamatham et al. & 2019 & Does not adress the present research question \\
Lin et al. & 2013 & Does not adress the present research question \\
Malmgren B et al. & 1984 & Does not adress the present research question \\
Mohadeb et al. & 2016 & Does not adress the present research question \\
Op Heij & 2006 & Neither primary nor SR study \\
Op Heij & 2003 & Neither primary nor SR study \\
Papageorgiou & 2018 & SR with differences in methodological approach compared to the present review \\
Ruan & 2018 & Does not adress the present research question \\
Thilander & 1999 & Duplicate/same subjects as another study \\
Vilhjamsson & 2013 & Does not adress the present research question \\
Jemt et al. & 2006 & Does not adress the present research question \\
\hline
\end{tabular}

employing a different methodological approach than the present review (Table 3).

\section{Primary studies}

The quality assessment resulted in seven studies with a low/ moderate risk of bias and four studies with a high risk of bias. Selection bias, exposure bias, detection bias, attrition bias, reporting bias, for the eleven studies are presented in
Figure 2(a) (low or moderate risk of bias), and Figure 2(b) (high risk of bias) [19,48-50].

Type of exposure, study population characteristics and outcome for studies classified as being of low or moderate risk of bias are shown in Table 4. Due to diversity in study design and outcome, statistical analysis was not applicable.

In a study by Aarts et al. [51], the potential difference in craniofacial growth cessation between short, average and long face subjects as an implication for the timing of implant 


\begin{tabular}{|c|c|c|c|c|c|c|}
\hline Study & $\begin{array}{l}\text { Selection } \\
\text { bias }\end{array}$ & $\begin{array}{l}\text { Exposure } \\
\text { bias }\end{array}$ & $\begin{array}{l}\text { Detection } \\
\text { bias }\end{array}$ & $\begin{array}{l}\text { Attrition } \\
\text { bias }\end{array}$ & $\begin{array}{l}\text { Reporting } \\
\text { bias }\end{array}$ & Summary \\
\hline $\begin{array}{l}\text { Aarts et al. } \\
2015\end{array}$ & & & & & & $\begin{array}{c}\text { Low/moderate risk } \\
\text { of bias }\end{array}$ \\
\hline $\begin{array}{l}\text { Bernard et al. } \\
2004\end{array}$ & & & & $\begin{array}{c}\text { Not } \\
\text { applicable }\end{array}$ & & $\begin{array}{c}\text { Low/moderate risk } \\
\text { of bias }\end{array}$ \\
\hline $\begin{array}{l}\text { Brahem et al. } \\
2017\end{array}$ & & & & & & $\begin{array}{c}\text { Low/moderate risk } \\
\text { of bias }\end{array}$ \\
\hline $\begin{array}{l}\text { Fudalej et al. } \\
2007\end{array}$ & & & & $\begin{array}{c}\text { Not } \\
\text { applicable }\end{array}$ & & $\begin{array}{c}\text { Low/moderate risk } \\
\text { of bias }\end{array}$ \\
\hline $\begin{array}{l}\text { Kawanami et } \\
\text { al. } 1999\end{array}$ & & & & & & $\begin{array}{c}\text { Low/moderate risk } \\
\text { of bias }\end{array}$ \\
\hline $\begin{array}{l}\text { Schwartz-Arad } \\
\text { et al. } 2013\end{array}$ & & & & & & $\begin{array}{c}\text { Low/moderate risk } \\
\text { of bias }\end{array}$ \\
\hline $\begin{array}{l}\text { Thilander et al. } \\
1994\end{array}$ & & & & & & $\begin{array}{l}\text { Low/moderate risk } \\
\text { of bias }\end{array}$ \\
\hline Low risk & & & High risk & & & \\
\hline
\end{tabular}

\begin{tabular}{|l|l|l|l|l|l|l|}
\hline Study & $\begin{array}{l}\text { Selection } \\
\text { bias }\end{array}$ & $\begin{array}{l}\text { Exposure } \\
\text { bias }\end{array}$ & $\begin{array}{l}\text { Detection } \\
\text { bias }\end{array}$ & $\begin{array}{l}\text { Attrition } \\
\text { bias }\end{array}$ & $\begin{array}{l}\text { Reporting } \\
\text { bias }\end{array}$ & Summary \\
\hline $\begin{array}{l}\text { Andersson et } \\
\text { al. 2013 }\end{array}$ & & & & & High risk of bias \\
\hline $\begin{array}{l}\text { Jemt et al. } \\
2007\end{array}$ & & & & & High risk of bias \\
\hline $\begin{array}{l}\text { Cocchetto et } \\
\text { al. 2019 }\end{array}$ & & & & & High risk of bias \\
\hline $\begin{array}{l}\text { Malmgren et } \\
\text { al. 2002 }\end{array}$ & & & & & High risk of bias \\
\hline Low risk & & & High risk & & \\
\hline
\end{tabular}

Figure 2. (a) Risk of bias in studies included in the SR conclusion. (b) Risk of bias in studies not included in the conclusion.

placement was investigated. Measurements of anatomical landmarks on cephalogram were performed at different timepoints. Orthodontic treatment was completed between 14-18years of age (males) and 13-17years of age (females). Cessation of facial growth was evaluated by e.g. if (Is-Pal) change was less than $1 \mathrm{~mm}$ between two measurements ( 2 , 5, 10 years follow up), and if so, considered stable. 169 patients were included. No statistical difference between facial type group were found.

Bernard et al. [52], evaluated the effects of the tooth-eruption process of teeth adjacent to implant-borne restorations in adult patients compared to patients in their late adolescence. Follow-up time was between 1 year 8 months and 9 years 1 month (mean 4.2 years). No difference was found in the amount of vertical displacement of the adjacent teeth between male and female patients, nor between different positions of the implant. The study included 28 subjects, divided in two equal age groups (young group (15.5-21 years), $n=14$, mature group ( $40-55$ years), $n=14$ ). Twelve out of the 28 patients had two implants inserted (right and left side) and for these patients the mean value was used for statistics which might have affected the result.

The study sample of Brahem et al. [53], measured standing height and implants were inserted after documented stabilisation of growth height. Fifty-seven patients (37 with preimplant orthodontic treatment and 20 without) were included. Ages of the study sample were between 18 and 61 years (mean 29.7 \pm SD 10 years). Time of follow up were from baseline examination aproximately five weeks after crown placement, to final follow-up examination of minimum five years ( $>5$ years. Mean 7 years \pm 1 year). Infraposition was evaluated according to a score. Twenty-eight patients recieved one single crown implant, 26 patients recieved two single crown implants and three patients recieved three single crown implants each. No relationship was found between maximal tooth displacement of incisors, pre-implant orthodontic treatment and orthodontic retention, sex, and age at the end of treatment. 


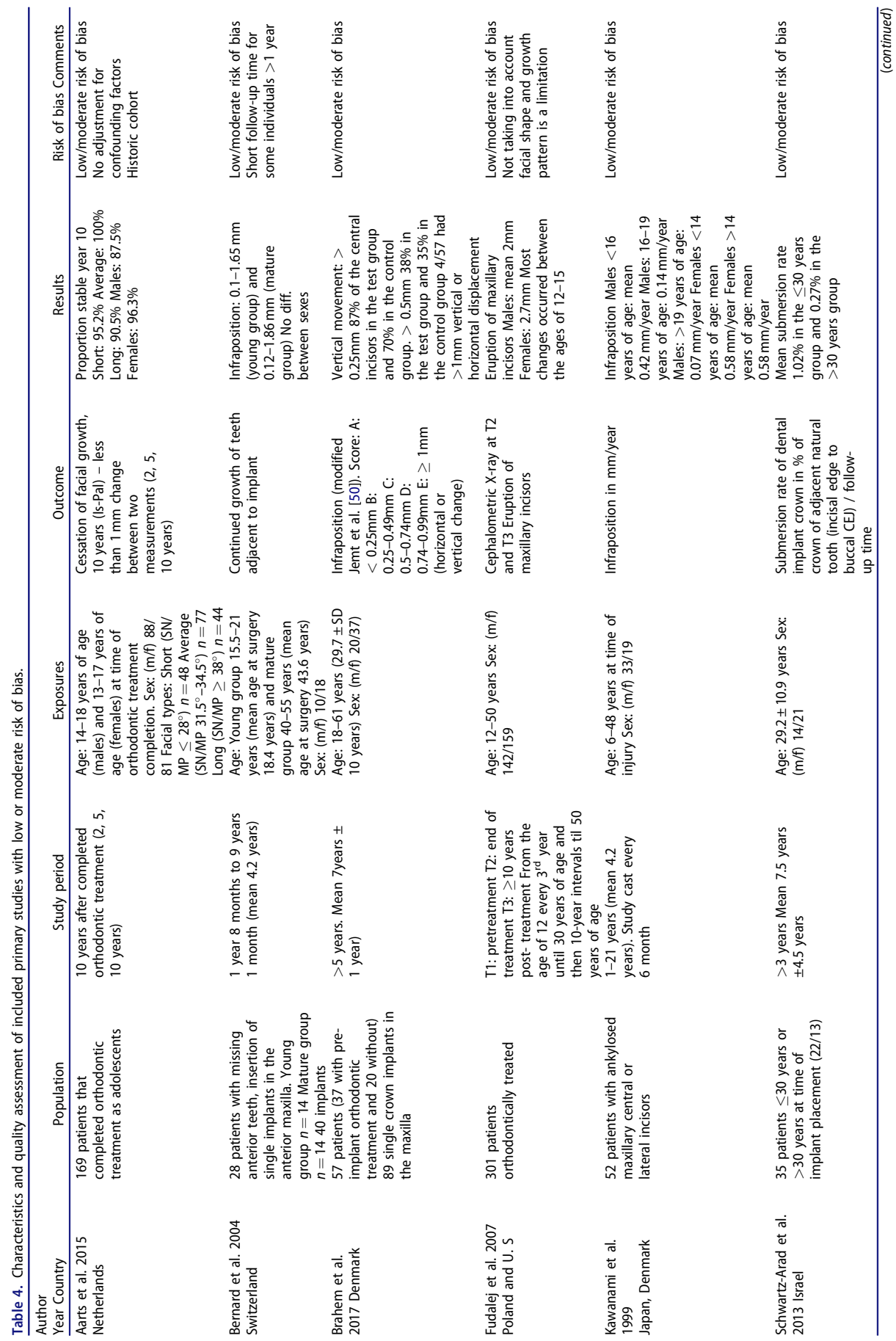


In a study by Fudalej et al. [54], the purpose was to evaluate the amount of craniofacial growth and the amount of eruption of the central incisors after puberty. Follow up time was from end of orthodontic treatment to ten years postretention. Observational age intervals were every 3 rd year from the age of 12 until 30 years of age and then ten year intervals til 50 years of age.The anteror facial height (AFH) in men increased by a total of $9.4 \mathrm{~mm}$ ( $\mathrm{SE}=0.7$ ) during the observation period from the ages 12 to 50 years. Over half of the increase took place before the age of 15 . In females, the total change in $\mathrm{AFH}$ over the entire observation period was $4.3 \mathrm{~mm}(\mathrm{SE}=0.4)$. About $40 \%$ of the growth in AFH occurred before the age of 15 . For both sexes, about $60 \%$ to $70 \%$ of the increase in $\mathrm{AFH}$ occurred in the lower anterior face height. Most of the changes in both facial height and in amount of eruption of central icisors occured at an early age but changes could be observed throughout the whole observation period.

In the study by Kawanami et al. [55], the purpose was to register the extent of infraposition after replantation of avulsed teeth and to relate this event to the age and sex of the patient.

The study samples were between 6 and 48 years at time of the dental injury. Follow-up time was 1-21 years (mean 4.2 years). Study casts were made every 6 month and a yearly increase in infraposition was calculated each year of age. Vertical distances from the reference plane to the incisal edges were measured by one examiner using a Jocal digital calliper (C.E. Johansson, Eskilstuna, Sweden). Almost all cases demonstrated increasing infraposition over time. Rapid increase in infraposition was identified in patients where ankylosis occurred during childhood and adolescence. Slowly increasing infraposition was also found in cases where ankylosis occurred after the age of 20-30years. The yearly increase in infraposition for males varied between 0.19 and $0.62 \mathrm{~mm}$ before the age of 16 and between 0.11 and $0.18 \mathrm{~mm}$ from 16 to 19 years of age. In females the yearly increase in infraposition ranged between 0.08 and $1.00 \mathrm{~mm}$ when ankylosis occurred before the age of 14 years.

Schwartz-Arad and Bichacho [56], investigated the submersion rate of single dental implants in the central maxillary incisor region compared with the adjacent natural tooth and association with age. The mean age at implant placement was $29.2 \pm 10.9$ years. A clinical and radiographic follow-up of at least three years with a mean follow-up time of $7.5 \pm 4.5$ years were performed. When investigating implant submersion rate according to age, there were statistically significant differences between the two groups ( 35 patients divided in two age groups $\leq 30$ years or $>30$ years at time of implant placement).

In the studies by Thilander et al. [29,57], dental implants in adolescents were investigated. The study population were 13 years 2 month to 19 years 4 month, with a mean age at implant placement of 15.1 years. The follow-up time was $>3$ years in the study published 1994 and 10-years follow-up in the study published 2001 on the same subjects. In three patients, four crowns in the maxilla were replaced and excluded. The crowns were changed for aesthetic reasons e.g. colour, 
Table 5. Summary of findings for effects of exposures on continued growth/eruption of teeth in the alveolar bone of the anterior maxilla.

\begin{tabular}{|c|c|c|c|c|c|}
\hline Exposure References & Outcome & $\begin{array}{c}\text { Number of } \\
\text { subjects (studies) }\end{array}$ & Results & $\begin{array}{l}\text { Certainty of } \\
\text { the evidence } \\
\text { (GRADE) }\end{array}$ & $\begin{array}{c}\text { Reason for } \\
\text { grading down }\end{array}$ \\
\hline $\begin{array}{l}\text { Age } \\
\text { Bernard et al. [52] } \\
\text { Brahem et al. [53] } \\
\text { Fudalej et al. [54] } \\
\text { Kawanami et al. [55] } \\
\text { Schwartz-Arad and } \\
\text { Bichacho [56] } \\
\text { Thilander et al. [29,57] }\end{array}$ & $\begin{array}{l}\text { Continued growth/ } \\
\text { eruption of teeth }\end{array}$ & $485(6)$ & $\begin{array}{l}\text { Six studies analysed the impact of } \\
\text { age. The results showed that } \\
\text { continued eruption was present at all } \\
\text { the ages included, some studies } \\
\text { were able to show that the rate of } \\
\text { growth was significantly higher in } \\
\text { younger subjects, i.e. those aged } 15 \\
\text { or younger. }\end{array}$ & $\begin{array}{l}\text { Very low } \\
\oplus \circ \circ 0\end{array}$ & $\begin{array}{l}\text { Risk of bias }-2^{\mathrm{a}} \\
\text { Inconsistency }-1^{\mathrm{b}}\end{array}$ \\
\hline $\begin{array}{l}\text { Facial type } \\
\text { Aarts et al. [51] }\end{array}$ & $\begin{array}{l}\text { Continued growth/ } \\
\text { eruption of teeth }\end{array}$ & $169(1)$ & $\begin{array}{l}\text { One study evaluated the impact of } \\
\text { facial type. There were no significant } \\
\text { differences in growth between } \\
\text { facial types. }\end{array}$ & $\begin{array}{l}\text { Very low } \\
\oplus \circ \circ 0\end{array}$ & $\begin{array}{l}\text { Risk of bias }-2^{c} \\
\text { Imprecision }-1^{d}\end{array}$ \\
\hline $\begin{array}{l}\text { Sex } \\
\text { Aarts et al. [51] Bernard } \\
\text { et al. [52] Brahem et al. } \\
\text { [53] Fudalej et al. [54] } \\
\text { Kawanami et al. [55] } \\
\text { Schwartz-Arad and } \\
\text { Bichacho [56] Thilander } \\
\text { et al. [57] }\end{array}$ & $\begin{array}{l}\text { Continued growth/ } \\
\text { eruption of teeth }\end{array}$ & $654(7)$ & $\begin{array}{l}\text { Seven studies looked at whether or } \\
\text { not the subject's sex influenced } \\
\text { growth. Only one study showed } \\
\text { significant differences with more } \\
\text { growth in female subjects. }\end{array}$ & $\begin{array}{l}\text { Very low } \\
\oplus \circ 00\end{array}$ & $\begin{array}{l}\text { Risk of bias }-2^{e} \\
\text { Inconsistency }-1^{f}\end{array}$ \\
\hline $\begin{array}{l}\text { Tooth position } \\
\text { Bernard et al. [52] }\end{array}$ & $\begin{array}{l}\text { Continued growth/ } \\
\text { eruption of teeth }\end{array}$ & $28(1)$ & $\begin{array}{l}\text { One study evaluated the impact of } \\
\text { tooth position in the anterior maxilla. } \\
\text { There were no significant differences } \\
\text { in growth between tooth positions. }\end{array}$ & $\begin{array}{l}\text { Very low } \\
\oplus \circ 00\end{array}$ & $\begin{array}{l}\text { Risk of bias }-2^{\mathrm{g}} \\
\text { Imprecision }-1^{\mathrm{h}}\end{array}$ \\
\hline
\end{tabular}

$\oplus_{0 \infty}$ Level of certainty of evidence according to GRADE.

a Weaknesses in study design and statistics.

${ }^{b}$ Inconsistency in the timings, outcome measures, and results between studies.

'Weaknesses in study design and statistics. One study (not duplicated).

${ }^{\mathrm{d}}$ Few events, not statistically significant.

'Weaknesses in study design and statistics.

f Inconsistency in the timings and outcome measures.

${ }^{9}$ Weaknesses in study design and statistics. One study (not duplicated).

${ }^{h}$ Few events, not statistically significant.. crown anatomy or because of fracture due to trauma. This drop out may influence the results since the study population was relatively small ( 11 patients and 17 fixtures in the anterior maxilla). In four of the patients, including a total of six implants in the upper incisal region, the position of the implant-crowns was vertically changed to an unacceptable position from a clinical point of view. This also involved the gingiva leading to an apical shift of the gingival margin of the implant-crown.

\section{Summary of findings}

Summary of findings for effects of exposures on continued growth/eruption of teeth in the alveolar bone of the anterior maxilla is presented in Table 5.

There is very low-quality evidence for continued growth in the alveolar bone of the anterior maxilla even after skeletal growth is considered finished, with a higher rate in young patients.

\section{Discussion}

The aim of this systematic review was to evaluate the potential relationship between several exposures and continued growth in the anterior maxilla, resulting in infraposition of ankylosed teeth or dental implants in relation to the adjacent teeth. We identified seven primary studies, with different aims, at low or moderate risk of bias. The studies' differing aims and heterogeneity between the seven studies precluded meta-analysis.

Hence, we were unable to clearly pinpoint the predisposing (risk) factors for infraposition of dental implants in the anterior maxilla. There is a lack of well-designed studies with multivariate analysis including investigation of craniofacial type, age, and sex. A previous systematic review [47], on a similar topic was identified, but unlike the current paper, this review included studies at either high risk, or unclear risk of bias in their meta-analyses.

The description 'unclear risk of bias' when a lack of information about material and methods precludes assessment of scientific quality is per se acceptable. However, including such studies in the meta-analysis as comparable to studies at either low or moderate risk of bias seems speculative and could be misleading to an inexperienced reader.

To summarise, meticulous and stringent quality assessment of primary studies and reviews are important before drawing conclusions, especially when the conclusions are relevant to clinical practice.

Our findings highlight the fact that there is a need of new studies with a thorough study protocol, including a proper number of subjects, and a well-defined and calibrated investigation technique, to improve the scientific knowledge. 


\section{Conclusion}

It was not possible to establish evidence for a certain timepoint being more suited for insertion of dental implants in order to avoid infraposition with time due to contiunued growth/development/eruption. The influence of the craniofacial height in association with infraposition needs to be further investigated.

\section{Note}

\section{Acknowledgements}

The authors would like to acknowledge Martina Wall, Malmö University Library, for skillful assistance.

\section{Disclosure statement}

No potential conflict of interest was reported by the author(s).

\section{Funding}

This study was supported by Malmö University.

\section{References}

[1] Andersson B, Ödman P, Carlsson G. A study of 184 consecutive patients referred for single-tooth replacement. Clin Oral Implants Res. 1995;6(4):232-237.

[2] Buser D, Janner SF, Wittneben JG, et al. 10-year survival and success rates of 511 titanium implants with a sandblasted and acidetched surface: a retrospective study in 303 partially edentulous patients. Clin Implant Dent Relat Res. 2012;14(6):839-851.

[3] Degidi M, Nardi D, Piattelli A. 10-year follow-up of immediately loaded implants with TiUnite porous anodized surface. Clin Implant Dent Relat Res. 2012;14(6):828-838.

[4] Fischer K, Stenberg T. Prospective 10-year cohort study based on a randomized controlled trial (RCT) on implant-supported fullarch maxillary prostheses. Part 1: sandblasted and acid-etched implants and mucosal tissue. Clin Implant Dent R. 2012;14(6): 808-815.

[5] Gotfredsen K. A 10-year prospective study of single tooth implants placed in the anterior maxilla. Clin Implant Dent Relat Res. 2012;14(1):80-87.

[6] Jemt T. Single-Implant Survival: More Than 30 Years of Clinical Experience. Int J Prosthodont. 2016;29(6):551-558.

[7] Winitsky N, Olgart K, Jemt T, et al. A retro-prospective long-term follow-up of Brånemark single implants in the anterior maxilla in young adults. Part 1: clinical and radiographic parameters. Clin Implant Dent Relat Res. 2018;20(6):937-944.

[8] Klinge B, Klinge A, Bertl K, et al. Peri-implant diseases. Eur J Oral Sci. 2018;126(S1):88-94.

[9] Ravidà A, Saleh MH, Muriel MC, et al. Biological and technical complications of splinted or nonsplinted dental implants: a decision tree for selection. Implant Dent. 2018;27(1):89-94.

[10] Salvi GE, Monje A, Tomasi C. Long-term biological complications of dental implants placed either in pristine or in augmented sites: a systematic review and meta-analysis. Clin Oral Impl Res. 2018; 29(S16):294-310.

[11] Adler L, Buhlin K, Jansson L. Survival and complications: a 9- to 15-year retrospective follow-up of dental implant therapy. J Oral Rehabil. 2020;47(1):67-77.
[12] Andreasen JO, Kristerson L. The effect of limited drying or removal of the periodontal ligament. Periodontal healing after replantation of mature permanent incisors in monkeys. Acta Odontol Scand. 1981;39(1):1-13.

[13] Andersson L, Blomlöf L, Lindskog S, et al. Tooth ankylosis: clinical, radiographic and histological assessments. Int J Oral Max Surg. 1984;13(5):423-431.

[14] Andersson L, Malmgren B. The problem of dentoalveolar ankylosis and subsequent replacement resorption in the growing patient. Aust Endod J. 1999;25(2):57-61.

[15] Andreasen JO. Analysis of pathogenesis and topography of replacement root resorption (ankylosis) after replantation of mature permanent incisors in monkeys. Swed Dent J. 1980;4(6): 231-240.

[16] Andreasen JO, Borum MK, Jacobsen H, et al. Replantation of 400 avulsed permanent incisors. 4. Factors related to periodontal ligament healing. Endod Dent Traumatol. 1995;11(2):76-89.

[17] Iseri H, Solow B. Continued eruption of maxillary incisors and first molars in girls from 9 to 25 years, studied by the implant method. Eur J Orthod. 1996;18(3):245-256.

[18] Lauridsen E, Andreasen JO, Bouaziz O, et al. Risk of ankylosis of 400 avulsed and replanted human teeth in relation to length of dry storage: a re-evaluation of a long-term clinical study. Dent Traumatol. 2020;36(2):108-116.

[19] Malmgren B, Malmgren O. Rate of infraposition of reimplanted ankylosed incisors related to age and growth in children and adolescents. Dent Traumatol. 2002;18(1):28-36.

[20] Thilander B, Ödman J, Gröndahl K, et al. Aspects on osseointegrated implants inserted in growing jaws. A biometric and radiographic study in the young pig. Eur J Orthod. 1992;14(2):99-109.

[21] Jensen SS. Timing of implant placement after traumatic dental injury. J Endod. 2019;45:52-56.

[22] Kurol J, Ödman J. Treatment alternatives in young patients with missing teeth. Aspects on growth and development. In: Koch $\mathrm{G}$ Bergendal T, Kvint S, et al., editors. Consensus conference on oral implants in young patients. Jönköping: Förlaghuset Gothia $A B$; 1996. p. 77-108.

[23] Taranger J, Hägg U. The timing and duration of adolescent growth. Acta Odontol Scand. 1980;38(1):57-67.

[24] Pancherz H, Bjerklin K, Hashemi K. Late adult skeletofacial growth after adolescent Herbst therapy: a 32-year longitudinal follow-up study. Am J Orthod Dentofac. 2015;147(1):19-28.

[25] Behrents RG. Growth in the aging craniofacial skeleton. Ann Arbor (MI): Center for Human Growth and Development, University of Michigan; 1985. Available from: https://hdl.handle. net/2027/mdp.39015009852487

[26] Bondevik O. Dentofacial changes in adults: a longitudinal cephalometric study in 22-33 and 33-43 year olds. J Orofac Orthop. 2012;73(4):277-288.

[27] Heij DGO, Opdebeeck H, van Steenberghe D, et al. Facial development, continuous tooth eruption, and mesial drift as compromising factors for implant placement. Int J Oral Max Impl. 2006; 21:867-878.

[28] Heij DGO, Opdebeeck H, van Steenberghe D, et al. Age as compromising factor for implant insertion. Periodontol 2000. 2003;33: 172-184.

[29] Thilander B, Ödman J, Lekholm U. Orthodontic aspects of the use of oral implants in adolescents: a 10-year follow-up study . Eur J Orthod. 2001;23(6):715-731.

[30] Björk A. The face in profile. An anthropological X-ray investigation on Swedish children and conscripts [PhD Thesis]. Sweden: Uppsala University Svensk Tandläkare Tidskrift; 1947.

[31] Coben SE. The spheno-occipital synchondrosis: the missing link between the profession's concept of craniofacial growth and orthodontic treatment. Am J Orthod Dentofac. 1998;114(6): 709-712.

[32] Solow B. The pattern of craniofacial associations: a morphological and methodological correlation and factor analysis study on young male adults. Acta Odontol Scand. 1966;24:123-135. 
[33] Klinge A, Becktor K, Lindh C, et al. Craniofacial height in relation to cross-sectional maxillary and mandibular morphology. Prog Orthod. 2017; 18(1):32

[34] Arbetsmiljöns betydelse för hjärt-kärlsjukdom: exponering för kemiska ämnen: en systematisk översikt och utvärdering av medicinska, sociala och etiska aspekter, Statens beredning för medicinsk och social utvärdering (SBU), Stockholm, 2017.

[35] Balshem $H$, Helfand $M$, Schünemann $H J$, et al. GRADE guidelines: 3. Rating the quality of evidence. J Clin Epidemiol. 2011;64(4): 401-406.

[36] Bohner L, Hanisch M, Kleinheinz J, et al. Dental implants in growing patients: a systematic review. Br J Oral Maxillofac Surg. 2019; 57(5):397-406

[37] Carmichael RP, Sandor GK. Dental implants, growth of the jaws, and determination of skeletal maturity. Atlas Oral Maxillofac Surg Clin North Am. 2008;16(1):1-9.

[38] Chrcanovic BR, Kisch J, Larsson C. Retrospective clinical evaluation of implant-supported single crowns: mean follow-up of 15 years. Clin Oral Implants Res. 2019;30(7):691-701.

[39] Jemt T, Ahlberg G, Henriksson K, et al. Changes of anterior clinical crown height in patients provided with single-implant restorations after more than 15 years of follow-up. Int J Prosthod. 2006;19:455-461.

[40] Kamatham R, Avisa P, Vinnakota DN, et al. Adverse effects of implants in children and adolescents: a systematic review. J Clin Pediatr Dent. 2019;43(2):69-77.

[41] Lin S, Schwarz-Arad D, Ashkenazi M. Alveolar bone width preservation after decoronation of ankylosed anterior incisors. J Endodont. 2013;39(12):1542-1544.

[42] Malmgren B, Cvek M, Lundberg $M$, et al. Surgical treatment of ankylosed and infrapositioned reimplanted incisors in adolescents. Scand J Dent Res. 1984:92(5):391-399.

[43] Mohadeb JVN, Somar M, He H. Effectiveness of decoronation technique in the treatment of ankylosis: a systematic review. Dent Traumatol. 2016;32(4):255-263.

[44] Ruan MJ, Chen G, Xu TM. Comparison of orthodontic tooth movement between adolescents and adults based on implant superimposition. PLoS One. 2018;13(5):e0197281.

[45] Thilander B, Odman J, Jemt T. Single implants in the upper incisor region and their relationship to the adjacent teeth. An 8-year follow-up study . Clin Oral Implants Res. 1999;10(5):346-355.

[46] Vilhjálmsson VH, Klock KS, Størksen K, et al. Radiological evaluation of single implants in maxillary anterior sites with special emphasis on their relation to adjacent teeth: a 3-year follow-up study. Dent Traumatol. 2013;29(1):66-72.

[47] Papageorgiou SN, Eliades T, Hämmerle CH. Frequency of infraposition and missing contact points in implant-supported restorations within natural dentitions over time: a systematic review with meta-analysis. Clin Oral Impl Res. 2018;29:309-325.

[48] Andersson B, Bergenblock S, Fürst B, et al. Long-term function of single-implant restorations: a 17-to 19-year follow-up study on implant infraposition related to the shape of the face and patients' satisfaction. Clin Implant Dent R. 2013;15(4):471-480.

[49] Cocchetto R, Pradies G, Celletti R, et al. Continuous craniofacial growth in adult patients treated with dental implants in the anterior maxilla. Clin Implant Dent R. 2019;21:627-634.

[50] Jemt T, Gunilla A, Henriksson K, et al. Tooth movements adjacent to single-implant restorations after more than 15 years of followup. Internat J Prosthodont. 2007;20:626-632.

[51] Aarts B, Convens J, Bronkhorst E, et al. Cessation of facial growth in subjects with short, average, and long facial types - implications for the timing of implant placement. J Craniomaxillofac Surg. 2015;43(10):2106-2111.

[52] Bernard J, Schatz J, Christou P, et al. Long-term vertical changes of the anterior maxillary teeth adjacent to single implants in young and mature adults. A retrospective study. J Clin Periodontol. 2004;31(11):1024-1028.

[53] Brahem E, Holm B, Sonnesen L, et al. Positional changes of maxillary central incisors following orthodontic treatment using singlecrown implants as fixed reference markers. Clin Oral Implants Res. 2017;28(12):1560-1566.

[54] Fudalej P, Kokich VG, Leroux B. Determining the cessation of vertical growth of the craniofacial structures to facilitate placement of single-tooth implants. Am J Orthod Dentofac. 2007;131:59-67.

[55] Kawanami M, Andreasen JO, Borum M, et al. Infraposition of ankylosed permanent maxillary incisors after replantation related to age and sex. Endod Dent Traumatol. 1999;15(2):50-56.

[56] Schwartz-Arad D, Bichacho N. Effect of age on single implant submersion rate in the central maxillary incisor region: a longterm retrospective study . Clin Implant Dent Relat Res. 2015;17(3): 509-514.

[57] Thilander B, Odman J, Gröndahl K, et al. Osseointegrated implants in adolescents. An alternative in replacing missing teeth? Eur J Orthod. 1994;16(2):84-95. 

ISBN 978-9I-7877-I 49-3 (print)

ISBN 978-9I-7877-I 50-9 (pdf)

MALMÖ UNIVERSITY 20506 MALMÖ, SWEDEN WWW.MAU.SE 